ASIAN VISUAL CULTURES

Ran Ma

\title{
Independent Filmmaking across Borders in Contemporary Asia
}

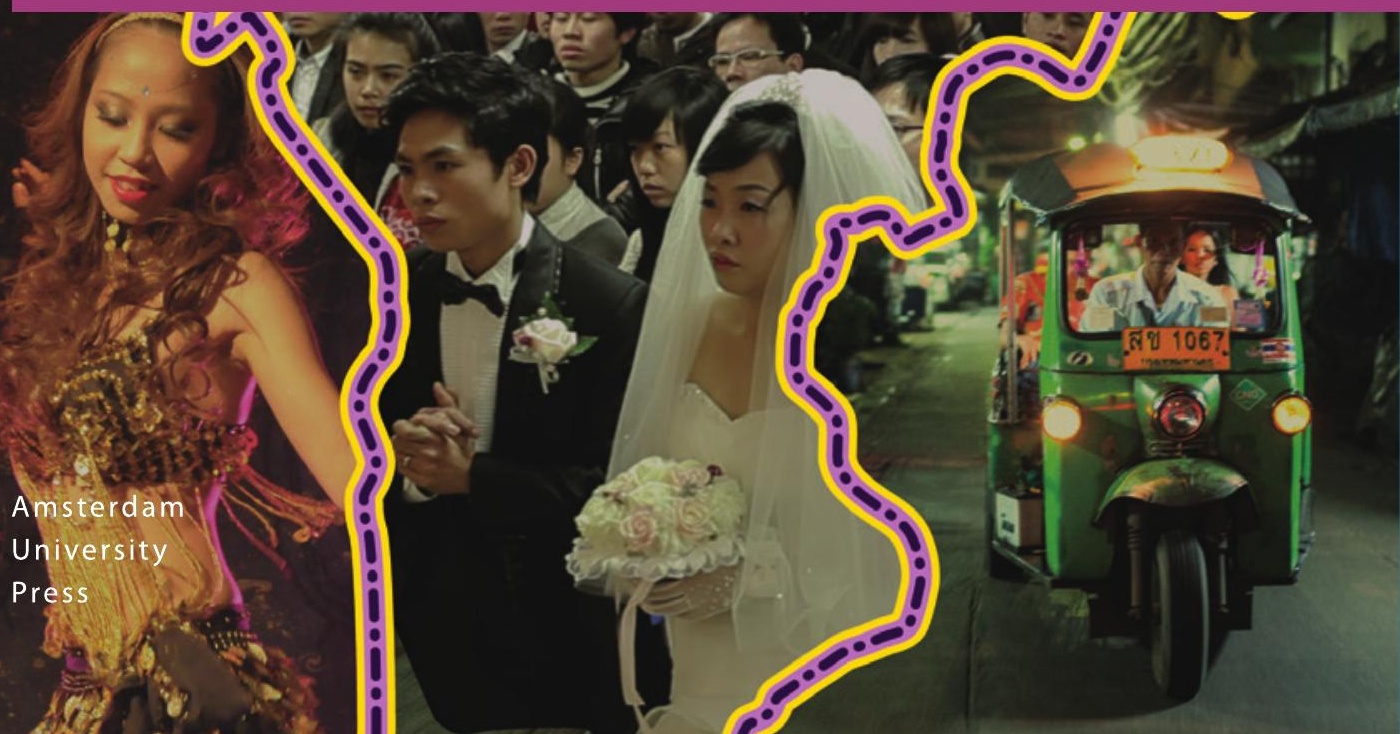


Independent Filmmaking across Borders in Contemporary Asia 


\section{Asian Visual Cultures}

This series focuses on visual cultures that are produced, distributed and consumed in Asia and by Asian communities worldwide. Visual cultures have been implicated in creative policies of the state and in global cultural networks (such as the art world, film festivals and the Internet), particularly since the emergence of digital technologies. Asia is home to some of the major film, television and video industries in the world, while Asian contemporary artists are selling their works for record prices at the international art markets. Visual communication and innovation is also thriving in transnational networks and communities at the grass-roots level. Asian Visual Cultures seeks to explore how the texts and contexts of Asian visual cultures shape, express and negotiate new forms of creativity, subjectivity and cultural politics. It specifically aims to probe into the political, commercial and digital contexts in which visual cultures emerge and circulate, and to trace the potential of these cultures for political or social critique. It welcomes scholarly monographs and edited volumes in English by both established and early-career researchers.

\section{Series Editors}

Jeroen de Kloet, University of Amsterdam, The Netherlands

Edwin Jurriëns, The University of Melbourne, Australia

\section{Editorial Board}

Gaik Cheng Khoo, University of Nottingham, United Kingdom

Helen Hok-Sze Leung, Simon Fraser University, Canada

Larissa Hjorth, RMIT University, Melbourne, Australia

Amanda Rath, Goethe University, Frankfurt, Germany

Anthony Fung, Chinese University of Hong Kong

Lotte Hoek, Edinburgh University, United Kingdom

Yoshitaka Mori, Tokyo National University of Fine Arts and Music, Japan 


\section{Independent Filmmaking across Borders in Contemporary Asia}

Ran Ma 
Cover illustration: Wang Wo

Cover design: Coördesign, Leiden

Lay-out: Crius Group, Hulshout

$\begin{array}{ll}\text { ISBN } & 978946298664 \text { o } \\ \text { e-ISBN } & 9789048537921 \text { (pdf) } \\ \text { DOI } & 10.5117 / 9789462986640 \\ \text { NUR } & 670\end{array}$

(C) Ran Ma / Amsterdam University Press B.V., Amsterdam 2020

All rights reserved. Without limiting the rights under copyright reserved above, no part of this book may be reproduced, stored in or introduced into a retrieval system, or transmitted, in any form or by any means (electronic, mechanical, photocopying, recording or otherwise) without the written permission of both the copyright owner and the author of the book.

Every effort has been made to obtain permission to use all copyrighted illustrations reproduced in this book. Nonetheless, whosoever believes to have rights to this material is advised to contact the publisher. 
For my parents

Shen Lijuan (1954-1984) and Ma Cunming (1951-1991)

and

my grandparents

Wang Suxian (1928-2010) and Ma Shouyou (1930-2019)

Rest in Peace 



\section{Table of Contents}

Acknowledgements

Author's Note

Introduction

Beyond the Homeland and Diaspora

1 The Art of the Dissensual

Independent Border-Crossing Cinema in Asia

Inter-Asia Transnational Cultural Productions $\quad 28$

Towards the Art of the Dissensual 30

A Cinema of Translocalism 33

Theorizing Border-Crossing Authorship $\quad 39$

Accented Cinema Reconsidered $\quad 39$

Minor Transnationalism $\quad 41$

Debating the Minor $\quad 45$

Realigning Independent Border-Crossing Cinema 48

Asia is One (1973): A Prehistory of Border-Crossing Asia 53

Circulating and Exhibiting Border-Crossing Films $\quad 58$

2 A Landscape Over There $\quad 69$

Rethinking Translocality in Zhang Lu's Border-Crossing Films
Reframing Translocality

Departing from Yanbian: Zhang Lu as a Translocal Auteur $\quad 73$

$\begin{array}{lr}\text { Three Takes of Border-Crossing } & 79\end{array}$

Desert Dream $\quad 80$

Dooman River $\quad 82$

Scenery $\quad 85$

Between Chinese Independent Cinema and Korean Diaspora Film 89

Re-envisioning the Chinese Indie $\quad 89$

A Korean-Chinese Diaspora Film? 93

3 Fading Hometown and Lost Paradise 99

Kuzoku's Politics of (Dis)location

Kuzoku as an Independent Film Collective $\quad 101$ 
Saudade: Beyond the Landscape $\quad 105$

Rethinking Fūkei $\quad 105$

$\begin{array}{ll}\text { The Long Takes } & 108\end{array}$

'Saudade': An Affective Critique 112

Bangkok Nites: Hidden Journey of a Thousand Miles 116

Almost a Road Movie $\quad 116$

Into the Jungle $\quad 122$

Coda

125

4 Li Ying's Films of Displacement $\quad 129$

Towards an Im/Possible Chinese-in-Japan Cinema

Reconsidering 'Chinese-in-Japan' 133

$\begin{array}{ll}\text { Cinema of Displacement } & 140\end{array}$

2H: Becoming Chinese-in-Japan Toward the Fin-de-Siècle 143

'A Certain Kind of Community' in Post-1989 China 143

Accented Style and Haptic Images $\quad 146$

Fin-de-Siècle Metaphor $\quad 15^{\circ}$

Aji: Tastes Like Home $\quad 152$

Towards a Chinese-in-Japan Cinema $\quad 155$

5 Okinawan Dream Show $\quad 163$

Approaching Okinawa in Moving Image Works into the New

Millennium

Prologue: Okinawa, Rage, and Tears... $\quad 164$

Okinawa-on-Screen: Beyond Representation $\quad 167$

Movement-Image, Time-Image, and National Identity $\quad 167$

Narrating Okinawa/Japan: Genealogies $\quad 169$

Okinawan Dream Show $\quad 173$

Island Voyages: Travelling in Time $\quad 178$

Loops of Rensageki (Chain Play): Toward a Stratigraphic Image $\quad 181$

$\begin{array}{ll}\text { Art of Fabulation } & 185\end{array}$

How to Remember the Battle of Okinawa? 188

$\begin{array}{ll}\text { Secrets of Time } & 191\end{array}$

6 Homecoming Myanmar 199

Midi Z's Migration Machine and a Cinema of Precarity

$\begin{array}{ll}\text { Points of Departure } & 199\end{array}$

Reframing Precarity $\quad 203$

Homecoming Trilogy 206 
Midi Z's 'Migration Machine'

206

The State of Precarity: Chinese Diaspora on the Move

210

Between Lashio and Hpakant: A Family Portrait 214

$\begin{array}{ll}\text { Road to Jade City } & 216\end{array}$

Affective-Authorial Risk-Taking $\quad 216$

At the Edges of Jade and Drug: Men at Work $\quad 218$

Coda: In the Name of a Visual Record $\quad 224$

Postscript

229

The Promise of Subversive Art

'From a High Vantage Point' 233

Gendering Border-Crossing Cinema $\quad 236$

Identity: A Document of Minor Objects $\quad 237$

ARAGANE: Wo/Men at Work $\quad 241$

$\begin{array}{ll}\text { Filmography } & 247\end{array}$

$\begin{array}{ll}\text { Bibliography } & 253\end{array}$

$\begin{array}{ll}\text { Index } & 271\end{array}$

\section{List of Illustrations}

1.1 Group photo of Waseda University's Camera Reportage Research Society (Kamera ruporutāju kenkyūkai), the predecessor of NDU. Photo was taken at a training camp in Hiroshima (August 1966). Middle row: second to the left (Nunokawa Tetsurō); fifth to the left (Inoue Osamu, also a NDU member)

1.2 A Tayal lady from a Piexau tribal village, Yilan County, Nan'ao Township (May 1972); from Asia is One $\quad 56$

A Tayal lady from a Piexau tribal village (May 1972)

2.1 Chang-ho lying on the frozen river

2.2 Jeong-ji (left) is welcomed by Chang-ho and his mute sister (right)

2.3 Jeong-ji is playing football with Chang-ho and other friends from the village

$2.4 \quad$ A wedding ceremony in Scenery 86

2.5 Foreign migrant worker in a light truck in Scenery $\quad 87$ 
3.1 Seiji and Hosaka at the top of a building, overseeing the city of Kofu in Saudade

3.2 Shooting Takeru (played by rapper Dengaryū) walking through the shopping street Mahiru (right) and Pinky (left) visiting the senior day care center, listening to the old lady's story

3.4 Installation project 'Hidden Journey of a Thousand Miles' by Kuzoku + Studio Ishi + YCAM A map illustrating the trip that Bangkok Nites took in Southeast Asia, from the brochure of 'Hidden Journey of a Thousand Miles'

3.6 Luck on Ozawa's motorcycle at the edge of the jungle in Bangkok Nites

4.2 Protagonists in $2 \mathrm{H}$ : Ma Jinsan (upper left and right) and Xiong Bingwen (bottom left)

4.3 Li Ying's Director's Note on $2 \mathrm{H}$, with a low-angle shot of Ma on the train

4.4 From the Japanese promotion brochure of $2 \mathrm{H}$, where Ma sees through the camera eye; $\mathrm{Li}$ is also introduced here as a 'China-born, Tokyo-based' filmmaker

5.1 8-mm image of an old lady and kids in Okinawan Dream Show 8-mm image of the street view in Okinawan Dream Show A black American soldier in Okinawan Dream Show, the footage of which is later being 'treated' by Papajō in Hengyoro

5.4 Tarugani's installation apparatus in Hengyoro, onto which images from Takamine's family album are projected

5.5 The projected images from the Takamine family album in Hengyoro

5.6 The image of the survivor's face is projected onto Yamashiro's face in Your Voice Came Out Through My Throat

5.7 The mud men and women, trapped in the tunnel, are showered in the light and sound of the moving images of the Battle of Okinawa 
6.1 Hpakant's barren landscape of mining pits dotted with almost unrecognizable human figures 202

6.2 Male labourers at work in Midi's Hpakant documentaries 219

6.3 De-chin on the way to Hpakant in City ofJade 220

6.4 Miners posing for the camera in Midi's installation work 'My Folks in Jade City' for the 2016 International Film Festival Rotterdam

7.2 Following the miners to the underground world in ARAGANE 



\section{Acknowledgements}

This book would have been unimaginable without the stimulating conversations, encouragements, and generous support from the various academic communities that I have been fortunate enough to be a part of. In particular, I want to share how excited I am with my colleagues at the Graduate School of Humanities at Nagoya University, a place where I started my first teaching job. It happens that I belong to two faculties at the same time, but it is the luckiest thing in the world to be able to work together with Fujiki Hideaki, Joo Woojeong, and Ogawa Shota in the program of Cinema Studies (Eizogaku), and they have always been patient enough to listen to my ideas and give me immediate responses. Also, my academic life in Japan would be less productive and less enjoyable without the companion of my colleagues at the Global-3o programme of 'Japan-in-Asia' Cultural Studies (JACS), Kristina Iwata-Weickgenannt and Nathan Hopson. I must also express my thanks to all the young people attending my classes and seminars, together with whom I have learnt about contemporary image politics.

This book is partly funded by JSPS Kakenhi under the project titled 'East Asian Film Cultures in the Post-Cold War Era: Film Festivals and their Transnational Network' (No. 15K16665, 2015-2017), and partially funded by Sinophone Imaginaries in Contemporary Asian Visual Cultures (No. 18K12263, 2018-2021). My research would not have gone smoothly without the aid of these two major sources of funding, and I am deeply grateful for the institutional support I have received from my university.

This book project has benefited from my translocal engagement with several small research groups. My talks and exchanges with Akiyama Tamako, Markus Nornes, and Nakajima Seio - members of our tiny Chinese independent cinema research group - made me realize where my foothold was at times when I was not sure where I was headed. I thank the lovely colleagues and friends at the Okinawa Cinema Society (Okinawa eiga kenkyūkai), who always welcomed me every time I visited. I also owe my insights to my late supervisor Dr. Esther Cheung and film scholars Gina Marchetti, Mitsuyo Wada-Marciano, Kim Soyoung, Zhang Zhen, Wang Yiman, Kiki Tianqi Yu, Lydia Wu Dan, Jennifer Coates, Yan Ni, Han Yanli, Aaron Gerow, JungBong Choi, Zhang Xianmin, Victor Fan, Chris Berry, Luke Robinson, Dong Bingfeng, Sing Song-Yong, and Yang Beichen. I must mention Cindy Hin-yuk Wong and Kitamura Hiroshi, two scholars whom I also regard as trusted friends - they were patient enough to review my half-baked ideas in the first place and gave me very constructive advices 
on several occasions. My deep gratitude also goes to Dogase Masato (who was not annoyed by my repeated requests for reviews), Zhou Chenshu, and Fujiki Kosuke, who spent lots of time and energy reading through my chapters and giving me their honest, brilliant comments. I cannot forget how Yin Zhixi took hours reading through the abstract theories by the Nihon Documentarist Union together with me; Natori Masakazu, Wang Wenyi, and Pan Qin were kind enough to help me with some of the Japanese translations whenever needed. Wen Hao and Zhang Shihao also helped with the editorial and image-processing matters. Special thanks go to Elaine Wing-Ah Ho, Liu Xi, Yu Xuying, Pan Lu, Bobo Wong, and Wang Bo, who, while being my best friends from my early days as a PhD student, have always remained by my side, cheered me up, and kept me motivated.

I still clearly remember how it felt when I watched Midi Z's Return to Burma (Guilai de ren) for the first time at the 2012 International Film Festival Rotterdam and started to ponder why the Burmese folks in the film were actually speaking accented Yunnanese, the dialect of my hometown. That, I believe, planted the seed for this book, and I owe everything to the independent filmmakers and artists whose works have profoundly inspired me along this unforgettable journey. Without their trust and precious time for interviews and meetings, this book would not have been realized in the first place, and my thanks go to the Nihon Documentarist Union and its member Inoue Osamu; Zhang Lu and his colleagues at Lu Film; Tomita Katsuya and Aizawa Toranosuke of Kuzoku; Ohno Atsuko of Flying Pillow Films; Li Ying; Takamine Gō and his producer Hama Haruka; Yamashiro Chikako and Chiba Yumiko Associates; Midi Z/Zhao Deyin and his colleagues at Seashore Image Productions; Matsue Tetsuaki; Oda Kaori; and last but not the least, Tan Chuimui and Liew Seng-tat, who were working together at DaHuang Pictures and were kind enough to accompany me when I visited Kuala Lumpur.

I am greatly indebted to Hata Ayumi, the programmer of the Yamagata International Film Festival. Some of the material and contacts could not be obtained without the help of the warm-hearted film expert Yasui Yoshio and his colleagues at the Kobe Planet Film Archive as well as the Taiwan International Documentary Film Festival and its programmers Wood Lin (Lin Mucai) and Chen Wanlin, Wu Fan. I am also amazed by the versatile Kaneko Yu, who basically knew everybody that I wanted to get in touch with in Japan(!). I also want to express my gratitude to the Okinawa Prefectural Museum \& Art Museum, where I was able to view some of the precious image materials from Okinawa. I am grateful to Gertjan Zuilhof, a brilliant programmer who has brought many exciting titles to me at various film 
festivals. And my thanks also go to Penny Lam of the Macau International Documentary Film Festival, and Feng Yu, the curator of the Fringe Film Festival (yisuiyingzhan) in Shenzhen, both of whom seem to share overlapping interests in these border-crossing films and auteurs. I appreciate the good care and professional support I received from Luo Ting, Yunxia, and their colleagues at Screen and Stage Review (Xijuyuyingshipinglun), a journal by Nanjing University; Artforum China and its editor-in-chief Du Keke; and also Davide Cazzaro, the editor-in-chief of the Asian cinema magazine NANG - they have given me wonderful opportunities to test some of my ideas via different formats and through various platforms.

Finally, I hope my parents and my grandparents like this book as a belated gift. Without their unconditional love, I would not have felt strong enough to pursue what I really enjoy doing. I hope they feel my love, too, and that they rest in peace. 



\section{Author's Note}

A modified Hepburn system of romanization is used to romanize Japanese as well as Okinawa's uchinā-guchi words, except for well-known variants for place names (Tokyo instead of Tökyō). Japanese names are written with the surname preceding the given name, with the exception of Japanese who have published their works in an Anglophone setting with known forms of namespelling. Their given names come first (e.g. Mitsuyo Wada-Marciano). For zainichi Korean names, I have followed the individual's preferred rendering (e.g. Yang Yong-hi; Sai Yōichi). The standard pinyin system has been adopted for romanizing Chinese names, with surnames preceding given names, too. For Sinophone (and ethnic minority) individuals whose names are known internationally in Westernized forms or alternate non-standard systems of romanization, I have used the spelling and sequence of names preferred by the respective individuals (e.g. Tan Chuimui; Royston Tan; Pema Tseden). Regarding the romanization of Korean terms, the practices outlined by the Ministry of Culture in 2000 are followed, and Korean names are spelt with surnames preceding given names. For the convenience of the readers, all film and artist video titles are given in English unless otherwise explained, wherein the official English title is used if it exists, or a translation if not. The original title is given in brackets following the first citation in each chapter, as well as in the filmography and index, both of which are ordered by the English titles. 



\title{
Introduction
}

\author{
Beyond the Homeland and Diaspora
}

\begin{abstract}
Departing from the omnibus film project 'Homeland and Diaspora' (Yuanxiang yu lisan), this introduction outlines important questions to be explored throughout the book regarding what I have proposed as 'independent border-crossing filmmaking'. I focus on a specific strand of auteurist independent cinema (and of image-making) emerging mainly since the late 1990 s and early 2000 s that project and articulate the experience of being mobile and displaced, being minority and diasporic, and/ or journeying within and across various Southeast Asian and East Asian places. Detailed chapter summaries are also proffered.
\end{abstract}

Keywords: contemporary Asia, border-crossing filmmaking, independent cinema, film auteur

In 2013, Hong Kong-based Phoenix Television (Fenghuang weishi), in collaboration with Kuala Lumpur-based independent film collective DaHuang Pictures (Dahuang dianying, est. 2005), ${ }^{1}$ invited six Asian filmmakers based in Malaysia (Tan Chuimui), Thailand (Aditya Assarat), Taiwan (Tsai Ming-liang, Midi Z/Zhao Deyin), and Singapore (Sun Koh, Royston Tan) to participate in an omnibus film (microfilm) project with the theme 'Homeland and Diaspora' (Yuanxiang yu lisan). The accomplished works that came out of this project - all shot in digital format - were broadcast on the satellite TV channel and streamed online on Phoenix TV's official

1 Since 2004, Tan Chuimui and other Malaysian (Chinese) filmmakers such as James Lee, Liew Seng-tat and Amir Muhammad, who were based in Kuala Lumpur at that time, leveraged the entity of DaHuang Pictures to carve out an independent space for like-minded independent filmmakers, regardless of their ethnicities, to work together on digital film projects in a collaborative manner. Also refer to Hee Wei-Siam's chapter (in Chinese) on DaHuang Pictures (see Hee 2018: 211-237; also see 'DaHuang Pictures').

Ma, Ran, Independent Filmmaking across Borders in Contemporary Asia. Amsterdam, Amsterdam University Press 2020 DOI: $10.5117 / 9789462986640$ INTRO 
site. Its afterlife, a self-curated programme entitled Letters from the South (Nanfang laixin), had its global film festival tour between 2013 and 2014. ${ }^{2}$

Whereas in Royston Tan's Popiah (Baobing), the transgenerational bonds between members of a big ethnic Chinese family are repaired through food and the practice of tradition, Sun Koh has taken a more parodical take in Singapore Panda (Xinxin xiongmao) to re-examine the history of Chinese Singaporean immigrants, also addressing the flow of capital from the People's Republic of China (PRC) into the city-state and the potential anxiety triggered by China's threatening economic power worldwide. With Walking on Water (Xingzai shuishang), Tsai Ming-liang films his long-term collaborator Lee Kang-sheng's slow walks through the city of Kuching, where Tsai spent his childhood, in order to explore a disparate sense of time. In A Night in Malacca (Maliujia yehua), Tan Chuimui reenacts an uncanny encounter in the historic city of Malacca between 'herself' (impersonated by an actress) and a mysterious friend, evoking the impressionist writing of diasporic Chinese novelist Yu Dafu (1896-1945) about the 'South Seas'/ Nanyang during the time of Malaya's occupation by the Japanese. ${ }^{3}$

Even though not every filmmaker in the omnibus project has thematized her/his short film with the actual geopolitical border zones or transborder movement, the anthology has nonetheless leveraged the narrative tropes of mobility and identity, in tandem with multilingualism, in making visible the interrelations between people and places across East Asia and particularly Southeast Asia. Places such as the city-state of Singapore (Royston Tan, Sun Koh); Kuching (Tsai Ming-liang) and Malacca (Tan Chuimui) in Malaysia; Bangkok (Aditya Assarat) in Thailand; and Lashio (Midi Z/Zhao Deyin) in Myanmar are foregrounded as liminal sites for the filmmakers and their characters to reflect upon and negotiate with the localized, fragmented experiences of modernity and social transformations as well as the multiple possibilities of belonging. Although 'Homeland and Diaspora' was originally launched by Phoenix TV under the leitmotif of celebrating the commonalities and cultural bonds that have been passed down and shared by generations of overseas Chinese in Southeast Asia across the Southern Seas/Nanyang (hence the 'South' in the title Letters from the South), I would contend that

2 Unlike its television and online versions, when exhibited on the festival circuit, 'Letters from the South' adopted the style of 'epistolarity' or 'letter-film', so that every short film comprised a letter addressed to someone (including the audience), each closing with a message from the filmmaker (also see C.-T. Chen 2014).

3 Generally speaking, Nanyang in Mandarin Chinese is used by Chinese émigrés and their descendants to refer to the region of Southeast Asia. For more works on Nanyang literature and cultural productions, read Bernards $(2012,2016)$ and Groppe (2013). 
these shorts have actually engaged the performativity of 'Chineseness' to canvass the interlacing yet uneven transnational movement of persons, commodities, cultures, and ideas as well as the sensibilities and feelings across Southeast Asian societies and communities. To put it differently, the omnibus is not simply one that narrowly concerns the Sinophone diaspora in Asia, if we can for the moment understand the Sinophone in terms of what was originally outlined by Shu-mei Shih as 'Sinitic-language communities and their expressions (cultural, political, social, etc.) on the margins of nations and nationalness in the internal colonies and other minority communities in China as well as outside it' (Shih 2011: 716; also see Chapter Four in this volume). As Aihwa Ong forcibly illustrates, 'the contemporary practices and values of diasporan Chinese are characteristic of larger questions of displacement, travel, capital accumulation, and other transnational processes that affect large numbers of late-twentieth-century subjects (who are geographically “in place” and displaced)' (Ong 1999: 86; emphasis in original).

Moreover, as much as 'Homeland and Diaspora' was advertised as a showcase of transnational collaboration among the diasporic Chinese filmmakers (as well as among film professionals such as actors and actresses from diverse backgrounds and locales), it has indeed highlighted the existing transnational nexus and creative momentum intersecting East Asian and Southeast Asian independent film movements and film auteurs since the early 2000 s in the new waves of digital filmmaking. Having based their filmmaking in urban centres in this region, filmmakers who participated in the omnibus are at the same time closely connected with the global visual regime through variously scaled networks of film production, circulation, and exhibition, such as those of the international film festivals.

The anthology of 'Homeland and Diaspora' spotlights a group of filmmakers and a body of film works that will be mapped out in Independent Filmmaking across Borders in Contemporary Asia. This book focuses on a specific strand of auteurist independent cinema (and image-making) that has emerged mainly since the late 1990 s and early 2000 s that projects and articulates the experience of being mobile and displaced, being minority and diasporic, and/or journeying within and across various Southeast Asian and East Asian places, which correlate with the filmmaker's negotiation with her/his layered identities and/or the trajectories of travelling and migrating across Asian locales. Whereas I place my survey within the geopolitical space of Southeast Asia and East Asia, I also pay specific attention to inter-Asia culture and media flows in the post-Cold War period and particularly in the era of globalization, into the new millennium. 
Importantly, I borrow the concept of dissensus from philosopher Jacques Rancière to consider how this study - which features a specific breed of border-crossing auteurs and image-makers together with their independently produced border-crossing projects - can be enframed within, and thus contribute to, a new understanding of the aesthetics and politics of contemporary cinema. In particular, as far as the 'independent border-crossing cinema' is concerned, I argue that for the independent filmmakers and image-makers canvassed here, their practices are political not simply because they have transgressed identities and/or borders of various scales (not unlike their characters in the diegetic world). The politics also concerns how the cinema works contribute to envisioning 'Asia' as a cultural text/imaginary of disjuncture, multiplicities, and unevenness wherein the connectivity between the previously marginalized and peripheral subjects, places, and feelings can be realigned, reconnected, and made perceptible.

Independent border-crossing cinema, which here includes both fiction film and documentary, is closely analyzed in the first chapter, and I have specifically situated it at the conjuncture of inter-Asian culture and media productions and the new waves of independent film movements across Asia since the late 1980 s and early 1990s. Leveraging the concept of translocality/ translocalism, I suggest that this border-crossing filmmaking comprises political acts in promoting and visualizing a new way of envisioning and reconfiguring the interconnections between (Asian) places, the (im)mobile subjects, and their layered identities. To better understand the dissensual potentiality of this border-crossing cinema, I zoom in on the issue of film authorship, which is understood in this project as the 'ways of doing and making' around which independent filmmakers and artists coordinate their authorial positionings and aesthetic preferences. Inspired by Françoise Lionnet and Shu-mei Shih's framing of 'minor transnationalism' (Lionnet \& Shih 2005) while also discussing ethnic, diasporic, and postcolonial filmmaking in critical parameters such as 'accented cinema' (Naficy 2001), 'intercultural cinema' (Marks 200o), and a 'cinema of transvergence' (Higbee 2007), I demonstrate how a 'minor' authorship connects with the dissensual in modifying the 'policed' articulations and representations of the minority and marginalized identities and groups. Also, the dissensuality of such an authorship concerns how it is institutionally situated and performed within the space of the international film festival network.

The fives chapters that follow Chapter One I have envisioned as an interAsia translocal trip that goes from North to South. The second chapter, 'A Landscape Over There - Positioning Zhang Lu's Border-Crossing Cinema', examines three border-crossing films by the Korean-Chinese filmmaker 
Zhang Lu, namely Desert Dreams (2008), Dooman River (2010), and Scenery (2013). Using the conceptual framework of translocality, this study first explores how Zhang, as a translocal auteur, leveraged his multi-layered identities to engage the global film festival network. The cinematic trope of border crossing is emphasized: not only has Zhang reinvented the border as a new scale to scrutinize the translocal movement of deterritorialized subjects and diasporic peoples, he also sheds light on the significance of place in identity formation and further interrogates the power geometry of globalization. As such, Zhang's translocal filmmaking intersects and challenges us to rethink both Chinese independent cinema and Korean diasporic films.

Titled 'Fading Hometown and Lost Paradise - Kuzoku's Politics of (Dis)location', the third chapter sets out to examine Kuzoku, a Japan-based independent film collective of multiple members founded in 2004 by selftrained filmmakers Tomita Katsuya and Aizawa Toranosuke. ${ }^{4}$ Set in the generic 'regional city' of Kofu in post-economic crisis Japan, Kuzoku's feature film Saudade (2011) looks at a group of marginalized labourers, part-timers, and rappers who find their lives and desires inextricably intersecting with the foreign immigrants in town. In Bangkok Nites (2016), Ozawa, an exsoldier of the Self-Defense Force, travels to Isan (northeastern Thailand) and feels trapped in between his home country and the Southeast Asian 'paradise' of sex and escape. This chapter first examines Kuzoku's location shooting by reconceptualizing fükeiron (theory of landscape), which was famously explicated by Japanese leftist critic Matsuda Masao in the 197os. Importantly, I look at how both Saudade and Bangkok Nites, in tandem with other media projects by Kuzoku, have reconfigured the mode of appearance in making visible previously marginalized subjectivities and locales and have interrelated with disparate temporalities and modes of affect as a gesture of resistance.

In Chapter Four, 'Li Ying's Films of Displacement: Toward an Im/Possible Chinese-in-Japan Cinema', I turn to a long-term Chinese resident in Japan, Li Ying, who has been mostly known for his controversial feature film Yasukuni (2007) which reflects upon the socio-political significance of Yasukuni Shrine, where Japan's war dead are commemorated. This study nevertheless frames two of Li's earlier documentaries $-2 H$ (1999) and Dream Cuisine (Aji, 2003) - as 'films of displacement'. I situate Li Ying's independent filmmaking at the conjuncture of diasporic filmmaking and Sinophone

4 Throughout this book of mine, I use 'Kuzoku' instead of 'Kūzoku' to refer to the collective members and their works, given that the former spelling is preferred by the film collective. 
cinema and consider how these documentaries have not only interlinked Li's becoming 'Chinese-in-Japan' subjectivity with other displaced subjects who have difficulty articulating any singular sense of national or cultural belonging. Also, these documentaries examine and archive transhistorical and transnational affective connections traversing various Sinophone and diasporic communities within Japan and beyond. We could, therefore, envision a Chinese-in-Japan cinema which, loosely assembling contemporary film and media works by Chinese-in-Japan filmmakers who have arrived in Japan since the mid-1980s, challenges us to question its unwritten historiography and to rethink Sino/PRC-Japanese transnational cinema.

Chapter Five, entitled 'Okinawan Dream Show: Approaching Okinawa in Moving Image Works into the New Millennium', deals with the oeuvre of Okinawan filmmaker Takamine Gō and video artist Yamashiro Chikako, with an emphasis on the former's fiction feature film Queer Fish Lane (Hengyoro, 2016). Taking as a point of departure Gilles Deleuze's framework of time-image, which underpins his explication of modern political cinema, this chapter examines how Takamine has experimented with textual strategies and forms of expression in configuring the 'stratigraphic image' apropos of Okinawa, wherein the boundaries between the actual and the virtual as well as the real and the imagined are blurred. The teleological narrative of any essentialized national identity is thus disturbed. Accordingly, spectators are challenged to read the film texts in their heterogeneous layers. Meanwhile, I also turn to Yamashiro Chikako's recent narrative-oriented video works that have been intricately connected to the legacies of the Battle of Okinawa and current waves of protests against the US military bases on the islands. I argue that from a stance not too dissimilar from Takamine's, Yamashiro grasps the political image of Okinawa less in terms of a truthful representation 'in' or 'as' reality but relates the work of memory, or remembering, to a series of operation on images.

Our meandering journey comes to an end with Chapter Six, 'Homecoming Myanmar: Midi Z's Migration Machine and a Cinema of Precarity', where I look at Taipei-based, Chinese-Burmese filmmaker Midi Z, whose 'homecoming' oeuvre includes three fictional films (also known as the 'Homecoming Trilogy') and two documentaries shot at Myanmar's most (in)famous highquality jade deposit, Hpakant in northern Myanmar. Reframing precarity from its theoretical framings in sociology and biopolitical theories, I first argue that Midi has explored how, when ensnared within the precarious, impossible conditions of mere biological existence, the disenfranchised diasporic Chinese subjects - both female and male - still gamble on gaining access to other possibilities in life. My focus then shifts to City ofJade (Feicui 
zhicheng, 2016), one of his Hpakant documentaries. Leveraging the notion of 'risk-taking' at both the textual and inter-textual levels, with an emphasis on the gendered perspective, I examine how Midi has leveraged a personal, subjective point of view to interweave the struggles of the Zhao family (particularly his brother's) with those of the male labourers on location.

In my postscript, in lieu of a comprehensive summary of the theoretical framings, I propose possible directions for future studies. I re-examine the Rancièrian thesis of politics and aesthetics apropos of border-crossing filmmaking by looking at, for instance, Human Flow (2017) by Chinese dissident artist Ai Weiwei, an English-language documentary addressing the current global refugee crisis and illegal immigration. More importantly, I leverage the perspective of gender in emphasizing the gendered body and sexuality as crucial issues underlying border-crossing filmmaking. To this end, I briefly turn to a documentary-cum-pornography video Identity (2004) by third-generation zainichi Korean filmmaker Matsue Tetsuaki and Oda Kaori's documentary ARAGANE (2015), which was shot by the filmmaker single-handedly in a coal mine in Bosnia-Herzegovina.

The journey has just begun.

\section{Works Cited}

Bernards, B. (2012). 'Beyond Diaspora and Multiculturalism: Recuperating Creolization in Postcolonial Sinophone Malaysian Literature', Postcolonial Studies, 15/3: 311-29. DOI: 10.1080/13688790.2012.728371.

- (2016). Writing The South Seas: Imagining The Nanyang In Chinese And Southeast Asian Postcolonial Literature. Singapore: NUS Press.

Chen, C.-T. (2014). 'Zugen yu zugen - Dongnanya huarendaoyan duanpianji "Nanfang laixin"' [Ancestral Roots and Moving Feet the Omnibus Film Letters from the South by Six Southeast Asian Filmmakers], Film Appreciation, 3: 97-107+135.

'DaHuang Pictures' (2016). DaHuang Pictures. Retrieved 15 March 2018 from <http://www. dahuangpictures.com/about>.

Groppe, A.M. (2013). Sinophone Malaysian Literature: Not Made in China. Amherst, NY: Cambria Press. Hee, W.-S. (2018). Huayudianying zai houmalaixiya:tuqiang fengge, huayifeng yu zuozhelun [Post-Malaysian Chinese-Language Film: Accented Style, Sinophone and Auteur Theory]. Xinbei, Taiwan: Linking Publishing.

Higbee, W. (2007). 'Beyond the (Trans)national : Towards a Cinema of Transvergence in Postcolonial and Diasporic Francophone Cinema(s)', Studies in French Cinema, 7/2: 79-91. DOI: 10.1386/sfci.7.2.79.

Lionnet, F., and Shih, S.-M. (2005). 'Introduction: Thinking through the Minor, Transnationally'. In Lionnet F. and Shih S. (eds.), Minor Transnationalism, pp. 1-23. Durham; London: Duke University Press.

Marks, L.U. (2000). The Skin of the Film: Intercultural Cinema, Embodiment, and the Senses. Durham; London: Duke University Press. 
Naficy, H. (2001). An Accented Cinema: Exilic and Diasporic Filmmaking. Princeton, NJ: Princeton University Press. DOI: 10.1177/1470412907075071.

Ong, A. (1999). Flexible Citizenship: The Cultural Logics of Transnationality. Durham; London: Duke University Press.

Shih, S.-M. (2011). 'The Concept of the Sinophone', PMLA, 126/3: 709-18. 


\title{
1 The Art of the Dissensual
}

\author{
Independent Border-Crossing Cinema in Asia ${ }^{1}$
}

\begin{abstract}
I situate 'independent border-crossing cinema' at the conjuncture of interAsia culture and media productions and the new waves of independent film movements across Asia since the late 1980s/early 1990s. Building upon the concept of translocality, and engaging with Françoise Lionnet and Shu-mei Shih's framing of 'minor transnationalism' in tandem with other discussions on cinematic transnationalism, I have developed a theoretical framework to examine the dissensual potentiality of border-crossing filmmaking, particularly from the perspective of authorship. Japanese film collective Nihon Documentarist Union and their 1973 documentary Asia is One are examined to illustrate how an inter-Asia independent border-crossing cinema can be realigned historically. I have also paid attention to the politics of the international film festival network.
\end{abstract}

Keywords: translocalism, minor transnationalism, film authorship, dissensus, politics of aesthetics

Police consists in saying: Here is the definition of subversive art. Politics, on the other hand, says: No, there is no subversive form of art in and of itself; there is a sort of permanent guerrilla war being waged to define the potentialities of forms of art and the political potentialities of anyone at all. Jacquese Rancière, 2007

Until the postwar period, the East China Sea had been a highly fluid space of human life, but as national borders became more highly demarcated, crossing them made you an 'other', creating the distinctions between zainichi Okinawans, fishermen, Japanese in Okinawa, Koreans, Taiwanese, and Taiwanese aborigines.

Nunokawa Tetsurō, 1973

Ma, Ran, Independent Filmmaking across Borders in Contemporary Asia. Amsterdam, Amsterdam University Press 2020 DOI: 10.5117/9789462986640_CHO1 


\section{Inter-Asia Transnational Cultural Productions ${ }^{2}$}

Rather than a brand new genre of transnational filmmaking that I am proposing here, 'independent border-crossing cinema' is leveraged as a critical heuristic to survey a breed of independent auteurs whose micropractices and projects ('border-crossing films') are both locally situated and contingently embedded in the translocal (local-to-local), transnational network of production, circulation, and exhibition.

As one of the most fascinating socio-cultural phenomena in the region, transnational media and cinema flows, exchanges, and collaborations across Southeast Asia and East Asia have captured scholarly attention in recent decades (see Berry 2013; DeBoer 2014; also see Lamarre 2015). In his stimulating take that accounts for the 'new transborder patterns' emerging from the 'transnational order', Chris Berry argues that filmmakers working on transnational projects do not have to subscribe to the cultural logic of what Michael Hardt and Antonio Negri have suggested as the 'Empire' (2000), proposing that the 'principles of profit maximisation and accumulation' are not necessarily the driving force for all filmmakers' transborder moves. Also, Berry illustrates that the notion of 'assemblage', here grasped as 'a contingent ensemble of diverse practices', should be introduced as 'an operating logic behind the superficially amorphous, chaotic and ever-changing characteristics of transnational cultural formations' (Berry 2013: 468). Through the notion of 'assemblage', therefore, it is possible to envision transnational formations that have accommodated heterogeneous and contingent components, the logic of which at the same time shall problematize any illusionist idea about a 'unified and coherent culture' in the region of East Asia (ibid.: 469). Berry's framing of 'assemblage' is instructive to grasp the inter-Asia media and cinema collaborations wherein, for instance, the 'Homeland and Diaspora' omnibus mentioned in the Introduction would be considered no less important in manifesting the dynamics of transnationalism than, say, epic costume blockbusters such as Legend of the Demon Cat (Yaomaozhuan / Kukai: Utsukushiōhi no nazo, 2017) directed by the former fifth-generation Chinese filmmaker Chen Kaige, a mega-budget coproduction between Japanese media heavyweight Kadokawa Corp., the Peoples' Republic of China (PRC)'s Wanda Media Co., and Emperor Motion Pictures from Hong Kong.

2 My use of 'inter-Asia' both as an adjective and a noun relates to the understanding that 'there is no unity to the imaginary entity called "Asia"' (Chen \& Chua 2007:1). The term specifically seeks to "highlight the existence of a plurality of "Asias", to emphasize the links, and to problematize the lines that are drawn between the local, national, regional and global' (Burgess 2004: 131). 
Nevertheless, if Berry has suggested a diverse, heterogeneous, and ever-shifting scenario to probe into inter-Asia cultural productions in the global age, much attention so far has been given to the market-driven film and media co-production projects and industrial collaborations that seem to be evidence of the trend towards and desire for Asian integration and regionalization (see Ben-Ari \& Otmazgin 2012; Berry et al. 2009; Gates \& Funnell 2012; also see Jin \& Otmazgin 2014). Meanwhile, research into inter-Asia film exchanges often revolves around cinematic genres such as action cinema (see Morris et al. 2006; Szeto 2011), horror (see Jinhee Choi \& Wada-Marciano 2009), and film noir (see Gallagher \& Shin 2015). It is not difficult to see how these genre productions have also become useful sites to explore the 'translingual filmmaking' between East Asia and the West - particularly with Hollywood (Lim 2011). Studies have often turned to how viable 'Asian' genres have been reappropriated and remade in Hollywood (see K. Chan 2009; Marchetti \& Tan 2007; Xu 2008). Moreover, surveys of the diasporic, migrant film auteurs (e.g. Ang Lee and John Woo), stardom (e.g. Jet Li and Zhang Ziyi, also see Leung \& Willis 2014; Yu 2012), and film professionals (like the martial arts choreographer Yuen Woo-ping) from East Asia have been habitually situated between the mainstream industries across the Asia Pacific and again with the spotlight on Hollywood (see Hunt \& Leung 2008). The practices of 'remaking East Asia', while seemingly having disturbed the unbalanced relations between Hollywood and East Asian film industries, also invite critique regarding the latter's self-perpetuated secondary positioning that serves the purposes of 'outsourcing Hollywood' (Xu 2008).

In her topological study conducted almost a decade ago on the ubiquitous phenomenon of 'cinematic transnationalism', Mette Hjort optimistically suggested that 'cinematic transnationalism is no doubt the future, but as such it is also an "open" phenomenon with the potential to develop in many different directions' (2009: 30). The lensing of assemblage indeed helps to shed light on the rhizomatic connections between independent filmmakers/collectives across the East Asian and Southeast Asian regions. Departing from the narratives of Asian transnationality in the studies of media and cinema, my project seeks to respond to observations/concerns that 'globalization has brought many others home but also sent many abroad, producing alternate circuits of transnationality that have been largely undertheorized' (Lionnet \& Shih 2005: 13). A refreshing framework is needed to rethink the cinematic transnationalism that the specific breed of border-crossing films have registered, embodied, and intersected at the level of both discourse and practice. 


\section{Towards the Art of the Dissensual}

For Jacques Rancière, both politics and aesthetics can be interrogated as 'forms of dissensus' (Corcoran 2010: 2) in the sense that either the activity of politics or that of aesthetics could be conceptualized as a process of modifying the social arrangements governing knowledge-sharing and the hierarchical order underlying such arrangements. The perspective of dissensus allows us to better grasp what I have proposed as 'independent border-crossing cinema': not only do I pay attention to the 'ways of doing and making', i.e. in the multiplicities and variances of such artistic practices, I will also highlight the ways in which border-crossing filmmaking has redistributed the forms of visibility. In this study, I contend that the specific strand of border-crossing filmmaking configures an intervention in cinematic transnationalism at the level of text and form, and also extra-textually, across the interlinked realms of production, circulation, and exhibition.

Dissensus does not simply relate to 'a conflict of interests, opinions or values' (Rancière 2010: 80) apropos the reigning social order, an order that for Rancière constitutes a situation of consensus maintained by the 'police' (May 2010). ${ }^{3}$ Rather, dissensus is viewed as a disruption in 'the perceptual and epistemic underpinnings of that order, the obviousness and naturalness that attaches [sic] to the order'; it concerns how the 'conditions of sense perception' may be challenged and reconfigured (Panagia 2014: 96). That is, dissensus essentially comprises a dispute over the partitioning and distributing of the sensible, namely what Rancière calls 'le partage du sensible' (the French word 'partage' meaning both division and sharing). As he affirms, politics 'revolves around what is seen and what can be said about it, around who has the ability to see and the talent to speak, around the properties of spaces and the possibilities of time' (Rancière 2011b: 13). Therefore, the aesthetics of politics interconnects with the politics of aesthetics by working with the contingency of the partage du sensible, both of which then relate to the 'mode of appearance' regarding who can say and hear what, where, and when (see Demos 2013).

It is, however, noteworthy that Rancière's discussion of dissensus leaves much room for ambiguity in order to accommodate the paradoxes he sees as

3 Here, the use of 'dissensus' also relates to that of 'disagreement' (La Mésentente), the latter of which according to the translator Gabriel Rockhill is 'a conflict over what is meant by "to speak" and "to understand" as well as over the horizons of perception that distinguish the audible from the inaudible, the comprehensible from the incomprehensible, the visible from the invisible' (Rockhill quoted in Rancière 2011b: 84). 
characterizing the project of art in the aesthetic regime. ${ }^{4}$ Dissensus, I argue, is not intended as a ready-made critical vocabulary for the close reading of specific texts and contexts of, say, twenty-first-century film works; nor should it be approached as a generic tag or imitative model to differentiate which work of art could (or could not) be recognized and categorized as dissensual. Nevertheless, it is crucial that Rancière has outlined how aesthetics can be grasped through the analytical nexus of poiesis, namely 'a way of doing', and aisthesis, or 'a way of being', which is 'a horizon of affect' resulting from poiesis (Rancière 2010:15-16). Hence aesthetics for him refers to 'a mode of articulation between ways of doing and making, their corresponding forms of visibility, and possible ways of thinking about their relationships (which presupposes a certain idea of thought's effectivity)' (Rancière 2011b: 10). Artistic practices and their politics can then be pinpointed in terms of "ways of doing and making" that intervene in the general distribution of ways of doing and making as well as in the relationships they maintain to modes of being and forms of visibility' (ibid.: 13).

I argue that dissensus comprises a refreshing framework for us to examine and envision the aesthetics and politics of contemporary image culture and cinema. At the same time, it is of crucial importance to use such a strand of 'independent border-crossing cinema' within/from the East Asian and Southeast Asian areas to exemplify and to further reconsider the art of the dissensual. Fully aware of the continental philosophical underpinnings of Rancière's theories on dissensus as well as the euro-centred case studies and 'sensibilities and texts' he deploys when canvassing contemporary film and art scenes (Tolia-Kelly 2019:124), I do not envision this study simply as a celebratory manifestation of the universal value apropos the grand Rancièrian edifice. For one thing, though often omitted in topographical surveys of Asian transnational cultural productions and less systematically discussed in Anglophone academia, independent filmmaking within/from Asia has proffered a crucial context as well as a vantage point from which to explore cinematic transnationalism in the global era. For another, as illustrated by Divya P. Tolia-Kelly's analysis of the dialogues between Rancièrian thesis and postcolonial studies, Rancière's dissensus can nevertheless be used to 'create or refigure the very frameworks and sensibilities through which "Other"

4 In what has been outlined by Rancière as the three regimes of art (the other two being the ethical regime of art and the representative regime of art), the aesthetic regime of art 'abolishes the hierarchical distribution of the sensible characteristic of the representative regime of art, including the privilege of speech over visibility as well as the hierarchy of the arts, their subject matter, and their genres' (Rockhill quoted in Rancière 2011b: 81). 
cultures can determine the cultural grammars and vocabularies through which their nations are narrated' (Tolia-Kelly 2019: 124). Focusing on the socio-political and historical complexities of East Asia and Southeast Asia and auteur-centred independent cinemas, this research constitutes a small experiment that seeks to recalibrate the consensual articulations about 'Asia', which is foregrounded here both as a crucial geopolitical and social context and a specific arrangement of knowledge, and to contest the dominant views about the 'Other', auteur-centred cinemas from within and outside of Asia.

Furthermore, I propose that dissensus opens up horizons for us to see how, for instance, the social and democracy movements and transformations across East Asian and Southeast Asian societies, specifically those that have taken place since the region's post-Cold War transformations in the late $1980 \mathrm{os}$ (e.g the post-authoritarian transitions of Taiwan and South Korea since 1987; the Chinese Democracy Movement in 1989), have intricately intertwined with the multifarious, multi-sited local and national-level art-making and filmmaking undercurrents and movements. Here I am not highlighting the cause-and-effect connections between the social movements and the new waves of art-making and filmmaking, or simply emphasizing art activism and political filmmaking, although they are not irrevelant topics. Rancière hinted at the interconnections between modern democracy and revolution and the 'new distribution of the sensible that delineates a specific space for art, a specific feeling called aesthetic feeling' (2011a: 8). I thereby propose that when the partage du sensible of a specific society is disrupted, specific sphere(s) of experience might emerge, and a certain 'aesthetic feeling' might find its space and time of appearance in the avant-garde and independent art-making and filmmaking movements. An example from the PRC could be offered here. The 'first wave' of Chinese independent film works like Wu Wenguang's documentary Bumming in Beijing - Last Dreamers (Liulang Beijing - zuihoude mengxiangzhe, 1990) and Zhang Yuan's semi-fiction Mama (1990), produced in the aftermath of the 1989 Democracy Movement, may not have been directly responding to the 1989 movement perse. But it is my contention that they became possible because the seismic transformation of Chinese society brought about by the Reform and Opening-up (Gaige kaifang) since 1978, together with the emergence of various underground and alternative cultural genres in Chinese urban centres in the relatively liberalized 1980s, introduced a dissensuality to dispute and redistribute the sensible fabrics configured by the rigid, ideological-laden yet gradually weakening centralized cultural system and socialist visual regime. Therefore, the 'birth' of Chinese indie cinema indeed commented on and interlinked with (if not necessarily carried on) the political energies of the doomed Tian'anmen Movement. 
To account for the art of the dissensual, it is necessary to explicate what I mean by 'appearance', which is not synonymous with 'representation'. Rancière proposes that 'appearance' is not 'an illusion that is opposed to the real. It is the introduction of a visible field of experience, which then modifies the regime of the visible. It is not opposed to reality. It splits reality and reconfigures it as its double' (quoted in Maimon 2009: 96). In this vein, I grasp 'appearance' in terms of the potential acting-out of the dissensual, and I understand politics as 'an event of appearance' (Panagia 2014:103). As an appearance is staged, it is when and where the boundaries between the visible and invisible, between speech and babble become disputable, which underscores the very dynamics of the 'permanent guerrilla war' apropos the sensible (Rancière et al. 2007: 266).

\section{A Cinema of Translocalism}

The critical lensing of translocality, which re-orients our attention toward questions of space, place, and scale, primarily underlines this study of border-crossing cinema. In recent decades, 'translocality' has provided refreshing insights into fields such as human geography and anthropology in foregrounding the dual dimensions of mobilities and localities. Translocality has provoked a rethinking of the politics of place that critically engages the territorialized notions of transnationalism, in emphasizing the 'interconnectedness between places, institutions and actors' in the age of globalization (Greiner \& Sakdapolrak 2013: 375). In migration studies, for instance, Brickell and Datta have inspiringly proposed a 'multiscalar approach to translocality', which views the latter as 'a situated mode of human agency and mobility through variegated spaces and places across nations, regions, cities, neighbourhoods, buildings and bodies' (Brickell \& Datta 2011: 7). Both authors suggest that instead of simply subsuming 'translocality' under a subset of transnationalism, the local-to-local connections indeed open up 'the local' to movement and linkages across a variety of scales ('body, home, urban, regional or national') and, as a result, diverse modes of mobilities - including all forms of migration (e.g. internal migration) as well as 'immobile', 'parochial' agents - could be taken into consideration (ibid.: 10).

In their anthology of 'Translocal China', Tim Oaks and Louisa Schein leveraged translocality to highlight 'a simultaneous analytical focus on mobilities and localities' (2006: 1; emphasis in original). For instance, the Reform and Opening-up launched since 1978 have made both external and 
internal migrations (e.g. rural-urban migration) more accessible to ordinary PRC citizens. Although Oaks and Schein's project was very much focused on case studies from the socio-economic realms, it would be intriguing to realize how Bumming in Beijing - Last Dreamers by Wu Wenguang, often celebrated as the inaugural work of Chinese independent documentary/ cinema, also underlined a sensitivity towards translocality in capturing poignantly how the roaming artists and writers engaged with both modes of migration in choosing to come to Beijing from their regional hometowns, and/or to finally leave China behind and go abroad.

Taking a stance not too dissimilar from that of the geographers and anthropologists outlined above, here I consider 'transnationalism' a specific manifestation of translocality, not the other way around. For Rancière, the distribution of the sensible relies on 'a temporary geography' wherein its politics concerns 'a disruption in the parcelling out of allocated space, time and sense' (Highmore 2011: 98). When made relevant to our survey of inter-Asia cultural and cinema flows, I will argue, translocalism configures a different way to approach and manifest 'place' as 'an evolving articulation of multiple flows and trajectories in space-time', without necessarily essentializing and fixating its identity as such (Ambaras \& McDonald 2019). It can be proposed that independent border-crossing filmmaking enacts dissensual aesthetics in redistributing how the subjects relate to various places, different modes of mobilities and senses of belonging so that the rigid arrangements upon their 'given roles, possibilities, and competences' could be reconfigured and imagined anew (Rancière et al. 2007: 263).

Despite their disparate filmic styles and aesthetic agendas, the film works analyzed throughout this book, including fictional ones, have been shot on location to 'image' - a term here used to describe the dynamics/practice of visualization and representation - Asian places that are connected to the becoming identities of the filmmakers and/or their filming subjects as well as their 'deterritorializing and reterritorializing journeys' (Naficy 2001: 5). Therefore, what has undergirded my mapping of inter-Asia border-crossing cinema is the 'place-based imagination' that, according to Arif Dirlik, underwrites a project that seeks to ground the observation and articulation of social relations and categories at the local level, 'from below' and (with)in everyday life in order to generate new contexts 'for thinking about politics and the production of knowledge' (Dirlik 1999: 151-152). The emphasis on 'place-based imagination' also echoes what Mette Hjort has espoused as the 'more valuable forms of cinematic transnationalism', here understood as 'a resistance to globalization as cultural homogenization' and 'a commitment to ensuring the pursuit of aesthetic, artistic, social, and political values' (Hjort 2009: 15). 
To grasp and engage the politics of place at both the textual and extratextual levels, therefore, I turn to the filming location and particularly 'location-shoot(ing)'. In his studies on location shooting, Dennis Hwa Lo has emphasized the dynamics of networking between human and non-human actors in 'place-making':

The site of location shooting is made into a place of production when the interactions between filmmakers, residents, and even non-human subjects - the material objects and landscapes within this production environment - produce new configurations of power and social relations. (2015:24)

I propose that 'location shoot(ing)' constitutes, for the translocal auteurs, the material, epistemic basis and research/working milieu for the 'filmic place-making' in relation to their border-crossing imaginaries and discursive articulation of displaced subjectivities and diasporic, ethnic, and postcolonial experiences. Such a perspective has been partially informed by, yet also needs to be differentiated from, Stephanie DeBoer's study of Sino-Japanese coproduction projects, where DeBoer underscores how 'location' configures the very material and epistemological site for national cinema and media actors, stakeholders, and entities to negotiate their industrial infrastructures, production (or co-production) edges and resources, as well as their sometimes competing cinematic visions/desires (see DeBoer 2014). ${ }^{5}$ Despite the overlapping concerns with DeBoer's project on 'co-producing Asia', my study nonetheless shifts the focus onto the independent filmmaker's auteurist agency and practice and pays more attention to Asian locations that are not necessarily mapped out and made visible in the transnational coproduction projects chronicled by scholars like DeBoer.

It is also in referring to the 'place-based imagination' that we can take a closer look at the 'border' in border-crossing cinema. Addressing the difficulties in grasping 'border', Étienne Balibar claims that

5 In her monograph project of 'Coproducing Asia', DeBoer has foregrounded film and media collaborations between Japan and Chinese-speaking regions like Mainland China, Hong Kong, and Taiwan since the Cold War era of 1960 s into the new millennium, exemplifying efforts to address the question 'How does Asia mean?' (see Sun 200o) by framing regional cultural productions historically. Conceptualizing co-production as 'a technology of assemblage', DeBoer further illustrates that the 'assemblage' is in itself constitutive of 'variously scaled production practices' which are not confined to the 'promotional and production practices' but entail the desire, imaginaries, and aspirations unevenly pursued by regional film and cultural industries (DeBoer 2014: 5, 28). She specifically proposes that 'Location...has come to be understood as ever "dynamic and changing", produced as it is across competing powers, practices, and locales' (ibid.: 7). 
the idea of a simple definition of what constitutes a border is, by definition, absurd: to mark out a border is precisely, to define a territory, to delimit it, and so to register the identity of that territory, or confer one upon it [...] The theorist who attempts to define what a border is is in danger of going round in circles, as the very representation of the border is the precondition for any definition (2002: 76).

My aim here is not to propose a 'better' solution to the conundrum posed by Balibar. In relation to the analytic framing of translocalism as outlined earlier, 'border' is primarily approached as the 'edges' or 'lines' of a geopolitically demarcated territory or spatial entity, the scale of which is differentiated at the local, national, regional, and even global levels. Importantly, departing from an understanding of their 'territorial boundedness', one may at the same time grasp borders in relation to the practices and discourses from which they are 'produced, reproduced, and transformed' (Paasi 2012: 2305). Not only is the process of 'bordering' historically contingent and socio-politically specific, the dynamic process itself is significantly connected with key issues of mobility, locality, and identity in our study of border-crossing cinema, thus underwriting the survey of its aesthetics and politics. As rightly suggested by Kōichi Iwabuchi, 'Border crossing does not necessarily bring about the transgression of borders. Transgression of borders requires one to fundamentally question how borders in their existing form have been sociohistorically constructed and also seek to displace their exclusionary power that unevenly divides "us" and "them" as well as "here" and "there"' (Iwabuchi 2015:3).

In this book, I foreground films telling stories about border-crossing journeys and/or subjects 'who are on the move, or remaining sedentary, have borders cross them' (Mezzadra \& Neilson 2013: 6). Shot on location, the works discussed here as such map out and imagine places configuring the ever-shifting inter-Asia borderscape while shedding light on the entangled geographical/geopolitical, historical, and symbolic dimensions of the border(s). This project does not limit itself only to studies on border and border-crossing at the phenomenological level. What shall be illuminated here is the idea of 'border as method' that leverages border as 'an epistemological viewpoint' (ibid.: 18). Through such a critical lensing, we can catch a glimpse of the ways in which the filmmakers and their works constructively yet also contingently engage the 'dialectic relationship' between 'mobility, connections, and circulations' and 'immobility, containment, gate-keeping, ghettoization, bordering, and so forth and so on' (J. Kim 2017: 940). As such, we are able to make sense of 'a deeply heterogeneous global space' in its making (Mezzadra \& Neilson 2013: 6). 
The task of rethinking the border can be pushed a bit further. It is worth pointing out that, although translocalism could fruitfully dialogue with cosmopolitanism in film studies, ${ }^{6}$ here it is not my intention to frame the border-crossing works in terms of 'cosmopolitan cinema' and the filmmaker as the 'cosmopolitan auteur'. It is beyond the scope of this introduction to thoroughly scrutinize the plurality and complexity of the critical spectrum of 'cosmopolitan cinema' (see F. Chan 2017; Mulvey et al. 2017). My aim here is not to negate the critical potentiality of cosmopolitanism but to rethink tendencies of 'liberal romanticisation' apropos of the modes and experiences of border-crossing. In her take theorizing different cinematic 'cosmopolitan encounters', Felicia Chan borrows insights from Galin Tihanov to warn us against valorizing the 'enforced cosmopolitanism' of the exilic experience and the "liberal consensus" which has chosen to see "the cross-border experience of migrant workers, worshippers or writers [as] always a source of cultural enrichment and a display of personal energy and endurance [...] glosses over - or simply fails to see and acknowledge - the attendant manifestations of inequality and disempowerment"' (quoted in F. Chan 2017: 5).

As I shall demonstrate, this study of mine is not oriented toward the overarching cosmopolitan ideal of engaging the world and the other at the representational level. Border-crossing imaginaries and movements in my case studies do not essentially testify to the 'fluid, global, and liquid powers' of globalism (Rancière et al. 2007: 264). Instead, I focus more on the itineraries and trajectories of border-crossing to fathom how, according to Rancière, 'in this world, the borders are as solid as inequalities' (ibid.: 264), which is to say not to take for granted the 'porousness of borders, the hybridity of cultures, and nonessential identities' but to always take into consideration the 'contexts and practices' that make such global flows possible (or impossible) (Paasi 2012: 2305).

Neither does this research seek to approach the filmmakers as cosmopolitan cultural producers and emphasize how they have smoothly negotiated

6 In their 'Editorial' on Cosmopolitan Cinema, James Mulvey, Laura Rascaroli, and Humberto Saldanha have proposed that the discussion of cosmopolitanism in cinema studies could be located in four areas: the first area concerns the cinematic representation, with regard to stories that 'have materialized and performed cosmopolitan outlooks'. A second area relates to the 'mobile characteristics of creative and artistic crews' (Mulvey et al. 2017:3), including both filmmakers and stars. A third area surveys how cosmopolitanism is embodied and practiced in projects such as film festivals and other formats of film exhibition and consumption. A final area looks at certain cosmopolitan cinematic language and/or styles and aesthetics that engage the local and the global. 
cultural differences and reconciled with different forms of belonging. For instance, this study does not highlight how they are associated with the 'deep' cosmopolitanism 'characterized by [...] intimate knowledge of cultural trends and forms', which arguably finds its fullest manifestation in the auteurship of Thai filmmaker Apichatpong Weerasethakul (see Ingawanij \& MacDonald 2006). As I shall address later, although the transgenerational auteurs examined throughout this book have been endorsed and celebrated by global arthouse film institutions and prestigious European-American film festivals, some of them are self-educated filmmakers who have not gone through professional training and have not necessarily undergone any 'educational pilgrimage' in the West. Instead, I shift the focus onto how they have been nurtured by - and have grown out of - specific local, regional independent film cultures and traditions.

A good example is the Japanese independent film collective known as Kuzoku, which has emerged from the world of jishu eiga (literally translated as 'autonomous' or 'do-it-yourself' cinema), a type of 'self-financed nonprofessional filmmaking' (Tezuka 2013: 171), or, to be more exact, an amateur film culture whose origin could be traced back to Japan's leftist filmmaking movement in the prewar period (see Sato 1981). Neither of the two core members of Kuzoku - Tomita Katsuya and Aizawa Toranosuke - were professionally trained in filmmaking. They started as cinephiles, amateur filmmakers, and scriptwriters with barely any connections to the mainstream film world (see Chapter Three). Okinawa-born auteur Takamine Gō, on the other hand, as one of the older generations of jishu eiga filmmakers, was part of the 8-mm amateur filmmaking scene in the early 1970 s when he was studying in Kyoto as an overseas student sent to Japan, back when Okinawa was still under American occupation (see Chapter Five).

As far as 'location shoot(ing)' navigates us to examine translocalism throughout the book, my aim is not to propose an overarching idea to theorize the 'filmic place-making' in relation to cinematic spatiality. Rather, I contend that the filmmakers/collectives under examination have developed their own 'ways of doing and making' to engage the production environments and cinematic spaces and thus have inspired diverse possibilities for theorybuilding, which will be contextualized and historicized in the chapters to follow. Generally speaking, my analysis looks at how the directors have opted for disparate aesthetic interventions and politics when approaching the time-space configuration of the location. Hence, this study also seeks to test the critical potentiality of theories on spatiality and location shooting that have originated from and intersected with vernacular film and cultural movements as well as those rooted in the historical trends of intellectual 
debates, such as the articulation of fükeiron (the theory of landscape) apropos of Japanese cinema, and a discourse about xianchang (a Chinese term meaning 'on the scene' or 'on the spot') in Chinese independent filmmaking.7

\section{Theorizing Border-Crossing Authorship ${ }^{8}$}

\section{Accented Cinema Reconsidered}

Another crucial dimension underlining independent border-crossing cinema concerns film authorship, which connects with my earlier discussions on translocalism. In this chapter and those to follow, I also frame authorship by looking at the interrelated aspects of: 1) cinematic texts, regarding the form of content (e.g. discourses and themes) and the form of expression (e.g. style), with a specific emphasis on the intersecting questions of mobility, identity, and subjectivity; and 2) the sites and spaces of film production, circulation, and exhibition, particularly that of the film festival network.

I consider 'border-crossing cinema' to be one that makes visible a translocal Asia from an auteurist mode of minorness and transvergence, in envisioning rhizomatic socio-political and cultural interconnections across Southeast and East Asian places and societies since the end of the Cold War. Furthermore, it constitutes an integral part of - and dialogues with - the irreversible, uneven processes of globalization experienced at different levels within and beyond the region. Filmmakers examined throughout this book are translocal subjects themselves given how they engage with multiple localities across different scales at the same time in

$7 \quad$ Film scholar Zhang Zhen not only associates xianchang ('on the scene') with the 'quasi documentary and hyper realist aesthetic' that characterizes the Urban Generation Chinese independent cinema. She also emphasizes how xianchang aesthetics has been facilitated by the development of video technology, capturing 'the contemporary spirit (dangxiaxing) of the Urban Generation in general and the "amateur cinema" in particular' (Z. Zhang 2007: 18-19). In his discussion of Chinese independent documentaries, Luke Robinson has examined the theory of xianchang, considering it "a product of the contingent "now" of shooting live, inflected by the particular interpretations of individual filmmakers at a given moment, and structured by the conditions of production under which they worked' (Robinson 2013: 101). For instance, Robinson has specifically proposed that many Chinese independent filmmakers have pursued 'on the scene' aesthetics through the use of long takes.

8 Here 'authorship' is used interchangeably with 'auteurship'. In particular, the former is grasped as a set of discourses as well as praxis foregrounding the central role of the filmmaker as the performative, creative agent in translocal/transnational filmmaking, while the 'auteurist' is used to describe the characteristics of such creative agency. 
relation to various types of (im)mobilities as well as modes of identification. Agreeing with Thomas Elsaesser that 'the author in the global context is both a construct and a person(ality)' (2017:23; emphasis in original), which stresses how the 'rhizomatic' tendencies nowadays have complicated any facile understanding of authorial autonomy, my study considers the auteur/ author as an actor/agency working through and within the dynamic interplay and tensions between identities/subjectivities, mobilities, and localities, without losing sight of the institutional configuration of authorship. What has been proposed here is a critical authorship that hinges on the contingent interrelations between authorial positionalities and translocality. Hence it is not only the cultural-historical context of authorship as a discourse that will be taken into consideration. It is also necessary to turn to how the authorship is at the same time placed within the horizontal, contemporaneous connections between the local, national, and regional cinema cultures and film industries.

It is important to foreground how this border-crossing cinema interlaces in significant ways with the auteurist mode of diasporic, minority, and postcolonial filmmaking and their evolving genealogies in this region, the study of which deserves a more thorough examination that cannot be achieved in this project. There have been plenty of studies exploring the auteur-centred 'independent transnational film genre' (Naficy 1994), 'accented cinema' (Naficy 2001), and 'intercultural cinema' (Marks 200o), the last of which according to Laura U. Marks also zooms in on auteurs who are 'cultural minorities living in the West', especially immigrants who produce their works in the US, Canada, and the UK (Marks 2000: 2). Premised upon his previous argument of 'independent transnational cinema', Hamid Naficy leverages the concept of 'accented cinema' to scrutinize works by the exilic, migrant, and diasporic filmmakers from the Third World (the Global South) working in Western cosmopolitan centres. He indicates that for an 'accented cinema', the 'accent' is not simply to be understood as a linguistic feature but is primarily contingent upon the auteur's conditions of displacement (both as the empirical subjects and in terms of their performative authorship) and the 'accented mode' of production, circulation, and exhibition. The accent particularly manifests itself as prominent visual styles, narrative structures, subject matters, motifs, and structures of feeling.

I am fully aware of how my study of border-crossing cinema can benefit from Naficy's conceptualization. For instance, although the examination of languages does not feature prominently in individual chapters, the linguistic and cultural-political connotations of 'accent' do apply to films scrutinized throughout this book, and not simply because these works tend to use 
multiple languages, accents, and dialects. If I could draw on and modify Brian Bernards' discussions on 'translingual' in Nanyang literary productions, the lensing of 'accent' interconnects with that of the 'translingual' in referring to 'a creolizing language practice' while relating to a body of inter-Asia border-crossing films that speak different languages 'that partake of the same national culture' (Bernards 2016: 27). Meanwhile, for instance, Shu-mei Shih also suggests that 'The radical audioscape of Sinophone cinema, in all its audible differences and multiplicities, challenges the ways in which national communities are understood (heard, seen, etc.), and it is therefore transformative and possibly productive of not only a "different common world" but also "a different people", which would be the ultimate aim of politics for Rancière' (Shih 2014: xi). For example, shedding light on Sinophone languages, accents, and articulations, the translingual perspective can be also leveraged to critique the hegemonic, imperial Japanese-language sphere (as I shall address in the section on the Nihon Documentarist Union; also see Chapter Five regarding Okinawa-on-screen) and possibly that of the Korean language in relation to Koryo saram from a post-diaspora perspective. ${ }^{9}$

\section{Minor Transnationalism}

It is, however, necessary to reflect upon how both Naficy's theorization of 'accented cinema' and Marks' 'intercultural cinema' risk essentializing the filmmaker's positioning as the diasporic/exilic as well as their 'national/ ethnic origins or identities' (also see Khorana 2013) or the geopolitical situatedness of the films as Third Cinema (see Suner 2006). ${ }^{10}$ To grasp

9 In their introduction to the anthology, Koryŏ Saram: Koreans in the Former USSR, editors German N. Kim and Ross King have used Koryŏ saram (romanization in original text) to designate 'Koreans who either personally experienced the forced deportation of 1937, or who are the descendants of Koreans who did'. They particularly focus their study on Central Asian republics like Kazakhstan, Uzbekistan, and Kyrgyzstan, places to which 'the Koreans were deported in 1937 and from which the Koreans in Russia today started moving in the 1950s' (G.N. Kim \& King 2001: R2). It has been pointed out how the research in Koryŏ saram language and linguistics could be divided into the tripartite areas of 'dialect mapping', 'Korean language education', and 'sociolinguistics' (ibid.: R11). While both authors did not specifically mention studies in visual culture and cinema, a symposium organized at the 2018 Busan International Film Festival is centred on Koryo cinema, which accordingly refers to 'a series of films produced by directors of Koryo people (ethnic Koreans in Central Asia and Russia)'. It is stated that 'Koryo cinema addresses the dire issues of language, religion, and ecology as well as ethnicity' ('Inter-Korea Archive and Research: "Koryo" Cinema' 2018).

10 For example, Asuman Suner has usefully questioned the location of accented cinema and seeks to illuminate the 'mutual entanglement between exilic/diasporic filmmaking and national cinema'. Working with a loosely defined category of 'accented cinema at large', Suner looks at 
border-crossing authorship in terms of authorial identity and positionality, I want to switch the lensing to 'minor transnationalism', a concept proposed by Françoise Lionnet and Shu-mei Shih as they sought to tackle the issue of transnationality in the twentieth century from a 'minor' perspective (Lionnet \& Shih 2005: 4). Here, both authors have foregrounded a transversal and horizontal perspective in not only turning to 'the minor cultural articulations in productive relationship with the major (in all its possible shapes, forms, and kinds)' but also the 'minor-to-minor networks that circumvent the major altogether' (ibid.: 8).

Lionnet and Shih mainly attribute the minoritized cultures or perspectives as those related to minority and diasporic persons. However, viewing the minor and minor articulations as something already creolized, hybrid, and therefore transnational, they propose that the positionality of the minor(ity)/ major(ity) should never be essentialized and fixed in dichotomous terms. For them, minor transnationality is contingent upon a cultural transversalism that 'produces new forms of identification that negotiate with national, ethnic, and cultural boundaries', which should be also differentiated from the conception of 'postnational, nomadic, and "flexible" norms of citizenship' that are considered 'relatively unmoored from the control of the state and bounded territories' (ibid.), reaffirming my previous take on cosmopolitan cinema. Arguing how minor transnational subjects 'are inevitably invested in their respective geopolitical spaces', Lionnet and Shih not only favour a politics of place, they also stress the importance of contextualizing and historicizing the 'minority issues' and their 'expressive discourses' (such as cinema) by extending critical perspectives horizontally and transversally (ibid.: 11).

It is important to see how Will Higbee's thesis on the 'cinema of transvergence' echoes the conceptualization of minor transnationalism. Specifically, Higbee intersects Marcos Novak's discussion on 'transvergence' with Félix Guattari and Gilles Deleuze's concept of rhizome in constructing the 'cinema of transvergence' as a critical framing to survey the postcolonial, diasporic cinema in terms of a transcultural phenomenon that would 'operate on both a transnational level - the relationship between the global and the local - and within the context of specific national cinemas and film cultures'

films within national cinema(s) that are equally interrogating issues of belonging and identity and shedding light upon 'the multiplicity of the experiences of displacement, deterritorialization and migration within and across the non-Western world' (Suner 2006:377-378). She has therefore argued for an 'accented genre' wherein neither a filmmaker's status of being ethnic/diasporic/ exilic nor the 'situatedness' of films shall be reified. 
(Higbee 2007: 87). For Higbee, such reframing offers 'a clear understanding of the discontinuity, difference and imbalances of power that exist between various film-makers, film cultures and film industries, as well as the elements of interconnectedness that may bind a film-maker to a given film culture of national identity at a given time'. His cinema of transvergence specifically foregrounds an auteurship whose rhizomatic nature poses challenges to the rigid, dichotomous power structure of centre/margin in configuring 'an engaged (politicized) site of resistance' (ibid.).

For now, we can return to Lionnet and Shih's concerns with the 'others' who are not 'the Third World cosmopolitan and the flexible citizen', and whose travels and movements do not necessarily follow the pattern of 'migration and travelling between the West and the non-West' (Lionnet \& Shih, 2005: 13). I contend that the border-crossing filmmaking examined throughout my project disturbs the implied power relation featured in critical models such as 'accented cinema' in having shifted away from the Third World/West dichotomy and drawn attention to filmmakers as well as filming subjects whose experiential subjectivities have been embedded in the uneven, incoherent socio-political and cultural spheres in Asia and the multifarious translocal flows (e.g. of persons, objects, ideas, images, and affect) within and beyond the region.

On the one hand, delineating the transnational trajectories of East Asian cinema, Song Hwee Lim has addressed the issue of Eurocentrism and pointed out that 'we should not pretend that an unequal power dynamic within East Asia that might impinge upon intra-Asian cinematic collaborations does not exist' (Lim 2011: 25), into which Stephanie DeBoer's project of 'coproducing Asia' has proffered crucial historical insights (see DeBoer 2014). Accordingly, we shall not turn a blind eye to how the border-crossing filmmakers featured here mostly base themselves in the 'media capitals' and Asian urban centres. For instance, Tan Chuimui decided to move to Beijing because of the better opportunities in Chinese-language filmmaking available on the Mainland, and Chinese-Burmese filmmakers such as Midi Z and Lee Yong-chao have chosen to base themselves in Taipei instead of Myanmar to pursue their filmmaking career (see M. M. Chan 2017; Lim 2018).

On the other hand, it has been well articulated by Lionnet and Shih that 'not all minorities are minoritized by the same mechanisms in different places, there is no universal minority position as such' (Lionnet \& Shih 2005: 10-11). In the same vein, I argue that not every border crossing tells the same story. We can return to the 'Homeland and Diaspora' omnibus for clarification. It is important to see how, for instance, Tan's journeying between Beijing and Kuala Lumpur/Malaysia and Midi Z's trips between 
Taipei and Lashio/Myanmar have contributed to exploring the limiting imagination' (Higson 2000) of independent film movement(s) that has often been theorized within a disparate, singular national space and sociocultural context. For Midi Z, Tsai Ming-liang, and even Tan, their filmmaking practices can be better characterized as 'transvergent' in the sense that they alternate 'at different times and in different contexts' between different local/national film cultures and industries; the identity of the transvergent auteurs, therefore, is constantly evolving through 'a process of "becoming", according to Higbee (2007: 88).

In 2010, Tan (b. 1978) relocated herself to Beijing partially to fulfil her ambition to work with Chinese arthouse filmmaker Jia Zhangke, by which time Tan was already internationally recognized as an arthouse filmmaker who played a key role in the emergence of a DV-initiated 'Malaysian New Wave." ${ }^{11}$ Through Jia's independent cinema initiatives (such as his company Xstream Pictures/Xihexinghui), Tan was able to interlace herself with and witness the new waves of legitimization and institutionalization of Chinese independent cinema when Malaysian New Wave as a movement began to decelerate and fragment. Tan did not immediately translate her experiences of displacement into a film work. Rather, in her take for 'Homeland and Diaspora', made during the creative period that overlapped with her sojourn in Beijing, in the phantasmal reenactment of Chinese diasporic intellectual Yu Dafu's diary about Malacca, it seems to be Tan (rather than the essayist) who laments, 'I am a foreigner, no matter where I go'.

Meanwhile, Chinese-Burmese filmmaker Midi Z (b. 1982), whose oeuvre Chapter Six is dedicated to, went to Taiwan to study at the age of 16 , following a migratory pattern that most Chinese-Burmese families that are struggling financially in the border town of Lashio would prefer. Through his internationally acclaimed 'homecoming' series, fictional works and documentaries included, Midi scrutinizes transborder subjects and their precarious lives across the Southeast Asian frontiers. It is intriguing how, while Midi's work such as Ice Poison (Bingdu, 2014) has been celebrated as the gem of Taiwan's national cinema and was entered into the $87^{\text {th }}$ Academy

11 Initiated by DaHuang, the so-called 'Malaysian New Wave' first remained obscure within their home country, principally because these films were not technically qualified as 'Malaysian films', and within the then existing national cultural-ideological system, such films potentially posed questions about the homogenous constructedness of Malay-ness, the national identity, and the official rhetoric of Malay-centric multiculturalism. On the other hand, the New Wave obtained legitimacy after a number of major European film festivals such as the International Film Festival Rotterdam programmed works by the emerging filmmakers in the competition category, where they drew worldwide attention. 
Awards for 'Best Foreign Film' on behalf of Taiwan (Republic of China), his 'homecoming' films have indeed proffered more insights into the everyday struggles of underprivileged folks in contemporary Myanmar.

Crucially, as implied by Lionnet and Shih as well as Higbee, but perhaps not clarified, I propose that the 'minor' articulation or perspective in cultural/film production and circulation should not be easily equated with the expressions and praxis only specific to ethnic minorities, the socially marginalized, and their political struggles, despite significant overlaps between these categories. It is noteworthy that without necessarily disavowing the agenda of identity politics as such, Lionnet and Shih have nonetheless illustrated how the politics of recognition has fixated the position of minorities as one engaging 'with and against majority cultures in a vertical relationship of opposition or assimilation' and thus tend to ignore 'other forms of participation in the transnational that may be more proactive and more creative' available to minorities (2005: 7). Also, they have reminded us that we must pay attention to the limited usage in changing contexts of application' of a strategic essentialism or the politics of authenticity and 'its exclusive tendencies even toward its internal members' (ibid.: 10). Correlating with translocalism, cultural transversalism has been leveraged by Lionnet and Shih to disturb the vertical configuration of established parameters of transnationalism (ibid.: 11). Although Lionnet and Shih are not in favour of Deleuze and Guattari's mapping of the 'minor' per se (ibid.: 2), I believe that the French philosophers' conceptualization of minor literature and minor cinema has provided valuable insights for us to elucidate the 'minor(ness)' and therefore the politics underwriting independent border-crossing films.

\section{Debating the Minor}

A comprehensive survey of the Deleuzian philosophical edifice on difference, repetition, and becoming is out of the question here. Although it is not my focus here to offer a systematic review regarding Deleuze and Guattari's thesis apropos a 'minor literature' (Deleuze \& Guattari 1983) as well as Deleuze's proposal for a modern political cinema, that is, a 'minor cinema', it would nevertheless be helpful to re-examine the minor so that we can envision how it contributes to renewing our understanding of dissensual art and its politics, and vice versa.

Elaborating on the rhizomatic work by Franz Kafka, the Czech-Jewish writer who wrote in German, Deleuze and Guattari have proposed the idea of a minor literature. As explicated by Claire Colebrook, a minor artist like Kafka does not have 'a language or the culture that he could consider his own 
or identical to his being'(2001: 103), which echoes Nick Davis's discussions that what Deleuze and Guattari are proposing with 'minor art' concerns how 'culturally marginalized members of a "major" culture internally recalibrate its expressive forms and grammars' (2013:5).

Moreover, Deleuze and Guattari stress that 'problem of immigrants and especially of their children' and 'problem of minorities' have also become 'the problem of us all' (Deleuze \& Guattari 1983: 19); they have thus pinpointed that "minor" no longer characterizes certain literatures, but describes the revolutionary conditions of any literature within what we call the great (or established)' (ibid.: 18). As Colebrook indicates, Kafka wrote 'not as a being with an identity, but as a voice of what is not given, a "people to come"'. And the identity of this 'people to come' is 'always provisional, in the process of creation' (Colebrook 2001: 118). That is, as is the case with all 'great' literature, 'language seems foreign, open to mutation, and the vehicle for the creation of identity rather than the expression of identity'(ibid.: 103-104; emphasis in original).

Deleuze was able to push further his interrogation of the relationship between the minor and minority vis-à-vis their cultural expressions in Cinema 2: The Time-Image. ${ }^{12} \mathrm{He}$ revisited some of the ideas in 'minor literature' and modified them in his framing of modern political cinema as part of his reconsideration of the crisis of (classical) political cinema in the wake of World War II and the rise of fascism, Stalinism, and so forth, with an eye on the exhausted visions of political alliances and the absence of revolutionary agency and subjectivity, namely the situation whereby 'the people are missing' (Deleuze 1989: 216). Offering an illuminating interpretation of Deleuzian cinema theory, D.N. Rodowick points out that 'minor cinema must produce collective utterances (énoncés collectifs) whose paradoxical property is to address a people who do not yet exist and, in so doing, urge them toward becoming' (Rodowick 1997: 154).

This project of mine foregrounds minority, diasporic, and postcolonial subjects and interweaves discussions on ethnic and national identities. Nonetheless, by reconceptualizing the minor (with Deleuze and Guatarri), my research contests the identity logics formulated upon 'cultural essentialisms and mythical views of authenticity' (Lionnet \& Shih 2005: 9). As explicated by Vered Maimon, 'minority is not a name for a marginalized social group but for a transformational group which, as Paul Patton explains, is defined by the

12 The original French version of Cinema 2: The Time Image (Cinéma 2, l'Image-temps) was published in 1985, precisely a decade after the publication of Kafka: Pour une littéruture mineure (Kafka: Toward a Minor Literature). 
gap that separates its members from a standard model or norm in the same manner in which the simulacrum challenges representation' (Maimon 2010: 333). No matter how the 'minor' might meaningfully overlap in designating minority identities (e.g. in terms of ethnicity, gender, and sexuality) and social groups on the margin, it is not leveraged here to simply recognize, categorize, and express the already-constituted subjects, identities, and their pre-existing community. To conceptualize the authorship of border-crossing cinema is therefore also to liberate the filmmaker from any essentialized and reified identity constructs of cultural, ethnic, racial, and even gender differences. And what we need to underscore is how the auteur's experiential subjectivity and identification may set forth transformations beyond the binarism of major/minor.

An inspiring example can be found in Olivia Khoo's study exploring the minor transnationalism of Asian queer cinema, wherein she illustrates how productive it would be to interweave Deleuze and Guattari's schema of 'minor cinema' with the idea of minor transnationalism. Khoo foregrounds the gendered dimension of the collective enunciations by women queer artists through their filmmaking despite 'the absence of an active community' (Khoo 2014: 38). Also, she points out how such a cinema would necessarily relates to the avant-gardist, independent filmmaking practices examined by Tom Gunning in his earlier formulation of a 'minor cinema' (see Gunning 1989), regarding their mode of production, circulation, and exhibition. Therefore, in reframing minor transnationalism, Khoo not only draws attention to the 'major exhibition' of the minor queer films at international film festivals, she also suggests that the 'minor-to-minor transnational connections between women filmmakers and queer film cultures in Asia' contributes to reimagining an authorship that is 'minor' (Khoo 2014: 41).

It can be further proposed that the politics of minor literature and minor cinema concerns the mode of appearance. This is not to make the facile assumption that the minor could easily be equated with dissensus conceptually. After all, Deleuze (and Guattari) and Rancière 'approach different questions from different metaphysical standpoints' (Phillips 2009: 2). Rather, I focus on how the minor artists and filmmakers have, through their image works, introduced 'lines of fracture and disincorporation into imaginary and collective bodies' to foreground 'uncertain communities that contribute to the formation of enunciative collectives that call into question the distribution of roles, territories, and languages' (Rancière 2011b: 36). I grasp the uncertain community as such also as a 'community of sense', which as Rancière illuminates, is not 'a collectivity shaped by some common feeling' but rather 'a certain cutting out of space and time that 
binds together practices, forms of visibility, and patterns of intelligibility' (Rancière 2009a: 31). Nick Davis thus characterizes the collective value for the work by 'minor artists' as 'less on behalf of existing "minorities" than for new coalitions they catalyze among the oppressed and invisible, along previously unrecognizable lines' (Davis 2013: 5).

In this book, therefore, my lineup of inter-Asia border-crossing auteurs is not confined to those who possess minority, diasporic, and postcolonial identities but extends to include other minor artists whose filmmaking intricately intersects the 'oppressed and the invisible' groups and their collective enunciations, and the independent mode of film production, exhibition, and circulation (Davis 2013:5). Given that it is no longer simply upon the politics of recognition and authenticity that a minor filmmaker envisions and expresses a community of hers/his, I contend that what independent border-crossing filmmaking aspires to and engages with would be a 'permanent guerrilla war' in (re)creating an uncertain community, that is, a 'community of sense' that is also contingent upon an active yet indeterminate spectatorship, since it would be 'up to the spectator' to affectively interact and react to such a work of art (see Rancière et al. 2007: 263). This topic will be further examined throughout the book.

\section{Realigning Independent Border-Crossing Cinema}

Based on the discussions above, it is possible to proffer a brief periodization to tentatively frame border-crossing auteurs and their works in contemporary Asia. Hamid Naficy indicates that what he has examined under the umbrella term of 'accented filmmakers' - namely the exilic, diasporic filmmakers from the Global South who have based themselves in Western urban centres - could be roughly grouped into two categories. The first group are 'displaced or lured to the West from the late 195os to the mid-197os' in the waves of Third World decolonization, Cold War confrontation, and the First World's own sociopolitical movements. And a second group 'emerged in the 1980s and 1990s' not only as a result of the erosion of nationalist, communist, and socialist ideals, in tandem with the disintegration of nationstates and the outbreak of wars triggered by ethnic and religious conflicts, but also due to 'the emergence of postindustrial global economies', which indirectly impacted the policies welcoming non-Western immigration (Naficy 2001: 10-11).

Keeping in mind the Nafician lineage, however, what I zero in on is a lineup of transgenerational Asian filmmakers whose experiences of 
journeying and/or migration, while partially reminiscent of Naficy's second grouping of accented auteurs, should be situated within the historical context of 'the disparity in the political-economic landscape in Asia, the aftermath of national and Cold War struggles, and the new economic realities since the 1980s' (Y.W. Chan 2014: 4). Some of the filmmakers or their families are part of waves of intra-regional migration in Asia, the process of which is even expected to speed up 'with the emergence of more advanced and rigorously developing economies' into the future (Y.W. Chan 2014: 2). Nevertheless, neither the Cold War and its end nor the waves of globalization have impacted upon the individual trajectories of travel and migration equally, an issue that is further complicated if we turn to how the filmmakers' diasporic, minority, and/or postcolonial identities relate to their border-crossing filmmaking across Asia.

Research into each set of independent filmmaking needs to be first placed within the socio-historical development of a specific national film culture and industrial infrastructure and to be examined in relation to the mainstream, commercial, and/or studio-oriented film industries (even when they are not necessarily playing active roles thereof), state socio-cultural apparatus and policies (including censorship), and so forth, in order to account for what independent cinema is 'independent from'. Meanwhile, the dual perspectives of translocalism and the minor help to realign and reterritorialize contemporary Asian independent cinemas. Specifically, the trope of border-crossing filmmaking could be leveraged to reconsider the methodological nationalism that is often practiced in the study of independent cinema, especially if we consider how the national nowadays has become 'a space increasingly populated by the diasporic, transnational, foreign, and global, in a similar way that it has become a battleground for various sub-national forces with heterogeneous ethnic, linguistic, religious, ideological, and class backgrounds' (Choi 2011: 188).

In the case of Japanese independent cinema, I shall emphasize Mitsuyo Wada-Marciano's approach to the 'post-studio condition' of Japanese cinema since the 1990s, wherein major Japanese film studios (e.g. studios like Shochiku, Nikkatsu, and Toho) already have their traditional vertical integration system dissected or transformed. ${ }^{13}$ She points out that 'independent filmmakers are now major players, producing films with much tighter budgets

13 Wada-Marciano argues that within the 'post-studio condition', studios are no longer the 'centers of production' (Wada-Marciano 2012:15), with the production number of the majors only accounting for a small percentage (15\%) (ibid.:14). But as she also points out in her note, the major three still outperformed the independents in terms of box-office revenues (ibid.: 143). 
and under more constraints due to their investors' unwillingness to shoulder significant risks' (Wada-Marciano 2012: 14). It would also be important to see how, while the discourse and practice of jishu eiga significantly interlace with post-studio Japanese independent cinema, as I shall illustrate in the discussions about Kuzoku, what this jishu eiga film collective has sought to pursue with its border-crossing filmmaking might be something drastically different from the cultural imagination of 'Asia as a borderless region' in some contemporary Japanese film works (ibid.: 23).

Chinese independent cinema may present a more complicated scenario. As mentioned earlier, in the aftermath of the 1989 Tian'anmen Square Incident, independent documentary and fictional filmmaking in the PRC emerged from the relatively liberalized socio-cultural terrain of the 1980 s and productively intersected with the then emerging underground cultural genres and contemporary art. Meanwhile, the birth of 'Chinese indie' also testified to the erosion of the planned economy and specifically the fraught - if not forced - transition of the state-owned film studios and their cultural-economic apparatus towards a market economy (see Zhang 2007). Moreover, several former 'underground' filmmakers such as Jia Zhangke, Wang Xiaoshuai, and Lou Ye, previously blacklisted by the Chinese censor and banned from filmmaking or attending international film festivals, were allowed in 2004 to make their first aboveground features. However, even before their 'collective' legitimization by the state's cultural authorities, Jia, Wang, and Lou had started to co-produce their films with overseas capital, even though it was not until later that they set their films in locations outside of China. ${ }^{14}$

But what is more significant for us to grasp the PRC's independent filmmaking is the popularization of Digital Video cameras (DV) since the dawn of the new millennium and the multi-layered, multi-sited DV culture widespread in the country (see Zhang \& Zito 2015). It is in the ever-shifting waves and currents of DV filmmaking that filmmakers of ethnic minority background such as Tibetan filmmakers Lhapal Gyal, Sonthar Gyal, and Pema Tseden (all of whom were trained at the prestigious Beijing Film Academy) have carved out a space for their own people to be seen and heard,

14 Since his second feature film Platform (Zhantai, 200o), Jia Zhangke already started to coproduce with Japanese filmmaker/comedian Kitano Takeshi's Office Kitano. But it was not until Mountains May Depart (Shanhe guren, 2015) that Jia set his own work in Australia. Since his third feature film Suzhou River (2000), Lou Ye started to collaborate with French producers. For his film with the controversial title Summer Palace (Yiheyuan, 2006), the protagonists self-exiled themselves in Berlin. Lou's seventh feature film Love and Bruises (Hua, 2011) is set in Paris, with most of its protagonists speaking French. 
while contributing to 'an alternative, transmediated DV culture whose significance amounts to an emerging regional cinema, critically amplifying and complicating the framework of a "DV-made China"' (Zhang \& Zito 2015: 15), connecting with Sinophone cultural articulations and productions in other Asian places.

As noted, there is no singular timeline or common criteria of valorization to outline and historicize the development of independent cinemas in the People's Republic of China, Japan, South Korea, or across Southeast Asian countries such as the Philippines, Malaysia, and Indonesia. Nonetheless, I have shown elsewhere that during the region's post-Cold War transformation in the late 1980s, Asian filmmakers did create an opportunity to gather together at the inaugural Yamagata International Documentary Film Festival (YIDFF) in Japan in 1989, where many envisioned an 'Asian' independent film culture to come (see Ma 2018). ${ }^{15}$

However idealist the 1989 Manifesto signed at Yamagata might appear, as the omnibus project 'Homeland and Diaspora' has attested, the introduction of affordable and accessible digital video technologies, editing software, and web-based platforms for the production, circulation, and exhibition of films since around the late 199os and the early 2000 s has powered up and renewed independent filmmaking movements across the region, the dynamics of which have been forcibly manifested in independent filmmaking across Southeast Asia (also see Ingawanij \& McKay 2012). For instance, Tilman Baumgärtel associates independent cinema emerging in Southeast Asia since the early 2000 s with the decisive arrival of digital cinema technologies in the region (Baumgärtel 2012: 6), while suggesting that probably only the Philippines can boast of an independent cinema of some sort prior to the arrival of DV to this region. ${ }^{16}$ John Lent further proposes that to answer what Southeast Asian independent cinema is 'independent of', one could turn to 'government regulation and censorship, big mainstream studios and traditional methods/styles of filmmaking' (Lent 2012:13). He discusses the

15 At the 1989 YIDFF, following a 5-hour-long 'Asia Symposium' in which filmmakers, curators, and other film professionals from East Asia and Southeast Asia, participated an 'Asian Documentary Filmmaker's Manifesto' was drafted by a few participating filmmakers, initiated by Japanese documentarist Ogawa Shinsuke, one of YIDFF's founders. The manifesto states: 'We, the Asian filmmakers present here, at the Yamagata International Documentary Film Festival' 89 , call attention to the sad absence of any Asian film in the competition. While this is not the fault of this festival, it puts into focus the fact that major obstacles exist in the making of relevant and interesting documentary films in the Asian region' (Teo et al. 2007: 63).

16 Lent reminds us that in the Philippines, there were filmmakers like Kidlat Tahimik who have worked 'completely outside of the system' since the 1970s (Lent 2012: 16). Tahimik made Perfumed Nightmare (Mababangong Bangungot) with his 16-mm camera in 1976. 
tripartite aspects by navigating through several national cinemas in the Philippines, Indonesia, Malaysian, Thailand, and Singapore.

Whereas it is suggested that DV filmmaking can be leveraged as an entry point to probe into a possible inter-Asia independent cinema culture, I also share Ani Maitra and Rey Chow's idea of 'disaggregating Asia', which seeks to contest the ethno-culturalist tendencies in viewing 'Asia' as 'a homogeneous geopolitical entity'. For Maitra and Chow, 'locality' should be approached 'through the material and infrastructural differences between digital multiplicities, differences that separate the urban from the rural, and the urban privileged from the urban underprivileged' (Maitra \& Chow 2016: 20-21; emphasis in original), the core argument of which indeed emphasizes the 'digital disparity and heterogeneity between geographically proximate spaces and people' (ibid.).

At the same time, I shall reiterate that within the transnational, translocal cultural assemblages across Southeast Asia and East Asia, an independent film auteur's positionality should not be fixated 'only in the interstitial and marginal spaces of national cinemas', if one refers to Will Higbee and Song Hwee Lim in their critique of Naficy's accented cinema and Marks' 'intercultural cinema' (Higbee \& Lim 2010: 10). For one thing, we could argue that Asian independent cinema including border-crossing films are not at all cut off or isolated from the mainstream commercial film industries and their industrial models and formulas, given how 'independent cinema' as a set of practice and discourse itself has been realigned and has diversified in recent decades. For another, what needs to be pointed out but cannot be further expanded on here is how the regional-level collaborative initiatives and projects among independent filmmakers, stakeholders, and the variously scaled entities, institutions, and so forth need to be investigated in their present tense as complex, still-evolving assemblages. What I have in mind are the diverse schemes, programmes, and projects founded by and/or associated with the variously scaled film festival network that seek to accentuate and orchestrate the translocal, regional film exchanges and connections between independent filmmakers and producers from/based in Asia, so that the latter can better navigate through the uneven, powerladen global film festival economy and mediascape. A ready and recent example is the Southeast Asian Fiction Film Lab (SEAFIC) founded in 2016 by Thai film producer Raymond Phathanavirangoon and filmmaker Visra Vichit-Vadakan. ${ }^{17}$

17 SEAFIC aims 'to strengthen the quality of feature-length films from Southeast Asian filmmakers by helping to advance their scripts and develop their projects'. In terms of eligibility for 


\section{Asia is One (1973): A Prehistory of Border-Crossing Asia}

With the theoretical framings of translocalism and minor transnationalism clarified, I want to use a 1973 Japanese documentary titled Asia is One (Ajia wa hitotsu) as an example to probe into the pre-digital, pre-Internet dynamics and politics of border-crossing filmmaking in this region. I contend that Asia is One features importantly in the historical survey of Asian border-crossing films, although this section cannot provide a comprehensive genealogy of border-crossing filmmaking across the region, a topic that deserves to be explored in a further study. In turning to the underestimated, almostforgotten Japanese independent film collective Nihon Documentarist Union (NDU, 1968-1973) together with their filmmaking and theories, ${ }^{18} \mathrm{I}$ aim to foreground how NDU acutely switched its critical lensing at a time when political imagination and activist momentum within Japan started to decelerate and disintegrate. ${ }^{19}$ NDU scrutinized national borders and various types of underprivileged border-crossers (who are not unlike the filmmakers themselves) to envision new political horizons and alternatives. Their methodology is arguably one of translocalism and transcoloniality, with the latter relating to transversal connectivities 'between subjects under different forces of empire, colonialism, and imperial legacy' (Chiang \& Wong 2016: 4).

application, SEAFIC stipulates that: 'Nationals of the following countries are eligible for SEAFIC participation: Cambodia, East Timor, Indonesia, Laos, Malaysia, Myanmar, the Philippines, Brunei, Singapore, Thailand, and Vietnam' and 'Passports must be from Southeast Asia (cannot be the resident only)'. For more, refer to the SEAFIC official site <http://www.seaficlab.com/>. 18 According to one of the key members of NDU, Nunokawa Tetsurō, NDU 'was a group formed of Waseda University dropouts' (Nunokawa 2012: 11). Another member, Inoue Osamu, remarked that NDU 'was a group of filmmakers who produced 16-mm documentary films and animated slide shows in addition to publishing issue-oriented newsletters. Most of the NDU's members were part of the so-called "Zenkyoto Generation", those who had lost any hope in a university education for their future or others who were kicked out of the university' (Inoue 2012:2). Their first feature film Onikko - A Record of the Struggle of Youth Laborers (Onikko: Tatakau seinen rodosha no kiroku, 1969) was planned by the Tokyo Headquarters of the Japanese Socialist Party. Inoue mentioned that the collective disbanded in 1974 (Inoue 2012: 6), with Asia is One its last work. Some of its members, like Nunokawa, continued to make independent films into the 2000s.

19 For instance, Nick Kapur points out that, in the aftermath of the massive social movements of the 1960 s, 'Japanese society was a dramatically different space in which massive extraparliamentary street protests carried out by a broad-based popular movement would become less and less imaginable, and the styles and techniques of protest employed by the anti-treaty movement would be replaced by new forms now associated with the worldwide "New Left" and the global counterculture that emerged in the latter half of the 196os' (Kapur 2018: 10). 
1.1 Group photo of Waseda University's Camera Reportage Research Society (Kamera ruporutāju kenkyūkai), the predecessor of NDU. Photo was taken at a training camp in Hiroshima (August 1966). Middle row: second to the left (Nunokawa Tetsurō); fifth to the left (Inoue Osamu, also a NDU member)

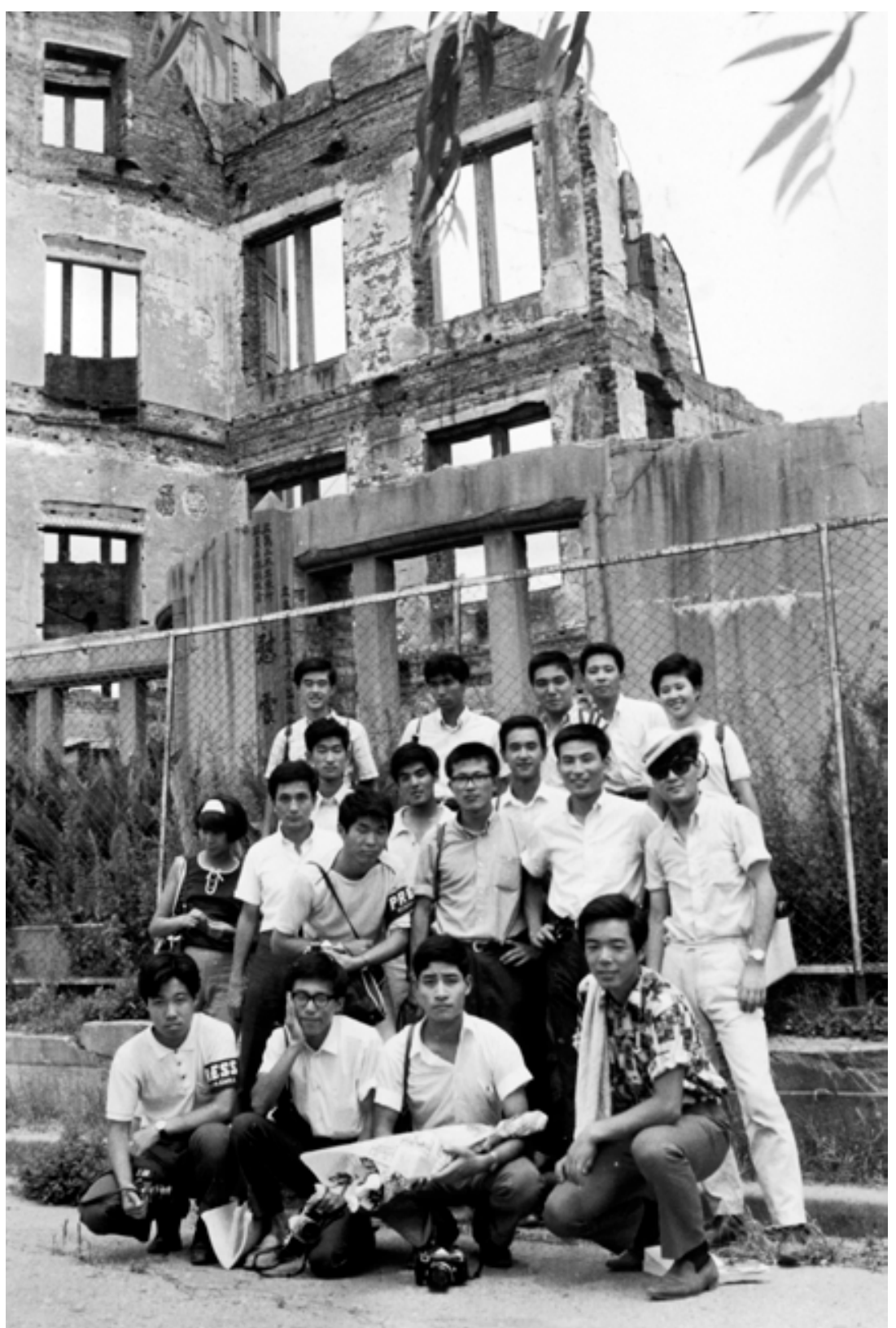


Asia is One was the third documentary feature produced by NDU, a film collective of members that started out with university-club-based filmmaking activities in the late 196 os. $^{20}$ Carrying along their $16-\mathrm{mm}$ camera, NDU members hopped in between places within the so-called 'Japanese-language sphere' (Nihongo-ken) across the East China Sea in-between Yaeyama islands in Okinawa, which had only recently been 'returned' to Japan as one of its prefectures, and Taiwan's northern port city of Keelung to meet and interview a transnational, multi-ethnic body of workers, fishermen, and labourers. The livelihood of these people was contingent upon their (enforced) bordercrossing movement under the influence of Japanese imperial power and its aftermath (e.g. former coal miners who were recruited from the Korean peninsula and Taiwan to work in Okinawa). The NDU also turned to new generations of border-crossers whose migratory trajectory correlated with the reconfigured East Asian geopolitics and capitalist structures in the early 1970s (e.g. young Okinawan workers sent to the 'mainland' of Japan following Okinawa's 1972 'reversion' and Taiwanese migrants who came to Okinawa on short-term manual labour contracts). Somehow unexpectedly, toward the end of the film, the NDU was welcomed by one of Taiwan's mountain villages (at Yilan County, Nan'ao Township) where senior members of the indigenous tribal community (the Atayal/Tayal people) shared memories, in fluent Japanese, about their experiences fighting as part of the Japanese imperial army toward the end of World War II.

Asia is One could be considered NDU's cinematic manifestation of its 'theory of national borders', or kokkyō-ron (see NDU 1973). Whereas a comprehensive review of NDU's universe of film theories (especially their theories on spectatorship) is beyond my focus here, it is necessary to grasp how kokkyō-ron intersects NDU's practice of translocal location shooting with their persistent critique of Japanese imperialism and colonialism against the historical context of the phantasmal 'East Asia Co-prosperity Sphere'. Also, kokkyō-ron interweaves with NDU's rethinking of the so-called 'space of management' (kanrikūkan) of postwar capitalist society, the regulatory power of which had become more and more 'dematerialized' in their time.

Specifically, NDU sought to break away from the constraints imposed by the 'national borderline (kokkyō-sen)' that is 'indispensable in outlining

20 It is worth pointing out how the documentary title purposefully refers to and rethinks the core thesis of Japanese scholar Okakura Tenshin (Okakura Kakuzo) regarding 'Asia is one', proposed at the beginning of the twentieth century in envisioning how 'the Orient's view of Asia' potentially poses 'a challenge to the Eurocentric view of civilization' but was nevertheless appropriated to buttress the Japanese empire's discourse of the Greater East Asia Co-Prosperity Sphere (Sun 2000: 21). 
1.2 A Tayal lady from a Piexau tribal village, Yilan County, Nan'ao Township (May 1972); from Asia is One

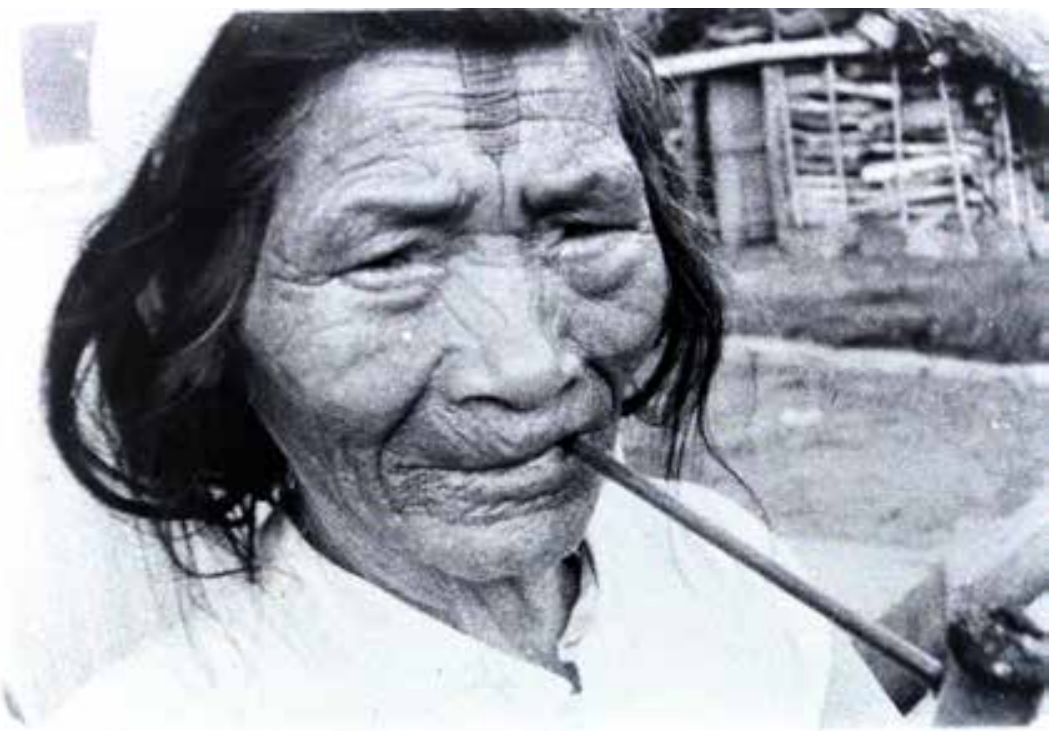

1.3 A Tayal lady from a Piexau tribal village (May 1972)

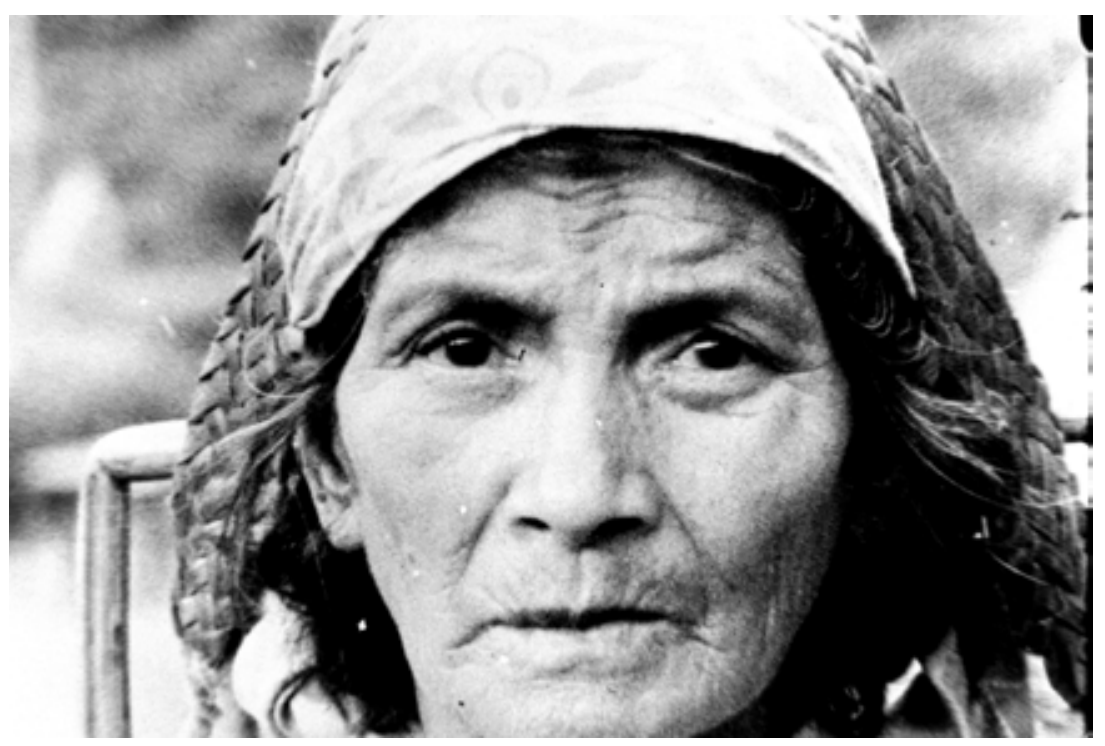


a country $(k o k k a)$ '. The collective aspired to transform the 'border as lines' (sen) into a 'border as sphere' (men) by foregrounding subjects who were the very 'embodiment of the borderlines' (NDU 1973: 32-33). The idea of the 'border as sphere' interlinks with translocalism: NDU transversally mapped out and scrutinized translocal subjects across multiple sites; thereby injecting the essentialist, imperialist ideology of 'Asia is One' with radically new connotations. Crucially, the translocal connections explored are also essentially transcolonial ones, which register the 'shared, though differentiated, experience of colonialism and neocolonialism' that 'construct[s] the shadowy side of the transnational' (Lionnet \& Shih 2005: 11).

NDU's gesture arguably illustrates the collective's sensitivity toward the changing paradigm of Japanese politics as well as of engaged filmmaking; they sought to rejuvenate their political imagination by turning to displaced persons and forgotten places at the margin of the empire that bore the scars of Japanese imperialism and colonization, as well as marginalized groups who, in the wake of the collapsed empire, struggled to survive within the cracks of the quickly developing capitalist economy by means of border-crossing.

Even though NDU was most active in the decades prior to the disintegration of the Cold War order, by shedding light on and critically re-examining the political economy of national borders, its cinematic realization of kokkyoron was already manifesting and predicting the 'trans'-force inherent in the border-crossing practice of a global age, as succinctly summarized by anthropologist Aihwa Ong:

Trans denotes both moving through space or across lines, as well as changing the nature of something [...] (it) also alludes to the transversal, the transactional, the translational, and the transgressive aspects of contemporary behaviour and imagination that are incited, enabled, and regulated by the changing logics of states and capitalism (1999:4).

The 'trans' force explicated by Ong here also concerns how Asia is One can be celebrated as a work of dissensual art. Through their border-crossing filmmaking, NDU modified the fabric of the sensible in carving out a space for the 'zainichi Okinawans, fishermen, Japanese in Okinawa, Koreans, Taiwanese, and Taiwanese aborigines' to emerge and speak for themselves, as pointed out by NDU's core member Nunokawa Testurō. ${ }^{21}$ In so doing,

21 With an eye on NDU's stylistic experimentation, meanwhile, one may propose that not only did its documentary intervention concern a documentation of the spatial, geographical 
NDU also created an uncertain community that 'call[s] into question the distribution of roles, territories, and languages' apropos a pre-given configuration of the sensible (Rancière 2011b: 40). As such, it intervened in and disrupted the imperialist and capitalist knowledge production about 'Asian places', 'Asian peoples', and their interrelations, so that 'Asia as one' could be envisaged anew.

\section{Circulating and Exhibiting Border-Crossing Films}

In this study, I map out the circulation and exhibition of border-crossing cinema by focusing on the international film festival network. ${ }^{22}$ Given the filmmaker's multi-layered identities and the translocal, transnational nature of their filmmaking (even in cases without actual transborder movements), it would be important to see how the circulation, exhibition, and even production of border-crossing films on the variously scaled film festival sphere have pushed us to rethink the positionality of the auteur in relation to critical paradigms such as national cinema and transnational cinema. More straightforward questions to be asked when foregrounding film festivals as a point of entry would be: what might some of the refreshing perspectives be for us to approach the aesthetics and politics of border-crossing works on the festival circuit if not those drawn from the framing of 'national cinema'? Alternatively, how can we benefit from emphasizing the film festival network and its affiliated entities as being integral to grasping the politics of independent border-crossing cinema?

In his thesis on global authorship, Thomas Elsaesser offers a provocative discussion on the 'unsymmetrical but reciprocal dependencies' between the international film festival institution and global auteurs. Leveraging the heuristic concept of 'double occupancy', Elsaesser suggests how the global auteur nowadays necessarily negotiates and performs her/his creative

movement but also, as Nakamura Yōko has pointed out, the collective grasped the border-crossing movement in temporal terms, too. As she explains, it is illuminating that what has emerged from the incommensurability between the sound and image/space and time is actually the 'different layers of history' (kotonaru rekishino chisō) (Nakamura 2013: 80).

22 The framework of the 'international film festival network' (Elsaesser 2005; Valck 2007) was developed from Bruno Latour's 'actor-network theory' in tandem with other sociological theories on space and globalization; it has become one of the most important approaches for the interdisciplinary field of film festival studies. I have pointed out elsewhere that the film festival network highlights 'a comparatively stable yet flexible template or benchmark outlining organizational structures and logistics, programming standards and ideals and so forth for individual festivals to follow and refer to' (Ma 2017:2). 
autonomy, not without self-contradictions though, in a delicate condition that he describes as 'serving at least two masters' (Elsaesser 2017: 25-26). He pays specific attention to auteurs who 'make films outside their home country, while still "representing" it by associating its national stereotypes', as is the case with the Russian maestro Alexander Sokurov. According to Elsaesser, Sokurov is "performing" the radical free spirit and independent auteur, both on and off film sets', given how the filmmaker has become fully aware of the importance of the "non-commercial, "art cinema" funds and investors', including international festivals (ibid.: 27-28).

In Elsaesser's incisive (yet somehow less celebratory) analysis of the intricate relation between 'the world's films and filmmakers' vis-à-vis film festivals, he has emphasized how the 'openness' of festivals can be highly deceptive:

It is an open invitation to self-conscious ethnicity and re-tribalization, it quickly shows its affinity or even collusion with cultural tourism, with fusion-food-world-music-ethnic-cuisine Third Worldism in the capitals of the first world, and more generally, with a post-colonial and subaltern sign-economy, covering over and effacing the new economy of downsizing, outsourcing, and the relentless search for cheap labor on the part of multi-national companies (ibid.: 25-26).

In other words, even though he does not necessarily view the filmmaker's agency in a reductionist light, Elsaesser has voiced how global auteurs and their films have adopted strategies close to 'a kind of "self-exoticizing" or "auto-orientalism"' to engage the already indispensable film festival circuit. His critique of the 'asymmetrical, but reciprocal dependencies' between the non-Hollywood, arthouse, and independent cinema auteurs and the film festival circuit (26) arguably highlights the consensual underpinnings of the international film festival network. For one thing, the festival network is such a hierarchical configuration in itself (see Abé Nornes 2011, 2014), with the 'currency' of global auteur 'stamped and certified at very few of the world's many festivals', such as the almighty Cannes in France (Elsaesser 2017: 24). Moreover, global festivals nowadays are mostly driven by the neoliberal imperatives and mechanisms of film markets (e.g. financing schemes for both finished and unfinished projects), pitching sessions and project labs, master classes, talent campuses, and so on and so forth.

Is it still possible to envision the politics of (international) film festivals? Would a film festival still constitute the space and time of appearance as far as dissensual art and minor artists/auteurs are concerned? If so, how? 
These are tough questions that this current study can only address partially. As Rancière has suggested, we could approach film festivals as 'specific distributions of space and time, of the visible and the invisible, that create specific forms of "commonsense"' (Rancière 2010: 141); then the politics of film festivals would also concern how the dissensual may be introduced into the 'distributions of space and the weaving of fabrics of perception' (ibid.). T.J. Demos posits that Rancière's reconceptualization of 'art's autonomy [...] supersedes traditional associations with isolationist escapism and artistic essentialism', which allows us to reconsider 'how the conflicted, institutionalized, and sheltered space of the biennale exhibition [...] might nonetheless offer moments of oppositional energy that are irreducible to the means-end logic of effectiveness' (Demos 2013: 91-92). Demos' observations about the world of contemporary art and biennales have inspired me to also grasp the film festival system in the light of 'conflicted, institutionalized, and sheltered space' wherein dissensus may occur, specifically concerning how a specific film festival arranges itself and orchestrates its heterogeneous actors, stakeholders, and components. Specifically, I argue that, however problematic the festival curation, selection, and programming might be in conforming to the consensus, disagreement might still be introduced into the public spheres of film festivals (the plurality of the 'spheres' has been emphasized by Cindy Wong in her survey, see Wong 2011) regarding how, for instance, the curatorial practices could include certain titles and auteurs and interrelate with film movements, making them a visible part of the global visual regime.

For instance, even with trend-setting, top-notch international festivals such as Cannes, Berlin, and Venice (known as the 'Big Three'), which boast unparalleled cultural capital, artistic prestige, and prominent market and industry presence, it is not difficult to recall how the festivals, as a certain 'pre-given sensible regime' themselves, have historically experienced 'moments of oppositional energy' wherein the specific 'commonsense' arrangement correlating stakeholders such as filmmakers and film professionals, film works, audiences, institutions, and state power were disrupted and redistributed, with a new common stage created for new players wherein a new assemblage of actors, stakeholders, and entities emerged to take part. ${ }^{23}$

23 For instance, in her pivotal monograph on film festival network, Marijke de Valck has pointed out that in the 1950s and 196os, despite the steady growth of European film festivals, 'The growing attention given to economic and glamour considerations created especially strong feelings of dissatisfaction' (De Valck 2007: 61). De Valck used the turmoil at the 1968 Cannes festival as an example where, in response to the leftist sentiments and social discontents prevalent in France, and particularly in protest against the dismissal of Henri Langlois, then the head of 
In addition, I have demonstrated elsewhere that the framing of the 'international film festival network' itself needs to be reconfigured to allow us to theorize and contextualize festival networking and scale-making at the local, national, and regional levels. Therefore, festivals that do not necessarily conform to the 'universal' neoliberal paradigm in the current global hierarchical architecture (namely, not in being the 'very few' prestigeous film festivals) can be taken into consideration and have their significance recognized and understood (Ma 2017). One good example would be the aforementioned YIDFF, a remotely located Asian-cinema-oriented international documentary festival that has been cultivating a network among Asian independent filmmakers since its foundation and has so far gone against the tide in not installing any film market or financing schemes. Or we can look at some of the short-lived independent film festivals in the PRC (e.g. the already defunct Yunnan Multicultural Visual Festival/Yunfest or the Beijing Independent Film Festival, which was forced to close down). Upon the landscape of the global film festival circuit, these less-discussed and often underestimated film festivals have indeed carved out a space for Asian independent filmmakers and films - including the border-crossing strand - to emerge and engage its spectatorship with their specific sociopolitical agendas.

Importantly, as if reverberating with Rancière's point that escapism and unconstructive critique of the market only serve to 'abandon all hope for emancipation' (Rancière et al. 2007: 263), Demos boldly proposes that, within the setting of contemporary art, 'the market can and does in certain cases reward politically conscious artistic practice - and not necessarily in ways that are immediately neutralizing' (Demos 2013: 93). Therefore, he states, 'viewing commercial institutions as complex, diverse, and at times contradictory does not mean capitulation. Rather, it entails acknowledging at present the inescapability of operating within a market-driven system, but not necessarily operating on its terms' (ibid.). His argument connects with Rancière's proposition that instead of simply denunciating the market and thus acknowledging our own powerlessness, 'the fundamental question is

Cinémathèque Française, Cannes was terminated earlier than scheduled (ibid.: 61-62). De Valck also pointed out how the revolt at Cannes (and also at the Berlin International Film Festival) impacted the global film festival system with regard to the emphasis placed on film auteurs. The selection procedures were even reformulated by gradually replacing the selection committees for/by national cinemas with professionals such as curators and programmers. Also see Cindy Wong's wonderful account of the 'the long 6os' concerning global (read: European) film festival history, which also mentions the 'more peaceful' changes with the Locarno International Film Festival (Wong 2011: 46). 
to explore the possibility of maintaining spaces of play' (Rancière et al. 2007: 263). Returning to our discussion about the tension-filled space of the film festival network, first, there is no need for independent filmmakers (and producers) to escape from the neo-liberalized festival economy and its everexpanding, diversifying project initiatives and market apparatus. Instead, the challenges concern how minor artists may learn about ways of carving out and maintaining 'spaces of play' while remaining part of the game, engaging with the neoliberal environment and its interconnected entities.

Hence, besides a re-examination of the film festival apparatus, our attention will shift back to filmmakers' agency and their aesthetic practices, in order to tease out how the authorial practices may 'produce forms for the presentation of objects, forms for the organization of spaces, that thwart expectations' and contest the 'inscription within given roles, possibilities, competences' (Rancière et al. 2007: 263). Elsaesser's take on the 'self-exoticism' reinforces the fact that the minor filmmakers have no choice but to subscribe to the 'second-order performed nationalism' in order to cater to the imagination of their cosmopolitan (festival) audiences. I propose that the perspective of 'double occupancy' has become nonetheless insufficient in addressing the politics of border-crossing cinema that deals with the issues of multi-layered identities and entangled national belongings, as is the case with Tibetan cinema vis-à-vis Chinese national/ethnic-minority cinema, or Okinawan cinema or zainichi Korean cinema vis-à-vis Japanese (ethnic) cinema. ${ }^{24}$ By means of Rancière and Demos, I also attempt to move away from Elsaesser's framing of global auteurs' performativity apropos of their creative constraints, where presumably the filmmakers are only left with assigned roles, scripts, capacities, or positions to fit into and play. Instead, I want to explore whether it is possible for minor transnational auteurs (based in Asia) to disturb the 'a priori distribution of the positions and of the capacities or the incapacities attached to those positions' that reaffirms the 'allegories of inequality' (Rancière 2009b:12). That is to say, one needs to pay attention to how the inter-Asia border-crossing auteurs are performing their creative autonomy in a very complicated manner, especially when we consider the tension between their ethnic, diasporic, and postcolonial

24 In her observations on post-studio Japanese cinema, especially with films with zainichi theme/characters, Mitsuyo Wada-Marciano proposes that, 'The underlying formation throughout the contemporary ethnic films is that those appealing, energetic, and ethnically marked characters - being oppressed and unfairly segregated in Japanese society - act out within the diegetic ideological justification, a point-of-view that can be easily shared with the audiences through their identification with those attractive Japanese stars' (Wada-Marciano 2012: 122-123; emphasis in original). 
articulations vis-à-vis the paradigm of national cinema(s) on the film festival circuit. Tensions and incongruencies as such have potentially opened up border-crossing filmmakers to 'spaces of play' both at the level of aesthetic experimentation and across the interrelated spheres of film production, circulation, and exhibition.

\section{Works Cited}

Abé Nornes, M. (2011). 'Asian Film Festivals, Translation, and the International Film Festival Short Circuit'. In Iordanova D. and Cheung R. (eds.), Film Festival Yearbook 3: Film Festivals and East Asia, pp. 42-45. St. Andrews: St Andrews Film Studies.

- (2014). 'Yamagata-Asia-Europe: The International Film Festival Short Circuit'. In Miyao D. (ed.) The Oxford Handbook ofJapanese Cinema, pp. 245-262. New York: Oxford University Press.

Ambaras, D.R., and McDonald, K. (2019). 'What We're Doing'. Bodies and Structures: Deep-Mapping Modern East Asian History. Retrieved 10 February 2019 from < https://scalar.chass.ncsu.edu/ bodies-and-structures/what-were-doing >.

Balibar, E. (2002). Politics and the Other Scene. (C. Jones, J. Swenson, and C. Turner, trans.). London; New York: Verso. DOI: 10.1177/030981680608800115.

Baumgärtel, T. (2012). 'Introduction: Independent Cinema in Southeast Asia'. In Baumgärtel T. (ed.), Southeast Asian Independent Cinema, pp. 1-10. Hong Kong: University of Hong Kong Press.

Ben-Ari, E., and Otmazgin, N. (eds.) (2012). Popular Culture Co-Productions and Collaborations in East and Southeast Asia (Kyoto Cseas Series on Asian Studies). Singapore: NUS Press; Kyoto: Kyoto University Press.

Bernards, B. (2016). Writing The South Seas: Imagining The Nanyang In Chinese And Southeast Asian Postcolonial Literature. Singapore: NUS Press.

Berry, C. (2013). 'Transnational Culture in East Asia and the Logic of Assemblage', Asian Journal of Social Science, 41/5: 453-470. DOI: 10.1163/15685314-12341314

-, Liscutin, N., and Mackintosh, J.D. (eds.) (2009). Cultural Studies and Cultural Industries in Northeast Asia : What a Difference a Region Makes. Hong Kong: Hong Kong University Press.

Brickell, K., and Datta, A. (2011). 'Introduction: Translocal Geographies'. In Brickell K. \& Datta A. (eds.), Translocal Geographies: Spaces, Places, Connections, pp. 3-2o. Farnham, England; Burlington, USA: Ashgate Publishing Limited. DOI: 10.1080/1369183X.2012.740986.

Chan, F. (2017). Cosmopolitan Cinema: Cross-Cultural Encounters in East Asian Film. London; New York: I.B. Tauris.

Chan, K. (2009). Remade in Hollywood: The Global Chinese Presence in Transnational Cinemas. Hong Kong: Hong Kong University Press.

Chan, M.M. (2017). 'Mail-Order Brides and Methamphetamines : Sinophone Burmeseness in Midi Z's Burma Trilogy', Concentric: Literary and Cultural Studies, 43/September: 11-31. DOI: 10.6240/concentric.lit.2017.43.2.02

Chan, Y.W. (2014). 'Asian Migration: Issues, Migrants, and Regional Updates'. In Chan Y.W., Haines D.W., and Lee J.H.X. (eds.), The Age of Asian Migration:Continuity, Diversity, and Susceptibility, Volume 1, pp. 1-17. Newcastle upon Tyne: Cambridge Scholars Publishing.

Chen, K.-H., and Chua, B.H. (2007). 'Introduction/the Inter-Asia Cultural Studies: Movement project'. Chen K.-H. and Chua B.H. (eds.), The Inter-Asia Cultural Studies Reader, pp. 1-5. London; New York: Routledge. 
Chiang, H., and Wong, A.K. (2016). 'Queering the Transnational Turn: Regionalism and Queer Asias', Gender, Place \& Culture, 23/11: 1-14. DOI: 10.1080/0966369X.2015.1136811.

Choi, Jinhee, and Wada-Marciano, M. (eds.). (2009). Horror to the Extreme:Changing Boundaries in Asian Cinema. Hong Kong: Hong Kong University Press.

Choi, JungBong (2011). 'National Cinema: An Anachronistic Delirium?', The Journal of Korean Studies, 16/2: 173-192. DOI: 10.1353/jks.2011.0012.

Colebrook, C. (2001). Gilles Deleuze. London; New York: Routledge.

Corcoran, S. (2010). 'Editor's Introduction'. In Corcoran S. (ed.), Dissensus: on Politics and Aesthetics, pp. 1-24. London; New York: Continuum International Publishing Group.

Davis, N. (2013). The Desiring-Image: Gilles Deleuze and Contemporary Queer Cinema. Oxford, UK: Oxford University Press. DOI: 10.1093/acprof.

DeBoer, S. (2014). Coproducing Asia: Locating Japanese-Chinese Regional Film and Media. Minneapolis: University of Minnesota Press.

Deleuze, G. (1989). Cinema 2: The Time-Image. (H. Tomlinson and R. Galeta, trans.). Minneapolis: University of Minnesota Press. DOI: 9781472512604.

—, and Guattari, F. (1983). 'What Is a Minor Literature?', (R. Brinkley, trans.), Mississippi Review, 11/3: 13-33.

Demos, T.J. (2013). The Migrant Image : The Art and Politics of Documentary during Global Crisis. Durham; London: Duke University Press.

Dirlik, A. (1999). 'Place-based Imagination: Globalism and the Politics of Place', Review (Fernand Braudel Center), 22/2: 151-187. DOI: 10.2307/40241454.

Elsaesser, T. (2017). 'The Global Auteur: Control, Creative Constraints, and Performative Selfcontradiction'. In Jeong S. and Szeniawski J. (eds.), The Global Auteur : the Politics of Authorship in 21st Century Cinema, pp. 21-42. New York; London: Bloomsbury Academic.

Gallagher, M., and Shin, C.-Y. (eds.) (2015). East Asian Film Noir : Transnational Encounters and Intercultural Dialogue. London: I.B. Tauris.

Gates, P., and Funnell, L. (eds.) (2012). Transnational Asian Identities in Pan-Pacific Cinemas: The Reel Asian Exchange. London; New York: Routledge.

Greiner, C., and Sakdapolrak, P. (2013). 'Translocality: Concepts, Applications and Emerging Research Perspectives', Geography Compass, 7/5: 373-384. DOI: 10.1111/gec3.12048.

Gunning, T. (1989). 'Towards a Minor Cinema: Fonoroff, Herwitz, Ahwesh, Lapore, Klahr and Solomon', Motion Picture, 3(1/2):2-5.

Hardt, M., and Negri, A. (200o). Empire. Cambridge, MA; London, England: Harvard University Press.

Higbee, W. (2007). 'Beyond the (trans) national : Towards a Cinema of Transvergence in Postcolonial and Diasporic Francophone Cinema(s)', Studies in French Cinema, 7/2: 79-91. DOI: 10.1386/sfci.7.2.79.

—, and Lim, S.H. (2010). 'Concepts of Transnational Cinema: Towards a Critical Transnationalism in Film Studies', Transnational Cinemas, 1/1: 7-21. DOI: 10.1386/trac.1.1.7/1.

Highmore, B. (2011). 'Out of Place: Unprofessional Painting, Jacques Rancière, and the Distribution of the Sensible'. In Bowman P. and Stamp R. (eds.), Reading Rancière: Critical Dissensus, pp. 95-110. London: Continuum.

Hjort, M. (2009). 'On the Plurality of Cinematic Transnationalism'. In Durovicová N. and Newman K.E. (eds.), World Cinemas, Transnational Perspectives, pp. 12-33. New York: Routledge. DOI: 10.1017/CBO9781107415324.004.

Hunt, L., and Leung, W.-F. (2008). 'Introduction'. In Hunt L. and Leung W.-F. (eds.), East Asian Cinemas: Exploring Transnational Connections on Film, pp. 1-13. London; New York: I.B. Tauris. 
Ingawanij, M.A., and MacDonald, R.L. (2006). 'Blissfully Whose? Jungle Pleasures, Ultra-Modernist Cinema and the Cosmopolitan Thai Auteur', New Cinemas: Journal of Contemporary Film, 4/1: 37-54. DOI: 10.1386/ncin.4.1.37/1.

-, and McKay, B. (eds.) (2012). Glimpses of Freedom: Independent Cinema in Southeast Asia. Independent Cinema in Southeast Asia. Ithaca, NY: Cornell University Press.

Inoue, O. (2012). 'What Was the NDU?--Forty Four Years of the NDU, from Onikko to Headhunter's Song'. In Yasui Y. \& Tanaka N. (eds.) The Legendary Filmmaking Collective NDU and Nunokawa Tetsurō, pp. 2-7. Tokyo;Kobe: Cinematrix; Kobe Documentary Film Festival Committee.

'Inter-Korea Archive and Research: “Koryo" Cinema' (2018). Trans:Asia Screen Culture Institute, Korea National University of Arts; Busan International Film Festival. Retrieved 1 November 2018 from <https://www.facebook.com/transkarts/posts/1083894721777753/>.

Iwabuchi, K. (2015). Resilient Borders and Cultural Diversity: Internationalism, Brand Nationalism, and Multiculturalism in Japan. Lanham: Lexington Books.

Jin, D.Y., and Otmazgin, N. (2014). 'Introduction: East Asian Cultural Industries: Policies, Strategies and Trajectories', Pacific Affairs, 87/1: 43-51. DOI: 10.5509/201487143.

Khoo, O. (2014). 'The Minor Transnationalism of Queer Asian Cinema: Female Authorship and the Short Film Format.', Camera Obscura, 29/1: 32-57. DOI: 10.1215/02705346-2408507.

Khorana, S. (2013). 'Crossover Cinema: A Genealogical and Conceptual Review'. In Khorana S. (ed.), Crossover Cinema Cross-Cultural Film from Production to Reception, pp. 3-13. London: Routledge.

Kim, G.N., and King, R. (2001). Koryŏ Saram: Koreans in the Former USSR. New Haven, CT: East Rock Institute.

Kim, J. (2017). 'Globalization, Transnationalism, and "Mobile Societies" from a Sociological Perspective: Comments on Engseng Ho's "Inter-Asian Concepts for Mobile Societies"', The Journal of Asian Studies, 76/04: 935-41. DOI: 10.1017/Soo21911817000936.

Lamarre, T. (2015). 'Regional TV: Affective Media Geographies', Asiascape:Digital Asia, 2/January 2015: 93-126. DOI: 10.1163/22142312-12340021.

Lent, J.A. (2012). 'Southeast Asian Independent Cinema: Independent of What?'. In Baumgärtel T. (ed.), Southeast Asian Independent Cinema, pp. 13-19. Hong Kong: Univeristy of Hong Kong Press.

Leung, W.-F., and Willis, A. (eds.) (2014). East Asian Film Stars. London: Palgrave Macmillan UK. Lim, S.H. (2011). 'Transnational Trajectories in Contemporary East Asian Cinemas'. In Lee V.P.Y. (ed.), East Asian Cinemas : Regional Flows and Global Transformations, pp. 15-32. London: Palgrave Macmillan UK. DOI: 10.1057/9780230307186.

— (2018). 'Towards a Poor Cinema: Ubiquitous Trafficking and Poverty as Problematic in Midi Z's Films', Transnational Cinemas, 9/2: 131-146. DOI: 10.1080/20403526.2018.1454700.

Lionnet, F., and Shih, S.-M. (2005). 'Introduction: Thinking Through the Minor, Transnationally'. In Lionnet F. and Shih S. (eds.), Minor Transnationalism, pp. 1-23. Durham; London: Duke University Press.

Lo, D.H. (2015). Imaging Communities [electronic resource]: Location Shooting as Place-Making in Contemporary Chinese and Taiwanese Cinemas. Dissertation (Ph.D.), University of California, Los Angeles.

Ma, R. (2017). 'Asian Documentary Connections, Scale-making, and the Yamagata International Documentary Film Festival (YIDFF)', Transnational Cinemas, 9/2, 164-180. DOI: 10.1080/20403526.2017.1379733.

Maimon, V. (2009). 'The Third Citizen: On Models of Criticality in Contemporary Artistic Practices', October, 129/2009: 85-112. DOI: 10.1162/octo.2009.129.1.85. 
- (2010). 'Towards a New Image of Politics: Chris Marker's Staring Back', Oxford Art Journal, 33/1: 83-101.

Maitra, A., and Chow, R. (2016). 'What's “in"?: Disaggregating Asia through New Media Actants'. In Hjorth L. and Khoo O. (eds.), The Routledge Handbook of New Media in Asia, pp. 17-27. London; New York: Routledge.

Marchetti, G., and Tan, S.K. (eds.) (2007). Hong Kong Film, Hollywood and the New Global Cinema: No Film is an Island. London: Routledge.

Marks, L.U. (2000). The Skin of the Film: Intercultural Cinema, Embodiment, and the Senses. Durham; London: Duke University Press.

May, T. (2010). 'Review of Dissensus: On Politics and Aesthetics'. Notre Dame Philosophical Reviews. Retrieved 10 December 2018 from <https://ndpr.nd.edu/news/ dissensus-on-politics-and-aesthetics/>.

Mezzadra, S., and Neilson, B. (2013). Border as Method, or, the Multiplication of Labor. Durham ; London: Duke University Press. DOI: 10.1215/9780822377542.

Morris, M., Li, S.L., and Chan, S.C. (eds.) (2006). Hong Kong Connections: Transnational Imagination in Action Cinema. Hong Kong: Hong Kong University Press.

Mulvey, J., Rascaroli, L., and Saldanha, H. (2017). 'For a Cosmopolitan Cinema - Editorial', Alphavile:Journal of Film and Screen Media, Winter/14: 1-15.

Naficy, H. (1994). 'Phobic Spaces and Liminal Panics: Independent Transnational Film Genre', East-West Film Journal, 8: 1-30.

Naficy, H. (2001). An Accented Cinema: Exilic and Diasporic Filmmaking. Princeton, NJ: Princeton University Press. DOI: 10.1177/1470412907075071.

Nakamura, Y. (2013). 'Kokkyō no aru fūkei: Ajia wa hitotsu ni okeru riarizumu ni tsuite' [The Landscape of the National Borders: About the Realism in 'Asia is One']. In Onozawa N., Nakamura Y., and Yasui Y. (eds.), Moyuru kaikyō : NDU to Nunokawa Tetsurō no eiga:undō ni mukete [Ablazing Strait: The cinema of NDU and Nunokawa Tetsurō:Toward a Movement], pp. 76-107. Tokyo: Inpakuto Shuppankai.

NDU (1973). 'Seisaku komento' [Production Notes]. Hanhakusho [Anti Whitepaper], p.122. Tokyo: Hanhakusho Henshūbu.

Nunokawa, T. (2012). 'Asia is One'. In Yasui Y. and Tanaka N. (eds.), The Legendary Filmmaking Collective NDU and Nunokawa Tetsurō, pp. 15-16. Tokyo: Cinematrix; Kobe: Kobe Documentary Film Festival Committee.

- (2012). 'Motoshinkakarannu'. In Yasui Y. \& Tanaka N. (eds.) The Legendary Filmmaking Collective NDU and Nunokawa Tetsurō, pp. 11-12 Tokyo; Kobe: Cinematrix; Kobe Documentary Film Festival Committee.

Oakes, T., and Schein, L. (2006). 'Translocal China: An Introduction'. In Oakes T. and Schein L. (eds.), Translocal China: Linkages, Identities, and the Reimagining of Space, pp. 1-35. London; New York: Routledge. DOI: 10.2307/20066191.

Ong, A. (1999). Flexible Citizenship: The Cultural Logics of Transnationality. Durham; London: Duke University Press.

Paasi, A. (2012). 'Border Studies Reanimated: Going Beyond the Territorial/Relational Divide', Environment and Planning A, 44/10: 2303-2309. DOI: 10.1068/a45282.

Panagia, D. (2014). '"Partage du sensible": The Distribution of The Sensible'. Deranty J.-P. (ed.), Jacques Rancière:Key Concepts, pp. 95-130. Durham, UK: Acumen Publishing Limited.

Phillips, C. (2009). 'Difference, Disagreement and the Thinking of Queerness', Borderlands, 8/2:1-17.

Rancière, J. (2009a). 'Contemporary Art and the Politics of Aesthetics'. In Hinderliter B., Maimon V., Mansoor J., and McCormick S. (eds.), Communities of Sense: Rethinking Aesthetics and Politics, pp. 31-5o. Durham; London: Duke University Press.

— (2009b). The Emancipated Spectator. (G. Elliott, transl.). London; New York: Verso. DOI: $10.1111 /$ wusa.12080. 
- (2010). Dissensus: On Politics and Aesthetics. (Steven Corcoran, transl.). London; New York: Continuum International Publishing Group. DOI: 10.1007/s13398-014-0173-7.2.

- (2011a). The Politics of Aesthetics: The Distribution of the Sensible. (G. Rockhill, transl.). New York: Continuum International Publishing Group.

- (2011b). 'The Thinking of Dissensus : Politics and Aesthetics'. In Bowman P. and Stamp R. (eds.), Reading Rancière: Critical Dissensus, pp. 1-17. London; New York: Continuum International Publishing Group.

—, Carnevale, F., and Kelsey, J. (2007). 'Art of the Possible: Fulvia Carnevale and John Kelsey in conversation with Jacques Rancière'. Artforum International, March: 256-269.

Robinson, L. (2013). Independent Chinese Documentary: From the Studio to the Street. London: Palgrave Macmillan UK.

Rodowick, D.N. (1997). Gilles Deleuze's Time Machine. Durham; London: Duke University Press. DOI: 10.1353/sub.2000.0010.

Sato, T. (1981). 'Sukurin rōdōsha ron-37-hageshiku moeta jishu eiga undō--puro kino no hakkutsu to hozon' [Review of Laborers on Screen--37--flourshing autonomous film movement--the discovery and preservation of Prokino], Gekkan Sōhyō, 284: 88-91. Nippon Rōdō kumiai sōhyō gikai.

Shih, S. (2014). 'Foreword: The Sinophone Redistribution of the Audible'. In Yue A. and Khoo O. (eds.), Sinophone Cinemas, pp. viii-xi. Basingstoke, UK; New York: Palgrave Macmillan.

Sun, G. (2000). 'How Does Asia Mean? (Part I)', (S.-L. Hui and K. Lau, transl.) Inter-Asia Cultural Studies, 1/1: 13-47. DOI: 10.1080/14649370050141186.

Suner, A. (2006). 'Outside In: “Accented Cinema" at Large', Inter-Asia Cultural Studies, 7/3: 363-382. DOI: $10.1080 / 14649370600849223$.

Szeto, K.-Y. (2011). The Martial Arts Cinema of the Chinese Diaspora:Ang Lee, John Woo, and Jackie Chan in Hollywood. Carbondale: IL: Southern Illinois University Press.

Teo, S., Erikawa, K., and Kazuyuki, K. (eds.) (2007). Asia Symposium 1989. Yamagata: Yamagata International Film Festival.

Tezuka, Y. (2013). 'Dynamics of the Cultures of Discontent: How Is Globalization Transforming the Training of Filmmakers in Japan?'. In Hjort Mette (ed.), The Education of the Filmmaker in Europe, Australia, and Asia, pp. 171-187. New York: Palgrave Macmillan US.

Tolia-Kelly, D.P. (2019). 'Rancière and the Re-Distribution of the Sensible: The Artist Rosanna Raymond, Dissensus and Postcolonial Sensibilities within the Spaces of the Museum', Progress in Human Geography, 43/1: 123-40. DOI: 10.1177/0309132517739141.

Valck, M. de (2007). Film Festivals: From European Geopolitics to Global Cinephilia. Amsterdam: Amsterdam University Press.

Wada-Marciano, M. (2012).Japanese Cinema in the Digital Age. Honolulu: University of Hawai'i Press. DOI: 10.21313/hawaii/9780824835941.001.0001

Wong, C.H.-Y. (2011). Film Festivals: Culture, People, and Power on the Global Screen. New Brunswick: Rutgers University Press.

Xu, G.G. (2008). 'Remaking East Asia, Outsourcing Hollywood'. In Hunt L. and Leung W.-F. (eds.), East Asia Cinemas: Transnational Connections on Film, pp. 191-202. New York: I.B. Tauris.

Yu, S.Q. (2012).Jet Li: Chinese Masculinity and Transnational Film Stardom. Edinburgh: Edinburgh University Press. DOI: 10.3366/j.ctt3fgsrm

Zhang, Z. (2007). 'Bearing Witness: Chinese Urban Cinema in the Era of "Transformation" (Zhuanxing)'. In Zhang Z. (ed.), The Urban Generation: Chinese Cinema and Society at the Turn of the Twentieth-first Century, pp. 1-33. Durham: Duke University Press. DOI: 10.1016/j. annemergmed.2012.11.003.

—, and Zito, A. (2015). 'Introduction'. In Zhang Z. and Zito A. (eds.), DV-Made China: Digital Subjects and Social Transformations after Independent Film, pp. 1-25. Honolulu: University of Hawaii Press. 



\title{
$2 \quad$ A Landscape Over There
}

\author{
Rethinking Translocality in Zhang Lu's Border-Crossing \\ Films ${ }^{1}$
}

\begin{abstract}
This chapter examines three border-crossing films by the Korean-Chinese (chaoxianzu) filmmaker Zhang Lu, namely Desert Dreams (2008), Dooman River (2010), and Scenery (2013). Using the conceptual framework of translocality, this study first explores how Zhang, as a translocal auteur, leveraged his multi-layered identities to engage the global film festival network. Not only does Zhang reinvent the border as a new scale to scrutinize the translocal movement of deterritorialized subjects and diasporic peoples, he also sheds light on the significance of place in identity formation and further examines the power geometry of globalization. As such, Zhang's translocal filmmaking both intersects and challenges us to rethink Chinese independent filmmaking and Korean diasporic cinema.
\end{abstract}

Keywords: film festival network, translocal auteur, chaoxianzu/ethnic Korean, Yanbian, Korean diaspora cinema

Born and raised in the Yanbian Korean Autonomous Prefecture (YKAP, Yanbian Chaoxianzu zizhizhou), part of Jilin Province in the People's Republic of China (PRC), third-generation Korean-Chinese filmmaker Zhang Lu taught literature at Yanbian University before venturing into filmmaking. ${ }^{2}$

1 A different version of this chapter was published as 'A Landscape over There: Rethinking Translocality in Zhang Lu's Border-Crossing Films', Verge: Studies in Global Asias, 4 (2018), 111-132, DOI:http://dx.doi.org/10.3138/jsp.40.4.399. I am deeply indebted to Zhang Lu for his generous help with this project. My deepest gratitude goes to Prof. Kim So-young for her documentary works and various wonderful research projects, workshops, and symposiums on Zhang Lu and on koryo saram in relation to contemporary visual cultures. Also, I am thankful to Jeon Tae-ho for his help with the Korean transliteration.

2 Zhang's grandfather fled from Uiseong County (Uiseong-gun), North Gyeongsang Province (Gyeongsangbuk-do, currently part of South Korea) to China in 1919, while his mother crossed

Ma, Ran, Independent Filmmaking across Borders in Contemporary Asia. Amsterdam, Amsterdam University Press 2020

DOI: 10.5117/9789462986640_CHO2 
It was after moving to Beijing and living there for ten years that Zhang had the impulse to direct a film of his own. Starting from zero background in filmmaking, Zhang's debut short Eleven (Shiyisui, 2000) was entered into the competition at the Venice International Film Festival and caught the attention of the international film community.

With his first dramatic feature film, Tang Poetry (Tangshi, 2003), Zhang moved on to collaborate with South-Korea-based companies for ensuing film projects, some of which would be co-productions between his own studio Lu Film (est. 2009) and various overseas cultural and film bodies. Zhang's oeuvre, which is independently produced and predominantly uses the Korean language including dialects, ${ }^{3}$ has mainly been circulated in and endorsed by international film festivals and through the arthouse niche market within South Korea and beyond. Upon accomplishing his supposed 'lifework' of Dooman River (Duman-gang, 2010) in his native Yanbian, Zhang once had the idea of quitting filmmaking when he relocated to Seoul for a college teaching job in 2012. Yet after a short hiatus, Zhang restarted with a commissioned film festival project. Starting from his seemingly light-hearted drama Gyeongju in 2014 (a semi-romance story takes place in the historical city of Gyeongju), Zhang is increasingly seen engaging the urban petite bourgeoisie's everyday life in contemporary South Korean society, wherein he also experiments with stylistic formulas and narrative tropes that blur the boundaries between dream, memory, and reality.

With his creative trajectory in mind, this chapter pays more attention to Zhang's early works prior to Gyeongju, particularly three of what I shall call 'border-crossing' films: fiction features Desert Dreams (Gyeong-gye, 2008) and Dooman River, and his first documentary feature Scenery (Pung-gyeong, 2013). I mainly frame my discussion from two perspectives. First, I turn to the auteur's flexible positioning as a translocal filmmaker whose creative work intricately intersects multiple film communities in South Korea, Mainland China, and beyond. It is crucial to see how Zhang leverages his translocal

the river from North Gyeongsang's Yongdeok County (Yeongdeok-gun) in the 1930s, a migratory trajectory typical of many ethnic Korean immigrants who resettled in Chinese territory (interview with the author in May 2017). I want to specify that 'ethnic Korean' is used in this chapter to highlight the discourse of 'ethnic minorities' (shaoshu minzu) within China, wherein the Chaoxianzu people are considered one of the 'minorities'. And my use of 'Korean-Chinese' (with the hyphen) while referring to these same people, lays more emphasis on the status of the ethnic Koreans/Chaoxianzu when they have migrated to South Korea and started to interact and intermingle with Korean society.

3 Zhang's first feature film Tang Poetry (Tangshi, 2003) and fifth feature film Chongqing (2008) are in the Chinese language (with Chinese regional dialect). 
identity and diasporic affiliations to engage the political economy of the global film festival network. Second, and more importantly, this chapter explores how Zhang's films have revolved around the cinematic trope of border crossing to explore the issues of location and dislocation, mobility and immobility, and identity.

\section{Reframing Translocality}

Before elucidating Zhang Lu's translocal authorship, it is necessary to examine the conceptualization of translocality - even though I have touched upon translocalism in Chapter One - to grasp how it may connect with our understanding of Zhang's authorial positioning and his transnational works. In their introduction to Translocal China, Tim Oakes and Louisa Schein emphasize approaching translocality with a 'simultaneous analytical focus on mobilities and localities'(Oakes \& Schein 2006: 1; emphasis in original). They also turn to the 'subjective dimension of translocality' without losing sight of the physical, material movement of both human and non-human actors, including objects, ideas, images, and so forth (ibid.).

The 'translocal' turn in geography studies, and in particular in Oakes and Schein's anthropological survey, has inspired film scholar Zhang Yingjin in his spatial studies of Chinese cinema, which highlights the PRC's post-socialist filmmaking specifically since China's entry into the World Trade Organization in 2001. Zhang has suggested how we could gain new perspectives into the production, circulation, and exhibition of contemporary Chinese cinema in terms of 'space and polylocality'. He has been quick to suggest how the 'everyday' no longer functions 'as the fixed local' but 'occur at various scales, from the local (or translocal) to the national and global' (2010: 75). And somewhat understandably, his examination has mainly foregrounded how Chinese independent filmmaking/filmmakers responded to and intervened in the drastically changing cityscape and disorienting urban experiences into the new millennium. Nevertheless, Zhang Yingjin's remapping of the '(trans)local' has been to a great extent confined to and contingent upon the social imaginary of a globalizing, urbanizing (Mainland) China and its geographical territory. His interrogation of subjectivity - whether of Chinese film auteurs or their film characters - is incorporated into a critique of the political economy of post-socialism, while he has shown less interest in reflecting upon the disparate articulations of 'Chinese' identities and senses of belonging. Such perceived dissatisfaction then leaves much to be explored regarding 
films from the PRC that address marginalized communities and cultural landscapes that are not necessarily Sinocentric and/or urban-located, and cases wherein the translocal movement and imagination on and off screen are related to auteurs and/or subjects who are from diasporan communities and/or ethnic minorities within and outside of China.

In his survey of translocality, Zhang Yingjin refers to Arif Dirlik and what the latter advocated as 'place-based imagination' (see Dirlik 1999). Dirlik's re-conceptualization is closer to what Oakes and Schein refer to as the 'cultural approach' to place, which, differing from the 'materialist approach', advocates 'a sense of local knowledge and experience as an alternative to the universal pretensions of abstract scientific discourse' (Oakes \& Schein 2006: 20). Nevertheless, Dirlik does not turn a blind eye to the 'absolute' process of deterritorialization (Buchanan 2005: 30 ). Nor does he simply try to resurrect any retroactive essentialization of 'place' as opposed to 'space'. Rather, his intervention envisions place and the place-based consciousness as a 'project' that, despite its utopian connotations, seeks to generate new contexts 'for thinking about politics and the production of knowledge'. Such a project can be achieved by means of grounding the observation and articulation of social relations and categories at the local level, 'from below' and in everyday life (Dirlik 1999:151-152). Sensibility as such towards place in the age of globalization plays a crucial part in reimagining the interconnection between the local (or national) and the global given the deceptive symmetry between the two.

Dirlik's challenge illuminates 'a recognition of the primacy of place, and of its autonomy, and, on that irreducible basis, to produce translocal or, better still, transplace alliances and cooperative formations' (quoted in Zhang 2010: 6; emphasis in original). Zhang Yingjin similarly suggests that translocality could be examined in three areas: 'places of attachment or identification, people whose physical or imaginary movements across scale connect disparate spaces and places, and technologies and modes of communication that facilitate such attachment, identification, movement, and connection' (ibid.: 9).

In emphasizing scale and place, translocality contributes to reconsidering transnational cinema studies. In Will Higbee and Song Hwee Lim's illuminating thesis calling for a 'critical transnationalism' in film studies, they stress that the conceptualization of 'transnational cinema' itself 'risks celebrating the supranational flow or transnational exchange of peoples, images, and cultures at the expense of the specific cultural, historical, or ideological context in which these exchanges take place' (Higbee \& Lim 2010: 12). Engaging Higbee and Lim's critique, Chris Berry argues, 'The multitude 
of transnational projects constituting these transborder cinema practices cannot all be reduced to and accounted for wholly in terms of the logic of the market, its so-called imperatives, and the even larger forces such as cultural affinity that shape it in certain ways' (2010:123). Translocality may therefore provide a useful framework to examine transnational filmmaking practices like Zhang Lu's, which do not necessarily register the celebratory discourse of Asian integration and regionalism characterizing most marketdriven co-production projects and industrial collaborations in the region. As already indicated in Chapter One, considering that the transnational is also one manifestation of the translocal, I prefer the latter to foreground the local-to-local connection apropos of independent filmmaking.

\section{Departing from Yanbian: Zhang Lu as a Translocal Auteur}

In arguing for Zhang Lu to be seen as a translocal film auteur, it is necessary to consider how the dual aspects of mobilities and localities frame the way we comprehend the interrelations between: 1) Zhang's ethnic Korean/ Korean-Chinese identity in relation to his authorial positioning; 2) his translocal, transnational filmmaking practice, especially the production, circulation, and exhibition of his films at variously scaled film festivals and on the niche market; and 3) his works that feature travelling subjects and their stories of journeying, migration, and displacement. Furthermore, 'translocal authorship' is used here to differentiate from the mode of transnational, commercial, generic co-production in Southeast Asia and East Asia despite their possible overlaps. The former foregrounds a mode of independent production and specific authorial agency in connecting places, network actors, and subjectivities. The emphasis concerns how Zhang's grassroots-level translocal alliance connects with the place-based imagination and everyday life experiences at the textual and extra-textual levels. Such tendencies shed light on how the auteur would 'favor street-level views over cartographic surveys, contingent experience over systematic knowledge, and bittersweet local histoires over a grand-scale global history' (Zhang 2010: 74; emphasis in original).

Oakes and Schein point out that translocality envisions how mobile subjects have developed multiple layers of attachment, since 'time-space compression has made it possible to translate identity into various scales simultaneously, by identifying with multiple localities in both practical and imaginary ways' (Oakes \& Schein 2006: 10; emphasis in original). The aim is not to make a problematic assumption about how Zhang Lu has 
conveniently developed cultural identifications with both China and South Korea on equal, undifferentiated terms, which was never the case. Rather, such potential translocal identifications need to be questioned and further contextualized in underlining how the ethnic Korean (or Chaoxianzu in Chinese) identity itself is historically structured and conditioned, with a focus on the locale of Yanbian (Yeongbyeon in Korean). Meanwhile, I should also mention that, although this chapter does not revolve around the conceptural framework of Sinophone, as indicated elsewhere, the heuristic of place-based imagination indeed interlinks with what has been repeatedly emphasized by Shu-mei Shih that 'Sinophone must be place-based' (Shih 2007: 34). As I will further highlight in the ending section, underpinned by its rethinking of diaspora as well as that of the essentialized notion of Chineseness, Sinophone studies have partially reverberated with what Oliver Dew has proposed as a 'post-zainichi' moment and the 'post-zainichi' mode in zainichi/Koreans-in-Japan cinema, the latter two of which for Dew have expressed 'an uneasiness, if not an outright rejection of, any fixed concept of identity' (Dew 2016:19). Meanwhile, it has inspired me to see how Zhang Lu's filmmaking and his works, while being potentially celebrated as a unique type of Korean diasporic filmmaking - that is, a Korean-Chinese cinema - also contest the idea of diasporic authenticity and question the 'axis of origin and return' oriented around the idea of a singular 'homeland' (Klein 2004: 26). As illuminated by Sonia Ryang, 'Koreans - as with any diasporic people - are divided, and their internal division has been a sharp, irreconcilable one, reflecting both the artificial partition of their homeland and the fratricidal civil war that impressed a finality on the expatriate community's split loyalties'(Ryang 2009: 8).

In his study on the geopolitical positioning of Yanbian, Daniel Gomà stressed that, 'Unlike other national minorities (shaoshu minzu) of the PRC, Koreans are one of the few ethnic groups that come from territories not under Beijing's control' (Gomà 2007: 870). With a population of approximately 2 million, ${ }^{4}$ ethnic Koreans or the Korean minority in China are the descend-

4 The number of ethnic Koreans in the YKAP used to exceed that of the Han nationality. According to online statistics released in 2018 by the government of Jilin Province, the population number of chaoxianzu was 757,200 , making up $36.04 \%$ of the total population of the prefecture (see 'yanbian chaoxianzu zizhizhou 2017nian guominjingji he shehuifazhan tongjigongbao'). As Gomà has stressed, 'But Yanbian is more than a simple autonomous zone: since 1952 it has become the touchstone of Korean culture for Koreans living in China. Beijing is also worried about Yanbian's geopolitical importance. Covering an area of 42,67o square kilometers, the autonomous prefecture shares a border of 623 kilometers with North Korea and 223 with Russia' (Gomà 2007: 879). 
ants of migrants from the Korean peninsula between the mid-1 $9^{\text {th }}$ century and the end of the Second World War. As explained by Gomà, 'The first wave of immigration arrived in the 1860 s when a terrible famine in the north of the peninsula forced numerous Koreans to cross the Chinese border and establish themselves in Yanbian' (ibid.). Although not the focus of this chapter, I want to make clear that the unfolding history of Korean people's transborder migration and displacement for over a century has intricately entangled with the geopolitical turbulence and social vicissitudes in this part of East Asia. ${ }^{5}$

In particular, from China's socialist era, ethnic Koreans in the PRC have been recognized and governed as one of the Chinese state's 55 'ethnic minorities' (shaoshu minzu, in addition to the Han majority). ${ }^{6}$ The identity formation for ethnic Koreans has been subjected to changing state policies and social-engineering projects that seek to integrate the ethnic minority groups into a multi-ethnic and unitary Chinese state. ${ }^{7}$ It was within the

5 The historical trajectories and contexts include but are not limited to: the Japanese empire's expansion and imperial war; the establishment and fall of the puppet regime of Manchukuo (1932-1945) in Northeast China; waves of Korean nationalist movements across Manchuria, the Korean peninsula, and Japan; China's civil war (1945-1949) fought between the Chinese Communist Party and the government of the Nationalist Party (Kuomintang); the founding of the PRC in 1949; the Korean War (1950-1953) and the subsequent division of Korea into the Democratic People's Republic of Korea (DPRK) and the Republic of Korea (ROK); and last but not the least, the Cold War.

6 In this chapter, 'ethnic minority', 'minority nationality', and 'minorities' are basically used interchangeably to indicate shaoshu minzu in the PRC. For law scholar Wang Linzhu, 'minorities have the rights to territorial autonomy under the Regional Ethnic Autonomy (REA) regime, as well as to other preferential policies respecting financial, technical, social, and cultural affairs' (L. Wang 2015: 2). Nevertheless, minzu was considered synonymous with 'nationality' within the PRC until the 1990s, when upon seeing the dissolution of the former socialist states and the problematic implications of nationality, the Chinese state started to prefer the use of 'ethnic minority' and 'regional ethnic autonomy' to register minzu in its official discourse (ibid.: 4). For more on minzu and shaoshuminzu as a discourse in Chinese cinema studies, refer to Zhang, Y. (1997).

7 The area of Yanbian was historically called 'Gando'. Important to our understanding of Yanbian's historical complicacy and its current role in the border dispute between the PRC and the ROC/DPRK is the Gando Agreement, signed between Japan and China (Qing Dynasty) in September 1909, which 'formally recognized Chinese control of the region known as Gando in Korean, Jiandao in Mandarin, and Kanto in Japanese'(Gomà 2007: 867). Due to its associations with Manchukuo's colonial rule, the name of 'Jiandao' was no longer in use since the founding of the PRC. The Yanbian Korean Autonomous Region (Zizhiqu) was established by the Chinese central government in 1952, and in 1955, the State Council officially promulgated the creation of Yanbian Korean Autonomous Prefecture (Zizhizhou). Scholars have approached, from various perspectives, how Yanbian remained a geopolitically significant locale, if not a sensitive zone in relation to the complicated power entanglements between the CCP, the former Soviet Union, 
context of China's post-socialist economic reform beginning in 1978, and particularly with the PRC's establishment of diplomatic relations with South Korea in 1992, that the ethnic Korean communities were able to establish and fortify their translocal connections on various fronts with South Korea - mainly in Yanbian and other locales in Northeast China. At the same time, currently the largest group of foreigners in South Korea are the Korean-Chinese (Joseonjok in Korean), who have mostly migrated to Korea as workers and job-seekers since the 1980 os. $^{8}$

Zhang Lu's native prefecture of Yanbian is not only a conjuncture for interrelations between the PRC and South Korea. Yanbian's geopolitical and geographical position is further complicated by the fact that the Yanbian Korean Autonomous Prefecture shares a border of 623 kilometres with North Korea (Gomà 2007: 879). The border zone therefore also constitutes a frontier for the ethnic Korean community to engage with North Korean people and learn about their conditions in everyday life, which were a major source of inspiration for Zhang's Dooman River.

We should not disregard how Zhang's (Korean) diasporic status, linguistic ability, and cultural insights have significantly underscored his transnational alliance - his working mobility presents an almost unrepeatable model for other (ethnic Han) Chinese filmmakers to copy. ${ }^{9}$ On the other hand, Zhang's translocal movement has complicated the way we approach his ethnic identity and diasporic affiliation when they are defined, set in motion, and are no longer essentially confined to 'the margins of China and Chineseness' (Shih 2011: 711). Zhang has arguably leveraged border crossing, both in terms of film practice and discursive articulation, to disturb the centre-periphery dichotomy within which his ethnic and cultural identity and his native Yanbian are implicated. It is proposed that he could even 'jump across' the given scale-hierarchy (local-national-regional-global) that underpins his positioning in relation to certain reified forms of identity construct and power structures.

China's Nationalist Party (Kuomintang/Guomindang), and the DPRK regime in its postcolonial transformations since the collapse of Manchukuo in 1945 (see Cathcart 2010; Colin 2003; Gomà 2007). 8 According to Sébastien Colin, Yanbian had its frontier opened to North Korea in the mid-1980s and South Korea in the early 1990s (Colin 2003: 2). Meanwhile, when it comes to possibilities of citizenship and legal rights, the Korean state has stipulated disparate schemes to privilege Korean-Americans over Joseonjok, the latter of whom are classified as foreign and are more regulated under low-skill work (see Seol \& Skrentny 2009).

9 Jin Guanghao, also an ethnic Korean filmmaker from YKAP, won the Busan International Film Festival's 'New Current' award with his debut film Life Track in 2007; this film was produced by Zhang Lu. 
I do not have enough space in this study to elaborate on this, but I believe it requires a separate project to canvass the cultural productions by generations of ethnic Korean/Chaoxianzu writers, poets, playwrights, intellectuals, and so forth who have used both the Korean and Chinese language in search of diversified tropes and styles to depart from and engage 'Yanbian' as a geopolitical territory and discursive foothold to frame and articulate layered sense(s) of identification and national belonging. ${ }^{10}$ It is not to contend that Zhang Lu's creative trajectory has necessarily interlaced with practices of these PRC-based minor artists as a collective. ${ }^{11}$ However, for one thing, as will be examined further, it still remains a crucial question whether we can also categorize Zhang's cinema as part of PRC's ethnic minority filmmaking, that is, as Chaoxianzu cinema. On the other hand, better knowledge of Chaoxianzu's diverse cultural articulations, despite the constrained, often ideology-laden discursive sphere available in the PRC for such engagements, is integral to a more delicate understanding of Zhang Lu's changing authorial positioning. I argue that fictions like A Quiet Dream (Chun-mong, 2016), Ode to the Goose (Gunsan: geowireul noraehada, 2018), and Fukuoka (2019), which were shot after Zhang relocated to Seoul, have taken a candid stance towards the issues of national identity and identification apropos of ethnic Korean subjects from Yanbian, North Korea, South Korea, and Japan, with somewhat humorous yet highly self-reflexive underpinnings.

Moreover, perhaps no connective sphere other than the international film festival network could better illustrate the dynamics of Zhang Lu's translocal filmmaking as well as the tension with which it is entangled. Zhang's South Korean productions often circulate under the national tag

10 In his chapter in the anthology of contemporary Chinese literature, Mark Bender only uses a few lines to describe 'ethnic Korean literature' (Bender 2016). Nevertheless, there has been no lack of academic attention directed towards ethnic Korean literature (Zhongguo chaoxianzu wenxue) within the PRC (see H. Jin 1992; Quan \& Zhao 1992; also see X. Jin 2002). Yanbian University (with its university journal published since 1974) has been playing quite a prominent role in initiating academic studies on chaoxianzu literature and translating/introducing related research output from, for instance, South Korean academia. In 2009, the university started a long-term, state-funded, gargantuan project of a 100-volume 'complete anthologies' on Chaoxianzu historical documents (chaoxianzu shiliao daquan) (see Zhongguo chaoxianzu shiliao quanji). 11 I am using 'minor' here in the Deleuzian sense so it is not merely about the ethnic minority status of these cultural creators (also see Chapter One). For Gilles Deleuze and Felix Guattari, minor literature is best embodied through Kafka's body of work, and it can be approached from a tripartite framing. First, it is 'not a literature of minority language' but one that 'a minority makes in major language' through the 'deterritorialization of the language'. Hence 'minor literature' should not be simply equated with a 'minority literature', despite possible overlaps between the two. Second, it is political in connecting with 'the question of the individual'. Third, it produces collective assemblage of utterances (Deleuze \& Guattari 1983: 16-19). 
of 'South Korea' on the film festival network, as evidenced by his decision to pitch his projects at the Busan International Film Festival's Asian Project Market, ${ }^{12}$ as is also the case with his romantic comedy Gyeongju (2014) premiered at the 67 th Locarno International Film Festival. The latter was also showcased at the New York Korean Film Festival 2014, an event launched by the non-profit Korea Society.

At the same time, Zhang's transnational affiliations with overseas film production entities and international festival funding schemes are not isolated cases for independent filmmakers in China, considering the complicated socio-political and economic situation within the PRC to produce, distribute, and circulate arthouse films. For instance, as one of the leading Chinese independent auteurs, Jia Zhangke not only founded his film company Xstream Pictures in both Beijing and Hong Kong, he also established a long-term partnership with Japan's Office Kitano for his second feature film, Platform (Zhantai, 200o). Nonetheless, as far as Sinophone cinema is concerned, Zhang's ethnic minority background often directs the focus away from the talk of transnational capital flow and technology transfer towards the implications of national identification. For instance, when Zhang Lu's tenth drama feature A Quiet Dream, also a Korean production, was premiered at the 2016 Busan International Film Festival, Chinese online entertainment media Tencent emphasized how the Chaoxianzu filmmaker situates his filmmaking in between Seoul and Beijing ('chaoxianzu yiminhoudai zhang lu: jiazaizhongguo, shiye zai hanguo [The Descendant of Chaoxianzu Immigrant Zhang Lu: Home in China, Career in Korea]').

International film festivals 'have become multilayered, global industrial events that link different players and entities in getting films made and shown' (Wong 2011: 129). However, this does not necessarily mean that the festival system has already transcended its inherited linkages with national cinema and its limiting' imagination, both discursively and institutionally (see Higson 200o). Festival programming becomes increasingly autonomous and performative in addressing desired curatorial ideals, extending to the choreography of all festival sectors and including the industry segments of marketplace and pitching sessions. Thus, festival programmers or its curatorial body can actually make strategic use of (or in some cases, not use) the 'country of origin' to reinforce certain curatorial agendas, which are not without political significance.

12 For instance, Zhang Lu entered his new project titled 'Yanagawa' for the 2018 Busan International Film Festival's Asian Project Market (APM), and the 'country' was designated as 'Korea' (Asian Project Market). 
The tags of national cinema should not be one-dimensionally equated with the author's truth claim of identity, but they always need to be contextualized and read in light of specific programming strategies. For instance, in 2009, the Locarno International Film Festival's Open Door, a film co-production initiative supporting independent film projects from countries 'in the South and East', was dedicated to Greater China ('Open Door'). According to Frederic Maire, the festival artistic director at the time, this edition included 'all Chinese-speaking people; i.e., continental China, Hong Kong, as well as Taiwan' (Blaney 2009). Zhang Lu pitched his project Father for the 2009 edition of Open Door as a filmmaker from mainland China. Intriguingly, a pitch from Guo Xiaolu, a diasporic filmmaker and novelist who has based herself in London since 2002, was also included in the line-up of Greater China projects. Another example is the fourth Chinese Independent Film Festival in Tokyo in 2013, which presented a mini-retrospective of Zhang Lu with a lineup of three films (Tang Poetry, Chongqing, and Dooman River). Such a curatorial gesture somehow leveraged the high visibility and acclaim of Chinese independent cinema as one controversial genre of contemporary Chinese cinema in the film festival and global arthouse circuits.

We could assume that the international festival system has difficulties accommodating and locating translocal, transnational projects like Zhang's within its globalizing yet inconsistently structured industrial and discursive interface. But it may also be worthwhile to switch the perspective. Critical transnationalism demands that we not lose sight of the 'scale, distribution, and diversity of such exchanges and their impact at a local level' and the effects such exchanges might have 'within and beyond the nation-state' (Higbee \& Lim 2010:12). Thus, the contesting labels of 'nationality' on Zhang's oeuvre actually connote how contingently yet creatively his border-crossing cinema has been in carving out alternative channels and networks and establishing different assemblages of alliance 'within and beyond' specific geographical and geopolitical spheres.

\section{Three Takes of Border-Crossing}

Desert Dream, Dooman River, and Scenery are three films that contest banal insights into places and senses of belonging by tracing the meandering trajectories of deterritorialized people such as immigrants, North Korean defectors, and foreign labourers. As Trinh Minh-ha insightfully points out, "To speak about the concept of border crossing as a major theme in contemporary cultural politics is, in a way, further to empty it, get rid of it, 
or else let it drift - thereby preventing it both from settling down and being "resettled"" (Trinh 2011: 46).

Zhang Lu's obsession with events of arrival and departure can be traced back to his debut short film titled Eleven. This 15-minute-long short, shot on 35-mm film, opens with the arrival of an 11-year-old boy, together with a middle-aged man who seems to be his father, at a desolate industrial belt used to stockpile coal. The boy tries to befriend a gang of boys who are playing soccer, and his efforts are invariably doomed. The minimalist cinematic grammar in Eleven is suggestive of Zhang's film style in its becoming: its mise-en-scène mainly consists of a monotonous landscape of coal piles, a tunnel, and a dilapidated hut. There is a sense of isolation and depression highlighted by the modernist film score, given how sparse the dialogue is in the film. Cinematic mechanisms such as the long shot and deep focus are deployed to frame a protagonist whose spatial existence is demarcated and constrained by visible or invisible grids (e.g. the track, the electric pole, the wire, and even the imaginary football pitch). Although the short itself is not specifically about journeying and mobility, it does look at how the visit of a stranger may disturb the given structure of interrelation and how it may predict acts of violence.

My analysis of Desert Dream, Dooman River, and Scenery departs from two perspectives. First, I look at how Zhang Lu leverages the narrative theme of border crossing to explore translocal connections on various scales. Another focus is on the protagonists and filming subjects regarding how translocal movement has modified their ways of identification and sense of belonging. 'Place' will be used in a similar fashion to Dirlik and Zhang Yingjin in order to emphasize the resistant potentiality of Zhang Lu's place-based methodology. Inspiration is also drawn from Oakes and Schein's affirmation that 'the concept of translocality maintains a focus on the body as a scale of spatial struggle and meaning by considering what mobility does to the body on the move and in place' (Oakes \& Schein 2006: 18). Therefore, although not highlighted in this study, translocality is grasped as a type of bodily knowledge in terms of its affective potential to engage viewers.

\section{Desert Dream}

In his third feature film Desert Dream, Zhang Lu developed a more complicated plotline where the characters are connected through parallel events of arrival and departure. Hungai (Bat-ulzii) and his family live in a yurt at the edge of the desert on the Mongolian steppe. One day, Hungai's wife leaves for the city seeking medical care for their daughter's hearing impairment. 
A North Korean woman named Choi (Seo Jung) later stumbles on Hungai's yurt with her son Chang-ho (Shin Dong-ho).

Despite its shooting location in Mongolia and its highlighting of the issue of North Korean defectors, Desert Dream is not meant to scrutinize the borderland conditions and the Korean peninsula's political geography per $s e$. The geopolitical tension is only vaguely hinted at with a brief sequence of tank patrolling. It is later suggested that Choi's husband died during the family's tragic effort to flee across the Gobi Desert and enter Mongolia, one of the well-trodden escape routes taken by defectors, but their terrifying adventure is never revealed in detail. As Zhang Lu explains, the film's original title was the Mongolian term hyazgar, which is specifically used to describe the borderline between the desert and grassland (see Lee 2007). It can be directly associated with Hungai's utopianist efforts to plant saplings at the edge of the steppe to fight against the encroaching desert. Supposedly, a second layer of hyazgar concerns the broadly defined 'boundary'. Zhang explores the translocal, transnational connections by turning to the various acts of border crossing and journeying.

Hungai takes in the defectors and welcomes them as his surrogate family. The host and his guests can hardly comprehend one another via verbal communication in Korean or Mongolian, but they manage to (mis)understand one another through a variety of alternative means such as gestures, sign language, painting, song, and even silence - a realm of bonding and knowing that goes beyond the grasp of even an omniscient audience aided by subtitles. When Hungai temporarily leaves for the city, the woman and boy are entrusted to care for the yurt and guard it until his return, and the roles between the host and guest are dramatically reversed. The consequence of the man's absence is tragic: Hungai's trader friends rape Choi when he is away. It might have been a punishment acted out on 'transgressors' like Choi, indicating the irrationality and fear directed toward people who have lost their home. The violence also signifies the rupture and inconsistency of Choi and Hungai's translocal, transcultural bond, if it had ever been achieved.

Zhang's exploration of the circumstances of the North Korean defectors, a gesture potentially associated with the auteur's own diasporic identity, is complicated by Hungai's untimely and reluctant trip on horseback from his remote yurt - an empty sign of the disappearing nomadic lifestyle - to the capital city of Ulaanbaatar. Seemingly unable to cope with his urban adventure and its shocking effects, Hungai finds himself a total stranger upon meeting his now fully recovered daughter and wife in a modern residential apartment. Here, a sense of loss and rootlessness connects Choi's refugeeism with Hungai's self-exile (in choosing not to follow his family to 
the city and to continue to plant the saplings in the first place). The latter is symptomatic of how 'modern society appears as a foreign country, public life as emigration from the family idyll, urban existence as a permanent exile' (Boym 2001: 24). Therefore, Zhang's humane approach to the issue of refugeeism is placed within a broader concern of how modern subjects constantly have to negotiate their sense of place and belonging in relation to translocal mobility and drastic social transformations. Instead of celebrating any 'fantasy of global smooth space' (Berry, 2010: 113), the filmmaker highlights the perils and frictions integral to the acts of border crossing. In other words, he reinvents the border zone as a new scale to position the North Korean defectors in their transnational connections with other places and other people in (East) Asia, without necessarily defusing the political urgency and precarious nature of their fleeing.

\section{Dooman River}

The theme of border crossing is further explored in Dooman River, a film named after a border river with multilingual names that insinuate the historical entanglement and regional geopolitics between China, North Korea, Russia, and Japan. ${ }^{13}$ This film is set and shot in a border village populated by ethnic Koreans on the Chinese side of Yanbian along the Dooman River (Tumenjiang in Chinese Pinyin). Zhang collaborated with a non-professional cast, with most locals and villagers playing themselves. As the filmmaker points out, the film plot was constructed upon the villagers' everyday experiences interacting with their North Korean neighbours from the other side of the river. Twelve-year-old Chang-ho (Cui Jian) lives with his mute sister and grandfather in the village. He recently befriended a North Korean boy of about the same age named Jeong-ji (Li Jinglin) who has risked his life to cross the frozen river in winter in search of food for his starving family. The continual arrival of escaping North Koreans starts to disturb the village's tranquil pace of life, and border control and patrolling tighten on both sides. Chang-ho's friendship with Jeong-ji also reaches a freezing point after he has learnt about his sister's rape by an anonymous North Korean defector to whom his family had kindly offered shelter.

Dooman River is an ambitious lifework that Zhang Lu had always dreamt of accomplishing. He had partially experimented with the idea, namely with characters like the North Korean defectors in Desert Dream. Through

13 Regarding the Sino-Korean border dispute, refer to Gomà (2007); and also Shen \& Dong (2011). 


\subsection{Chang-ho lying on the frozen river}

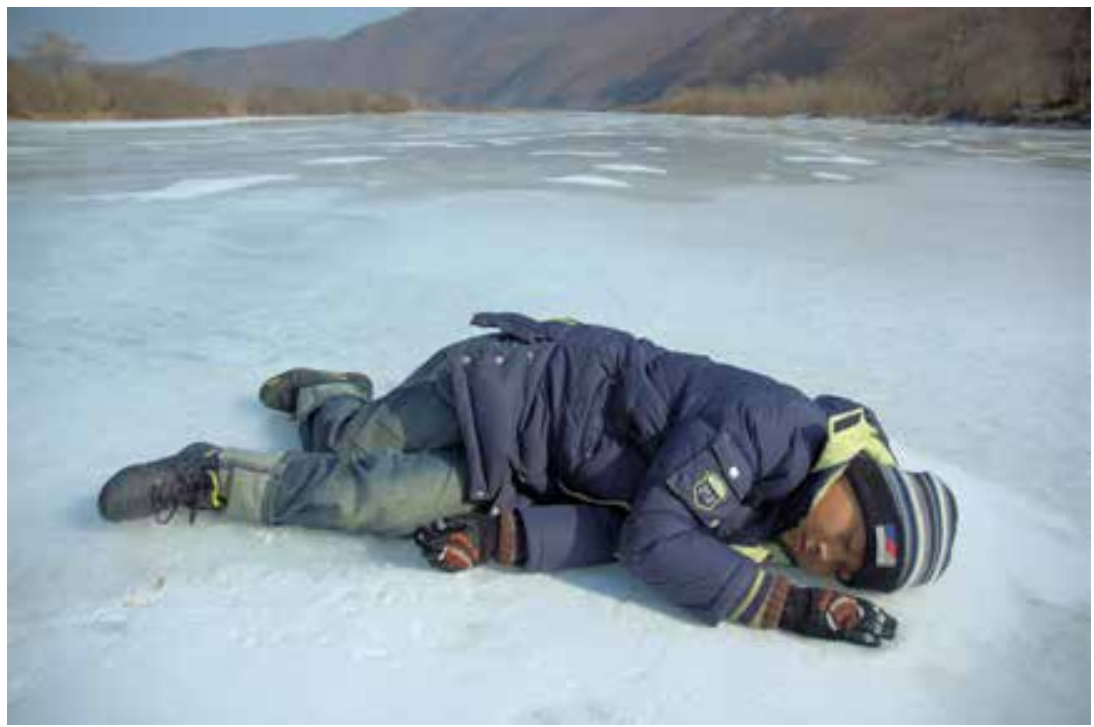

this film, the director wanted to 'describe how this river could integrate both people, make them be in close connection, and how it could isolate and estrange them, which is sometimes transparent, sometimes inundated or sterile' (The Global Film Initiative 2011: 3). Departing from the river border, Zhang examines the translocal connections between three Korean communities across the PRC and the Korean peninsula. The border village is not one-dimensionally portrayed as a peaceful 'home' invaded by the North Korean border-crossers and transgressors but rather as a site to negotiate multiple Korean identities as well as the regional geopolitical and economic entanglements implicated in such identifications. Accordingly, the filmmaker not only turned to defectors and refugees from North Korea, who crossed the river either in guerrilla style (as Jeong-ji and his young friends did) or by organized action. He also looked at Korean-Chinese villagers who have migrated to South Korea as foreign labourers, as is the case with Chang-ho's absent mother, who is never seen but only heard on the phone when she calls home.

It is intriguing to see how Zhang has again complicated the acts of border crossing. The various forms of mobilities registered by the defectors and migrant workers illustrate the inequality and hierarchy inherent in the translocal connections across borders. Refugeeism foregrounds regional geopolitical complicacy and the precarious conditions of the border crossers from North Korea, but the Korean-Chinese migrants' trajectory is no less 


\subsection{Jeong-ji (left) is welcomed by Chang-ho and his mute sister (right)}

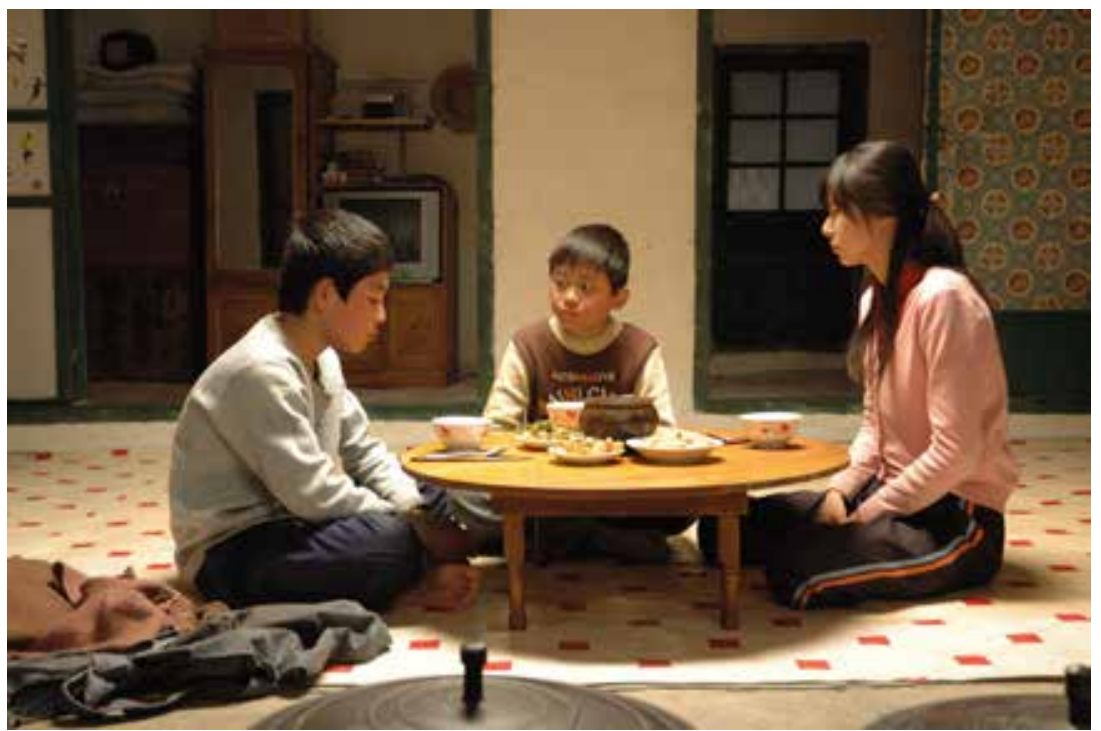

prescribed and delimited by the power structure of global capitalism. As suggested by Zhang Yingjin, the politics of Dirlik's project on 'place-based imagination' lies in how it modifies the local-global asymmetry and its agenda in giving voices to the weak over 'the voices of globalism that erase both people and places' (quoted in Zhang 2010: 6). We can see how Zhang Lu seeks to retool the border as a new trans-national, inter-regional dimensionality to mediate the 'local-global' dichotomy. Therefore, border crossing has constituted a vantage point to shed light on people and places that were previously obscured by the globalist discourse.

Second, and more importantly, a new scale as such is also utilized to rethink the Korean-Chinese identity and its diasporic affiliation. Towards the film's end, Chang-ho, protesting in vain against Jeong-ji being taken away by the PRC border police, jumps off the roof. We could interpret Chang-ho's suicidal jump as a demonstration of the villagers' unrequited love for their aggressive neighbours, but we can also consider it as a violent, emotionally charged eruption of the frustration and anger over the impossibility of formulating a bond of affection across borders that potentially relates to a unified sense of being Korean and belonging to one community.

In A Time to Live and a Time to Die (Tongnian wangshi, 1985) by Taiwanese arthouse maestro Hou Hsiao-Hsien, a stubborn grandmother wants to follow a railway in suburban Taiwan to return to her hometown in Southern China. In Dooman River, similarly there is an old lady from the village who seems 


\subsection{Jeong-ji is playing football with Chang-ho and other friends from the village}

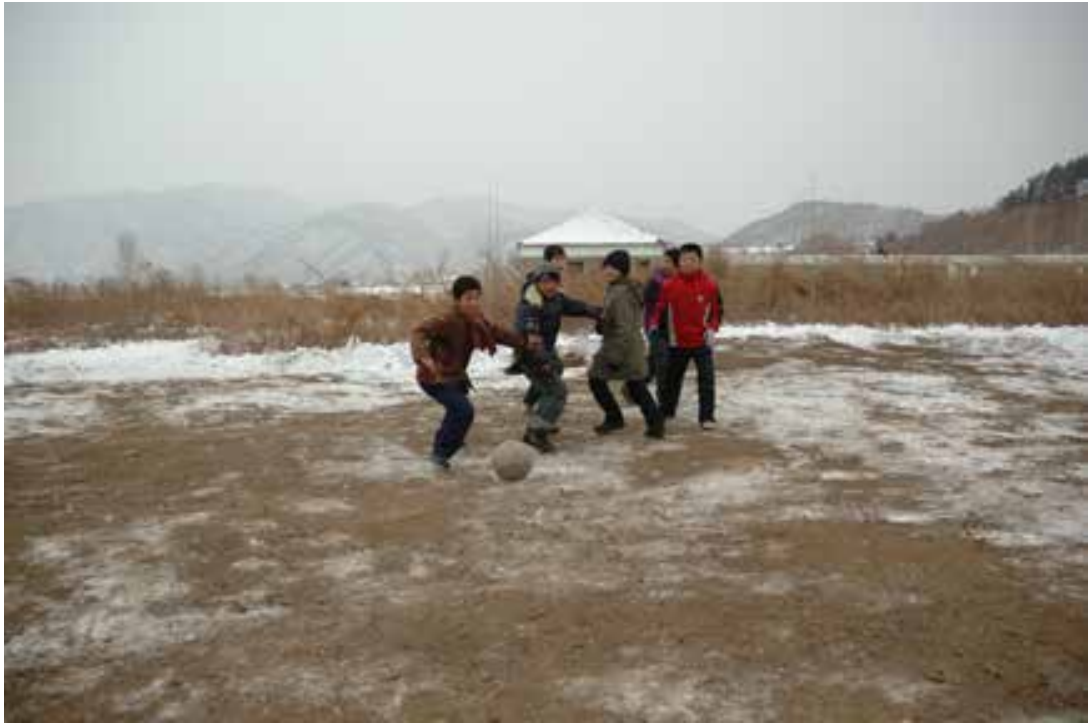

to suffer from dementia and persistently searches for her way back to the side that is today's North Korea. The closing credit sequence of Dooman River then features a horizontally composed long-take shot, where from a distance we see a tiny black figure, which is the old village lady, moving excruciatingly slowly on a snow-covered bridge over the river. Her futile efforts to find her way home, together with the repeated tale about how she held her mother's hand and crossed a bridge over the river to the China side when she was still young, are poignantly interwoven with Zhang Lu's moving family history of migration and displacement. Nevertheless, Zhang engages the border village, border river, and all types of border crossers not to envision and eulogize 'a sense of grandiose transnational belonging and connection with dispersed others of similar historical origins' (Ang 2001: 12) but to address the impossibility of homecoming and to problematize a homogeneous, essentialized idea of 'homeland'.

\section{Scenery}

In 2013, Zhang Lu was commissioned by South Korea's Jeonju International Film Festival to complete a digital short under the theme of 'stranger' for the festival's annual omnibus initiative. The result was Over There (2013), a work inspired by the filmmaker's experience after settling down in Seoul and seeing more foreign workers than foreign tourists in the city (see Ji 2013). 


\subsection{A wedding ceremony in Scenery}

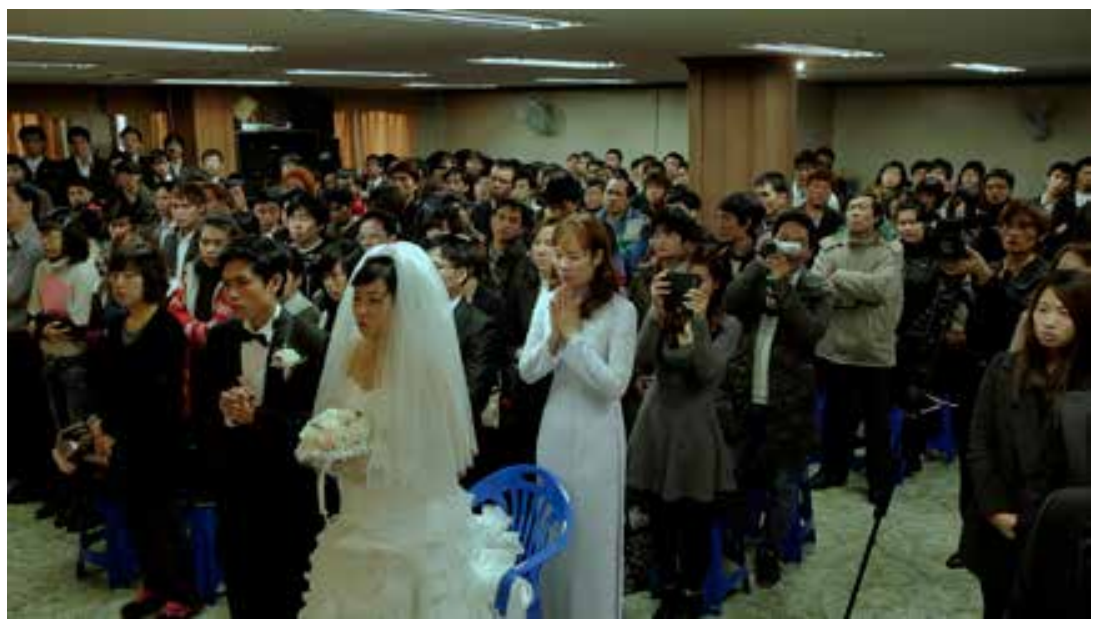

As Zhang's first venture into documentary, foreign workers of diverse ethnic and national backgrounds are interviewed in the metropolitan area of Seoul, with a majority of the interviewees coming from developing countries across Southeast Asia and the Asia-Pacific (including central Asian countries such as Kazakhstan). ${ }^{14}$ Zhang then developed Over There into the featurelength Scenery (2013), considering the 'scenery' one made of strangers on the street. This documentary work arguably marked a turning point in Zhang's translocal filmmaking. Observing South Korean society at closer range by living inside it, Zhang reframed his diasporic perspective to develop a new format of place-based imagination. His focus shifted away from his survey of intersecting Korean communities at the border area to the translocal subjects living on the margins of Korean society.

Instead of simply taking up an on-the-spot observational style to record the daily lives and working routines of foreign immigrants, most of whom are low-wage manual labourers, Zhang proportionally uses static long takes to foreground a heterogeneous urban landscape, of which these migrants are becoming an essential part. The filmmaker turns to an array of nondescript places such as working sites (e.g. a workshop, office, factory, greenhouse, market, and abattoir), private realms (e.g. a home and dormitory), public spaces for gathering and socializing (e.g. a church, mosque, market, and

14 According to the central government organization for statistics, Statistics Korea (KOSTAT), the number of employed foreigners amounted to 962,000 people as of 2016 , with a majority of them being 'Korean-Chinese’ (45.9 percent) (see ‘2016 Foreigner Labour Force Survey’ 2016) 


\subsection{Foreign migrant worker in a light truck in Scenery}

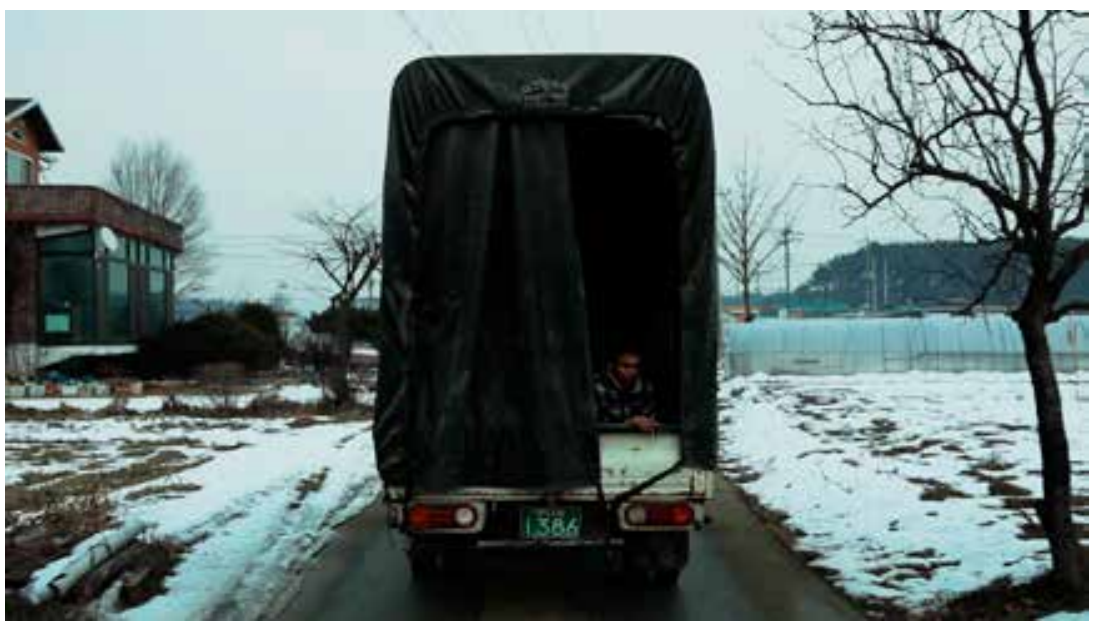

ethnic enclaves), and sites for transportation and passage (e.g. the subway and airport). Such a methodology is reminiscent of Zhang Yingjin's thesis that 'the notion of the translocal acknowledges the coexistence of different locals in the same urban area, albeit in different spaces and places; it also means that not all locals are equally indigenous to a locality, thereby leaving room for questions of migration and diaspora' (Zhang 2010: 75). Zhang Lu's observational segments are also uncanny in capturing several moments of disappearance: upon the arrival of the subway, waiting passengers are suddenly gone; a swing in the park moves without a rider; a toy tricycle glides with no one pedalling it. These spectral moments connote the untimely arrival or departure of subjects absent from the spectators' sight, which is symptomatic of the haunting, unrecognized presence of the immigrant labourers.

Oakes and Schein pose that translocality has enabled us to view subject formation as 'a place-making process imbricated with the experience (real or imaginary) of mobility and connection across space and scale' (Oakes \& Schein 2006: 20). They pose that place travels with the body, 'as it is constantly being made and remade as part of the ongoing process' in constructing the subject (ibid.). Scenery invents an innovative way to explore how such a place-making process is corporeally and affectively experienced by inviting the subjects to speak about their most memorable dreams during their stay in Korea. Blurring the dividing line between fiction and reality and between the private and the collective, dream-telling is used in this documentary as a powerful narrative device to trace the translocal connections and flows 
that overwrite the foreign migrants and restructure their sense of affiliation and belonging as embodied experiences.

The dreams suggest how transnational identity formation for migrant workers is a negotiated process that also generates a complicated range of repressed desire, yearning, and feelings such as confusion, fear, despair, and anger, and also an affective dimension of the precarious labour that has often been ignored or paid little attention to. The stylized 'talking heads' interview sequence tightly frames the interviewees against generic backdrops to underscore a sense of immobility and stereotype, whereas the dream-telling sequence constitutes an act of remembrance and performance that liberates the subjects and allows them to engage with other temporalities, places, and experiences. For instance, the documentary opens with the narration of Augustino, a young man from East Timor whom we later see giving an interview while preparing to leave the country in a well-lit airport lobby. Augustino confesses that in his dreams of East Timor, he often meets and chats with his mother who had passed away. With slight variations, several of the shared dreams are about hometowns; relationships with families, friends, and lovers; nightmarish visions; or wishful thinking of returning, reunion, or becoming successful on foreign soil. Some narratives are an intriguing mixture of dreams during sleep and those strived for in waking life.

Despite its focus on migrant workers, Scenery does not privilege an activist tendency that seeks to interrogate the precarious human-rights conditions of immigrants under the political economy of globalization. The film also shifts away from directly drawing on the labourers' accounts of their everyday struggles or hints of success in order to elicit sympathetic responses from audiences. In archiving dreams and delineating an assemblage of sensibilities and feelings that these mobile subjects have yet to fully recognize and articulate, this documentary proffers audiences an alternative perspective to engage the politics of translocal mobility. The politics does not simply lie in how the film reveals that the migrants' modes of experiences are as much contingent on the hierarchical global neoliberalism system within which South Korea and other developing countries in Asia are unequally positioned. More importantly, the politics concerns how Zhang's documentary experimentation has disturbed the 'meaningful fabric of the sensible' (Rancière 2011:63) that defines 'who can say and hear what, where and when' (Demos 2013: 28), in modifying the ways migrant subjects could make themselves visible and audible, thereby creating new horizons for spectators to see and hear 'people caught in the cracks of globalization' (Ezra \& Rowden 2006: 7). 


\section{Between Chinese Independent Cinema and Korean Diaspora Film}

\section{Re-envisioning the Chinese Indie}

This concluding section turns to how Zhang's translocal filmmaking has intersected Chinese independent cinema with Korean (and Korean-Chinese) diaspora filmmaking, where 'borders' have been invented as a new scale to interrogate but also to connect to the practice and discourse of translocality in both film modes. The first highlight is how Zhang's place-based imagination has interconnected with and also extends Chinese independent cinema's diversified projects of 'visualizing polylocality' (see Zhang 2010). In the context of this study, Chinese independent cinema is used as an umbrella term to encompass a wide spectrum of fiction and documentary works emerging since around the late 1980 s that have been produced, circulated, and exhibited outside of the party-state's ideological apparatus as well as outside of the domestic mainstream film market.

Since the early 20oos, the political economy of Chinese independent cinema has been further diversified and differentiated, with more independent filmmakers actively seeking to obtain screening permits from the censor in order to gain access to domestic theatres. The introduction of digital video cameras to the PRC since the early 2000 s and the proliferation of online media channels and digital platforms have also opened up unprecedented opportunities for amateur filmmakers to produce and circulate their own works. Also labelled the 'Urban Generation', Chinese independent filmmakers respond to and work through the disorienting and destructive process of urbanization and city-making in contemporary China. Their works often seek to engage the tension between polylocality and translocality by turning to different modes of mobility, experiences of entrapment, migration (mostly internal), and displacement as well as various groups of marginalized, floating urban subjects (e.g. migrant workers).

As suggested earlier, Zhang Lu's filmmaking originates from within Beijing's dynamic cultural milieu (his debut, Eleven, was shot in collaboration with a crew of Beijing Film Academy students), even though when he first started out he had barely any affiliations with the local independent film circle. His debut short film is a highly personal, self-reflexive experimentation that can be interpreted as a middle-aged man's haunting dream about his own childhood. However, the dystopian spatiality as well as the estranged human relation also overlap with the recurrent tropes found in other Chinese independent works. Although Zhang's first feature Tang Poetry was already a co-production project 
with Korea, it was not until his second feature Grain in the Ear (Mangzhong, 2005) that Zhang consciously directed his attention toward the ethnic Korean people as well as their multifarious connections with the two Koreas.

Notably, in his 2010 monograph on polylocality and contemporary Chinese cinemas, Zhang Yingjin had yet to shift his attention to a spectrum of independent films (both documentary and fiction works) that structure their place-based imagination around ethnic minority identities, cultures, communities, and the spaces of these ethnic groups (which were usually used as shooting locations). ${ }^{15}$ These productions themselves deserve a thorough analysis that is beyond the scope of this study. Nevertheless, for the sake of argument, these films can be called 'new ethnic films' - for lack of a better term - in order to differentiate these works from the Chinese national cinema's ideologically and politically sanitized genre of 'ethnic minority films/ minority nationalities film' (Shaoshu minzu dianying). Specifically, ethnic minority films are closely associated with the PRC's centralized studio system in the Mao era. They often feature 'picturesque landscapes, melodious music and song, beautiful costumes, exotic customs, and romantic love', which are motifs that had been integral to espousing cross-ethnicity solidarity under the Chinese Communist Party's enlightenment and guidance (Zhang 2004: 208). Importantly, in these 'minority films', minority people hardly occupy a position as the subject of knowledge but 'are always directed to pay their homage to the nation-state' (Zhang 1997: 80). ${ }^{16}$ Chris Berry further suggests that 'minority nationalities films' currently need to be reconsidered given that 'central control has given way to a market economy and citizen initiative', when the minority nationalities start to tell 'their own stories' (Berry 2016: 90).

Into the 200os, for instance, we see the emergence of a 'Tibetan New Wave', namely 'indie Tibetan-language films made by native Tibetans' that also exhibit 'a particular genre and cultural theme concerning the current state of Tibetan life in China' (Yü 2014: 126). Pema Tseden is the most representative auteur of this genre. All of his independently produced works (which are submitted to the state for legitimization, for obvious reasons) are widely circulated at international film festivals. These films usually register a minimalist realist style characterized by 'the use of Tibetan language, all Tibetan cast and crew as well as Tibetan location' ('Tibetan

15 With this said, in one of his 1997 articles, Zhang Yingjin indeed examined the ideology of 'Chineseness' in reviewing Chinese film history, wherein he closely examined the genre of 'minority film', that is, the ethnic minority film, or shaoshuminzu dianying.

16 For instance, The Story of Jin Yuji, a 1959 war film directed by Wang Jiayi of Changchun Film Studio, portrays the eponymous heroine, an ethnic-Korean female resistance leader who eventually dies in the anti-Japanese war. 
New Wave Cinema'). Vanessa Frangville posits that Pema Tseden's oeuvre has constituted a 'minor' cinema in creating space for the virtual community of Tibetan people to emerge and speak for themselves (see Frangville 2016). However, Dan Smyer Yü leverages the notion of 'transnational' to situate Pema Tseden's filmmaking and his cinematic approach to Tibetan Buddhist values within its multi-scalar connectivity with China (between Beijing - his 'pre- and post-production and marketing location' - and Qinghai/Amdo as 'his homeland and filming site') and beyond (Yü 2014: 126).

According to Chris Berry, the fact that Pema Tseden is a 'minority nationality' doesn't necessarily mean that he makes 'minority nationality films' (2016: 90), an assumption that could also be extended to Zhang Lu. However, questions arise when we turn to Han-Chinese filmmakers who approach ethnic minority identities and their communities. Would identity politics constitute a productive discursive framework for us to scrutinize such a diverse body of new ethnic films?

As an example, consider Tuya's Marriage (Tuya de hunshi, 2006), a film that competed in the 2007 Berlin International Film Festival along with Desert Dream. Director Wang Quan'an turns to a Mongolian woman called Tuya (Yu Nan) and her ethnic community in Inner Mongolia. We may problematize the fact that the protagonists in this film speak slightly accented Mandarin, while the Mongolian language is only used as nondiegetic sound and in songs. However, Wang succeeds in examining the local Mongolian community's anxieties over modern transformation by turning to Tuya's persistent search for remarriage partners. Throughout the process, she struggles to reposition herself as a woman, wife, and mother in a reconfigured socioeconomic fabric that seems to put more value on commodity exchange and economic calculation.

An equally intriguing case might be Li Ruijun's River Road (Jia zai shuicaofengmao de defang, 2014), a road movie (not by car but on camel) lamenting the ruined nomadic landscape and the disappearing ethnic Yugur (yugu) culture. The film is set in Su'nan Yugur Autonomous County in the filmmaker's native province of Gansu in China. As part of the preparation, Li even had his nonprofessional cast (a mixture of Yugur and Han) trained to speak the dying Old Turkic language. We may say that Li, whose independent arthouse productions to date mainly rely on international film festivals for distribution and circulation, is motivated by a strong preservationist if not exhibitionist drive in rediscovering the remote landscape and the eroded cultural traditions of the Yugurs and of Gansu. But it would be reductionist if we were to only emphasize Li's identity as ethnically Han to undermine his continuing efforts since his earlier works such as The Old Donkey (Laolutou, 
2010) and Fly with the Crane (Gaosu tamen, wo cheng baihequle, 2012) in scrutinizing how people from some of the least developed rural areas in China have painfully negotiated the process of urbanization and modernization. ${ }^{17}$

Generally speaking, Zhang Lu has dialogued with and even occasionally participated in Chinese independent cinema's artistic intervention in disrupting and redefining the ideologically rigid and hierarchical (centralized) apparatus of image production and circulation in the PRC. Here, Chinese independent cinema's artistic intervention includes but is not limited to practices of deploying accents and dialects (sometimes ethnic languages), representing regional/remote locales and the migrating/floating populations across the expansive territory of the PRC, and, importantly, utilizing their rhizomatic, variously scaled networks of exhibition and circulation within and outside of the PRC, the last of which have also significantly intersected with the proliferating digital online media and video platforms nowadays. Meanwhile, a perspective of translocality could be revamped to contest any essentialist division between Han-Chinese and non-Han ethnicities when we consider the independent filmmakers' authorship/authorial positionality. Translocality can also be useful in revealing how Zhang Lu's border-crossing films interrelate with these new ethnic films at two levels. At one level, by reinventing scales to explore border zones, frontiers, and the marginalized territories extending beyond national borders, Zhang's filmmaking joins forces with the latter in disturbing the conventional geographical and geopolitical imagination of China and the Han-Chinese ideology in independent works. In other words, both cinemas have contested Chinese independent cinema's seemingly habitual (dis)engagements with the issues of identity through rethinking 'Chineseness' - whether it correlates with continental Chinese culture, the Chinese nation-state, its ethnic constituents, or the use of Chinese languages.

At another level, we may also grasp the 'heightened sense of polylocality' (Zhang 2010: 90) in Chinese independent cinema and the sensibilities

17 In future studies, it may be productive to see how the 'new ethnic films' mentioned here, including those by $\mathrm{Li}$, can be related to the so-called New Chinese Cinema in the 1980 os by the Fifth Generation filmmakers that also feature ethnic minority characters and places, such as Zhang Nuanxin's Sacrificed Youth (Qingchunji, 1985), which turned to the remote mountain area where the Dai (Thai) people lives. Zhang Yingjin proposed how New Chinese Cinema as a whole, including ethnic minority-themed works like Sacrificed Youth, arguably functioned as a 'minority discourse' vis-à-vis the state discourse; at the same time, these works of New Cinema also 'participated in reshaping cultural nationalism in contemporary China' with its 'characteristic, or even obsessive, fascination with an entire repertoire of recognizable cultural symbols and traditions in the nation'(Zhang 1997: 82-84). 
toward the local and global imbalance in light of what Raymond Williams terms the 'structures of feeling', namely the sets of social relations and experiences that are yet to be fully consolidated into fixed structures but have already manifested themselves as a certain tendency and style, given that the drastic modern transformations are still ongoing in everyday life. Therefore, Zhang's oeuvre connects with the structures of feeling or the multifarious vernacular experiences of urbanization and globalization found in the independent works that are not necessarily produced or located at the centre of China or Chineseness.

\section{A Korean-Chinese Diaspora Film?}

In this part of conclusion, I want to briefly turn to how Zhang's translocal filmmaking can help us to grasp a possible Korean-Chinese diaspora film, ${ }^{18}$ although it is a pity that I will not be further analyzing Zhang's film works produced since Gyeongju, which may help to extend some of the debates presented here. In the context of critiquing Chinese diasporic identity, Ien Ang cautions against the tendency to essentialize diaspora as the 'sameness-in-dispersal' instead of 'difference-in-togetherness', thus pointing out that diasporic identity 'can be the site of both support and oppression, emancipation and confinement' (Ang 2001: 12). Wang Yiman, however, shifts her attention to the 'symbolic and affective significance' of 'home' and the 'imagined togetherness' of the diasporic formation, proposing that we should see how the diasporic filmmakers, not unlike their diegetic characters, relate to their 'home' and 'homeland' laterally, in a contingent manner (Wang 2012: 537-538). What has been proposed by Wang also connotes a cultural transversalism that underlines the framing of minor transnationalism. I shall argue that the transversal perspective helps to dislocate the minority and the diasporic from a hierarchical model that valorizes 'the most dominant and the most resistant', so that the 'horizontal communication' amongst minority cultures as well as the 'postcolonial minor cultural formations across national boundaries' can be made visible and compared (Lionnet \& Shih 2005: 11).

It is by now well known that some of the most inspirational discussions on Korean diaspora filmmaking nowadays can be found in the studies on

18 In September 2014, Harvard University's Korea Institute programmed a 'Korean Cinema and Transnationality' film series, in which Zhang Lu's Dooman River was screened under the title of 'Korean-Chinese Diaspora Film'. Their use of this term has been adopted. See https://korea.fas.harvard.edu/event/korean-cinema-and-transnationality-film-series. 
zainichi or Koreans-in-Japan cinema culture (see Dew 2016; Ko 2010; Ogawa 2017; also see Wada-Marciano 2012). Despite the consideration of zainichi as the 'diaspora without a homeland' (see Ryang \& Lie 2009), diaspora as a research framework is not necessarily foregrounded with equal emphasis in zainichi cinema studies. It is tempting to view Zhang Lu's transnational, translocal trajectory in light of his trans-generational zainichi Korean filmmaker counterparts such as Sai Yōichi, Yang Yong-hi, and Matsue Tetsuaki (a third-generation naturalized when he was young), to name just a few.

Zainichi Korean filmmakers have taken different points of departure when they work on identity issues to articulate senses of belonging. ${ }^{19}$ At the level of film production and circulation, however, while zainichi filmmakers are seen as mostly being integrated within the Japanese film industry and domestic networks, it is also noticeable that the filmmaker Yang Yong-hi who is the daughter of a high-ranking member of Chongryun (The General Association of Korean Residents in Japan), which is the DPRK's de facto embassy in Japan - was able to obtain South Korean nationality later and leverage her South Korean connections to find new audiences and sources for funding (Ogawa 2017: 33). Shota Ogawa also reminds us that, 'Other Zainichi Korean talents such as Sai Yoichi, Kim Su-jin, and Lee Bong-ou have, for instance, carved out a niche in the film industry by actively collaborating with South Korean studios, producers, and directors' (ibid.).

In comparison, with hardly any connections to the Chinese film industry, ${ }^{20}$ Zhang Lu has developed closer ties with film and cultural entities and filmmakers' communities in South Korea. The bonds have become even stronger since he moved to Seoul, considering how Zhang was able to convince the trio of A-list Korean actors Ahn Sung-ki, Moon So-ri, and Park

19 Sometimes the articulations by second- and third-generation filmmakers can take rather confessional, self-reflexive, and tension-filled forms. In his survey on video documentaries by (Japan-born) second/third-generation zainichi filmmakers within a framework of 'intimate ethnography', for instance, Oliver Dew has illustrated how filmmakers like Matsue Tetsuaki (third generation) and Yang Yong-hi (second generation) have leveraged the format of 'family portrait' to work through and react to 'familial' traumas, that is 'the dilemma faced by the first generation of diasporic Koreans-in-Japan, between "assimilating” into Japanese society or "repatriating” to Korea'. Dew has illuminated how, through their own embodied performance in the documentaries, Matsue and Yang have attempted to 'salvage the agency of their ancestors from overdetermining historical narratives'(Dew 2016:190).

20 With this said, it is also worthy noticing that Zhang Lu's $11^{\text {th }}$ feature film Ode to the Goose and the 2019 film Fukuoka have been distributed by PARALLAX Films, the distribution arm of Midnight Blur Films (Wuyeshijiao), which is self-labelled as a 'Chinese film production company, devoted to developing and producing director-driven films, both commercial and arthouse' (see 'About Midnight Blur Films' n.d.). 
Hae-il to volunteer for his experimental feature Love and ... (Pilreumsidaesarang, 2015), which was developed from a short film commissioned by a Korean film festival. Arguably, Zhang's diasporic affiliation has effectively constituted the lines of flight through which he not only positions himself outside of the aforementioned strand of 'ethnic minority film' in the PRC. $\mathrm{He}$ is also able to disregard the worrying environment and constraints faced by independent arthouse filmmaking within the PRC, where ethnic minority topics often entail extra censorship procedures that even involve decisions from bodies such as the State Ethnic Affairs Commission (The CFI Guide to Film Production in China).

Although I can only mention this in passing, another aspect regarding Korean diasporic cinema that is relevant here is the so-called Soviet/Russian Koreans, the Koryo saram. For instance, film scholar and filmmaker Kim So-young reflects on her documentary project about the Koryo people, the Korean diaspora in Eurasia that entered Russia around the 1860 s and were deported by Stalin to Central Asia in 1937 (see G. Kim 1993; G.N. Kim 2004; German N. Kim \& King 2001). In Heart of Snow, Heart of Blood (2014), the first documentary of her 'Exile Trilogy' series (2014-2017), Kim turns to how Alex Kim, one of the Uzbekistan-born Koryo diaspora protagonists, struggles to survive in an ethnic town near Seoul since his 'return' to South Korea. Kim grasps Koryo identity in terms of the traumatic experiences of 'exclusion, deportation, migration, and state violence' (Kim 2016). In Goodbye My Love, North Korea (2017), the finale of her trilogy, Kim traces back the drifting trajectories of eight North Korean students at Moscow Film School who became political exiles in 1958 after denouncing Kim Il-Sung. Kim So-young has arguably taken a place-based methodology to shift away from a macro-chronology revolving around the axis of 'origin and return' and to pay attention to the rhizomatic trajectories of migration and mobility. She posits that 'The dispersion and dissemination might trigger a productive re-orientation of a geopolitical sense of sovereignty centred on the peninsula, which has been the stage of a protracted turf war between the big powers of China, Russian, Japan, and the US' (Kim 2016). Seen from such a perspective, Zhang Lu's border-crossing works have proffered no less compelling narratives regarding the complicacy of Korean-Chinese diasporic formation. I shall contend that translocality constitutes a useful framework to thread together the disparate strands of Korean diaspora filmmaking across multiple locales, not in terms of any homogenized identification with a homeland but exactly through envisioning how the formation of diasporic identities has been a painful, contingent process of fragmentation, friction, and differentiation. 


\section{Works Cited}

2016 Foreigner Labour Force Survey (2016). Statistics Korea. Retrieved 1o October 2017 from <http://kostat.go.kr/portal/eng/pressReleases/1/index.board?bmode=read\&aSeq=358181 $>$.

About Midnight Blur Films (n.d.). Midnight Blur Films. Retrieved 1 February 2019 from $<$ https:// www.midnightblurfilms.com/about>.

Ang, I. (2001). On Not Speaking Chinese: Living Between Asia and the West. London; New York: Routledge.

Asian Project Market (APM) (2018). Busan International Film Festival. Retrieved 10 November 2018 from <http://apm.asianfilmmarket.org/eng/database/list_ppp_history.asp?this_year=2018>.

Bender, M. (2016). 'Ethnic Minority Literature'. In Zhang Y. (ed.), A Companion to Modern Chinese Literature, p. 302. West Sussex, UK: John Wiley \& Sons, Ltd.

Berry, C. (2010). 'What is Transnational Cinema? Thinking from the Chinese Situation', Transnational Cinemas, 1/2: 111-127. DOI: 10.1386/trac.1.2.111_1.

— (2016). 'Pema Tseden and the Tibetan Road Movie: Space and Identity beyond the "Minority Nationality Film"', Journal of Chinese Cinemas, 10/2: 89-105. DOI: 10.1080/17508061.2016.1167334.

Blaney, M. (2009). 'Locarno's Open Doors to focus on Greater China'. SCREENDAILY. Retrieved 10 August 2017 from <http://www.screendaily.com/festivals/other-festivals/locarnos-opendoors-to-focus-on-greater-china/4043238.article>.

Boym, S. (2001). The Future of Nostalgia. New York: Basic Books.

Buchanan, I. (2005). 'Space in the Age of Non-Place'. In Buchanan I. \& Lambert G. (eds.), Deleuze and Space, pp. 16-35. Edinburgh: Edinburgh University Press.

Cathcart, A. (2010). 'Nationalism and Ethnic Identity in the Sino-Korean Border Region of Yanbian, 1945-1950', Korean Studies, 34: 25-53.

Chaoxianzuyiminhoudaizhang lu:jiazaizhongguo, shiye zai hanguo [The descendant of chaoxianzu immigrant Zhang Lu: Home in China, Career in Korea]' (2016). Tencent Video. Retrieved 27 September 2018 from <https://v.qq.com/x/cover/oekd8sg2qed7ynl/foo2143bpb4.html>.

Colin, S. (2003). 'A Border Opening onto Numerous Geopolitical Issues - The Yanbian Korean Autonomous Prefecture', China Perspectives, 48:1-25.

Deleuze, G., \& Guattari, F. (1983). 'What Is a Minor Literature?', (R. Brinkley, transl.), Mississippi Review, 11/3: 13-33.

Demos, T.J. (2013). The Migrant Image: The Art and Politics of Documentary during Global Crisis. Durham; London: Duke University Press.

Dew, O. (2016). Zainichi Cinema: Korean-in-Japan Film Culture. Cham, Switzerland: Springer International Publishing; Palgrave Macmillan.

Dirlik, A. (1999). 'Place-based Imagination: Globalism and the Politics of Place', Review (Fernand Braudel Center), 22/2: 151-187. DOI: 10.2307/40241454

Ezra, E., \& Rowden, T. (2006). 'General Introduction: What is Transnational Cinema?'. In Ezra E. \& Rowden T. (eds.), Transnational Cinema: The Film Reader, pp. 1-12. New York; Abingdon, UK: Routledge

Frangville, V. (2016). 'Pema Tseden's The Search: The Making of a Minor Cinema', Journal of Chinese Cinemas, 10/2: 106-120.

Gomà, D. (2007). 'The Chinese-Korean Border Issue: An Analysis of a Contested Frontier', Asian Survey, 46/6: 867-88o. DOI: 10.1525/as.2006.46.6.867.

Higbee, W., \& Lim, S.H. (2010). 'Concepts of Transnational Cinema: Towards a Critical Transnationalism in Film Studies', Transnational Cinemas, 1/1: 7-21. DOI: 10.1386/trac.1.1.7/1.

Higson, A. (2000). 'The Limiting Imagination of National Cinema'. In Hjort M. \& +MacKenzie S. (eds.), Cinema and Nation, pp. 63-74. London; New York: Routledge. 
Ji, Y. (2013). 'I Might Be Addicted to the Beauty of Documentaries: Interview with the Director of Over There'. Korean Film Biz Zone. Retrieved o May 2017 from <http://www.koreanfilm. or.kr/jsp/news/interview.jsp? mode=INTERVIEW_VIEW\&seq=40\&blbdComCd=601019>.

Jin, H., \& Zijin (1992). 'Bianxie zhongguo chaoxianzuwenxueshi de jigewenti [A few questions regarding the historiography of ethnic Korean literature]', Journal of Yanbian University, 3: 86-92. DOI: 10.16154/j.cnki.cn22-1025/c.1992.03.020.

Jin, X. (2002). 'Zhongguo chaoxianzuwenxuezuopin jingcui [Selection of Chinese Chaoxianzu Literature]'. Yanji: Yanbian People's Publishing House.

Kim, G. (1993). 'The History, Culture and Language of the Koryǒ Saram', Korea Journal, 33/1: 47-68.

Kim, G.N. (2004). 'Koryo Saram, or Koreans of the Former Soviet Union: In the Past and Present', Amerasia Journal, 29: 23-30.

Kim, German N., \& King, R. (2001). Koryŏ Saram: Koreans in the Former USSR. New Haven, CT: East Rock Institute.

Kim, S. (2016). “Towards a Technology of the Dead: Kim Soyoung on Her "Exile" Documentary Trilogy', Senses of Cinema, 78. Retrieved 1o May 2017 from < http://sensesofcinema.com/2016/ feature-articles/kim-soyoung-exile-trilogy/>.

Klein, C. (2004). 'Crouching Tiger, Hidden Dragon: A Diasporic Reading', Cinema Journal, 43/4: 18-42. DOI: 10.1353/cj.2004.0035.

Ko, M. (2010). Japanese Cinema and Otherness: Nationalism, Multiculturalism and the Problem ofJapaneseness. London; New York: Routledge. DOI: 10.4324/9780203866719.

Lee, H. (2007). 'Sacrificing showers to explore our mental desert'. Korea Joongang Daily. Retrieved 10 May 2017 from <http://koreajoongangdaily.joins.com/news/article/Article.aspx?aid=2872652>.

Lionnet, F., \& Shih, S.-M. (2005). 'Introduction: Thinking through the Minor, Transnationally'. In Lionnet F. \& Shih S. (eds.), Minor Transnationalism, pp. 1-23. Durham; London: Duke University Press.

Massey, D. (1993). 'Power-Geometry and A Progressive Sense of Place'. In Bird J., Curtis B., Putnam T., Robertson G., \& Tickner L. (eds.), Mapping the Futures: Local Cultures, Global Change, pp. 59-69. London; New York: Routledge.

Oakes, T., \& Schein, L. (2006). 'Translocal China: An Introduction'. In Oakes T. \& Schein L. (eds.), Translocal China: Linkages, Identities, and the Reimagining of Space, pp. 1-35. London; New York: Routledge. DOI: 10.2307/20066191.

Ogawa, S.T. (2017). 'A Long Way Home: The Rhetoric of Family and Familiarity in Yang Yong-hi's Pyongyang Trilogy', Journal of Japanese and Korean Cinema, 9/1: 30-46. DOI: 10.1080/17564905.2017.1289296

Quan, Z., \& Zhao, C. (1979). 'Zhongguo chaoxianzu wenxuegaikuang [General Review of PRC's Chaoxianzu Literature]', Journal of Yanbian University, 4: 43-59.

Rancière, J. (2011). The Politics of Aesthetics: The Distribution of the Sensible. (G. Rockhill, transl.). New York: Continuum International Publishing Group.

Ryang, S. (2009). 'Introduction. Between the Nations: Diaspora and Koreans in Japan'. In Ryang S. \& Lie J. (eds.), Diaspora without Homeland: Being Korean in Japan, pp. 1-2o. Berkeley; Los Angeles; London: University of California Press.

—, \& Lie, J. (eds.) (2009). Diaspora Without Homeland: Being Korean in Japan. Berkeley; Los Angeles; London: University of California Press.

Seol, D.-H., \& Skrentny, J.D. (2009). 'Ethnic Return Migration and Hierarchical Nationhood: Korean Chinese Foreign Workers in South Korea', Ethnicities, 9/2: 147-174. DOI: 10.1177/1468796808099901

Shen, Z., \& Dong, J. (2011). 'Zhongchao bianjiezhengyi de jiejue (1950-1964) [Resolutions of Sino-Korean Border (1950-1964)]', Twenty-First Century [ershiyishiji], 124: 34-51. 
Shih, S.-M. (2007). Visuality and Identity: Sinophone Articultions across the Pacific. Berkeley; Los Angeles; London: University of California Press.

- (2011). 'The Concept of the Sinophone', PMLA, 126/3: 709-718.

The CFI Guide to Film Production in China (2016). ChinaFilmInsider. Retrieved 10 May 2017 from $<$ http://chinafilminsider.com/cfi-guide-10-things-know-working-film-china/>.

The Global Film Initiative (ed.) (2011). Dooman River: Global Lens 2011 Discussion Guide. San Francisco: The Global Film Initiative.

Trinh, M.-H. (2011). Elsewhere, Within Here: Immigration, Refugeeism and the Boundary Event. London: Routledge.

Wada-Marciano, M. (2012).Japanese Cinema in the Digital Age. Honolulu: University of Hawaii Press. DOI: 10.21313/hawaii/9780824835941.001.0001.

Wang, L. (2015). 'The Identification of Minorities in China', Asian-Pacific Law \& Policy Journal, 16/2: 1-20.

Wang, Y. (2012). 'Alter-centering Chinese Cinema The Diasporic Formation'. In Zhang Y. (ed.), $A$ Companion to Chinese Cinema, pp. 535-551. Hoboken, NJ: Wiley-Blackwell.

Wong, C.H.-Y. (2011). Film Festivals: Culture, People, and Power on the Global Screen. New Brunswick: Rutgers University Press.

Yanbian chaoxianzu zizhizhou 2or7nian guominjingji he shehuifazhan tongjigongbao [statistical communique of Yanbian Korean Autonomous Prefecture on the 2017 national economic and social development ] (2018). People's Government of Jilin Province. Retrieved 29 April 2018 from <http://www.jl.gov.cn/sj/sjcx/nbcx/gdzs/201804/t20180412_4505365.html>.

Yü, D.S. (2014). 'Pema Tseden's Transnational Cinema: Screening a Buddhist Landscape of Tibet', Contemporary Buddhism, 15/1: 125-144. DOI: 10.1080/14639947.2014.890355.

Zhang, Y. (1997). 'From “Minority Film” to "Minority Discourse”: Questions of Nationhood and Ethnicity in Chinese Cinema', Cinema Journal, 36/3: 73-9o.

- (2004). Chinese National Cinema. New York; London: Routledge.

- (2010). Cinema, Space and Polylocality in a Globalizing China. Honolulu: University of Hawaii Press.

Zhongguo chaoxianzu shiliao quanji [Complete Historical Accounts of Chaoxian Nationality] (2016). Yanbian University. Retrieved 10 January 2019 from <http://skc.ybu.edu.cn/ info/1040/1201.htm>. 


\title{
3 Fading Hometown and Lost Paradise
}

\author{
Kuzoku's Politics of (Dis)location ${ }^{1}$
}

\begin{abstract}
This chapter focuses on Kuzoku, a Japan-based independent film collective of multiple members founded by self-trained filmmakers Tomita Katsuya and Aizawa Toranosuke in 2004. This study first examines Kuzoku's location shooting by reconceptualizing fükeiron (theory of landscape). Importantly, I turn to how Kuzoku's fictional works Saudade (2011) and Bangkok Nites (2016), in tandem with other media projects by the film collective, reconfigure the mode of appearance in making visible previously marginalized subjectivities and locales, and connect with disparate temporalities and modes of affect as a gesture of resistance against the 'endless everyday' as well as the powerful globalization. Kuzoku's filmmaking contributes to rethinking the transnational potentialities ofJapanese cinema as well as Asian independent cinema.
\end{abstract}

Keywords: jishu eiga, fükeiron (theory of landscape), location shooting, affect, the immiscible/immiscibility

Audience members from my previous feature Saudade often told me the ending looked like a blind alley. That this type of rural town which I had portrayed in the film had no future. So we questioned what could lie beyond this dead end. It was starting from this questioning that the idea of a 'paradise' arose [...] After March 11, the issue of the state of the world arose before my eyes in the most radical manner. It's also to answer the questions that emerged as a result of the disaster that I made Bangkok Nites. In order to better understand the world in which we live, and how we relate to it as Japanese people.

Tomita Katsuya, 2016

1 My deepest gratitude goes to Dr. Fujiki Kosuke for his help in proofreading all the Japanese spellings and terms and for correcting some of my translations. Unless otherwise indicated, all translations from Japanese to English are mine.

Ma, Ran, Independent Filmmaking across Borders in Contemporary Asia. Amsterdam, Amsterdam University Press 2020 DOI: $10.5117 / 9789462986640 \_C H 03$ 
'The films advertising tourist resorts, those you see on the plane or on TV in the hotel, do not touch your heart at all, since we all know that the world is not like those. Then, what kind of images can show us what the world is like? I think Saudade is one such example' (Kuma et al. 2012: 217), said Japanese architect Kengo Kuma in his talk with Kuzoku (which literally means 'Sky Tribe'), ${ }^{2}$ a Japanese independent film collective of multiple members founded by the self-trained filmmakers Tomita Katsuya and Aizawa Toranosuke in 2004. As if to continue his dialogue with Kuma, commenting on his 2016 feature film Bangkok Nites, Tomita admitted how the March 11th Fukushima triple disaster in 2011 radically changed the way he perceived the world; for him, Bangkok Nites is used to 'better understand the world we live in, and how we relate to it as Japanese' (Tomita \& Aizawa 2016).

This chapter sets out to explore Kuzoku's independent works and, in particular, the 'world' explored, mediated, and interrogated in two fiction features, Saudade (2011) and Bangkok Nites, in tandem with other film works by the collective. While Saudade is set in Kofu, a provincial city in central Japan, Bangkok Nites sets out a more ambitious journey into places and communities across Southeast Asia. With Saudade, Kuzoku manoeuvres to scrutinize the landscape of a post-bubble Japan enmeshed in economic downturn and deepened social stratification, manifesting how global capitalism has extended its asymmetrically developed power into various realms of daily life. In Bangkok Nites, Kuzoku follows the journey of several Japanese (male) subjects who finally leave Japan behind in search of the so-called 'peach-blossom paradise' or tōgenkyō in Southeast Asian cities, such as Bangkok, and the frontier area along the Thailand-Laos-Vietnam borders.

Film scholar Aaron Gerow's critique regarding how contemporary Japanese cinema dialogues with the Other and globalism (see Gerow 2009, 2016) in terms of auteurism (e.g. with Kitano Takeshi, Miike Takeshi, and Kurosawa Kiyoshi), themes, styles (textual and inter-textual), and industrial layouts (extra-textual) sheds light on how we can rethink Japanese cinema and its border-crossing, transnational potentialities (or the impossibilities thereof) at various levels today. Specifically, Gerow elaborates on the recurrent imaginary or trope about an 'inescapable Japan' in the national cinema: no matter how much the protagonists yearn to leave the island behind and run

2 This collective borrowed its name from an unfinished sci-fi novel project by the two filmmakers' mutual friend, in which 'Kuzoku' (sky tribe) refers to a species of creatures that used to fly freely in the sky but end up surviving in the underground world and could only catch glimpses of the sky by looking up from the ditches (see 'Kuzoku tokushū jōei' [Retrospective of Kuzoku 2011]). Regarding the spelling of 'kuzoku', I have followed the way how the collective addresses itself in all types of English publications and promotional materials. 
away from its suffocating landscape, their efforts are often doomed, and it is 'impossible to escape even with the supposed transcending of boundaries that globalism promises' (2016: 88). As he pinpoints, the sense of entrapment must be perceived less as a problematic only unique to Japanese society and its national subjects (as for an 'island nation') than as the manifestation of the cultural politics of globalization, which functions in a mode of 'capitalist realism' that 'both enables and undermines dreams' and contests alternative 'imagination (imagining/mediatization)' (90).

This study primarily situates Kuzoku within the socio-cultural context of contemporary Japanese independent cinema. Then, departing from Gerow's discussions, I contend that if Saudade has demonstrated how present-day Japanese cinema (with its younger generations' filmmakers) confronts an urban landscape of disillusioned subjects and exhausted imagination, then the project of Bangkok Nites speaks of Kuzoku's yearning to look elsewhere for an alternative. The analytic heuristic of (dis)location takes its departure from Kuzoku's practices of location shooting. More importantly, the question at stake concerns how we can leverage the dialectics of mobility and entrapment that characterize Kuzoku's thematic tropes as well as their filmmaking practices to reconsider the politics of Japanese cinema today. According to Ian Buchanan, to engage with the deterritorialized world, we need to switch from a neurotic mode that tries to discover meaning and interpret codes to a schizophrenic mode that underpins the 'delirious' experiences of living through and coping with the 'frictionless space' of a global age (Buchanan 2005: 27-28). I argue that Kuzoku's oeuvre is significantly underscored with an affective dimension. This chapter, therefore, looks at how both Saudade and Bangkok Nites have engaged with (dis)location in terms of narrative tropes and sensibilities and feelings, especially in relation to the layered senses of 'home' and belonging.

\section{Kuzoku as an Independent Film Collective}

In a 2002 essay, Aaron Gerow points out how, into the twentieth-first century, the assumed differences and even contestations between 'major and independent, dominant and alternative' in Japanese cinema, when examined from the perspectives of 'industry, style, and politics', are becoming more ambiguous and untenable (Gerow 2002: 12). Reverberating with Gerow's observations, however, Mitsuyo Wada-Marciano seeks to characterize Japanese cinema since the 199os with what she describes as the 'post-studio' condition, wherein 'the whole film industry has gradually become financially 
dysfunctional' (Wada-Marciano 2012: 51), with independent filmmakers becoming the 'norm' (ibid.: 14). Indeed, Wada-Marciano has leveraged the 'post-studio' as an analytical prism to survey Japanese cinema in the global era that is, for instance, characterized by the 'assimilation of digital media and the presentation of the transnational' (ibid.: 15). Reviewing the conditions of Japanese film education in the post-studio era, however, Tezuka Yoshiharu has highlighted the significance of jishu eiga (sometimes written as jisyu eiga), which literally means autonomous filmmaking or 'self-financed nonprofessional filmmaking' (Tezuka 2013: 171). ${ }^{3}$ Whereas a historical review of jishu eiga as a diversified assemblage of vernacular discourses, film practices, works, and filmmakers is beyond the focus of this chapter, here I underscore jishu eiga as a type of independent, amateur cinema and film culture that connotes the contingent and transitional condition of the filmmaker's 'amateur-auteur' status. ${ }^{4}$ Somehow, it incorporates a future dimension toward the transformation or upgrading into the stage of 'professionalism', as suggested by Tezuka (2013).

Self-labelled as an eizō seisaku shūdan or image-making collective, Kuzoku has originated from and should be grasped from within the world of jishu eiga. The collective favourably affirms the independent/autonomous activities' (jishu-teki na katsudō) as central to its self-positioning, of which jishu jōei or the self-organized screening/exhibition also constitutes an indispensable dimension. ${ }^{5}$ Neither Tomita nor Aizawa were professionally trained in film production or scriptwriting, nor did they have any

3 According to Tezuka Yoshiharu, the postwar development of jishu eiga as a fertile ground to nurture film talent can be directly related to the structural transformations of the Japanese studio system since the 1970s. He suggests that, 'making jishu-eiga became established as an alternative to undergoing an apprenticeship in the industry and today it is not unusual for a young amateur to direct a commercial feature film without having working experience as an assistant director or equivalent on-the-job training' (Tezuka 2013: 176-177).

4 In her observation on Chinese amateur DV documentary filmmaking in the post-199os, Wang Yiman leverages the seemingly oxymoronic conceptualization of 'amateur-auteur' to look at 'a self-consciously assumed subject position that is defined in response to specific material circumstances, and that directly affects the ways of documenting one's material surroundings and individual experiences'. As such, the positioning of 'amateur-auteur' configures the 'precondition' of China's DV documentary in post-socialist China (Wang 2005: 17). Mitsuyo Wada-Marciano borrows insights from Wang and posits that for Japanese documentists working under the new production environment of post-studio, 'it is not the filmmakers' intentional stress on their "independent creative consciousness", but the "material circumstances" that strongly determine how they produce their works' (Wada-Marciano 2012: 66).

5 As integral to Kuzoku's gesture of resistance, they also decided not to release their films on home video formats, such as DVD, but emphasize film screening/exhibition as an important platform to engage their audiences (see Tomita 2014). 
specific affiliations with the Japanese film industry when Saudade was accomplished. Most of Kuzoku's projects are self-financed (recently with crowdfunding and co-production funds), and the collective mainly relies on jishu jōei and the alternative, arthouse network (such as the theatres known as 'mini-theatres') for distribution and exhibition. Situated within the environment of 'media convergence' in Japan, Kuzoku's image-making is also closely interwoven with independent culture (e.g. hip-hop music), and as evidenced by the long-term project of Bangkok Nites, the collective has also ventured into contemporary art with video installation works, as I shall explore in the following sections.

Gerow stresses how, against the contemporary setting, the 'independence' of Japanese independent cinema is not necessarily associated with any pronounced or homogeneous political stances but instead 'divisions, overlaps, and alliances between different camps have become more and more minute and complex, resisting any simplified mapping' (2002: 12). It is noteworthy that upon its establishment, Kuzoku envisioned its filmmaking as acts of intervention in the status quo apropos of contemporary Japanese cinema (also see Tomita 2014: 17-18). In other words, modes of independent cinema or jishu eiga have not been considered by them simply as a 'stepping stone' to 'become professional' (Tezuka 2003: 176) but are leveraged by the collective to identify their own idiosyncratic practices and to carve out a space of autonomy so that, as they claim, they can 'create whatever films we want to create and screen them whenever we want to' (tsukuritai eiga wo katte ni tsukuri, katte ni jōei suru) in a gesture of resistance (see Tomita 2014).

Specifically, Kuzoku's location shooting is an intriguing site to interrogate the translocal, transnational dynamics of contemporary Japanese cinema, the practices of which are emphasized here to lay the groundwork for my case studies to follow. In a radical fashion, to orient their ways of life around their own film projects (Tomita 2014), the collective has been known for its longer pre-production cycle, which seems rare among today's independent projects. ${ }^{6}$ During the shooting, Tomita and Aizawa sometimes alternate their roles as part-time workers and travelling ethnographers who embed themselves in local communities and in people's everyday life. Kuzoku does not necessarily restrain their research agenda beforehand but would usually launch a film project based on the fieldwork from 'on

6 Tomita pointed out how, since the project of Above the Clouds (shot on 8-mm film), the collective members started to use weekdays for their contracted work while using weekends to gather for the location shoot. Above the Clouds took almost three years to finish (Tomita 2014). 
location' participation and investigation, usually through a process of interviewing, documenting, and archiving, in order to make sense of 'a history of locations and a location of histories' (Clifford 1992: 105). Such ethnographic impulses have found their most powerful manifestation in Saudade and particularly in Bangkok Nites, a 'road movie' that traverses over 4000 kilometres across various Asian locales. The idea for Bangkok Nites, for instance, came into being a decade ago, and the actual film scenario, a collaboration between Aizawa and Tomita, was revised seven times over a period of two years (see Tomita, Aizawa, \& Nomura 2017:4). ${ }^{7}$ Furthermore, the filmmakers' journeys to Southeast Asia and their in situ interactions with the local people significantly shaped their framework and vision of the screenplay, the creation of which occasionally involved the participation of the filming subjects and interviewees. Moreover, logistically speaking, as an independent film collective with limited funding and infrastructural support, Kuzoku had to be resourceful and flexible enough to figure out its own ways of gaining access to potential shooting locations, which demanded an extraordinary investment of energy and time (see Tomita \& Aizawa 2017). ${ }^{8}$

Understandably, Kuzoku has been versed in cinematic genres like essayistic travelogues and particularly (quasi-)road movies. While their oeuvre is distinguished with a realist visual style built upon a collaborative, research-based screenplay and a mostly non-professional cast who often play themselves and speak their own dialects and/or foreign languages, it is noteworthy that with individual works, such as Flower Story Babylon (Hana

7 As the director, Tomita spent altogether four years travelling on and off to Bangkok in order to prepare for the project, until the decision was made that he himself would play the male protagonist Ozawa. Before the shooting actually kicked off, Tomita then settled down in the city for a whole year under an artist-training scheme by the Japanese government and learned the Thai language, during which period Aizawa travelled to Bangkok to work together with Tomita on the scenario. For details, refer to the core members' diary of film shooting, which was later collected in a book of theirs, Bankoku naitsu: Senkō issen ri [Bangkok Nites: Hidden Journey ofa Thousand Miles].

8 For instance, the female protagonist of Bangkok Nites, Luck, works at a hostess club on Thaniya Road, one of the most notorious red-light districts of central Bangkok that predominantly caters to Japanese clients. Understandably, it is an area that cannot possibly be promoted in the list of locations recommended by the Thailand Film Office. Therefore, the huge challenge comes in how to secure permission from these entertainment clubs and bars, which are closely tied to the local shadow economy. It was after a long period of communication and relationship-building (four years) that the filmmakers finally gained enough trust and understanding from the club managers and people who earn their lives there, including the prostitutes and hustlers. Kuzoku explained to them that they planned to tell a story about ordinary people's struggles in life, centring around the idea of 'chiiwit' the Thai word for 'life' (Tomita \& Aizawa 2017). 
Monogatari Babylon, 1997) and Babylon 2: The Ozawa - Guns of Babylon (2012) directed by Aizawa, the director has opted for an essayistic approach that blends voice-over narration, experimental superimposition of images, and the use of archival materials. ${ }^{9}$

\section{Saudade: Beyond the Landscape}

\section{Rethinking Fūkei}

Kuzoku's 2011 award-winning feature Saudade, a co-scripted film directed by Tomita, was shot in the latter's home city of Kofu (the capital city of Yamanashi Prefecture), a place ridiculed by the protagonists in the film as the 'countryside' (inaka). Loosely developed from Tomita's previous feature film, OffHighway 20 (Kokudō nijū gōsen, 2007), Saudade was also based upon the collective's documentary short FURUSATO 2009 (2009), a pre-production research on the urban condition of Kofu in the wake of the Lehman Brothers shock in 2007. ${ }^{10}$

Kuzoku identifies Saudade with three keywords, namely 'construction workers', 'hip hop', and 'immigrants' - themes that also grew out of their one-year research in Kofu. The work features an ensemble of characters whose life trajectories parallel, converge, and separate around the tripartite themes. At a building site, construction worker Seiji (Takano Tsuyoshi) befriends Hosaka (Ito Jin), who claims that he has recently returned from Thailand, and freelance-labourer Takeru (Dengaryū), a rapper/musician who leads a local hip hop group called 'Army Village'. Meanwhile, Denis (Denis Hamatsu), a third-generation Japanese-Brazilian who recently lost his factory job, heads a hip hop band called 'Small World' consisting of Brazilian members from similar backgrounds. When 'Small World' happens to outperform 'Army Village' in a live showdown, the humiliation further fuels Takeru's xenophobic sentiments. Meanwhile, Seiji is finally confronted by his Japanese-Thai hostess girlfriend Miyao, who finds his dream of leaving Japan and settling down in Thailand naïve and impossible.

9 At the same time, we also need to note how Kuzoku's works are highly self-referentially and inter-textually related: characters with the same name pop up in different movies and are often played by the same (non-professional) actors; familiar shooting locations are explored in consecutive works; and unfinished storylines are picked up and reinvented in a new project but still remain open. Films that were produced by Tomita and Aizawa prior to the founding of Kuzoku have also been closely knitted into the micro-cosmos of intertextuality of the collective's oeuvre. 10 Saudade was partially financed by Tomita's part-time job as a truck driver commuting between Yamanashi and Tokyo, which he also used for location hunting (see Tomita,2014). 


\subsection{Seiji and Hosaka at the top of a building, overseeing the city of Kofu in Saudade}

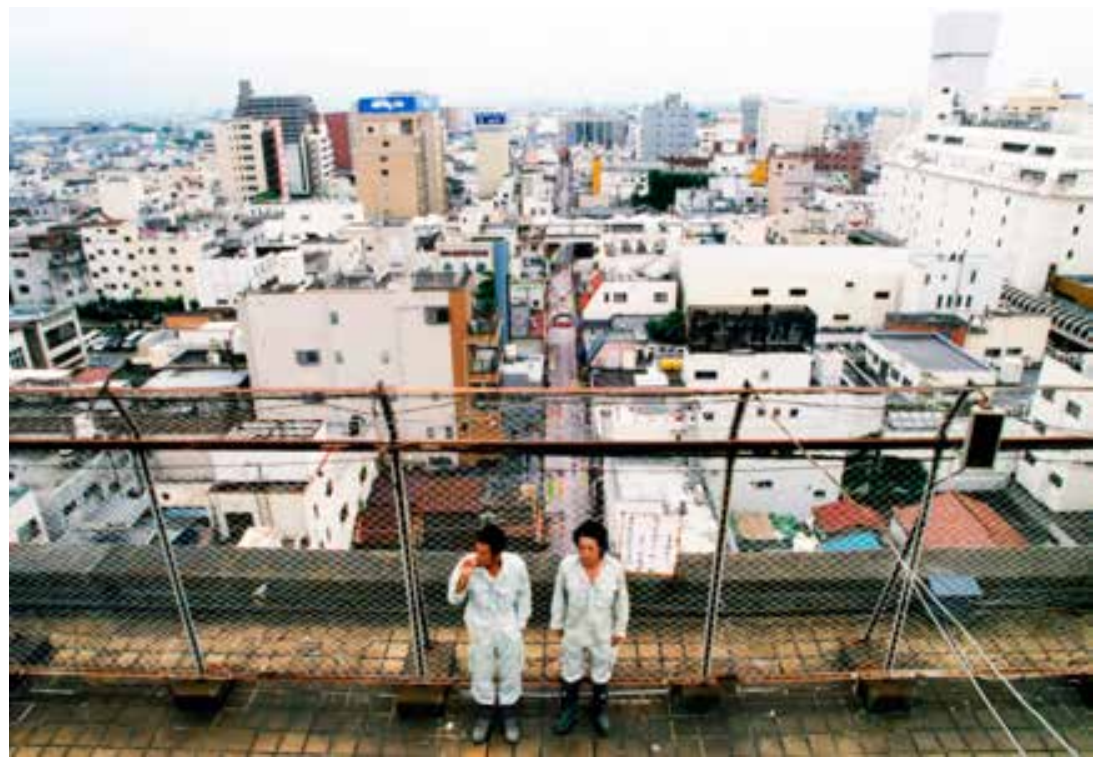

Saudade configures a cityscape of construction sites, dilapidated shopping streets, flashy pachinko parlours, parking lots, nondescript shopping malls, fast food chains, nightclubs, love hotels, snack bars, and so forth. When Hosaka overlooks the city of Kofu from the rooftop, he is not particularly touched by the night view but murmurs, 'the city is dead'. His sensibility uncannily echoes Walter Benjamin, who observed decades ago, 'In the convulsions of the commodity economy we begin to recognize the monuments of the bourgeoisie as ruins even before they have crumbled' (Benjamin 1978: 162). Nevertheless, as Tomita explains, by focusing on a provincial city like Kofu, its cityscape registers the homogenized urban condition of Japan as a whole, wherein the sense of boredom does not change 'be it in Kofu or in Tokyo' (see Kuma et al. 2012: 216).

Arguing that Saudade could be grasped in connection with leftist filmmaker/film critic Matsuda Masao's concept from the 1970s of fükeiron or 'the theory of landscape', film scholar Mika Ko has similarly departed from a critique of space and power. Leveraging Furuhata Yuriko's interventionist reading of fükeiron in relation to so-called 'landscape films', such as A.K.A Serial Killer (Ryakushō renzoku shasatsuma), a documentary produced in 1969 by a collective of leftist filmmakers toward the end of the 'season of politics' (in which Matsuda also participated), Ko argues that Saudade 
could be approached as Kuzoku's critique of an assemblage of 'landscape' under the new circumstances of global capitalism. Ko has specifically indicated that Kuzoku has made visible an external reality that is not readily perceptible in the everyday world. For Ko, Saudade's fükei is not only composed of and incorporates spatial formations - such as the banal cityscape, danchi complex (apartment complex or public housing estate in the Japanese setting), streets, and alleys - it also includes subjects such as foreign labourers and immigrants, and the social relations and affective formations that interweave various identities, soundscapes (a mixture of foreign languages, dialects, and music), and memory (Ko 2016: 190).

In her brilliant take on landscape films, Furuhata points out that under her examination such films have shifted their focus onto 'the nonspectacular and nonrepressive mechanisms of control and governance built into the everyday environment'(Furuhata 2013: 117-118). ${ }^{11}$ According to Furuhata, films like A.K.A Serial Killer even went ahead of the perception of their creators (including Matsuda himself) in thinking beyond a classical model of state power, presciently addressing and reflecting upon 'the symptomatic waning of the centralized mode of imagining political resistance, which had been anchored around the anthropocentric figure of the subject [shutai] that had for so long dominated the political imagination of postwar Japanese intellectuals' (2007: 361).

I contend that Furuhata's discussion reverberates with what Gilles Deleuze has framed as modern political cinema, wherein 'the people are missing' (Deleuze 1989: 216), indicating how the 'biopolitical subjection of people destroys any hope of the masses acting as revolutionary subject' (Wiese 2014: Kindle Location 157). Arguably, the two landscape films that Furuhata uses as examples - A.K.A Serial Killer and Oshima Nagisa's The Man Who Left His Will on Film (Tokyo sensō sengo hiwa, 1970) - emerged in response to Japan's drastic transition into a late capitalist consumer society around the 1970s, when a reconceptualization of state power and governmentality

11 In her illuminating analysis of landscape film and the filmmaking practice of fükeiron, Furuhata Yuriko posits that fükeiron converges with the European-American conceptualization of landscape in considering fükei as 'an idea' as well as 'a practice'. The theory itself forcibly examines 'the immanent relations of power that produce homogenized landscape' (Furuhata 2007: 353-354). Furuhata bases her reading of fükeiron by analyzing the documentary film A.K.A Serial Killers (1969), which, despite a topical title suggestive of its links with a notorious serial killer, threads together 'actuality footage of urban and rural landscapes from the tip of the northern island of Hokkaido to the southwestern cities of mainland Japan' (ibid.: 346). As a collective effort, it was shot by a group of leftist filmmakers, including Matsuda, whose participation in the filmmaking was also in order to practice fükeiron. 
became necessary, if not urgent, as has also been suggested by Ko. The socio-political transitions facilitated a rethinking of the ways of imaging and representing political struggles and confrontations visually, that is, cinematically, upon which, for instance, 'the militant documentary filmmaking' by documentarist Ogawa Shinsuke of Ogawa Production in the late 196os left an indelible mark (Furuhata, 2007:346). As is well articulated by Furuhata, the politics of landscape films could be approached 'as interlocking sites of visibility and invisibility'(ibid.: 360$),{ }^{12}$ the dissensual potentialities of which lie in the spectatorial engagement reconfigured and activated through redistributing what could be seen, experienced, and felt, and for whom. Matsuda and his fellow filmmakers' practices, therefore, forcibly critiqued the activist spectacle of political documentary cinema of its own time precisely by introducing a new way of seeing (see ibid.: 355,361 ) and, arguably, in emphasizing a new mode of appearance.

Whereas Saudade has not premised its cinematic style upon the 'formal strategy' leveraged either in the early actuality films or landscape films like A.K.A. Serial Killer, namely the patterns emphasized by Furuhata, it would be important to argue how Kuzoku's take has similarly introduced dissensuality through aesthetic acts that have redistributed a 'landscape' of images, sounds, sensibilities, and affective flows that contribute to reimagining the social conditions in a globalized, post-bubble, post-financial-crisis Japan, wherein the interrelations between the filmmaker(s), filming subjects, and audience have also been reconfigured.

\section{The Long Takes}

With their early collaborative works, such as Above the Clouds (Kumo no $u e, 2004$ ) and OffHighway 20, we could already see how Kuzoku members, leveraging their personal experiences (and particularly Tomita's uncanny experience of returning to his hometown Kofu after living in Tokyo for years), had developed an acute consciousness of the nondescript urban landscape and ennui in the provincial cities and suburban areas of Japan. They have, in particular, identified with marginalized subjects or precariats,

12 For Furuhata, the 'politics' of the cinematic experimentations of fükeiron are not only achieved through 'an antistate cartographic endeavor' in assembling shots of a banal, homogenous landscape devoid of human subjects or narrative drives but also in making visible the diagrammatic function of power configuring such landscapes. Also, A.K.A. Serial Killer channels the 'politics' of the pre-documentary mode of actuality films that lays emphasis on 'display' in foregrounding the 'exteriority of the spectator in relation to the image', namely in placing the latter outside of the 'screen space'. See Furuhata $(2007,2013)$. 
such as part-timers, sex workers, and small-time criminals (e.g. members of the yakuza, drug dealers, hustlers, and loan sharks). These jishu eiga works are dedicated to a neorealist rendition of urban malady with its loosened storytelling, everyday mise-en-scène, and non-professional performance and camerawork, which, according to Tomita, is supposed to embody certain characteristics of 'amateurish-ness' (shirōto-sa) (Takano et al. 2011: 15-16). In Saudade, nevertheless, Kuzoku demonstrated a more mature film style that not only relies on an ensemble of characters and parallel narratives but also a form of expression that consciously utilizes editing and camerawork to survey the relations between the characters and their urban milieu.

Working on the project of Saudade, Takano Yoshiko, Saudade's cinematographer, shared the opinion with both Aizawa and Tomita that 'the city is the protagonist of the film' and decided that she would treat both human subjects and the landscape 'as equal' (Tomita et al. 2011: 19). It needs to be pointed out that Tomita also became more self-conscious of his 'on-thescene' film practice and their aesthetic implications in Saudade. Unlike OffHighway 20, which was shot on 16-mm, Saudade was shot on HDV since Tomita valued how the digital camcorder could respond to the variables and contingencies for an unusually long period of location shooting (ibid.: 17).

Here, Tomita learned how to give up his previous method of following a pre-established storyboard and to suspend his 'attachment' to any specific character, which thus allowed more space for in situ experimentations and improvisation on the parts of the actors and his cinematographer. The director has accordingly underpinned his own role less as a person who 'directs' than as someone who 'leads', indicating the creator's sensibility towards the profilmic contingencies on the scene (ibid.: 10). Tomita then admits that while in the script there is still the central-peripheral differentiation between the characters, Takano shot them together with - and as not all that different from - the fükei/landscape.

I shall argue, therefore, that as far as Kuzoku is concerned, its landscape theory' is not meant to simply reveal how the protagonists have been subjugated to the hegemonic power configuration of global neoliberalism per se, which is necessarily premised upon a pre-established conceptual signification system that unpacks symbols and metaphors for the purpose of ideological critique, as is partially manifested in Ko's approach to fükeiron and Kuzoku's works. Here I find Rancière's discussions of Portuguese filmmaker Pedro Costa's 'politics of art' useful to illustrate my point. Rancière illustrates that the politics 'is not the one that made a show of the state of the world to expose structures of domination and mobilize energies to change them' (Rancière 2014: 137). We can borrow Vered Maimon's insight 
that 'the problem for political artistic practices is no longer the disclosure of "facts", since it is not necessarily opacity or secrecy that underlines the economy of power in "the age of information" but precisely binary divisions into such defined groups as enemy and friend, our people and "their" people' (Maimon 2009: 103).

Hence I am more interested in exploring how the landscape in Saudade can be approached in terms of the space-time of appearance in the Rancièrian sense, wherein Kuzoku (especially with the creative contribution of cinematographer Takano) has leveraged formal mechanisms such as the deep focus and the long take to re-structure ways of seeing and feeling the 'location' as well as seeing and feeling on location. In so doing, the conventions and systems of signification that correlate human subjects with their surroundings are suspended and disrupted, allowing for the interconnections between the filmmakers, characters, and audiences to be re-imagined.

For example, one could look at how the filmmakers have used long takes to follow how three of the male protagonists - Takeru, Seiji, and Denis - have roamed around the decaying city of Kofu. In a mobile long take toward the end of the film, for instance, Seiji, after his break-up with Miyao and frustrated by Hosaka's unexplained departure, walks numbly into the emptied shutter streets at night, where he suddenly has the bizarre illusionary vision of a queue of mannequin-like figures waving to him. In the sequence that follows, in which a popular song reminiscent of Japan's prosperous 'bubble era' is played extradiegetically, Seiji is seen moving passively along the crowds on the boisterous night street where a band of yakuza on motorcycles is parading flamboyantly. As Gerow demonstrates, 'attractive images' as such end in disillusion in a shot of him 'standing in front of the same shuttered businesses and empty hopes' (Gerow 2016: 90). Nevertheless, sequences of Seiji's stroll are not to be approached merely spatially, as they also register the anachronic temporalities wherein Seiji's imagined future (apropos moving to Thailand with his loved one, Miyao) is at the same time eroded and overlayered by the present (long-take of the parade) of which he is not essentially a part. He is also haunted by the past: not only the lingering melody from the good old days is played, also the sight of desolate shopping arcades interweaves with the memories of a disappearing friend and a lover who has bid farewell.

Another long take with Takeru's roaming is more performative and illustrative of my point. We see early in the film that after he walks out of the Thai night club at night, disappointed and irritated by Seiji and Hosaka's 'pastime' of seeking companions among the Thai hostesses, he wanders around town alone. Before he turns to the so-called 'shutter street' 


\subsection{Shooting Takeru (played by rapper Dengaryū) walking through the shopping street}

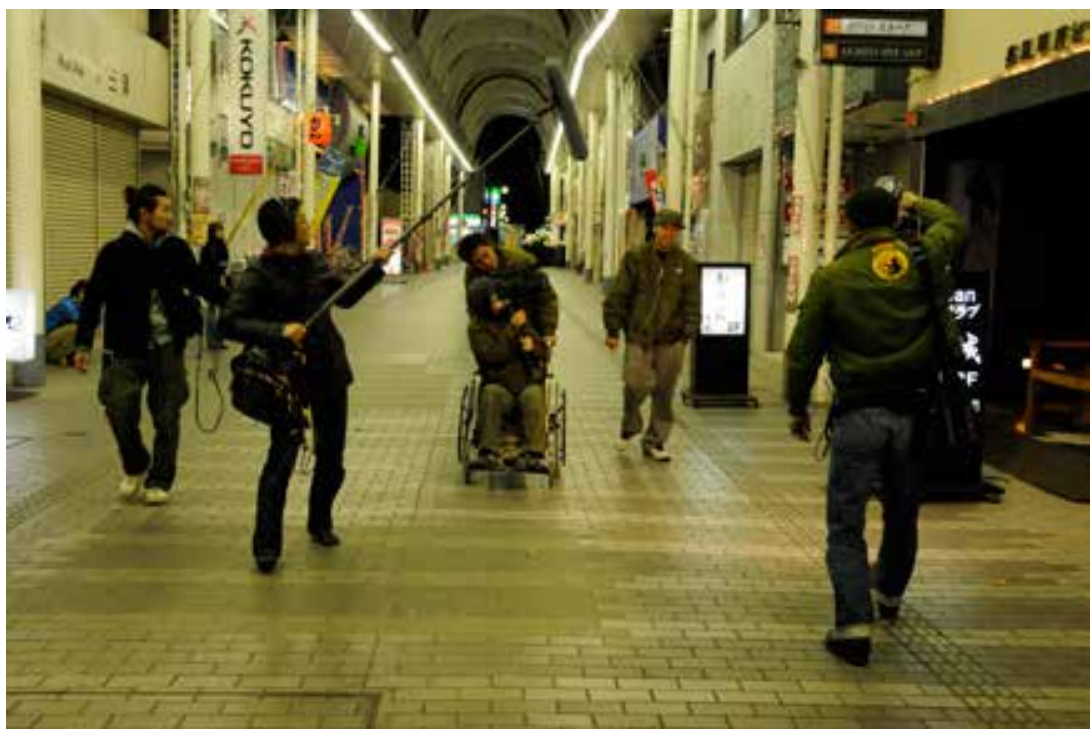

where most shops have gone out of business, Takeru encounters a street singer whose folk tune of San'ya (the song of 'San'ya Blues') is somewhat picked up by himself in the sequence to follow, ${ }^{13}$ when he expresses a mixed feeling of anger and melancholy. In a horizontally moving tracking shot of more than ninety seconds long, one sees how the rapper spits his rhymes as a way to vent his dissatisfaction with the unbearable ('The town's dying/ It's suffocating/It's a vacuum, a void/ Both the town and its people/They gave up, full of indifference'). Here with his improvised rap song (owing to the affective labour of rapper Dengaryū, who attempted many takes), Takeru also shares his family story, disclosing the origin of his xenophobia - recalling how his father went bankrupt due to the recession and the influx of migrant workers.

This long take leverages Takeru's flâneurie to navigate through the bleak scenario of the shopping arcade, where the roller shutters are decorated with bright-coloured election posters for a local politician whose slogan ironically

13 In his monograph, Edward Fowler has provided unique insights into San'ya, 'the largest of several Tokyo yoseba, or gathering places for casual laborers who get work off the street' (Fowler 1996: 9). According to Fowler, San'ya was 'home to as many as fifteen thousand day laborers during its heyday in the late 1950 s and early 196os' (ibid.). Folk song singer Okabayashi Nobuyasu debuted with 'San'ya Blues' in 1968, a song that was about the dire conditions of the day labourers. 
reads, 'To Revitalize the Hometown!' The MTV-style sequence displaces Takeru from the milieu of construction and labour and relocates him in the dark lane, where the audience observes how it has been turned into a stage by the rap singer's moving body and his storytelling. It is no longer Takeru's personal story that Dengaryū narrates: his voice and gestures interconnect in between Takeru's bitter family memory, the street-singer's accounts of the conditions of San'ya's day labourers (played by a homeless singer himself) (also see Ko 2016: 202), and the collective experiences shared by labourers and workers who struggle to cope with the conditions of precarity, whether from Kofu, San'ya, or Brazil. Meanwhile, the long take builds upon the tension between showing and narrating that works with multiple layers of temporality: whereas the shutter street visually registers a future of the past that has already come true, the lyrics return to a past of the present that cannot be overwritten. Nevertheless, Takeru's moving body opens up the present to a future that can be drastically different from the doomed ending where he will stalk Denis and stab him to death.

\section{'Saudade': An Affective Critique}

It is necessary to briefly explicate how the idea of 'affect' is used here. In the first place, affect is grasped as a personal emotional state and a physiological sensation of the body; it is the translated, signified, and subjectified version of the affective matter. A second way to understand affect is as 'a dimension of bodily experiences and encounter' that is non-representational, which registers 'a dynamic force that passes through but also beyond personal feelings, a force being purely transitive' (Chang 2009: 35). In my discussion of Kuzoku's works, both aforementioned perspectives intermingle. Primarily I situate the study of entangled emotions and feelings within specific socio-cultural contexts and affective formations. Inspired by Sara Ahmed's approach to ask 'What do emotions do?', attending to how 'emotions might show us how all actions are reactions, in the sense that what we do is shaped by the contact we have with others' (Ahmed 2014: 4), I also turn to an interpretative framework that focuses on the cinematic narrative in terms of how the protagonists react to what has happened to them through articulating/acting out their feelings while living in and through the conditions of the unbearable and the impossible.

Probably not unlike Takeru or Seiji, other characters in Saudade engage the generic city and react to the new spatial politics by centring their daily activities around the forces of deterritorialization and reterritorialization, shuttling between hope and despair, evidencing the observation regarding 
how affect has underpinned 'the organisation of the way we live now' to the extent that 'production, consumption, participation: in every case we are addressed as (and retain relevance by) being affective operators' (Sharma \& Tygstrup 2015:4). Meanwhile, what has been perceived as the real problematic by Kuzoku concerns the compartmentalization of their subjects as they are trapped in their own predicament (see Tomita 2014), manifesting what Patricia Pisters enumerates as the characteristics of modern political cinema wherein not only is there no unified people anymore but also the story is permeated with the feeling of 'the impossible and the intolerable' (Pisters 2003: 90-91). Nevertheless, I agree with Kuzoku that Saudade is not in itself a dark or pessimistic film (see Takano et al. 2011: 21). Instead of imagining how its protagonists have given themselves over to the entropy, the work also turns to how they look for alternatives in exploring relations and (re)configuring affective connections among themselves.

For example, faced with the prospect of unemployment and disillusioned by his marriage, Seiji turns to the Thai bar, Hosaka's marijuana greenhouse, and his Thai-Japanese girlfriend Miyao for consolation. Trying to convince Miyao that choosing Japanese nationality is not a good idea, he dreams that one day he could leave Kofu and move to Thailand. Meanwhile, Takeru cannot escape from his family's devastated circumstances and can only channel his growing sense of crisis into enmity towards the foreigners in town. He nonetheless still seeks to connect to his passion for hip hop music, however wrongheaded he is in his belief that he could teach the Brazilians a lesson by leading his band to win the live-house showdown. Also, even though Denis and his friends have borne the brunt of the financial crisis and can do little to reverse the prejudice against Japanese-Brazilian immigrants in Japan, there is still the vague hope that their music and performance may potentially open up a space to not only claim and distinguish their own voices but also to make cross-cultural connections possible with the 'locals'. However, their differences are essentialized and considered exotically 'hybrid' by the latter. Toward the end of Saudade, Seiji loses his way in the parade (as analyzed above), and Takeru turns himself in to the police after stabbing Denis. Seemingly, all their efforts end up nowhere, yet the actions taken to formulate affective associations, even the violent ones, configure the lines of flight from what sociologist Miyadai Shinji (who plays a politician in Saudade) calls the "endless everyday" (owaranai nichijō) where all is empty and nothing changes' (Gerow 2016: 89).

Here we finally return to the title of the film. It is well known that the Portuguese term of 'saudade' conveys a feeling of longing, melancholy, and nostalgia, underpinned with a temporal dimension that connects the past 
with the present (see Laplantine 2015). In the film, 'saudade' is also used as a pun, wherein the characters tend to mix it up with the Japanese word of 'Sannō Danchi' due to their close pronunciation. The latter is an existing 'danchi' in suburban Kofu where Japanese-Brazilian workers and their families actually live, which in the film narrative turns out to be Takeru and his brother Yukihiko's old neighbourhood when they were young.

As awkward as it may seem, the nexus of 'saudade-sannō danchi' has intersected and also complicated the multi-layered meaning-making of home(s). What is foregrounded here is not simply a case of transcultural miscommunication. Rather, the nexus poses the question regarding whose 'home' or 'hometown' it is that has been occupied, lost, and found and whether the seemingly discrepant strands of sensibilities of feeling alien and being displaced (e.g. either for Takeru, or for the Japanese-Brazilian workers) could be interrelated and shared translocally and across various temporalities. For instance, whereas Takeru and his younger brother Yukihiko believe that it is the foreign migrant workers who are now occupying their old 'home' and turning the danchi into a neighbourhood that is unfamiliar to them (Yukihiko tells Takeru about his recent visits to Sannō Danchi, which now feels 'different' for him), they have ignored how the Japanese-Brazilian immigrants are also cornered in this public housing-cum-ethnic enclave, caught in between Brazil and their supposed 'ancestral land' of Japan. ${ }^{14}$

Here we may then turn to the sequence where one of the Sannō Danchi's Japanese-Brazilian families is seen having dinner together. Over the meal, the father Mario asks their young daughters where they would choose to go when they have to leave Japan - Brazil or the Philippines, the place where

14 Endō Toake points out that 'Brazil is the heartland of Japanese immigration in South America', and the country 'embraces more than 1.5 million multi-generational descendants living in its vast territory, forming the largest Japanese community outside Japan' (Endo 20o9: 26). Endō also reminds us that 'the history of Japanese migration to Brazil started on the eve of the twentieth century and evolved in tandem with the coffee industry' (ibid.: 27). Japanese Brazilians are often referred to as 'Nikkei Burajirujin', wherein as illustrated by Joshua Hokata Roth, 'Nikkeijin' (literally means 'sun line people') is used to refer to overseas Japanese and 'members of the Japanese diaspora' (Roth 2002: 23). Meanwhile, although not specifically discussed in this chapter, the recent return migration of Nikkeijin has been encouraged by the Japanese state since the end of the 1980 os in immediate response to the labour shortage in Japan. Most of the migrants 'came to Japan looking for better incomes' (Ishikawa 2009: 59). Ishikawa also indicates what kind of impact the revision of the Japanese Immigration Control and Refugee Law in 1990 had upon the return migration, which 'allowed Japanese descendants, up to the third generation, to live and work in Japan, even if they lacked professional skills' (ibid.: 62). According to a 2015 report by The Japan Times, the number of Nikkei Brazilians 'peaked at over 313,000 in 2007 before Japan offered them incentives to repatriate amid the global financial crisis, and fell to under 174,000 in 2015' (Twaronite 2017). 


\subsection{Mahiru (right) and Pinky (left) visiting the senior day care center, listening to the old lady's story}

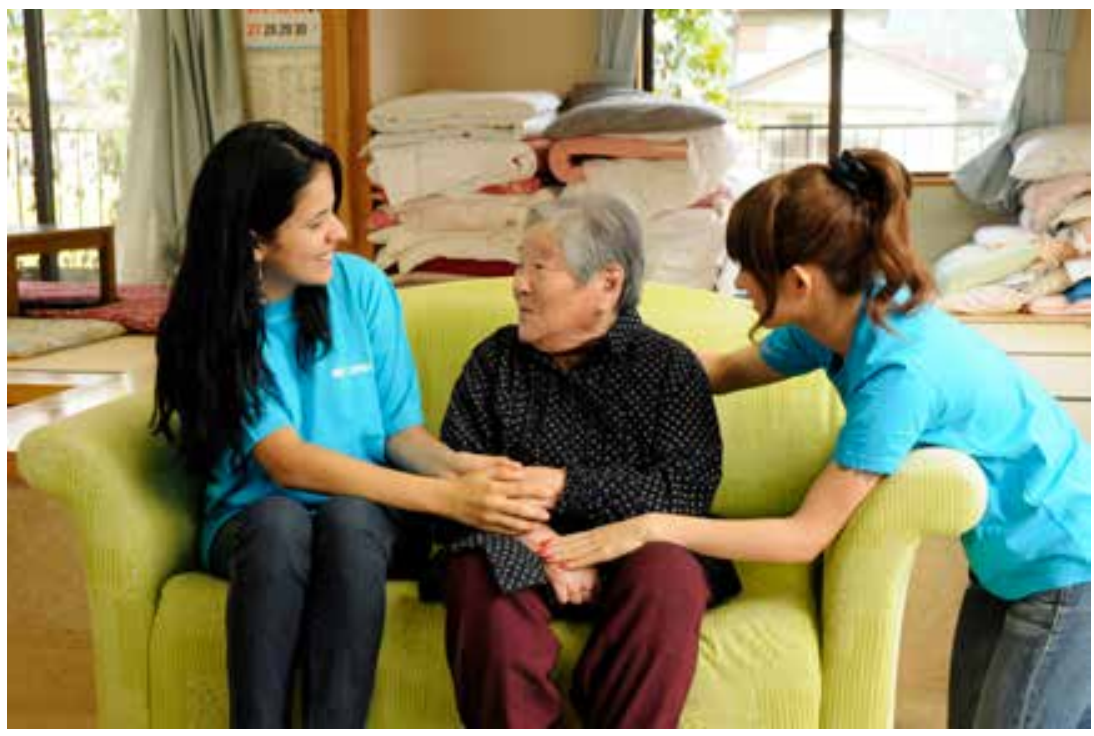

their mother came from. The ambiguous answers he gets from the kids only leave more questions open. It is noteworthy that the sequence is played by real family members whose conversations smoothly switch between Japanese, Portuguese, and Tagalog. However, rather than reinforcing the triumphalist vision of a borderless, cosmopolitan world where the translocal subjects would always feel 'at home in the world', Saudade foregrounds with the scene of Mario's dining table the fragmented temporalities that this 'international' family intersects with. And their sense of 'saudade', I shall argue, is directed toward a precarious future where both 'home' and 'hometown' remain unknown destinations.

Meanwhile, as also mentioned by Ko, there is a documentary-style sequence in which two of the female protagonists, Mahiru (Ozaki Ai) and Pinky (Almeida Hamatsu), the rapper singer from the Brazilian band 'Small World', volunteer at a senior day care centre. It is intriguing that when surrounded by Mahiru and Pinky, an old Japanese lady starts to share with them memories about her relatives who migrated to Brazil and the local specialties they sent back to Japan, such as coffee beans. The old lady's reminiscences, based on the actual stories of first-generation Japanese immigrants to Latin America (usually referred to as issei), interlace with the daily conversations at Mario's dining table - both strands of narratives complement each other, foregrounding the transgenerational interrelations 
between the translocal subjects and their micro-histories of deterritorialization. The nexus of 'saudade/sannō-danchi' therefore also comprises an affective critique that connects in between the seemingly estranged characters, disconnected communities, and their disparate temporalities, wherein 'other" sensibilities and affective expressive politics' can emerge and intermingle (Tolia-Kelly 2019: 127).

\section{Bangkok Nites: Hidden Journey of a Thousand Miles}

\section{Almost a Road Movie}

Backed by transnational funding from several cultural and film entities and money raised through a crowdfunding platform within Japan, ${ }^{15}$ Bangkok Nites best illustrates Kuzoku's vision in further experimenting with a complicated narrative structure of parallel plotlines and an ensemble cast. Also, the collective's long-term preparation and fieldwork underpinned its unusually expansive geographical/geopolitical framework, making the work itself an unprecedented project not only for Kuzoku but also for Japanese independent cinema. It is further noteworthy that in this 2016 feature, Kuzoku worked with a larger (transnational) crew from various backgrounds. For instance, their cinematographer team Studio Ishi consisted of two hip hop musicians who brought to the film refreshing yet rather mixed camerawork and a visual style that begs us to approach them with different perspectives (also see Watanabe \& Yūki 2017).

Kuzoku also labels Bangkok Nites with three keywords: 'paradise' (rakuen), 'prostitute' (shōfu), and 'colony' (shokuminchi). The film opens with a former soldier of the Japanese Self-Defense Force (Jieitai), Ozawa (played by director Tomita himself), bumping into his ex-girlfriend Luck (Subenja Pongkorn) at a nightclub in Bangkok, five years after their break-up. Luck has become the top cabaret hostess working at Thaniya Road, a red-light district infamous for its tailored service to Japanese clients that flourished in the 1980 os as a result of Japan's bubble economy. Clueless about his future, Ozawa joins his former officer in the Self-Defense Force to work for a Japanese company's

15 According to the crowdfunding site 'motion gallery', a total of 282 people participated in the fundraising action, raising up to 11,302,862 Japanese yen for Bangkok Nites and reaching Kuzoku's goal ('Kuzoku ga hatsuno kuraudo fandingu ni "ikarinodesurōdo hōshiki” de idomu! Zenpen tai • raosu satsuei o kankō! saishinsaku 'Bangkok Nites'! [Kuzoku's first crowd-funding for their latest movie 'Bangkok Nites']' 2015). 


\subsection{Installation project 'Hidden Journey of a Thousand Miles' by Kuzoku + Studio} Ishi + YCAM

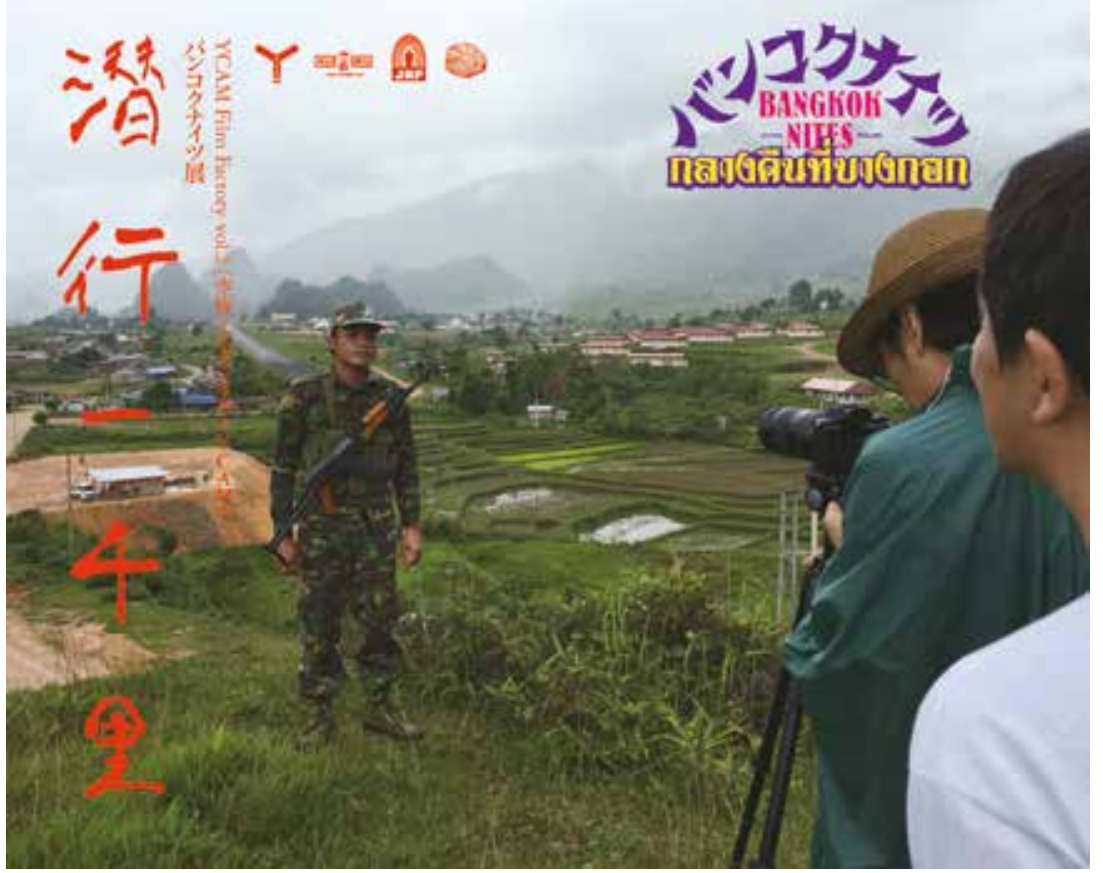

real estate development project in Southeast Asian countries that dabbles in the grey area of the sex industry. Upon leaving for Laos to investigate the local business there, Ozawa is joined by Luck, but their destination is the Northern frontier province called Nong Khai in the Isan (Issan) area, Luck's hometown.

Bangkok Nites extends Kuzoku's interest in exploring Japan's positioning in and connections with Southeast and East Asia by examining the legacies of World War II, the Vietnam War, and the Cold War. Their endeavour is complicated by the historical memory and trauma of colonialism, authoritarianism, (anti-)communism, as well as the persistent hegemonic power of the US. According to Tomita, although Japan and mainland Asia 'is separated by the ocean', he believes that 'they are linked today by the colonial history' (2016). ${ }^{16}$ Meanwhile, Kuzoku's questioning regarding Japan's

16 Bangkok Nites' survey of colonialism needs to be examined in intertextual and self-referential terms by first of all turning to two 8mm-film short films by Aizawa, Flower Story Babylon (1997) and its sequel, The Ozawa: Guns of Babylon (2012). Both films, in following the aimless journey of 
3.5 A map illustrating the trip that Bangkok Nites took in Southeast Asia, from the brochure of 'Hidden Journey of a Thousand Miles'

The Journey the Fim "Bangkok Nites" took
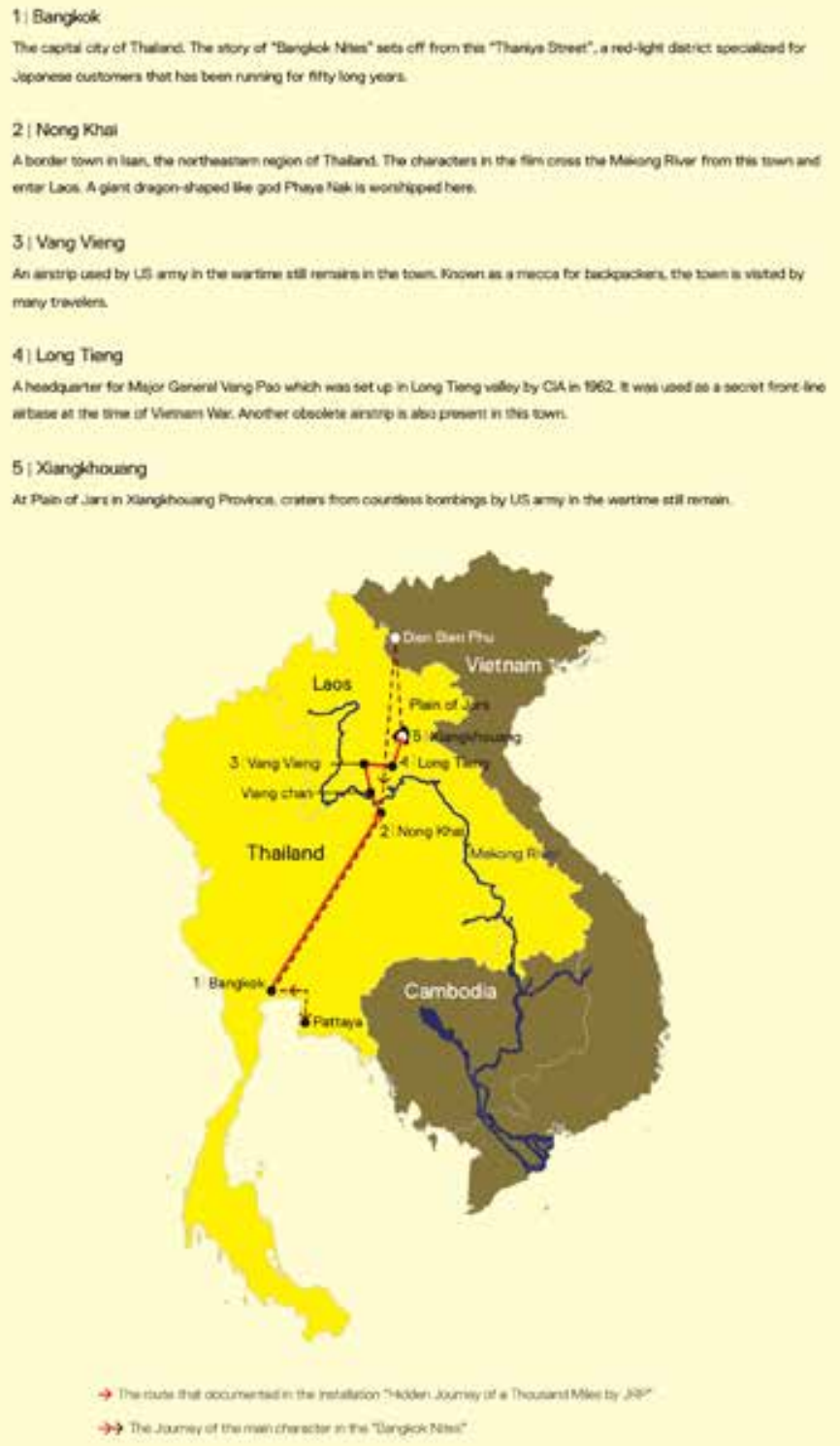
inter-Asia historical connections is also achieved through several transmedia projects developed from their location shooting and fieldwork for Bangkok Nites, particularly a multi-screen video installation work collaboratively accomplished by Kuzoku, Studio Ishi, ${ }^{17}$ and the Yamaguchi Center for Arts and Media (YCAM). These projects are intriguingly titled 'Hidden Journey of a Thousand Miles' (Senkō yisen ri), ${ }^{18}$ which also refers to the autobiographical novel, 'Hidden Journey of 3000 Li' (Senko sanzen ri), a 1950 bestseller written by Tsuji Masanobu, the controversial former military officer of the Japanese Empire and war criminal (also see Kuzoku et al. 2016). ${ }^{19}$

One could approach Bangkok Nites as a road movie. In highlighting Ozawa and Luck's re-encounter, journey, and final separation, however, the narrative of Bangkok Nites is less driven by the protagonists' wanderlust than by the collective's own desire to trace and delineate the irregular network of the shadow economy (e.g. the sex industry, the drug trade, trafficking, and smuggling), which is underpinned by the political-historical contingencies at the local and translocal levels. Specifically, as explained by Tomita and Aizawa, Bangkok Nites is a film about the futile search for paradise. The work itself embodies two types of movement: 'one geared towards the future as a quest for a place to live, to escape, and another being a necessary confrontation and exploration of a past and a painful history' (Tomita \& Aizawa 2016). Their location shooting, therefore, ventured into places such as Bangkok, Pattaya, and Nong Khai in Thailand; Vang Vieng, Long Tieng,

their characters (who are male Japanese tourists) in Southeast Asia, constitute part of Aizawa's lifework under the title of 'Asian Informal Economy Trilogy' (Ajia ura-keizai sanbusaku). The two Babylon films leverage diverse archival materials and visual documentations (including footages by the filmmakers themselves) to rethink Southeast Asia's socio-political and economic conditions in the aftermath of the Vietnam War.

17 For instance, the cinematographers of Bangkok Nites worked with the footage they took throughout the Southeast Asian trip and re-edited them into a documentary for the video installation.

18 The title of the novel uses the unit of 'li', the Chinese mile. However, the pamphlet for Kuzoku's art installation, which derives from the novel's title, uses 'mile' in its English version without further differentiation. We should bear in mind such differences when using the English title of '30oo Miles'.

19 In this novel, Tsuji chronicled his journey of fleeing from Thailand right after the Japanese army's defeat in 1945. In Bangkok Nites, Ozawa's northbound trip reminds us of two of Tsuji's decisive journeys into Southeast Asia. The first is his retreat from Thailand. Disguised as a Buddhist monk at first, Tsuji went north to Laos and Vietnam and crossed the border to enter into China, where he was even offered a job to work for the Chinese Nationalist Party's Nanjing government before he decided to return to Japan in 1948. The other is Tsuji's fateful business trip in 1961 to Vietnam and Laos as the Japanese government's representative, at the end of which he mysteriously went missing (see Tsuji). 
and Xiangkhouang in Laos; and Dien Bien Phu in Vietnam (also see Kuzoku et al. 2016). The translocal and transnational journey in the film departs from and also winds back to metropolitan Bangkok because Kuzoku realized that it is impossible to understand this city's modern conundrum without positioning it within the region's geopolitical and historical entanglements (see Tomita \& Aizawa 2016).

Accordingly, the characters repeatedly bring up topics regarding 'paradise' or 'tōgenkyō' in Japanese, which translates as the 'peach blossom land'. While tōgenkyō may stand for the opposite of the intolerable and thus implies hope, paradoxically, as the ancient tale cited in the film goes (e.g. characters in the film mention 'Peach Blossom Spring'/taohua yuanji by Chinese essayist Tao Yuanming from the $5^{\text {th }}$ century), it is also somewhere untraceable and unreachable. Or, as one of its characters bitterly points out, 'Once you leave the tōgenkyō, you'll never find it'. In the film, Thaniya Road figures as one of Bangkok's most uncanny, prosperous 'Japanized' enclaves of the sex industry. Whereas the Japanese (male) clients can still be entertained and satisfied by the service provided by Thai ladies as if in 'paradise', to return to one of the keywords underscoring the work, the very existence of 'Thaniya Road' is evocative of memories of imperial Japan during WWII in the region. Also, it is indexical of the changing Japan-Thailand relations and in particular their economic ties and power relation during Japan's bubble era and into the post-bubble transitions in the new millennium.

For Kuzoku, their 'hidden journey' extends the critique of Japanese society by turning to how Ozawa and his male Japanese collaborators are frustrated by the post-3.11 malaise in Japan, for which one could think of Ozawa's complaints in front of Luck that Japan is 'no good' nowadays: 'Economy down! Meltdown! Everything down!' Nevertheless, what is really at stake is not simply a transcending of the geographical boundaries in order to gain an alternative vantage point to reimagine 'Japan' or to rejuvenate the Japanese identity. Arguably, what really haunts the male subjects now may not be so much an 'inescapable Japan' or the 'endless everydayness' but powerful 'globalism' itself (Gerow 2016: 88-89). According to Tomita, 'at the start you wonder where you can find paradise. You set out in search of it, going as far as possible. But in the end you realize it doesn't exist anywhere, it's simply under our feet ... all in all Ozawa undertook this journey to realize he had never left the Buddha's palm' (Tomita \& Aizawa 2016).

If we refer to the Deleuzian thesis on modern political cinema, its character is no longer an action-oriented agent but a 'seer' who has 'given over to something intolerable, which is simply their everydayness itself' and is thus 'condemned to wander about or go off on a trip' (Deleuze 1989: 40). 


\subsection{Luck on Ozawa's motorcycle at the edge of the jungle in Bangkok Nites}

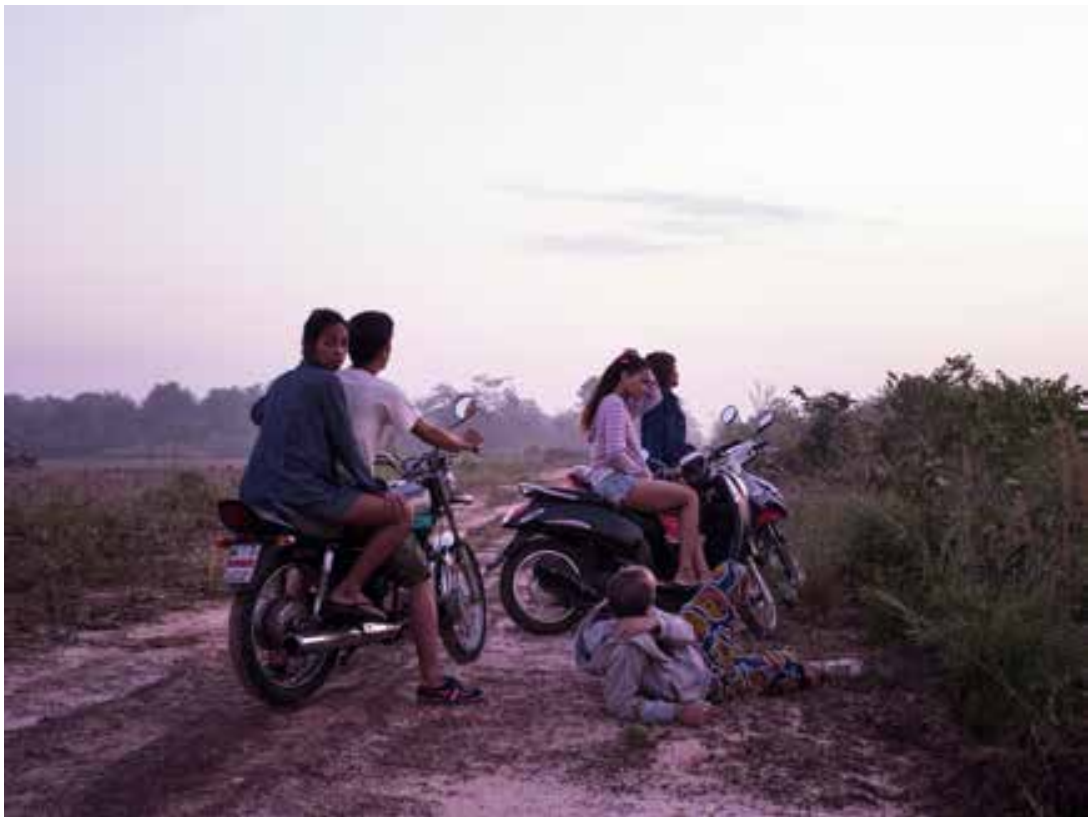

With Bangkok Nites, people's search for 'paradise' across Southeast Asian cities and frontier zones seems to end up nowhere. As a former Jieitai soldier, Ozawa now returns to Bangkok without any clarified motivation or ambition. Later on, he accepts the offer to visit Laos not because he is particularly keen on his former officer's secret plan for the connoisseur but simply because he cannot think of better ways to get out of his economic and personal dead-ends. As is typical with most sex workers on Thaniya Road, on the other hand, Luck leaves Isan behind in order to earn money in Bangkok to provide for her family. The film opens with a medium-length shot of Luck's reflection on the window as she is emotionlessly overlooking Bangkok's stunning night view from her luxurious residential tower and murmurs to herself, 'Bangkok ... Shit!' This sequence, reminiscent of the disillusioned Hosaka in Saudade, similarly speaks of Luck's aloofness and ennui.

Both Ozawa and Luck are, therefore, to a great extent defined or even allied by their desperate efforts to regain a sense of home and belonging on the margins of Thai and Japanese societies. The relationship between the two is, however, not fixated by any dichotomized, hierarchical positions such as Japanese/Thai, male/female, or client/prostitute. After both of them return to Bangkok from their journeys, however, nothing radical has taken place - Ozawa has not been cured by his trip to Isan or the romantic 
relationship; Luck does not rely on Ozawa for salvation of any type. We see toward the end that Ozawa returns to work on Thaniya to distribute flyers for hostess clubs, whilst Luck retreats to her home in Nong Khai after finding out that she has contracted AIDS without ever realizing her dream of opening a fancy restaurant in Bangkok.

\section{Into the Jungle}

Not necessarily disagreeing with Tomita's pessimism apropos the ubiquitous neoliberal globalism, I propose that the politics of Bangkok Nites is realized through Kuzoku's aesthetic acts to disrupt, if not to break free from, the given power geometry of time-space compression (see Massey 1993) by walking into Isan's jungle. Interwoven with the characters' disparate, if not desperate, efforts in search of 'paradise', Kuzoku's filmmaking journey into the frontier and borderland traversing Thailand, Laos, and Vietnam is intended as a multi-layered practice of counter-mapping. It is then no coincidence that Luck's hometown is set in Nong Khai in the Isan region of northeastern Thailand, a border town that spreads itself along the banks of the Mekong River that separates it from Laos. In her homecoming trip, Luck brings Ozawa as well as the audience closer to her struggles and the 'life stories' of many other migrant workers and labourers in Bangkok from the Isan area. More importantly, as David Teh has pointed out in his study on Thai filmmaker Apichatpong Weerasethakul, whose works are mostly set in the Isan area and have directly inspired Bangkok Nites, the historical experience of Isan, despite its presence in the national imaginary 'thanks to decades of labour migration and irrepressible popular cultures', has actually been 'under-represented in national historiography and politics' apropos Thailand (Teh 2011: 6oo). Kuzoku has regarded its marginality and difference in economic, historical, and cultural-political terms in relation to central Thailand or the official articulation of Thai-ness as points of resistance. Specifically, in blending in their realism segments of fantastic and ghostly encounters in the frontier region in Isan, as mentioned earlier, Kuzoku has intertextually correlated their oeuvres to those of Apichatpong.

It is well known by now that most of Apichatpong's feature films and shorts are set in Isan. In his award-winning feature Uncle Boonmee Who can Recall His Past Lives (2010), for instance, Uncle Boonmee, a dying patient who suffers from kidney failure, sometimes has confusing dream sequences and also remembers how he killed communists while serving in the Thai army. One day, he reunites with his missing son at their dining table, who now returns as a red-eyed monkey ghost from the jungle. According to Natalie 
Boehler, Boonmee's ghosts 'are carriers of the Northeast's traumatic past', referring to the Thai government's violent oppression of local communities in the 1970s when the activities of communists were extended to the jungles of Isan (Boehler 2014: 70).

Tomita and Aizawa are highly conscious of the jungle of Isan as a 'metaphor' of history (Tomita, Aizawa, Arai, et al. 2017). Accordingly, I would like to push the discussion of 'counter-mapping' further in proposing that Ozawa's road trip potentially wanders into the heterogeneous temporalities of Asia. In her studies on the fantastic and horror cinematic genres from Asia, particularly drawing on Filipino national cinema, Bliss Cua Lim has keenly pointed out how the supernatural, uncanny, and spectral have posed a 'temporal critique' in 'translating' the heterogeneous temporalities into the universalizing code of homogeneous time which, while a violent process in itself, is always a 'mistranslation' in still preserving the untranslatable, namely elements 'of resistance, counterappropriation, or evasion' (Lim 2009: 32). Further, Lim calls the uncanny hint of untranslatable time 'immiscible', which is like oil and water, which seemingly mingle in the same place but can never 'coalesce to the point of full dissolution' (ibid.: 144). With Lim, we may contend that the fantastic (for which I also include the imaginary of tōgenkyō) and the phantasmal in Bangkok Nites also 'gestures at temporal differences that cannot be fully homogenized' (ibid.: 33). Therefore, Isan has constituted a site in making visible the 'immiscible', where the fantastic and the spectral have emerged to contest the teleological, progressive time of Asian nations as well as the temporality underscored by global neoliberalism, as instanced by the invasion of American and Japanese capital. One of the haunting problematics that intersects the entwined modes of time has been the issue of 'colonialism and its aftermath' (Lim 2009: 12), as pointed out by Lim, in tandem with the historical traumas of war (WWII and the Vietnam War) and state violence, if we become more specific with the historical context of Isan vis-à-vis Thailand's modern history and waves of social movements.

In Bangkok Nites, not only does the serpent-like Phaya Naga, a divine creature that the locals in Isan believe in, mysteriously appear in the Mekong River, but also Ozawa comes across the phantoms of a group of guerrilla fighters when passing by the jungle on his motorbike (they may be the artist-revolutionaries who are in search of tōgenkyō but could also be the spectres of the communists and progressive students who retreated to the forests in the 1970s). His journey to Isan is at the same time haunted by the ghost of an anonymous aging man who, when they encounter him for the first time, emerges from the darkness and approaches him while 
lamenting, 'it's sad not to have a place to call home, do you agree?' He then comforts Ozawa by saying, 'this will be your home one day'. The ghost that Ozawa meets is Chit Phumisak (also spelt as 'Jit', 1930-1966), a famous Marxist poet, the so-called 'Che of Thailand' who joined the Communist Party of Thailand in the jungle and was finally murdered in the mountains of Isan. ${ }^{20}$ It is noticeable that, although the ghost could not totally make himself understood by Ozawa, the poem he recites to us, the audience, is composed of impressionist stanzas highlighting Bangkok/Thailand with the senses of smell ('stench of night'), touch (of flesh), and vision ('like fire, it swallows citizens lost in lust'). ${ }^{21}$

Kuzoku has therefore come to an understanding of the jungle also as a space of liminality in locating new structures of feeling. In his interview with Eiga Gejutsu, for example, Aizawa shows great interest in how, during the era of the Vietnam War, Isan's jungle became the fertile ground not only for communist insurgency but also for protest music genres such as phuea chiwit or 'song for life'22 (see Tomita, Aizawa, Arai, et al. 2017; also see Mitchell 2011; Myers-Moro 1986). Hence, no less powerful than the poetry appropriated in Bangkok Nites is the use of Thai folk songs and country music (lukthung) with realist connotations in the film. Kuzoku's sensitivity to popular music genres has much to do with its long-term collaboration with independent hip hop bands and DJs within Japan's media convergence culture. ${ }^{23}$ In Bangkok Nites, although the Thai country music is mostly used non-diegetically, it nonetheless underscores the work with the counter-hegemonic forte that characterizes this music genre, which often reverberates among the 'rural peasants and the urban working class' because these listeners 'have found common ground in the stories and melodies' (Mitchell 2011: 459).

20 The 'ghost' is played by Surachai 'Nga' Jantimatawn, the vocalist, songwriter, and also one of the founders of the legendary folk rock band known as Caravan. Formed in 1973 by two student activists (Surachai, together with Wirasak Suntornsii) when Thailand was experiencing its political transformations following the fall of the military dictatorship of Field Marshal Thanom Kittikachorn, Caravan has been famous for their music which contains political messages for social struggles as the 'art for the people' (see Myers-Moro 1986). Members of Caravan also fled to the forest in the aftermath of the 6 October 1976 Massacre, and they did not return from their exile until 1979, the year they were granted amnesty.

21 The translation is transcribed from the film's English subtitle; presumably it is one of Chit Phumisak's famous poems.

22 The genre of morlam (traditional Lao folk music) is also used in the soundtrack of Bangkok Nites. According to James Mitchell, 'Lukthung was already identified with Isan culture', and morlam and lukthung 'have been conflated across generic boundaries' (Mitchell 2011: 458-459). 23 Although the film collective has not released their works on digital format, including DVDs, they have been quite passionate about releasing the films' soundtracks via CDs and LPs. 
Whenever Bangkok Nites is screened outside of Thailand, the language barrier (even with the carefully translated subtitles) may discourage Japanese-speaking audiences, for instance, from further engaging with a cultural genre that was originally distinguished by a specific class of local listeners and consumers back in Thailand. ${ }^{24}$ However, I would stress that the Isan-originated folk music flowing throughout the film is also leveraged as a repository of affect in narrativizing grassroots feelings, experiences, dreams, and desires. This may further reverberate with and circulate among their transnational audiences, who could potentially become part of a community of empathy and thus a 'community of sense' in the Rancièrian sense, however contingently it may be formed. After all, Kuzoku's appropriation of Thai folk music may not be targeted at the latter's perfect translation into other cultural contexts but can be considered a gesture interconnecting with the immiscible temporalities contained in the jungle, which has necessarily retained and foregrounded their 'untranslatability', even when the film itself has been translocally circulated and exhibited.

\section{Coda}

Ian Buchanan has suggested that deterritorialization foregrounds the rupture between postmodern subjects and their everyday space, namely a process that challenges the very foundational basis of identity. And therefore one may cease to be considered different, look 'like everybody else', and start 'merging with landscape' (Buchanan 2005: 23). Reterritorialization, then, does not simply mean a restorative 'return' to the extremely localized 'place' as well as to its conditions of 'pre-territorialization' but rather involves efforts that leverage the deterritorialized as 'new objects' to stand for the 'lost territory' and thus 'compensate for' or 'substitute' the 'home that has been lost' (ibid.: 30).

Whereas Saudade zooms in on a fading 'hometown', namely a generic, degenerating Japanese city, the travellers in Bangkok Nites strive to (re) discover a lost utopia/paradise that they never possessed in Southeast Asian border-zones and the former-colonial territories. At the meta-level, I would propose that Kuzoku's filmmaking itself constitutes a series of efforts at reterritorialization, in keeping with searching for the lost homes/hometowns.

24 Kuzoku and a closely knit network of cultural workers are collaborating with and have indeed dedicated themselves to cultivating a small group of local connoisseurs who may be specifically keen on Thai folk music for its exotic, alternative flavour and connotation of temporality. 
It is quite thought-provoking that in his 2014 interview, Tomita suggested, "Indeed the word "local" has continued to stay with us (Kuzoku). Then this "local", if approached from within history, has actually connected together places like Kofu and Bangkok. That is also to say "local" as a keyword has attained its new significance. It is possible to view Tokyo as the local too' (Tomita 2014: 40). To relate to what I have outlined regarding Kuzoku's works of reterritorialization, what Tomita has stressed here as 'local' is actually the 'translocal'. As such, Kuzoku's oeuvre has interlinked Japanese national cinema with Asian transnational cinemas not simply at the levels of production (multi-sited location shooting and coproduction) and circulation (festival screening and limited theatrical release) but most importantly through the translocal imaginaries they have persistently explored, created, and examined. Hopping between Asian locations such as Kofu (a generic regional city), Tondo (the largest slum in the corner of metropolitan Manila), and Bangkok (a cosmopolitan city), Kuzoku has chosen each place as an entry point to interrogate how the (trans)local dialogues with the deterritorializing/reterritorializing forces of globalization, and how people, especially those who are not necessarily privileged in the newly formed structures of hierarchy and stratification, have accordingly developed and negotiated multiple ways and layers of identification across these places. Here, I would argue, Kuzoku has also daringly provided with Bangkok Nites - in a departure from Saudade - an alternative to envision inter-Asia border-crossing cinema. They have borrowed the vernacular visual and narrative tropes as well as genres of music/sound from Southeast Asia to configure a translocal landscape of affect and feeling, so that an 'Asia' that has been repressed or made invisible in other transnational productions and genres could be made visible and audible and can be experienced anew.

\section{Works Cited}

Ahmed, S. (2014). The Cultural Politics of Emotion. Second edition. Edinburgh: Edinburgh University Press.

Benjamin, W. (1978). 'Paris, Capital of the 19th Century'. In Demetz P. (ed.), Reflections: Essays, Aphorisms, Autobiographical Writings, pp. 146-162. New York: Schocken.

Boehler, N. (2014). 'Haunted Time, Still Photography and Cinema as Memory: The Dream Sequence in Uncle Boonmee Who Can Recall His Past Lives', Journal of Modern Literature in Chinese, 12/1: 66-78.

Buchanan, I. (2005). 'Space in the Age of Non-Place'. In Buchanan I. \& Lambert G. (eds.), Deleuze and Space, pp. 16-35. Edinburgh: Edinburgh University Press.

Chang, H.-H. (2009). 'Transnational Affect: Cold Anger, Hot Tears, and “Lust, Caution”', Concentric: Literary and Cultural Studies, 35/1: 31-50. 
Clifford, J. (1992). 'Traveling cultures.' In Grossberg L., Nelson C., and Treichler P.A. (eds.), Cultural Studies, pp. 96-116. New York: Routledge.

Deleuze, G. (1989). Cinema 2: The Time-Image. (H. Tomlinson \& R. Galeta, transl.). Minneapolis: University of Minnesota Press. DOI: 9781472512604.

Endō, T. (2009). Exporting Japan: Politics of Emigration toward Latin America. Urbana: University of Illinois Press.

Fowler, E. (1996). San'ya Blues: Laboring Life in Contemporary Tokyo. Ithaca, NY: Cornell University Press. Furuhata, Y. (2007). 'Returning to Actuality : Fûkeiron and the Landscape Film', Screen, 48/3: 345-362. DOI: 10.1093/screen/hjmo34

- (2013). Cinema of Actuality:Japanese Avant-Garde Filmmaking in the Season of Image Politics. Durham: Duke University Press.

Gerow, A. (2002). 'From Independence to Detachment in Recent Japanese Film' [cong dulizouxiang chouxiang: dangdai riben dianying]. In Focus on Japan: Independent Cinema, pp. 6-12. Hong Kong: Hong Kong International Film Festival.

- (2009). 'The Homelessness of Style and the Problems of Studying Miike Takashi', Canadian Journal of Film Studies, 18/1: 24-43.

- (2016). 'Globalism, New Media, and Cinematically Imagining the Inescapable Japan'. In Iwabuchi K., Tsai E., and Berry C. (eds.), Routledge Handbookfor East Asian Popular Culture, pp. 86-92. London: Routledge.

Ishikawa, E.A. (2009). 'The Return of Japanese-Brazilian Next Generations: Their Post-198os Experiences in Japan'. In Conway D. and Potter R. B. (eds.), Return Migration of the Next Generations: 21st Century Transnational Mobility, pp. 59-78. Farnham, England: Ashgate Publishing.

Ko, M. (2016). "Fūkeiron” saikō - kōsaku suru fūkei Saudade' [Rethinking the landscape theory the intersecting landscape of Saudade]. In Kawai Y. (ed.), Kosaku suru tabunka shakai: Ibunka komyunikeshon o toraenaosu [Intersecting Multicultural Society: Reconsidering Cross-cultural Communications], pp. 188-219. Kyoto: Nakanishiya Shuppan.

Kuma, K., Tomita, T., and Aizawa, T. (2012). 'Saudade ni miru haikyo to mirai' [The Ruins and Future Seen from Saudade], Sekai, 832: 212-9.

'Kuzoku ga hatsuno kuraudo fandingu ni “ikarinodesurōdo hōshiki” de idomu! Zenpen tai raosu satsuei o kankō! saishinsaku Bangkok Nites!' [Kuzoku's first crowdfunding for their latest movie Bangkok Nites] (2015). Motion Gallery. Retrieved 10 December 2015 from <https:// motion-gallery.net/projects/bangkoknites>.

Kuzoku, Mukoyama, M., Furuya, T., and YCAM (eds.) (2016). Senko Yisenri [Hidden Journey of a Thousand Miles by JRP]. Yamaguchi: Yamaguchi Center for Arts and Media [YCAM].

'Kuzoku tokushū jōei' [Retrospective of Kuzoku 2011] (2011). OUTSIDE IN TOKYO. Retrieved 20 May 2017 from <http://www.outsideintokyo.jp/j/news/kuzoku2011.html>

Laplantine, F. (2015). Life of the Senses. Introduction to a Modal Anthropology. London: Bloomsbury Academic. DOI: 10.5040/9781474219204.0005.

Lim, B.C. (2009). Translating Time: Cinema, the Fantastic, and Temporal Critique. Durham; London: Duke University Press. DOI: 10.1093/screen/hjqo33.

Maimon, V. (2009). 'The Third Citizen: On Models of Criticality in Contemporary Artistic Practices', October, 129/2009: 85-112. DOI: 10.1162/octo.2009.129.1.85.

Massey, D. (1993). 'Power-Geometry and A Progressive Sense of Place'. In Bird J., Curtis B., Putnam T., Robertson G., and Tickner L. (eds.), Mapping the Futures: Local Cultures, Global Change, pp. 59-69. London; New York: Routledge.

Mitchell, J. (2011). 'Red and Yellow Songs: A Historical Analysis of the Use of Music by the United Front for Democracy against Dictatorship (UDD) and the People's Alliance for Democracy (PAD) in Thailand'. South East Asia Research, 19/3: 457-494. DOI: 10.5367/sear.2011.0058 
Myers-Moro, P.A. (1986). 'Songs for Life: Leftist Thai Popular Music in the 1970s', Journal of Popular Culture, 20/3: 93-113. DOI: 10.1111/j.0022-3840.1986.2003_93.x.

Pisters, P. (2003). Matrix of Visual Culture:Working with Deleuze in Film Theory. Palo Alto: Stanford University Press.

Rancière, J. (2014). The Intervals of Cinema. (J. Howe, transl.). London; New York: Verso.

Roth, J.H. (2002). Brokered Homeland:Japanese Brazilian Migrants in Japan. Ithaca: Cornell University Press.

Sharma, D., and Tygstrup, F. (2015). 'Introduction'. In Sharma D. and Tygstrup F. (eds.), Structures of Feeling: Affectivity and the Study of Culture, pp. 1-19. Berlin; Munich; Boston: De Gruyter.

Takano, Y., Ashizawa, A., and Tomita, K. (2011). 'Kanōse aruno fūkei' [The Landscape with Possibility]. NOBODY, 14-21. Tokyo.

Teh, D. (2011). 'Itinerant cinema: The Social Surrealism of Apichatpong Weerasethakul', Third Text, 25/5: 595-6og. DOI: 10.1080/09528822.2011.608973.

Tezuka, Y. (2013). 'Dynamics of the Cultures of Discontent: How Is Globalization Transforming the Training of Filmmakers in Japan?'. In Hjort M. (ed.), The Education of the Filmmaker in Europe, Australia, and Asia, pp. 171-187. New York: Palgrave Macmillan US.

Tolia-Kelly, D.P. (2019). 'Rancière and the Re-Distribution of the Sensible: The Artist Rosanna Raymond, Dissensus and Postcolonial Sensibilities within the Spaces of the Museum', Progress in Human Geography, 43/1: 123-140. DOI: 10.1177/0309132517739141.

Tomita, K. (2014). 'Interview'. In Teraoka Y. and Morimune A. (eds.), Eiga wa dokoni aru: indipendento eiga no atarashinami [Where is Cinema: New Waves of Independent Cinema], pp. 9-46. Tokyo: Firumu Ātosha.

- (2016). 'Director's Note'. In Kuzoku (ed.), Bangkok Nites Pressbook. Tokyo.

- , and Aizawa, T. (2016). 'Interview with Katsuya Tomita and Toranosuke Aizawa'. In Kuzoku (ed.), Bangkok Nites Pressbook. Tokyo.

- (2017). Bankoku naitsu: Senkō issen ri [Bangkok Nites: Hidden Journey of a Thousand Miles]. Tokyo: Kawade Shobō Shinsha.

—, Aizawa, T., Arai, H., and Inagawa, M. (2017). 'Bangkok Nites', Eiga Gejutsu, 458: 58-63.

—, Aizawa, T., and Nomura, M. (2017). 'Bankoku Naitsu kyakuhonka, kantoku Intabyū' [Interview with Screenwriter and Director of Bangkok Nites], Scenario, 73/4: 4-10.

—, Aizawa, T., and Urasaki, H. (2011). 'Intabyū: Tomita Katsuya + Aizawa Toranosuke - Saudade kyakuhonka, kantoku ni kiku' [Interview with Saudade's Screenwriter and Director], Scenario, 67/12: 14-21. Shinario sakka kyōkai.

Tsuji, M. (2016). Senko Sanzenri [Hidden Journey of 3 ooo Li]. Tokyo: Mainichi Wanz.

Twaronite, L. (2017). 'Roving vans serve Japanese-Brazilian community's banking, food and other needs'. The Japan Times. Retrieved 10 March 2019 from < https://www.japantimes.co.jp/ news/2017/06/22/national/roving-vans-serve-japanese-brazilian-communitys-bankingfood-needs/\#.XKV2keszaPc >.

Wada-Marciano, M. (2012).Japanese Cinema in the Digital Age. Honolulu: University of Hawaii Press. DOI: 10.21313/hawaii/9780824835941.001.0001.

Watanabe, S., and Yūki, H. (2017). 'Interview with MMM, Mr. Maro, YOUNG-G', NOBODY, 46: 13-9. Wiese, D. (2014). The Powers of the False: Reading, Writing, Thinking beyond Truth and Fiction. Kindle edition. Chicago: Northwestern University Press. DOI: 10.2307/j.ctv43vs7s. 


\title{
$4 \quad$ Li Ying's Films of Displacement
}

\author{
Towards an Im/Possible Chinese-in-Japan Cinema ${ }^{1}$
}

\begin{abstract}
This chapter turns to a long-term Chinese resident in Japan, Li Ying, and frames two of Li's earlier documentaries, $2 H$ (1999) and Aji (2003), as 'films of displacement'. This study situates Li Ying's independent filmmaking at the conjuncture of Sinophone cinema and diasporic filmmaking. I argue how these documentaries have explored and archived transhistorical and transnational affective connections traversing various Sinophone and diasporic communities within Japan and beyond. We could, therefore, envision a Chinese-in-Japan cinema which, loosely assembling contemporary film and media works by Chinese-in-Japan filmmakers who have arrived in Japan since the mid-1980s, challenges us to question its unwritten historiography and to rethink Sino/PRC-Japanese transnational cinema.
\end{abstract}

Keywords: Sinophone studies, Chinese-in-Japan identity, accented style, Sino-Japanese transnational cinema

A long-term resident in Japan, Chinese documentary filmmaker Li Ying is mostly known for his fifth documentary feature film, Yasukuni (2007). Prior to the public screening of Yasukuni in 2008 in several Japanese arthouse theatres, there were controversies over how Li handled the sensitive issue of Yasukuni Shrine, where more than two million of Japan's war dead during World War II are honoured (see Harootunian 1999). ${ }^{2}$ In the heated debates

1 Unless otherwise indicated, all Chinese/Japanese-English translations are mine. I am thankful for Dr. Fujiki Kosuke's patient work with the Japanese transliteration and some of the translations of book titles.

2 Li Ying spent almost 10 years filming and producing Yasukuni. In this work, Li approached Yasukuni Shrine (est. 1869) by rethinking its complicated, sometimes ambiguously addressed historical and symbolic significance in relation to the spiritual/religious structure of the Japanese nation and the so-called Japanese psyche. In particular, for Li, Yasukuni Shrine configures

Ma, Ran, Independent Filmmaking across Borders in Contemporary Asia. Amsterdam, Amsterdam University Press 2020

DOI: 10.5117/9789462986640_CHO4 


\subsection{Poster of Li Ying's Yasukuni}

\section{WHAT IS SAMURAI SPRIT?}

WHAT IS PEACE?

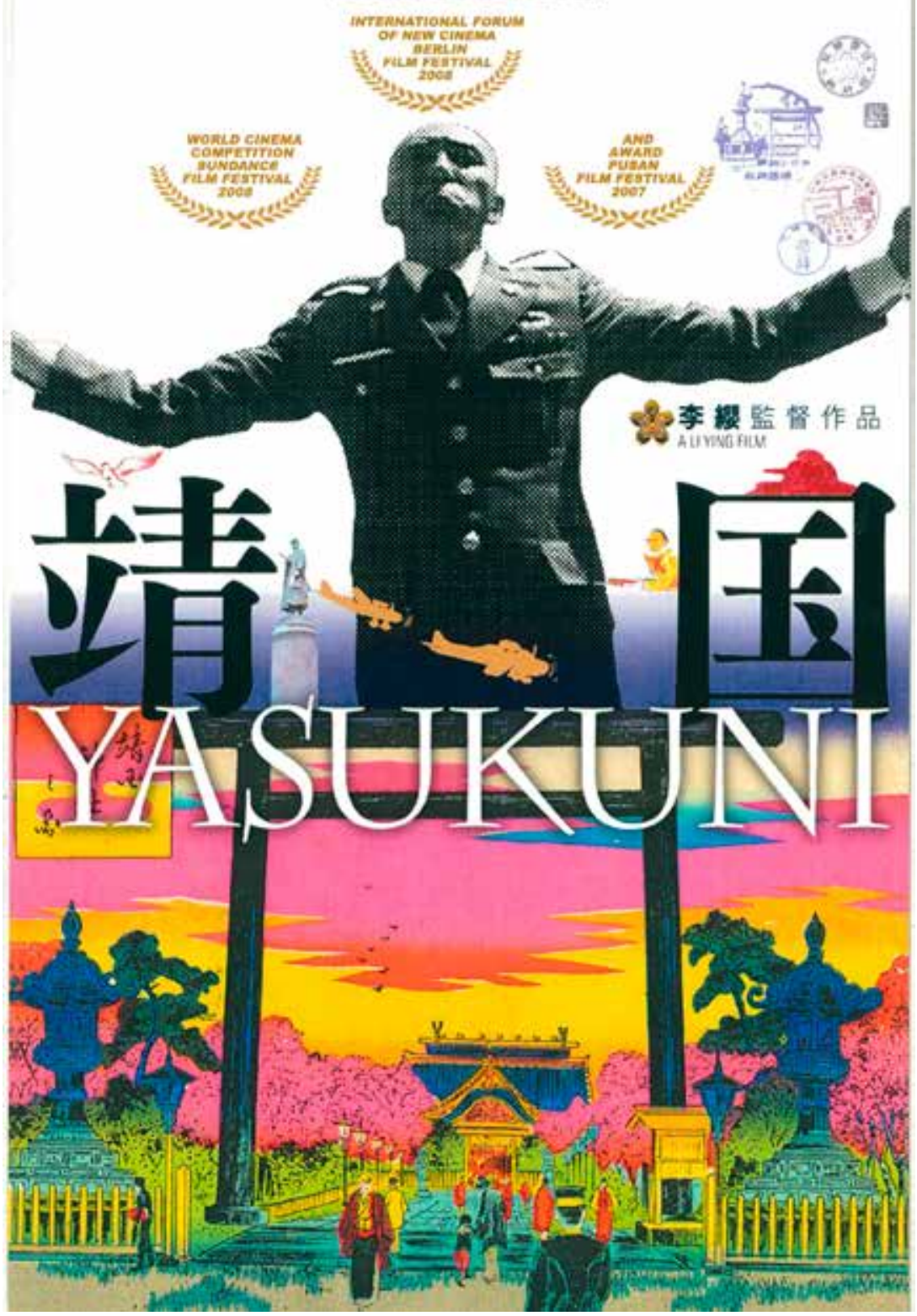


involving various opinion groups and political factions within Japan, questions arose regarding whether the Japanese rightists' radical reactions were less because of the taboo subjects that his film highlights than because of Li's identity as a citizen of the People's Republic of China (PRC) (see Mori, Suzuki \& Miyadai 2008). ${ }^{3}$ To further complicate the situation, Yasukuni was never officially distributed or exhibited in mainland China, even though Li was allowed to appear in Chinese mainstream media talking about this work. ${ }^{4}$

Arriving in Tokyo in 1989, Li Ying belongs to a group known as the 'new overseas Chinese' (shin kakyō), the preferred label of Chinese migrants (mostly of mainland origin) who started arriving in Japan from around the mid-1980s (see Liu-Farrer 2012, 2013). Unlike the older generations of 'overseas Chinese' who arrived before WWII, the inflow of these so-called newcomers was directly related to the PRC's policies of reform and opening-up (Gaige kaifang) since 1978, but it also needs to be examined in light of the Japanese government's changing immigration regulations, aspects of which cannot be further examined here. ${ }^{5}$

an important site/space not only to examine some of the most controversial and pressing issues apropos imperial Japan's role in World War II; Li also observed how the shrine became a cacophonous political theatre where veterans of the Imperial Army, rightist politicians, leftist activists/students, common Japanese citizens as well as multi-national foreign visitors gathered and acted out their disparate understandings/memories of the war. Importantly, Li turned his camera to Kariya Naoji, one of the last swordsmiths of the so-called 'Yasukuni-tou', a type of Gunto or high-quality sword supplied to high-ranking officers in the Imperial Army that was only forged within the Yasukuni Shrine between 1933 and 1945. The documentary also touches upon Japanese Emperor Hirohito's role in WWII (see Argo Pictures, 2008). The screening of Yasukuni (originally scheduled to take place in many domestic theaters within Japan in 2008) encountered unprecedented difficulties and challenges, primarily because of 'its subject matter, the source of its funding, and the nationality of the director' (Takenaka 2009: 118).

3 For instance, whereas the rightists were infuriated by the fact that Yasukuni, an 'anti-Japanese' film in their eyes, was funded by the semi-official cultural body of the Agency for Cultural Affairs/Nihon Geijutsu Bunka Shinkōkai (Japanese yen 7.5 million), the filmmaker pointed out that the work was actually an independent project coproduced/funded by China, Japan, and South Korea. A pitch selected by the Asian Network of Documentary (AND), an inter-festival coalition and funding scheme affiliated with South Korea's Busan International Film Festival, Yasukuni also signified how Li also started to engage with the global film festival's production and financing cycle of film projects (see Brasor 2008).

4 Speculations include that the Chinese government was not sure whether they could channel the sentiments triggered by the film in such a way as to benefit their foreign policy toward Japan. Most Chinese viewers probably accessed this film through its illegal circulation via pirated videodiscs and online video sharing platforms despite the fact that the film was entered into the Hong Kong International Film Festival in 2008.

5 In her 1997 monograph, Mori Hiromi provides solid data and analysis regarding the various aspects of Japan's immigration policies (including but not limited to the Immigration Control Act, amended in 2014, and the Alien Registration Law) and how they impacted upon the inflow 
A reductionist reading of Yasukuni in terms of Li's national identity does, on the one hand, turn a blind eye to the documentarist's bordercrossing trajectory as well as his lived experience in Japan for over 20 years. On the other hand, I have deep reservations concerning Rob Efird's optimism towards how independent film projects like Yasukuni might achieve regional integration in proffering 'foreign perspectives' for the sake of 'Japanese revitalization' (Efird 2012: 179). Although Efird is partly correct in pointing out that to essentialize Li's Chinese identity also risks ignoring the multicultural, multiethnic potentialities of contemporary Japanese society itself, we should also bear in mind Mika Ko's warning regarding how 'contemporary Japanese nationalism is wearing a mask of multiculturalism' (Ko 2010: 26).

Using theoretical lensing borrowed from Sinophone studies (see S.-M. Shih, 2007; S. Shih et al. 2013; Tan 2013a, 2013b; Bernards 2016) and diaspora studies, this research considers 'Chinese-in-Japan' an open and critical identity category. I frame Li's earlier documentaries $2 H$ (1999) and Dream Cuisine (Aji, 2003; I shall use its Japanese title in the chapter) - with a focus on the former - as films of displacement. I specifically situate Li Ying's independent transnational filmmaking at the conjuncture of diasporic filmmaking (see Naficy 2001; Marks 200o) and Sinophone cinema (see Yue \& Khoo 2014, 2012), considering how these documentaries have connected Li's identity of becoming 'Chinese-in-Japan' with other displaced subjects who have had difficulty articulating any singular sense of national or cultural belonging. My discussion highlights how these works have examined and archived the transhistorical and transnational affective connections traversing various Sinophone and diasporic communities within Japan and beyond. Building upon Li's filmmaking practice and his works, I shall turn to several contemporary film and media works by Chinese-in-Japan filmmakers who have arrived in Japan since the mid-198os, such as Ban Zhongyi, Ren Shujian, and Zhang Liling - all of whom were from the PRC - as well as Lim Kah-Wai (Lin Jiawei) from Malaysia (to name some of the more active and well-known filmmakers) and question whether it is possible to envision a 'Chinese-in-Japan cinema'.

patterns of foreign workers (registered and unregistered) into Japan throughout different periods of time, especially since the mid-1980s. For instance, as Mori attests, 'An inflow from the People's Republic of China showed an enormous increase in 1987 after the partial liberalization of departures put into effect in 1985' (H. Mori 1997: 72). She also highlighted how Japan's immigration regulations toward PRC citizens were tightened after it was made clear that many Japanese language schools were actually used by their registered students as concealed channels for illegal labour (ibid.: 22). 


\section{Reconsidering 'Chinese-in-Japan'}

Before I move on to examine Li Ying's oeuvre, it is necessary to take the intricate issue of diasporic Sinophone subjects in Japan as my point of departure. Although in this chapter I limit my discussion of 'Chinese-inJapan' filmmaking mainly to film and TV works by Chinese residents of PRC origin, such as Li's, the framing aims to probe into the very identitarian category of 'Chinese', as in 'Chinese-in-Japan'.

According to the Japanese Ministry of Justice's annual statistics on the demography of 'foreign residents' (zairyu gaikokujin) in Japan (see 'Zairyū Gaikokujin Tōkei (Kyu Tōroku Gaikokujin Tōkei) Tōkeihyō' [Statistics of Foreign Residents], n.d.), which categorize each group of foreigners under the ambiguously defined labels of 'nationality' (kokuseki) and the 'area' (chiiki) they are from, the zairyu (signifying the status of residency) population from 'China' has topped the list since 2007 (replacing the category of 'Korea/South Korea'), reaching a total of 741,656 by the end of June 2018 ('Zairyū gaikoku ninzū nitsuite' [Number of foreign residents by the end of June 2018]). However, a closer look at the official statistics suggests that residents from 'Taiwan', previously categorized as part of 'China'(chügoku), have been put in a separate category since 2012. ${ }^{6}$ In other words, currently, the category of zairyu chügokujin (Chinese residents) is mostly associated with PRC nationals, including those who are Hong Kong/Macau passport holders. As the initial merging and subsequent split of China/Taiwan in the official data partly demonstrates, if 'China' can be used as a sliding classifier that simultaneously crosses over and associates with territory, state sovereignty, and ethnicity - all of which are entangled with the historical contingencies and complexities of Sino-Japanese relations since the period of Imperial Japan (Nagano \& Guo 2010) - then the Japanese government's old and new surveys (and biopolitical control) of zairyu chügokujin, regardless of whether these include Taiwanese passport holders, have nevertheless failed to recognize and address the messiness and multiplicity of 'Chinese-inJapan' either as an existing body of people intersecting diversified diasporic Sinophone communities or as a concept used to understand the various

6 Mori illustrated that during 1939-1945, Japan introduced approximately 8o,ooo workers from China, including Taiwan, 'who were mostly forced to move to satisfy emergent labour needs caused by the massive military mobilization of the native labour force' (H. Mori 1997: 34). According to Nagano and Guo, right after WWII, among more than 90,0oo Chinese residents in Japan, most were repatriated back to the PRC and Taiwan, with only around 30,000 of them staying behind in Japan, who constituted the main body of zainichi kakyō (Nagano \& Guo 2010: 43-44). 
modes of identities and subjectivities of theirs. At the same time, with my preferred use of 'Chinese-in-Japan' throughout this chapter, I also want to emphasize how this identitarian label is used in tandem with the Japanese term of zainichi chügokujin (literally: Chinese who are residing in Japan, see Note 7). The gap and discrepancies between these two labels are partially tackled in my discussions to follow. ${ }^{7}$

While a solid, extensive historical investigation into issues about the Chinese-in-Japan in multilingual scholarship is beyond the focus of this chapter, it can be observed that within Japan, most related works are currently from the fields of sociological and anthropological/ethnographical studies, which are often confined to the critical modes of Overseas Chinese Studies and Chinese Overseas Studies, known respectively as kakyō kenkyū and kajin kenkyū in Japanese academia (see Nagano 2010). In these research areas, discussions addressing the zainichi chügokujin about national/transnational identities and identifications (see Liu-Farrer 2013, 2012) have usually considered continental China as the unproblematic origin or ancestral land underlying the formation and transformation of Chinese migrants' identity. ${ }^{8}$

7 Sonia Ryang has emphasized the conundrum of zainichi: 'the term zainichi, meaning "existing in Japan”, has become common currency for representing Koreans in Japan'; yet she also points out that, despite the fact that the Koreans do not have Japanese nationality, 'By calling them zainichi, as if they merely "exist" inside Japan, the name obscures their clear disenfranchisement' (Ryang 2009: 11). Ryang's provocative discussion also made me think about the inconsistency between the designation of 'Chinese-in-Japan' and the term zainichi chügokujin.

8 For instance, Nagano and Guo differentiated kakyō (overseas Chinese; Huaqiao in pinyin) from kajin (Chinese overseas, Huaren in pinyin), pointing out that legally speaking, the former refers to Chinese citizens who still possess Chinese nationality, albeit PRC citizens living overseas; and kajin refers to those who, despite their various connections with China/Chügoku (e.g. as Chinese decedents), have obtained their citizenship from (other) countries and are given the legal rights of residence. It is important to see how Nagano and Guo also emphasized that the boundaries between the $k a k y \bar{o} / k a j i n$ categories were getting muddy if one took into consideration the lived experiences of different generations of kakyō in Japan and also the specific resident statuses of the Chinese immigrants, based on their sociological observations in 2010 (Nagano \& Guo 2010a: 26-27). However, in English-language literature, the use of 'overseas Chinese' is interchangeably used and interrelating with those of Huaqiao/kakyō and Huaren/kajin. For example, while Shu-mei Shih uses haiwai huaqiao to designate 'overseas Chinese'(S.-M. Shih 2011: 710), E.K. Tan approaches Overseas Chinese Studies as haiwai huaren yanjiu (Tan 2012, 2013b). In Guo Fang's Japanese-language monograph on zainichi kakyō, for instance, he has narrowed down zainichi chūgokujin to residents from the PRC who have not obtained Japanese nationality or permanent residency (Guo 1999). As Guo has noticed in his observations, the so-called 'old-comers' actually mixed and collaborated with the newcomers (mostly from the PRC), including overseas students from China and so forth, in configuring a community of zainichi chūgokujin in Kobe, in their post-disaster relief and support activities right after the 1995 Great Hanshin Earthquake (Guo 1999: 191-213). 
Symptomatic of the problematic of kakyō/kajin kenkyū, studies on the Chinese migrant identity, including research on those shin kakyō (newcomers) from the PRC who have arrived since the mid-1980s, have mostly lacked critical reflections over the constructedness of 'Chineseness' itself. ${ }^{9}$ Such framing has usually pursued a teleological discourse of historical lineage and homogenization (i.e. to envision a collective identity of transgenerational migrants), while also resorting to dichotomous critical grids to mark differentiations within the heterogenous migrant group itself (e.g. the binary division between their status of naturalization and permanent residence in Japan; the categorization of 'oldcomer' versus newcomer), without bothering to question the hegemony of 'China' or 'Chineseness' that underlines the articulations of the kakyō or kajin identity.

I look at the 'Chinese-in-Japan' identity with critical insights borrowed from Sinophone studies and diaspora studies, both of which have arguably problematized the essentialist understanding of Chineseness and Chinese identity as such. These reified identity categories should be also examined by turning to the new trends of population movement and displacement across Asia within the historical-cultural and social conditions of globalization, as suggested in Chapter One of this book.

In her field-defining works for the interdiscipinary Sinophone studies (huayuyuxiyanjiu) (see S.-M. Shih 2007, 2011; S. Shih et al. 2013), Shu-mei Shih reinvents the concept of Sinophone (huayuyuxi; also translated as huayifeng in other related research works) to pinpoint 'a network of places of cultural production outside China and on the margins of China and Chineseness, where a historical process of heterogenizing and localizing of continental Chinese cuture has been taking place for several centuries' (Shih 2007: 4). With the concept of Sinophone, which has been inspired by studies on postcolonial language-based communities like the Francophone, Shih seeks to shift attention from the 'ethnicity or race' to the Sinitic languages, their affiliated linguistic communities, and especially to their networks and relations in between. As she suggests in her Forward to the anthology of Sinophone Cinemas, what is foregrounded in the critical enterprise of Sinophone then is the 'audible', namely the 'radical soundscape' of the Sinophone (Shih 2014: $\mathrm{x}$-xi). Film scholar Sheldon Lu also illustrates how

9 For instance, Liu-Farrer has leveraged analytical perspectives in migration studies and social psychology to explore the 'new overseas Chinese' identity, especially regarding Chinese migrants' preferred 'partial membership in Japanese society' (a majority of whom, according to her, chose not to obtain Japanese citizenship/naturalization but applied for permanent residency), and their strategies to mobilize their 'flexible citizenship' to connect Japan with the PRC in the 'transnational economy' between the two states (Liu-Farrer 2012: 167-168). 
'the multiple tongues and dialects used in varieties of Sinophone cinema testify to the fracturing of China and Chineseness' (Lu 2014: 22).

Crucially, claiming that 'diaspora has an end date' and 'everyone should be given a chance and become a local' (S.-M. Shih 2007: 185), Shih highlights how Sinophone should be grasped as 'a place-based, everyday practice and experience' that comprises 'a historical formation that constantly undergoes transformation reflecting local needs and conditions' (ibid.: 30). Arguably, Sinophone articulation has found its full manifestation in 'the expressive act of art and filmmaking', and understandably, some of the most engaging discussions are from studies canvassing visual media and literature from Sinophone sites (Bernards 2012; also see Chiang \& Heinrich 2014; S.-M. Shih 2007; Tan 2013a; Yue 2012; Yue \& Khoo 2014). In this study of mine, the Sinophone is introduced to contest Han centrism and China-centric ideology in overseas Chinese studies and Chinese diaspora studies, given that both kinds of studies tend to pay less attention to the 'strikingly idealist, teleological understanding of the nation-state' (Brubaker 2015: 127) and thus are unable to 'recognize Chineseness as a designator for multiple Sinitic ethnicities, not a singular and uniform Han-centric one' (Shih, quoted in Tan 2013b: 16).

Nevertheless, having elucidated the ideological underpinning of Shih's Sinophone as 'anti-Sinocentrism', Sheldon Lu has stressed how it 'sounds like a theory of Chinese diaspora that does not privilege ancestral home' (Lu 2014: 21). What Lu and probably other critics of Sinophone (see Ng 2018; Tan 2013a) have found insufficient if not problematic is how the theoretical enterprise is 'predicated upon the exclusion of China in the same way francophone is built on the exclusion of France' (Lu 2014: 22). I suggest that the interrogation of Sinocentrism and Han-centric ideology does not necessarily mean that Sinophone shall be configured upon the radical exclusion of or disengagement from 'China' (as the empire, the colonial power, and especially the spectacular rising superpower in the comteporary setting if we follow Shih's take). Neither shall Sinophone be simply celebrated as a 'better' articulation of 'everything Chinese' (if not an oppositional concept), since that may potentially enact a new set of dichotomous logic. After all, as E.K. Tan reminds us, 'even when discussing the importance of the Sinophone, Shih cannot avoid referring to Sinophone cultures as the "local translation, revision, and reinvention of Chinese culture"' (Tan 2013a: 36; emphasis in original). In his survey of Chinese-language cinema studies, for example, Lu advocates the inclusion of mainland China 'within the range of Sinophone' (Lu 2014: 23). Taiwan-based Chinese-Malaysian writer Ng Kim Chew has provoked a more radical stand: he argues that 'Chinese' can be approached 
as a discursive terrain as well as a set of everyday practices that intersects aspects such as culture, language, identity, and so forth; it should not be narrowly understood as being only related to 'China' (Zhongguo) in the first place. Meanwhile, when translated into other languages, differentiations between the PRC or mainland China and other Sinophone places shall be foregrounded depending on the various contexts ( $\mathrm{Ng} \mathrm{2018).} \mathrm{In} \mathrm{other}$ words, 'Chinese' is not one, either; arguably, it is capable of multifarous manifestations and therefore can be leveraged to engage Sinophone identities and discursive articulations, as 'versions of Sinophone' (Tan 2013a: 35) that extend beyond the delimited designation of zhongguoren/chügokujin, and to also interrelate with the concept of huaren/kajin.

My use of 'Chinese-in-Japan' in my survey of Li Ying's films is premised upon a broadened understanding of the Sinophone in taking into consideration mainland China, while I also illustrate that the use of either 'Sinophone' or 'Chinese' should always be contextualized given the different emphasis embedded in each term. Admittedly, to find an accurate translation of 'Chinese-in-Japan' into the Japanese language is challenging, but for the sake of my discussions in this chapter, the idea of 'Chinese' itself shall intersect with both chügokujin, kajin, and kakyō, given how in the Japanese context the boundaries between these latter categories are already become quite murkey. In so doing, my aim is also to open up the very labels of chügokujin, kajin as well as kakyō to discursive interrogations while taking into consideration their historical complicacy and contingency.

At the same time, keeping in mind Shih's critique of diaspora, I would like to consider how it can be engaged productively (see L.L. Chen 2015). Diaspora studies could potentially break away from the rigid analytic framework in kakyō/kajin kenkyū that works with a teleological narrative about luoye-guigen (a return to one's roots) or its reverse version signifying full assimilation (zhancao-chugen). Instead we could conceive a more productive model of luodi-shenggen; namely 'growing roots when the [overseas] Chinese land', if we refer back to Wang Gunwu's critical agenda (quoted in Tan 2013b: 7-8). For E.K. Tan, the approach of luodi-shenggen indeed 'restores agency to overseas Chinese communities, whose constituents can now speak for or of themselves, at the very least, academically in the study of Chinese diaspora' (Tan 2013b: 8). Debating what diaspora studies might contribute to 'revamping overseas Chinese studies', Tan points out that 'It is more urgent for one to endorse the Chinese diaspora as a process that involves the struggle and negotiation between the myth of return and the acculturation to local realities than it is an essence' (ibid.: 9). Without discarding the diasporic angle, in light of the Sinophone, Tan has retooled 
'Chineseness' as a discursive sphere to mean production with an emphasis on the local situatedness (Tan 2013a; also see Tan 2013b) rather than a reified, essentialized, ahistorical category signifying the characteristics and delimitations of being/becoming Chinese.

The Chinese-in-Japan identity could, therefore, be approached as an opened-up, fluid assemblage of multiple Sinophone articulations, a thorough exploration of which is to be accomplished in future projects. Not dissimilar to Tan, Rogers Brubaker has pointed out that diaspora as a 'category of practice' actually 'does not so much describe the world as seek to remake it' (emphasis mine). Shu-mei Shih illumines how Sinophone culture 'even in its strongest expression of nostalgia or longing for a mythical China or the actual one, is place-based and is of the place where it is produced' (S.-M. Shih 2011: 714-715). The emphasis of my inquiry is also on the agency of the diasporic Sinophone subjects, specifically in relation to their situatedness within the Japanese socio-historical contexts and cultural formations. One needs to therefore pay more attention to their unfolding narratives and lived experience in Japan, regarding how they have engaged in the dynamic process of negotiation in positioning themselves within the variously layered networks of national, regional, ethnic, and local identities, as Tan has forcefully illustrated. Accordingly, we should approach the Chinese-in-Japan communities (kyōdōtai) in their plurality and understand that these communities/entities are themselves highly heterogeneous, inconsistent, and contingent networks of Sinophone subjects, whose modes of identifications are highly diverse and sometimes contentious, which include cases of accusation, avoidance, and total denial of 'Chinese' as the (sole) identity label.

In reconsidering the 'Chinese-in-Japan' identity, the diasporic lensing carves out space to examine the zainichi chügokujin identity horizontally by juxtaposing it with other zainichi ethnic groups in Japan, including but not limited to the zainichi Koreans or Koreans-in-Japan. ${ }^{10}$ Furthermore, the issue of being (or becoming) Chinese-in-Japan could be surveyed in relation to other Sinophone diasporic experiences of living across and beyond Asia. Moreover, the reconceptualization allows us to engage in questions of identification with regard to Japanese repatriates back from China since the end of WWII (like the female chef Sato Hatsue featured

10 This chapter cannot further explore how the discursive perspective borrowed from Sinophone studies regarding how we may rethink 'Chineseness' vis-à-vis the 'Chinese-in-Japan' identity, indeed interrelates with Oliver Dew's analysis of 'a "post-Zainichi” moment' in his studies on 'Zainichi cinema'(see Dew 2016: 19-20). 
in $A j i)$ and in particular Japan's war orphans (zanryū koji), stranded war wives (zanryü fujin), and their descendants who returned to Japan since the normalization of relations between the PRC and Japan in 1972 (Efird 2010, 2004; Chan 2011). ${ }^{11}$

On the other hand, the Sinophone perspective enables us to intervene in and debunk the consensual narrative that usually situates the diasporic Chinese within the multifarious 'Sino-Japanese' connections and frictions in socio-cultural, political, as well as economic realms, but never critically interrogates the inherent tension of the 'Sino' and what is actually made (in) visible through the consensual categorization and discourse surrounding the 'Sino'. We could explore how the Chinese-in-Japan prism actually intersects with diasporic subjects who have become or have been made stateless in Japan (such as General Ma Jinsan in Li Ying's $2 H$ ). ${ }^{12}$ These people are caught in between and are struggling to engage with the various modes of identification prescribed less by the Japan/China dichotomy than by the very multiplicity and complexity of 'China' itself, wherein the PRC (a socialist state founded in 1949), the Republic Of China/Taiwan (a nation striving to become a state after it lost its legal status in the United Nations in 1971), and Hong Kong (a former colony returned to the PRC as a Specially Administrated Region in 1997) have become the overlapping yet competing sites of meaning-production.

11 In his Ph.D. thesis, Robert Arther Efird has pointed out that 'war orphans' refer to 'people of Japanese parentage who were stranded in China as children at the end of World War II'. The Japanese expressions used to "identify these people translate literally as "remaining orphans" (zanryū koji), "remaining Japanese" (zanryū höjin), or "repatriates from China"(chügoku kikokusha)' (Efird 2004: 1). Efird has helpfully highlighted that 'the terms and conditions under which war orphans and other repatriates have been identified in the post-war period suggest the ways in which the ethnic categories of "Japanese" and "Chinese" are constructed, maintained and contested in Japan, particularly with recourse to "blood" descendants and historical suffering' (ibid.: 2). In her take on zanryū hōjin, nevertheless, Yeeshan Chan clarifies that, according to the definition by Japan's Kōseishō (the former Ministry of Welfare, Health, and Labor), 'persons under the age of 13 on August 91945 were officially labelled zanryū-koji or abandoned war orphans. Persons over the age of 13 on that date were mostly women who had married Chinese men for survival but had been considered by the Japanese state to have stayed in China by their own choice' (Chan 2011: xix). The latter group has been identified as zanryü-fujin. Since China's Reform and opening-up policy in the 1980s, there has been no lack of films and television dramas created about the issue of zanryü-höjin, some of which were collaborations between the PRC and Japan (see Kirsch 2015; DeBoer 2014).

12 For more on Taiwanese subjects' citizenship before and after World War II, and specifically the socio-historical context underlying the two 'Chinas' - the People's Republic of China/PRC and the Republic of China/ROC - in relation to Japan's shifting diplomatic policy, which is key to grasping the conditions of becoming mukokuseki (stateless), refer to Chen Tien-shi's 'Minorities “in between" China and Japan: Complexity of Legal Status and Identity'(2007). 


\section{Cinema of Displacement}

Before migrating to Japan, Li Ying worked at China Central Television in the department of television documentary production, with his own documentary work (about Tibetan ethnography) already entered for an international documentary film festival. Lured by the cosmopolitan, multicultural image of Tokyo, Li joined his then-wife for her language studies in Japan and arrived here in March 1989, at a time when the nationwide democracy movement - the largest in modern Chinese history - was in full swing back in the PRC (Li 2009: 18, 24-25). Even though he dreamt of finding jobs related to image production and making his own films in order to make ends meet, Li spent years doing typical menial jobs held by foreign migrants - jobs characterized by the three Ks - kitanai (dirty), kiken (dangerous), kitsui (tough). It was not until 1993 that Li founded his own image production company Dragon Films (Longying) in Tokyo, together with another new migrant from China, Zhang Yunhui (or Zhang Yi, who later became Li's producer). ${ }^{13}$ Dragon Films mostly collaborated and coordinated with Japan's television broadcasters such as NHK and Asahi for China/Hong Kong-related TV documentary projects (Li 2009). Since his debut documentary, $2 \mathrm{H}$, Li's independent projects have been mainly supported by his business activities at Dragon Films, which often had Japanese TV stations as co-producers.

$2 H$ and $A j i$ are films of displacement not simply because Li directs his camera to displaced subjects like himself. Li Ying has leveraged his diasporic filmmaking to interrogate the Chinese-in-Japan identity to not only envision it as an assemblage of layered, heterogeneous, sometimes conflicting modes of identification and positioning but also to see how it intersects and entangles with other diasporic identities and experiences.

Meanwhile, the Deleuzian discussions on the minor as well as on minor literature have underlined how we may rethink the cinema of displacement apropos its politics. For now, it is instrumental to point out that for Gillez Deleuze and Félix Guattari, a majoritarian mode of difference and one that is minoritarian have proffered different ways of drawing distinctions. Whereas in a majoritarian mode, the opposition is grasped as 'already

13 For comparison/reference, it is worth pointing out that it was in 1990 that Lee Bong-ou's independent film company cine qua non was founded. It was to become a crucial entity in producing, circulating, and screening works related to the zainichi/Koreans-in-Japan issues and support the creative activities of some zainichi filmmakers. Oliver Dew suggests that cine qua non could be considered a 'mini-major': 'independent ("mini"); and yet a vertically integrated producer, distributor, and exhibitor (with its own chain of six boutique screens in Tokyo, Kobe and Seoul), organised like the major studios had been in their heyday ("major")' (Dew 2016:15-16). 
given and based on a privileged and original term' (Colebrook 2001: 104), a minoritarian mode 'does not ground the distinction on a privileged term, and does not see the distinction as an already-given order' (ibid.). Instead, it functions through the creativity and contingency of 'becoming', which proffers crucial insights into how we may further engage Deleuze's take on identity. For instance, in the socio-cultural terrain of contemporary Japanese society, a majoritarian mode designates the differences between the Japanese and non-Japanese, the latter of which include the zainichi, a distinction that could be traced back to the discourse about a quintessential Japanese identity as we may find in nihonjinron (i.e. the ideology/discourse of Japaneseness) (see Ko 2010). A minoritarian mode of difference, however, may depart from 'becoming-zainichi' in for instance 'becoming-zainichi Koreans' or 'becoming-zainichi Chinese', which does not simply seek to oppose or negate Japaneseness as such, since that would still be working on the 'privileged term', with its foundation on the authenticity of 'being Japanese'. Rather, 'becoming-zainichi' may open up new possibilities for considering non-Japanese identities without subscribing to any pre-given order or norm, and therefore it can envision an identity that is provisional and always 'in the process of creation' until it becomes majoritarian, in expressing 'being zainichi' as such in constituting a new standard by which to include/exclude those who do (or do not) fall into such defining characteristics.

Therefore, I shall contend that it is not that works by zainichi Chinese filmmakers like Li Ying have proffered the defining, authentic representations of Chinese-in-Japan persons and their communities, since in making such claims we are assuming that a pre-given norm and standard exists for one to pin down and delimit the 'Chinese-in-Japan', as if films as such only function to inscribe the already existing group. Rather, as a critical heuristic, this 'cinema of displacement' seeks to engage 'a people to come', the identity of which 'is always provisional, in the process of creation' (Colebrook 2001: 118). If I could borrow the way Colebrook highlights works by Australian Aboriginal poet Mudrooroo, I shall propose that Li Ying's works are minor 'not by being a pure representation of some origin' but by 'creating a specific territory' in which being Chinese-in-Japan 'is presented as a process of becoming and negotiation, incorporating and transforming images from without through its own mode of work' (ibid.).

Furthermore, I will underpin the politics of Li's filmmaking by exploring how his works have approached the multiplicity and complicacy of the Chinese-in-Japan identity and subjectivity in interrelating with various aspects of affectivity. At the textual level, one could grasp Li's documentary aesthetics by turning to what Hamid Naficy has framed as an emergent mode 
of 'accented style', which is 'rooted in the filmmakers' profound experiences of deterritorialization' and manifests as 'dislocatory feeling structures' (Naficy 2001: 26-27). As such, accented films not only feature themes of 'sadness, loneliness, and alienation', they are also populated by 'sad, lonely, and alienated people' (ibid.).

It is also important to locate the examination of the structure of feeling at the extra-textual level. Jie Yang has explained how affects might be experienced and articulated differently in accordance with individuals' multifarious 'ways of existence', thereby underpinning the formation of subjectivity, namely in contributing to the understanding of 'oneself and others as subjects' (Yang 2014: 10). Meanwhile, in his survey of minority affects, John Erni has indicated that these can be grasped as 'a lived experience of intensity that engages - and creates - an individual's corporeal responses ... shapes their social actions, and constitutes a different kind of power relation underpinned by (subtle and surprising) social passion' (Erni 2017:3). Agreeing with both Yang and Erni regarding how affect needs to be 'contextualized and examined culturally, historically, and politically' (Yang 2014: 10), I explore how Li Ying's auteurist documentaries have interconnected in between the diasporic subjectivity as a specific mode of lived experience of intensity and the socio-historical and political contexts within which such affective formations have been generated, circulated, and contested.

Naficy's discussion of the accented affective formation has assumed a difference in the diasporic experiential mode from that of the exilic, and thus the 'chronotopical configuration' in the accented style approaches the homeland as 'utopia and open', contrasting with the 'dystopia and claustrophobic' exilic (Naficy 2001: 27). Whereas Naficy suggests that both the diasporic and exilic subjectivity are contingent upon a sense of belonging and being oriented towards the 'homeland', his thesis has been problematized by Wang Yiman in her historical re-examination of Sinophone diasporic filmmaking. Wang notes how diasporic filmmakers are not simply emotionally invested in the 'homeland' toward its 'there and then', namely in a vertical manner; rather, they have simultaneously reterritorialized their identification with 'homeland' into more fluid, multifarious strands of affective, political engagements with 'home' (Wang 2012). Therefore, the diasporic Sinophone subjects - including both diasporic filmmakers and the characters in their diegetic world - need to constantly redefine and rearticulate their sense of belonging through what Wang has termed 'homing' imaginaries and tactics, so that it becomes possible for them to conceive a type of 'togetherness' either imagined or situated in the 'here and now' of the Sinophone communities. Also, the 'homing' strategy helps to negotiate the 
diasporic persons' relations with a homeland (China) that is 'never a static "past" to be related to vertically' but rather 'the ever-present' and 'constantly changing' (Wang 2012: 544), and thus to continuously question its meaning.

This study leverages Wang Yiman's interventionist reading in seeing how the diasporic filmmakers have kept a coeval yet tension-filled relationship with both 'home(s)' and 'homeland(s)' and how the auteurs have worked with the lived experiences and imaginaries negotiating with such formations. Specifically, I look at how Li's documentaries connect the diasporic Sinophone communities in a metaphorizing Japanese society with a rapidly transforming China (especially given Li's mainland origin) spanning from 1989 to the 200os, illustrating what Lionnet and Shih have proposed as 'minor transnationalism' (see Chapter One). Nevertheless, it is noteworthy that in de- territorializing/re-territorializing the imaginaries of the homeland, $\mathrm{Li}$ has turned his camera to protagonists such as the stateless citizen General Ma in $2 \mathrm{H}$ and a Japanese repatriate, Sato Hatsue, in $\mathrm{Aji}^{14}{ }^{4} \mathrm{The}$ former, living alone in Tokyo, had not only alienated himself from three Chinas but also distanced himself from his families dispersed overseas. And the latter, a Japanese citizen in her seventies, dreamed of leaving Tokyo and 'returning' to her birth city of Jinan in mainland China, a place that she considers her 'hometown' (furusato) (Sato \& Sato 2002: 120). ${ }^{15}$ These are diasporic subjects whose migrant trajectories and modes of identification have nonetheless complicated and enriched the 'homing' imaginaries and tactics as mapped out by Wang Yiman.

\section{H: Becoming Chinese-in-Japan Toward the Fin-de-Siècle}

\section{'A Certain Kind of Community' in Post-1989 China}

In his debut documentary feature film $2 \mathrm{H}$, Li purposefully avoids boisterous street views of Tokyo (except at the film's beginning and ending) and patiently observes how General Ma (Ma Jinsan, or Chongliu), a former Kuomintang (KMT) high-ranking officer (as Sun Yat-sun/Sun Zhongshan's military consultant), spends his last days in his claustrophobic, dark-lit Tokyo apartment. Most of the time, it seems, the old man is accompanied only by

14 It is also noteworthy that in the documentary film Yasukuni, the Sinophone subjects foregrounded are actually a group of aboriginal people from Taiwan.

15 In her autobiographical novel, Sato Hatsue considers Jinan her 'hometown' (furusato), while she sees Japan as the 'alien country' (ikkyou) (see Sato \& Sato 2002). 
4.2 Protagonists in 2H: Ma Jinsan (upper left and right) and Xiong Bingwen (bottom left)
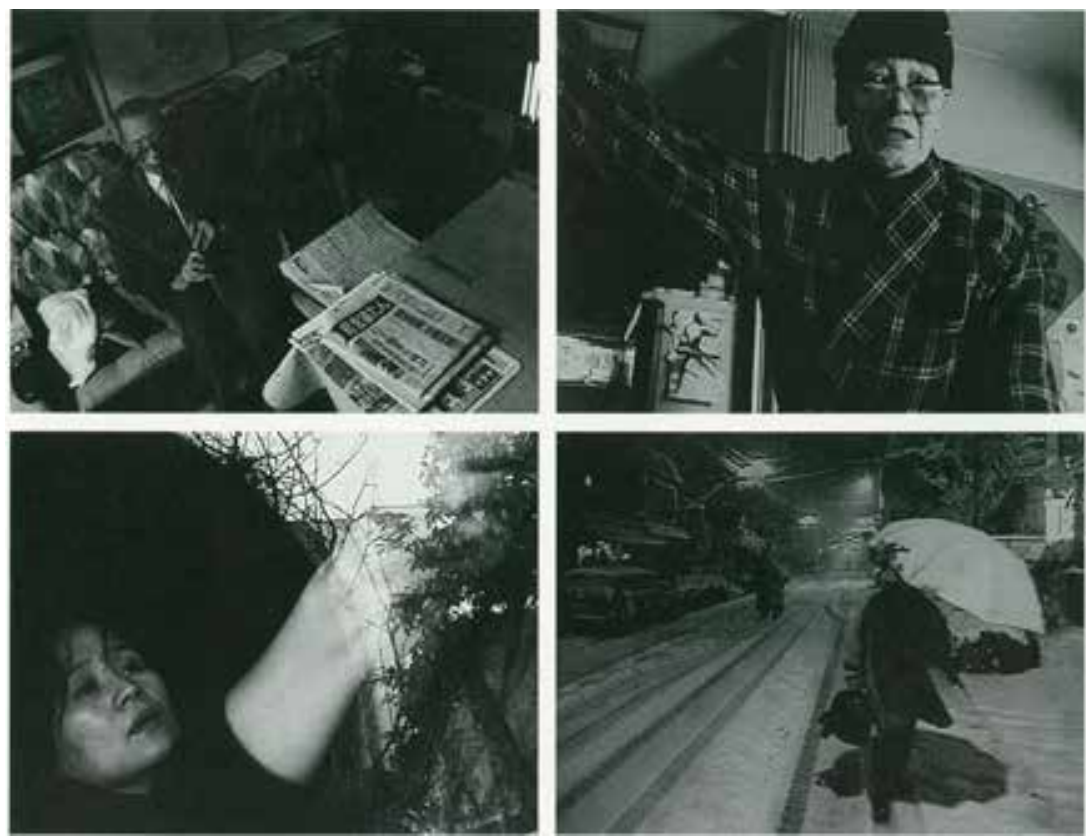

a television set and Li's camera. Despite his legendary past in which he led the KMT army to fight against the Japanese imperial army during WWII, after the KMT was forced to retreat from the mainland, Mr. Ma refused to follow General Chiang Kai-shek's echelon to Taiwan. He also did not reunite with his family dispersed overseas (many of whom had emigrated to the US) after the war ended. It is intriguing that even though he opted for Japan as his last stop (he relocated to Japan in 1953), Ma chose to become stateless (mukokuseki) by refusing to acquire any nationality.

Another thread of the documentary traces a younger female artist named Xiong (Xiong Bingwen), who has befriended the ageing general and often spends time with him in his apartment. The filmmaker also follows Xiong back to her place in Tokyo - seemingly a deserted, spacious house she has adopted as her makeshift studio. Throughout the film, Xiong's background as a new migrant is never explored, and she rarely tells her own story. Mostly the audience sees Xiong, an indoor creature too, either working on her own painting (given her identity as an artist) or posing meaninglessly in front of the camera, being highly performative. The voyeuristic camera also sneaks into one of the bedrooms and observes how Xiong erotically interacts with 
a male artist named Zhang (Zhang Qikai), also a migrant from the PRC. Although it is hinted that they are simply asked to act out their intimacy (Xiong is married), it is never made clear to what extent Li had scripted their on-screen romance.

One needs to turn to a broader socio-historical context within which $2 \mathrm{H}$ was produced to see how the documentary mediates between Li's own decades-long diasporic experience of becoming Chinese-in-Japan and the transformation and diversification of Chinese-in-Japan communities in the aftermath of China's 1989 pro-democracy movement (hereafter simply referred to as the Movement). It is noteworthy that the Movement contributed to carving out and making visible a diasporic public space through which $\mathrm{Li}$, then a total stranger to Tokyo, was able to gain insight into the Chinese-in-Japan people and their communities, as he started to join the gatherings and demonstrations in town to support the Beijing democracy protests. ${ }^{16}$ It was also through these gatherings that Li got to know Mr. Ma (the two met in 1991) and a group of people who admired and followed the old man. However, it was only around 1997 that Li decided to turn his camera to Ma and start this documentary project (personal interview with $\mathrm{Li}$ ).

As much as the 1989 Movement opened up space for trans-generational diasporic subjects like Ma, Xiong, and Li to connect with each other and to emerge as a collective, the very failure of the Movement disrupted, if not crushed, the illusion that their togetherness could be articulated through 'a unified and unquestioned Chinese identity ... represented by the socialist state' (Dirlik \& Zhang 1997: 4). Instead, the sense of togetherness was built upon their shared yet enhanced experiences of loss, fragmentation, and void. Li admits how confused he was around the time of the 1989 Movement, burdened by questions like 'where I am going to and whether I have a place to return to'. He confesses, 'I cannot figure out where is my own country (kuni), or where is my own home (ie) anymore ... my feeling at that time might be quite similar to that of the exiles' (Li 2009: 24).

Li has pointed out that although he had no previous understanding of the communities/collectives (kyōdōtai) of Chinese-in-Japan people, he did witness how, throughout his eight-year-long relationship with Ma (dating from 1991 until Ma's death in 1998), the individuals surrounding the gentleman had actually formed 'a certain kind of community' (isshu na kyōdōtai), regardless of where they were from ( $\mathrm{Li} \&$ Jinno 2000: 236). Li thus believes

16 For instance, Li Ying admitted that during the time of the 1989 Movement, while participating in the events and gatherings, he was 'surprised to learn about the fact that there are so many Chinese people in Japan, and they are dispersed in so many different places' (Li 2009: 24). 
that $2 \mathrm{H}$ has documented how, despite the crumbled, fragmented image of one's nation and family, the displaced people were still envisioning and striving for the alternative communities/kyōdōtai to come, even though their experiments were doomed (ibid.: 236-237).

\section{Accented Style and Haptic Images}

Returning to the film text, it is important to approach how Li has underscored the diasporic structure of feeling of displacement, alienation, and loneliness through an accented style. ${ }^{17}$ Here one can turn to how the filmmaker has blended his cinéma vérité aesthetics with highly stylized mise-en-scène composed of hand-held camerawork, sepia-toned and monotonous colour, and claustrophobic spaces as well as the extensive use of close-up shots and long takes, wherein the documentarist's physical presence and intervention are clearly made known to the viewer. Li admits that, during the process of making the documentary, he experienced great difficulty in relocating Ma back to the historical situation from which he had been exiled. The filmmaker came to realize that his interviews of Mr. Ma contained nothing more than different versions of 'lies' (uso) - that is, the interviewee's subjective and partial reconstructions of the past (Li \& Jinno 2000: 236). The hybridized cinematic style was arguably intended by Li Ying to problematize mainstream film and television documentaries' claim to progressive teleology when approaching the legendary life of a great man, thereby distancing his own take from the conventional biographical historical documentary genre.

Understandably, Mr. Ma's legendary past is only backgrounded in $2 H$. Instead of using archival footage and 'talking heads' interviews with the ageing general to suture the latter within an orthodox narration of the Chinese nation, Li places Ma in his 'here and now' by meticulously documenting and observing the 9o-year-old's everyday routine, mostly through long observational takes. It is telling that it is not until the end of the film that the audience is allowed to gain more insight into the old man's historical role, when Ma showcases to Li his military medals awarded by the US government that, according to him, were given only to 'presidents and heads of states'. Nevertheless, in the sequence that follows, when Ma is encouraged by Li to comment on his own role and valuable 'historical experiences' (lishijingyan),

17 Regarding the linguistic aspect of the accent in $2 H$, the documentary is multilingual, with its protagonists mostly speaking a mixture of Chinese local dialects. Ma mostly spoke Yunnan (Dali) dialect. 


\subsection{Li Ying's Director's Note on $2 \mathrm{H}$, with a low-angle shot of Ma on the train}

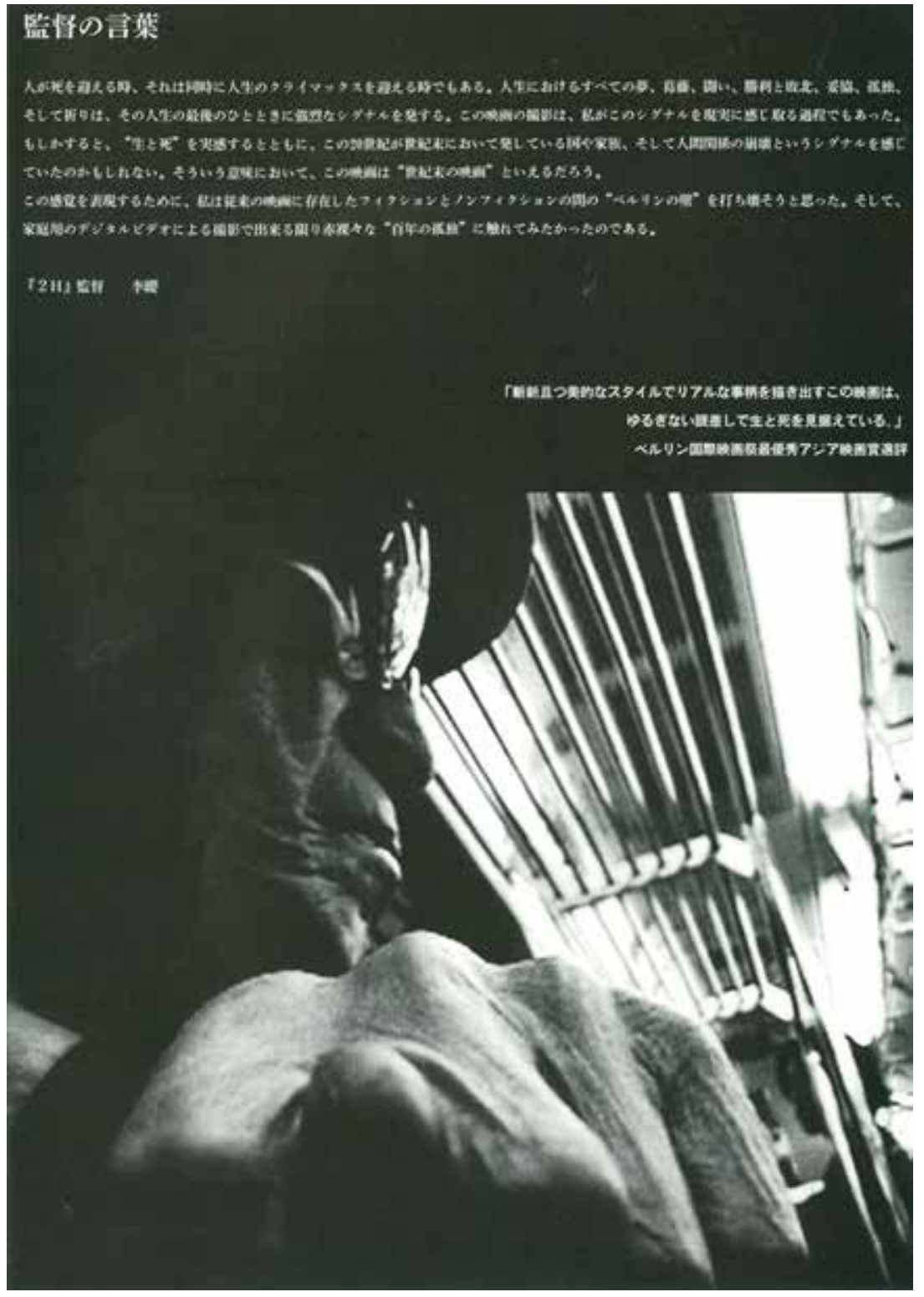

the old man only sneers at the thought by cursing, 'What's history? It's all shit!' (Shenme lishi? Doushigoushi!). It is curious that Li has refrained from corroborating Ma's narrative about his glorious past with any photographic evidence. It is only towards the last five minutes of the film that the audience 
sees a portrait photo of the general dressed in military uniform decorated with medals. It is also in these precious photographs that the viewers see, for the first and only time, a younger, stern-looking Ma surrounded by his extended family or standing tall among KMT high-ranking officers, including the Generallissimo Chiang Kai-shek.

For Naficy, one affective dimension integral to the accented style emphasizes how the experiences and sensibilities of displacement are embodied through 'tactile optics', namely the films' 'nonlinear structure' that is 'driven by the juxtaposition of multiple spaces, times, voices, narratives, and foci - the montage effect', and especially a filming style that redistributes the senses in emphasizing the spectatorial engagement with the 'tactility', which can be triggered by 'nonaudiovisual ways in which displaced people experience the audiovisual media' (Naficy 2001: 29). As a way to extend Naficy's discussion of 'tactile optics', Laura Marks has usefully proposed the concept of 'haptic visuality' in her discussions of intercultural cinema, namely 'a visuality that functions like the sense of touch', to rethink and critique visual mastery (Marks 2000: 22). Marks focuses on the cinematic mechanism through which the audiene engages the 'haptic images'. These are images that invite haptic looking that 'moves on the surface plane of the screen' to privilege the perception of the materiality and texture of the images, and thus to establish a direct relation between the perceiver and 'the sensuous object'. Under such circumstances, the audience is encouraged to 'contemplate the image itself instead of being pulled into the narrative', throughout which they engage in participatory spectatorship in resorting to 'his or her resources of memory and imagination' (ibid.: 163).

Film critic Jinno Toshifumi has stressed how, by transferring $2 \mathrm{H}$ to $35-\mathrm{mm}$ film, the screen presence of Mr. Ma is made impressive because of the felt 'graininess' of the celluloid molecules. Jinno also points out how the photogenic quality blurs the boundary between fiction and non-fiction, which echoes Laura Marks' observations regarding how the haptic images 'may raise ontological questions about the truth of photographic representation' (ibid.: 172). $2 H$ has proffered examples of haptic images par excellence. Particularly, Li uses close-ups to 'bring vision as close as possible to the image' (ibid.: 159), which has the effect of enlarging Ma's thick eyeglasses and the deep wrinkles on his face, hands, and feet as if to recognize his weakening, dying body as the only site for the filmmaker and the audience to get in touch with him, an exile from history.

Nevertheless, the film deviates from Marks' examples of first-person intercultural video works that tend to mobilize personal narrative and bodily performance to interweave a rich tapestry of sense memories about 
4.4 From the Japanese promotion brochure of $2 \mathrm{H}$, where Ma sees through the camera eye; $\mathrm{Li}$ is also introduced here as a 'China-born, Tokyo-based' filmmaker

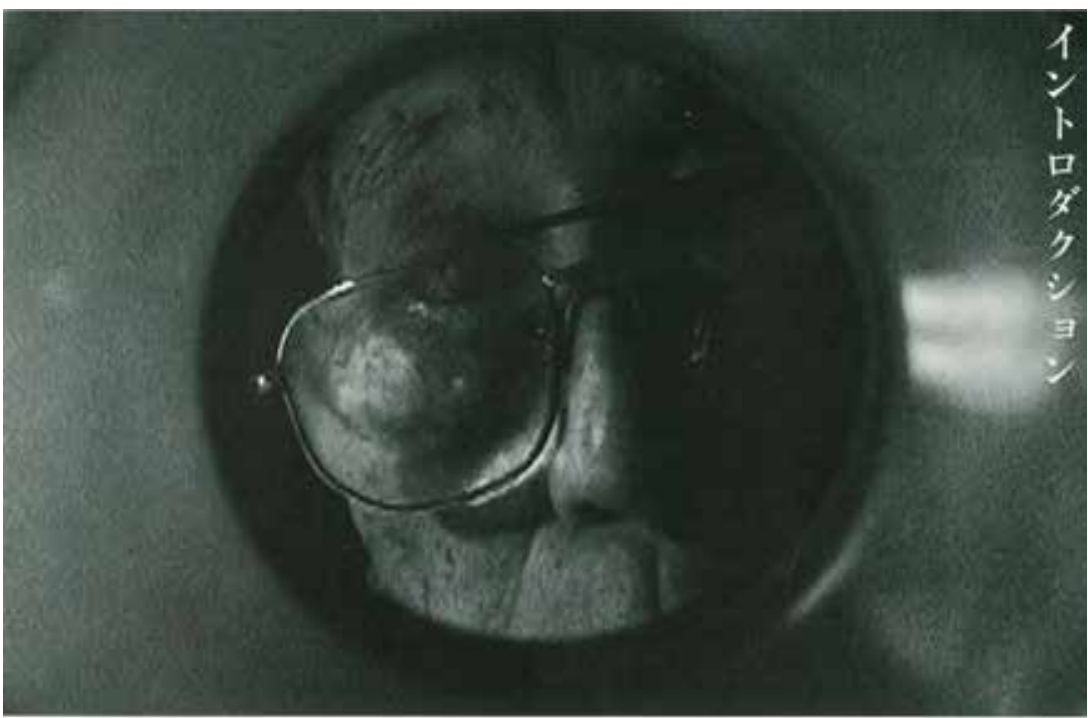

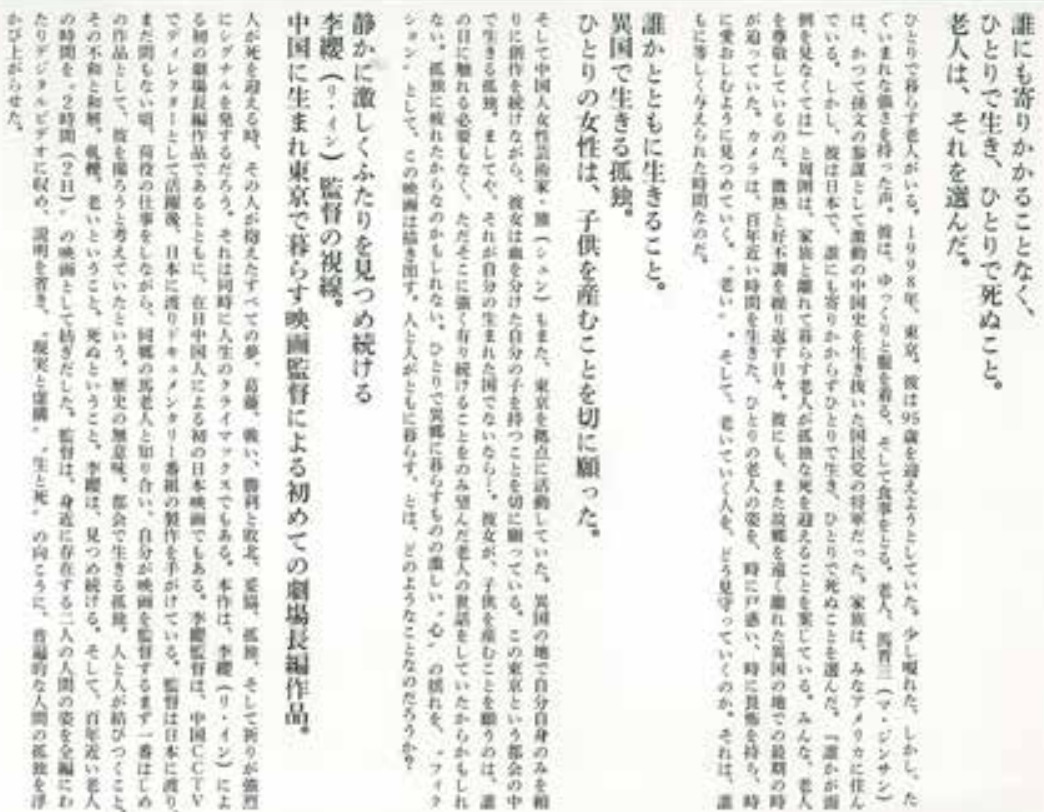

displacement. Li's long takes, which are often fixed close-up shots, can be discussed in terms of the Deleuzian time-image as suggested by Marks, which sheds light on the spectatorial engagement with direct 'sense perception'. 
Importantly, in watching time go by and observing how characters simply wait 'not necessarily for anything to happen' (S.H. Lim 2014: 20), the long takes foreground alternative mode(s) of experiencing time that Chinesein-Japan subjects such as the stateless Ma or new migrants like Li, Xiong, and Zhang have struggled to articulate and contend with.

For instance, it is telling that in a high-angle long take overlooking Ma's living room, the old man is seen watching the TV broadcast of the handover ceremony of Hong Kong in a dark corner, far from both the camera and the TV set. The handover is a significant ceremony that closed the historical lacunae narrating the Chinese nation in the $20^{\text {th }}$ century. Nevertheless, with only his facial contour lit up by the TV set, it is quite difficult for the audience to identify with the protagonist, as it is difficult to tell whether Ma is emotionally reacting to the event and in what way, particularly when the host of the ceremony comments (in Japanese via the simultaneous interpreter): 'From this moment on, Hong Kong is once again part of China'. This may be the only moment in this film referring to a specific date, namely 1 July 1997 (the handover took place at midnight). However, the TV programme's indexability can be highly unreliable without any further historical registers to fixate its meaning - it can be merely a recorded or replayed segment. Therefore, instead of situating and synchronizing Ma and Li with the historical time of the PRC, the long take foregrounds Mr. Ma's everyday condition of ennui and loneliness in only recognizing him as a distant onlooker who is marginalized by the grand narrative of the Chinese nation, which is symptomatic of Ma's paradoxical condition of statelessness as a mode of belonging detached from the very context within which it is produced and situated.

\section{Fin-de-Siècle Metaphor}

${ }_{2} \mathrm{H}$ arguably constitutes a fin-de-siècle metaphor for the Chinese-in-Japan identity, which can be leveraged to imagine the 'difference-in-togetherness' among the diasporic Sinophone individuals (see Ang 2001). The work approaches the emerging collective/community (kyōdottai) that the filmmaker participated in in Japan's social sphere as contingent, fluid affective formations that were generated, performed, and rendered visible and audible through the long takes archiving Ma's everyday life as well as the intervening dramatized confrontations into the latter half of the documentary, with the outbursts of anger and tears. Paralleling the conflicts between Xiong and $\mathrm{Ma}$, who fight over how the ageing general could be taken good care of without being sent to a home for the elderly or without caretakers being 
summoned to his home, the sequences of intimacy between Zhang and Xiong are reenacted to foreground their failed attempt to have sex, indicating how Xiong was deeply troubled by her desperate loneliness and the desire of having a baby of her own.

As reminded by $\mathrm{Li}$, on the other hand, the only truth that he has captured in $2 \mathrm{H}$ is Mr. Ma's death. It could be argued that the film itself is structured in such a way that it can be seen as a long goodbye to the general. In remembering and mourning the loss of a loved one, the documentary also witnesses the dissolution of the kyōdotai of these displaced people. One day after the filmmaker returns to Ma's apartment, he is told that Ma's body was found in his toilet, already dead for days. Here Li inserts a haunting, purposefully muted long take shot of when Ma was still alive in which the camera, as if consciously keeping distance from its filming subject, looks in the direction of Ma's bedroom and watches how the old man is getting himself dressed at an excruciatingly slow pace. After he puts on everything, Ma is seen moving closer to a mirror, seeming quite satisfied to look at himself in the mirror, and appears ready to take off. Shot against the light so that the old man is only visible as a dark contour, this long take - stylistically not so different from other observational takes of his daily routine - performs a ritual of commemoration in imagining how Ma is preparing for his own departure from this world, gracefully.

One can also recall how Li uses the general's last will, handwritten by Ma himself, to end the documentary. The will reads, 'I was born on December $26^{\text {th }} 1902$ in Yunnan. For nearly 100 years, I faced the world's turmoil and disorder in China, doing what I could and enduring much'. It is a poignant comment on all the displaced Chinese persons who drifted away from their home and homeland in the $20^{\text {th }}$ century. We may contend that General Ma's statelessness registers one of the most radical, paradoxical forms of becoming Chinese-in-Japan: as an important witness and participant of an exciting, tumultuous century in modern Chinese history, he decided to escape from it in a gesture of self-exile; as a cosmopolitan Sinophone subject who connected with three Chinas, he didn't celebrate his nation ('homeland'), nor did he seek company with his family ('home').

In her examination of the interrelation between diasporic subjectivity and the film apparatus in transnational diasporic first-person films, Alisa Lebow emphasizes that 'the camera is not simply a recording device that captures the experiences of the displacement, it can be a symptom of that very displacement' (Lebow 2012: 230-231). It is intriguing that on several occasions, Li has emphasized how he considered Ma's 'lonely figure' to be potentially an image of his 'future self' (Li 2009: 25). Coming to realize 
the significant role that his DV could play as the 'diasporic apparatus', however, Li does not locate the dynamics in the 'back and forth movement' of transnational migration within a contemporary, digitalized environment. Instead, revolving around the aesthetics and style of cinéma vérité, we need to consider how Li as a filmmaker and member of the kyōdōtai participates and intervenes in the unfolding story through his shaky, mobile camerawork, point-of-view shots, and sporadic conversations with his subjects. Although $2 H$ is not a first-person documentary per se, we need to pay attention to how Li has also intended this to be a documentation of his own diasporic subjectivity. Mr. Ma's exilic, stateless experience has prefigured and interconnected with Li's diasporic trajectories and 'cultural homelessness' (Marks 2000: 4), which were underpinned by the filmmaker's personal conditions of alienation and disorientation trapped in between a post-bubble Japanese society and a post-socialist China undergoing market-oriented transformations at the turn of the millennium. Such affective connections are trans-generational and trans-historical, and the filmmaker believed that it is through his documentary-making that he himself and the general had become 'one community' and 'one family', even though they had no clue where they were headed (Li \& Jinno 2000: 236-237).

\section{Aji: Tastes Like Home}

Aji (Dream Cuisine) follows a Japanese couple known as the Satos (wife Hatsue and her husband Kōroku) who ran a restaurant in central Tokyo named 'Jinan Hotel' (Chinan Hinkan, est. 1969; closed around 2006) that was famous for its authentic Chinese/Shandong Cuisine (Lucai). Their star chef, Hatsue, was born in Jinan in 1925, the capital city of Shandong province in the Republic of China era, and grew up there. Before Hatsue was forced to leave China in 1948, she had the rare chance of getting trained at a renowned Shandong cuisine restaurant (Taifenglou) and learned lots of recipes from the master chefs there. Into the 2000s, in her late seventies, Hatsue, already accredited by the Shandong government for her contributions to lucai, was thinking of realizing her dream of opening a restaurant in Jinan and passing down her lucai recipes to young chef trainees at a local Chinese culinary school (also see Sato \& Sato 2002).

Produced in collaboration with NHK and a more professionalized team, the style of $A j i$ is conventional and more narrative-driven. Probably not unlike other NHK TV documentaries about contemporary China, Aji seeks to get a glimpse of a rapidly changing Chinese society by turning to the 
transformations occurring in the culinary tradition of lucai into the new millennium. It is telling that the documentary begins with archival footage of China's Cultural Revolution (1966-1976), with scenes of mass parades and the Red Guards' violent raids destroying antiques and brand signs of old shops. While this suggests the extent of the disruption, - if not eradication - of time-honoured traditions resulting from the political turmoil in the socialist era, it also prefigures how China's fast-paced modern development and marketization are built exactly upon such disruptions of traditions, against which Hatsue's new episode with China unfolds and twists.

Li Ying leverages Japanese repatriate (hikiage-sha) Hatsue's diasporic experiences to examine how displaced subjects negotiate the meaning of 'homeland' and 'home' in between China and Japan, which arguably interrelates with Li's own changing self-positioning as a Chinese-in-Japan. Referring to Wang Yiman's discussions of 'home' and 'homing' imaginaries, it is important to see how Aji juxtaposes the Sato family's restaurant Jinan Hotel (also the old couple's residence, only open to reservations as a restaurant) with a Jinan city mostly preserved in Hatsue's memories of her youth, which laid the basis for the documentary's tripartite narrative segments starting with the Satos' debates over relocating their restaurant to China (the husband Kōroku believes it would be difficult for him to get used to life in a foreign country at such an old age), and climaxing with their trip to Jinan, which is followed by their return.

Hatsue is displaced not simply because of her experiences of repatriation but also because of her nostalgia for a 'hometown' that was out of reach for decades. ${ }^{18}$ Crucially, her affective linkage with Jinan is trans-historical (temporal) and trans-national (spatial) in that it has interwoven together the disjunctive, fragmented experiences of modernity in the Republic of China of the 1940 s and the People's Republic in the 200os, which are significantly mediated by Hatsue's own struggles in postwar Japan for almost four decades. Jinan Hotel, therefore, registers a time-space disjuncture that is out of sync with the 'here-and-now' of either Japan or Jinan. Rather, Hatsue used Jinan Hotel as a site to keep her connections with the 'there and then' of China alive through the cooking, tasting, and sharing of lucai. Understandably, the restaurant is characterized by the mise-en-scène foregrounding a sense of enclosure, tranquillity, and stasis that seems to be isolated from the larger socio-cultural context of Japan. For the old couple, preserving the authenticity of the cuisine (the basic rule of which is to use no addition of

18 Sato Hatsue was not able to visit the PRC until 1981, which she called 'going back to my home country'(kikoku) (Sato \& Sato 2002: 177-178). 
extra seasonings, such as sugar) is about valuing and preserving the tradition, in resisting the erosion of changes.

However, for the Satos, their trip to fulfil Hatsue's wish to return to her birthplace (for which she chose the Japanese word of kaeri, or 'returning', instead of $i k u$, namely 'going') proves to be a disappointing 'homecoming' journey. As much as Hatsue is eager to guide her husband Kōroku around Jinan, in sharing with him her favourite landscape and people, she has little 'evidence' to offer besides the details pieced together from her fading memories. When she is standing side by side with one of her former chef colleagues (from Jinan) on the top floor of a tall building and looking over the transfigured city view, she is seen pointing at somewhere and laments, 'you see, my (old) home is gone. I cannot find it'.

More importantly, originally envisioning a trip to impart her recipes to younger Chinese chefs and to open a restaurant serving authentic lucai, Hatsue comes to understand that the 'original' taste they are so proud of is actually considered outmoded. Her authentic cuisine is being challenged, though mildly, by local practitioners who passionately advocate the taste of xinlucai (New Shandong Cuisine), one of fusion, rich flavoring, and always changing in order to cater to customers in the new age - a symbol of the new mode of modernity. Therefore, the culinary school's schoolmaster cautiously expresses his dissatisfaction with the Satos' stubbornness by calling their culinary practice huashi, namely 'fossil'. Hatsue, who has no interest in collaborating with the culinary school in opening their branch back in Tokyo, came to realize that their Jinan Hotel could not be relocated to Jinan after all. Uncannily, it evidences Wang Yiman's illustration of the 'diasporic paradox' that, 'for a home to remain a home, it must exist elsewhere as an idea evoked and desired through letters, phone calls, and imagination' (Wang 2012: 547).

With Hatsue, Aji opens up a critical terrain to historicize the diasporic subject's intricate positioning in relation to home and homeland, posing no less powerful questions about a static, reified conceptualization of national and cultural identity. The work closes with one of Li Ying's signature long takes, with Hatsue and Kōroku bidding farewell to the filmmaker at the entrance of Jinan Hotel, the camera gazing at the door until the couple slowly disappears from the viewfinder. As much as Li uses such an everyday scenario to suggest that it is exactly the old couple's persistent love and understanding that give meaning to Jinan Hotel as a 'home', their stand-alone togetherness also adds a sentimental footnote to Hatsue's dream about an unreachable hometown (toward the end, the documentary suggests that the old couple had to succumb to their failing health while coping with the 
changes in Tokyo itself, however gradual). This is probably why Hatsue's favourite Chinese song, 'When Will You Come Again' (Heri jun zailai, in Mandarin), originally performed by the legendary film star/singer Zhou Xuan from Shanghai, is played as the ending theme. The song is about regrets of missed encounters with loved ones, lamenting the constant changes and the transience of life. It is a tune of unhappiness if we agree with Ackbar Abbas that unhappiness is not a state of mind but 'describes the structure of a space and time that is out of joint' (Abbas 2010: 25).

\section{Towards a Chinese-in-Japan Cinema}

In the BBC documentary 100 Years of Japanese Cinema (Nihon eiga no hyaku nen, 1995), Japanese filmmaker Oshima Nagisa ends his expansive yet provocative observation of the cinematic century by commenting that 'the greatest visible change with modern Japanese cinema is the emergence of non-Japanese who reside in Japan'. Drawing on the zainichi Korean filmmaker Sai Yōichi and the latter's All Under the Moon (Tsuki wa dochi ni dete iru, 1993) as his final example, Oshima even predicts that 'as the number of non-Japanese in this country continues to grow at an astounding rate, this change would undoubtedly have a profound effect on Japanese cinema'.

Here it is worth recalling that after Li Ying's $2 H$ won the Asian Film Award from NETPAC (The Network for the Promotion of Asian Cinema) as a Japanese entry in 1999, the filmmaker was shocked that the Japanese mainstream news report about this work hardly mentioned the fact that the film was directed by a zainichi chügokujin, with zainichi chügokujin as protagonists, and speaks the Chinese language/dialects (Li 2009: 26-27; also personal interview with $\mathrm{Li}$ ). Li saw this ignorance itself as a further indication of how little Japan was interested in other Asian cultures and their people, even when these foreigners were already playing active roles within Japan's socio-cultural sphere. It was Li's puzzlement over how Japan has distanced itself from 'Asia' that led to his next project Yasukuni, a film profoundly connected with Li's own diasporic positionality.

It is important to point out that this chapter does not approach Chinesein-Japan cinema as if it is already a well-established body of film practices as well as discourses as diverse and rich as zainichi cinema (see Dew 2016; also Ko 2010). The aim is not to argue for a similarly 'comparable' strand of zainichi chügokujin cinema per se. Rather, 'Chinese-in-Japan cinema' is tentatively proposed here as a critical heuristic to survey an array of diasporic Sinophone filmmaking practices as well as discursive articulations 
that are closely associated with the Chinese-in-Japan subjectivity and their diasporic experiences.

Several problems have foregrounded my critical engagement with Chinese-in-Japan cinema. First, Chinese-in-Japan cinema raises the question of representation and self-representation regarding the film images of Chinese-in-Japan, if we refer to Oliver Dew's useful agenda in his studies on zainichi cinema (Dew 2016: 1). Historical studies in Japanese, English, and Chinese highlighting film works by the Manchurian Motion Picture Production and Distribution Co. (Manshū Eiga Kyōkai, or Man'ei) have provided fertile ground to survey the representation of the colonized Chinese/ Manchurian people as imperial subjects (see Baskett 2008; Ryū 2011, 2016). Griseldis Kirsch might have proffered one of the most comprehensive accounts regarding the screen representation of Chinese-in-Japan characters in Japanese TV dramas and films (mainly fictional) during the period spanning from 1989 to 2005 . She has categorized, somewhat too neatly, these zainichi chügokujin characters into her quartet of representational patterns, each of which indexes how Japan has been imagining 'China' against a backdrop of changing Sino-Japanese power relations as the PRC gained increasing socio-economic leverage since the end of Cold War. ${ }^{19}$ Nonetheless, with no interest in examining the very constructedness of 'China' from historical and geopolitical perspectives, Kirsch seems to have invented these patterns to only allow the on-screen zainichi character roles to contest 'Japanese homogeneity' as another homogenous collective itself, namely as the Other. She has failed to examine whether Japanese TV and film productions have approached the 'Chineseness' differently when they engaged the zainichi from the three Chinas and beyond.

Second, and more importantly, despite my focus on several Chinese-inJapan filmmakers/image-makers who have ventured into independent film and TV productions in Japan from around the mid-199os and have followed disparate creative trajectories, the historical genealogy of Chinese-in-Japan filmmaking has not been comprehensively studied. Regrettably, little is understood regarding the history of image-making by previous generations of kakyō, kajin, or other Sinophone groups prior to the emergence of the

19 According to Kirsch, in the first pattern, the Chinese are represented as the marginalized group in need of help and support; A second cultural trope highlights China as the 'vision of horror' (Kirsch 2015: 55); the third pattern nevertheless responds to the PRC's miraculous economic growth and Japan's economic downturn in the 1990s, which in turn registers China and its tradition as the source ofsalvation and energy. Finally Kirsch looks at characters who are of rather mixed ethnic/national identities and whose international backgrounds could potentially create heterogeneous cultural space for Japanese society. 
'new overseas Chinese' filmmakers like Li. It would also be crucial to see whether, as is the case with several Chinese-in-Japan filmmakers mentioned above, their zairyu status can be sometimes transitional and fluid so that they do not necessarily have to base themselves in Japan to continue their filmmaking careers.

It is with the above-outlined limitations in mind that I turn to several examples of contemporary Chinese-in-Japan films (including TV productions) as part of my concluding remarks. It should be stressed that the emergence of these independently produced works coincided with - and should be situated within - the post-studio era of Japanese cinema, wherein independent productions have become the 'norm' in the film industry since the 199os, with major film studios shifting their roles and reshuffling their infrastructural configurations and industrial agendas (see Wada-Marciano 2012). Among these independently produced Chinese-in-Japan works, there are also films similar to Li Ying's diasporic, accented filmmaking. For instance, Ren Shujian (b. 1975) came to Japan in 1998 and studied filmmaking at the Japan Academy of Moving Images (Nihon Eiga Daigaku). His debut feature, My Lyrical Times (Watashitachi nojojō tekina jidai, 2009), which won him two awards at the domestically run Pia Film Festival in 2009, looked at the zainichi chügokujin community from the perspective of an overseas student from the PRC, Zhao, which also juxtaposes stories about migrants from other Asian countries. In Summer Vacation in North Korea (Kitachōsen no natsuyasumi, 2005), a diary film narrated by the filmmaker himself in Mandarin, Ren joins a group tour with northeastern Chinese tourists and records his everyday encounters along their North Korean trip.

Li Ying is not an exception among Chinese-in-Japan filmmakers who have turned to people like the Japanese repatriates, including zanryū kojin, zanry $\bar{u}$ fujin, and their second (nisei) or third (sansei) generations, whose senses of belonging are arguably caught 'in between' China and Japan, despite their Japanese nationality (Kirsch 2015: 118-120). ${ }^{20}$ Among the auteurist-oriented zainichi chügokujin filmmakers, one could also mention Ban Zhongyi, whose documentaries such as Gaishanxi and Her Sisters (Gaishanxi he tade jiemei, 2007) and Give me the Sun (Taiyo ga Hoshii, 2016) have evidenced

20 In Feng Yan's 1997 TV documentary A Long Journey Back Home: Stranded War Wives and Their Families'Journeys (Kokyō karukani: Chūgoku zanryū fujin kazoku no tabiji), produced and broadcast by Kansai Television, for instance, she turned her camera to families of the stranded war wives and war orphans who returned to Japan from a remote town in Heilongjiang province (in former Manchuria). Another filmmaker who was studying in Japan was Ji Dan (between 1988-1992). Also refer to Sato Ken's discussions on both female filmmakers (in Japanese) (K. Sato 2019). 
his decade-long efforts collecting and archiving the verdicts of Chinese 'comfort women' (wei'anfu). ${ }^{21}$

On the other hand, there are more commercially viable works, such as $A$ Guide of the Sleepless Town (Kabukicho annaijin, 2004) by Chinese-in-Japan filmmaker Zhang Jiabei, a film that is loosely based on Chinese migrant Li Xiaomu's semi-autobiography about his own 'success' story in transforming himself from a 'newcomer' from South China into a veteran 'Kabukicho guide' in Japan's most infamous red light district of Kabukicho in Shinjuku, Tokyo. ${ }^{22}$ Meanwhile, directed by the Chinese-in-Japan TV director Zhang Liling, Persisting with Tears in Eyes (Hanlei huozhe; Japanese title: Nakinagara ikite) chronicles the 15 years of struggle of its protagonist, Old Ding (Ding Shangbiao) as an illegal migrant in Japan, separated from his family in Shanghai and working hard to earn money for his daughter's overseas studies. Highly acclaimed by domestic audiences in Japan when it was aired on Fuji TV, Persisting with Tears in Eyes had its theatrical release in Japanese theatres in 2009 (Wang 2012). ${ }^{23}$

Labelling himself as a 'film drifter', Lim Kah-Wai (Lin Jiawei, b. 1973), a Chinese-Malaysian filmmaker, has exemplified a more flexible, fluid positioning travelling in between China (Hong Kong and Macau), Malaysia, and Japan to have his projects produced and therefore located. Having majored in engineering at Osaka University, after graduation, Lim quit his job at a Japanese company and studied filmmaking at Beijing Film Academy before deciding to return to Japan (see K.-W. Lim 2014). Before his commercial attempt with Love in Late Autumn (Aizaishenqiu, 2016) with Hong Kong's Emperor Film Production, Lim was closely associated with the Japanese independent cinema circle (see Kotzathanasis 2017). In his earlier low-budget features, such as After All These Years (Qihou, 2010), New World (Shin Sekai, 2011), and Fly me to Minami (Koisuru minami, 2013) - three films that he calls the 'Stateless Trilogy' (mukokuseki sanbusaku) - Lim seems to show interest in exploring the romantic encounters of young urbanites

21 For more, refer to Ban Zhongyi's monographs (Ban 1992, 1996).

22 As an annaijin, Li usually escorted customers to 'bars, restaurants, strip shows, night clubs, porn shops'; and since he made his own annaijin stories known through the publication of a series of (semi-)autobiographies, for instance (see Asakura 2002), Li has been often featured in news reports, television interviews, and so forth. A 2016 documentary I Want to Run for Office (Senkyo ni detai) by Chinese filmmaker Xing Fei (who got her MA degrees in Japan and the UK) chronicles Li Xiaomu's new challenge in life campaigning for the Shinjuku Ward Assembly election as a politician, for which he had become Lee Komaki, after being naturalized as a Japanese citizen.

23 The finale was released in 2009 under the same title. 
who are from different national, cultural, and ethnic backgrounds in Asian cosmopolitan cities such as Osaka, Hong Kong, and Seoul.

I believe the emergence of Chinese-in-Japan cinema in the contemporary setting is not simply indicative of the inherent yet often underestimated heterogeneity and diversity within 'Japanese cinema' itself, as predicted by Oshima decades ago. Crucially, it also opens up Japanese film culture to the various assemblages of regional and global film cultures. Moreover, as E.K. Tan has illustrated, the Sinophone's 'dialogue with the national, be it China or the settler societies, cannot be overlooked, even in a postnational, deessentialized, non-China-centric discourse' (Tan 2013b: 21). This project of mine then seeks to contribute a different perspective to the ongoing debates on Sinophone cinema studies vis-à-vis Chinese-language cinema studies (see Zhang 2016; Yue \& Khoo 2014; Shih et al. 2013; Lu 2007). I use the dialectics of 'im/possibility' to explore the minor status of Chinese-in-Japan films and filmmakers in the studies of Sino-Japanese transnational cinema and film cultures in order to draw attention to the absence of a Sinophone perspective in the historiography of Sino-Japanese film exchanges (DeBoer 2014; Ryū 2011, 2016b). This book hopes to spark such discussions.

\section{Works Cited}

Abbas, A. (2010). 'Affective Spaces in Hong Kong/Chinese Cinema'. In Braester Y. and Tweedie J. (eds.), Cinema at the City's Edge: Film and Urban Networks in East Asia, pp. 25-35. Hong Kong: Hong Kong University Press.

Ang, I. (2001). On Not Speaking Chinese: Living Between Asia and the West. London; New York: Routledge.

Argo Pictures (ed.) (2008). Li Ying's YASUKUNI. Tokyo: Dragon Films.

Asakura, T. (2002). "'Kabukicho guide” offers punters a walk on the wild side'. The Japan Times. Retrieved 1 December 2018 from <https://www.japantimes.co.jp/news/2002/o9/29/national/ kabukicho-guide-offers-punters-a-walk-on-the-wild-side/\#.W81jAhMzZnY>.

Ban, Z. (1992). So obasan no umi [Grandma Zeng's Sea]. Tokyo: Asahi Shinbunsha.

- (1996). Chikakute tōi sokoku [Near and far homeland]. Tokyo: Yumani Shobō.

Baskett, M. (2008). The Attractive Empire: Transnational Film Culture in Imperial Japan. Honolulu: University of Hawaii Press.

Bernards, B. (2012). 'Beyond Diaspora and Multiculturalism: Recuperating Creolization in Postcolonial Sinophone Malaysian Literature', Postcolonial Studies, 15/3: 311-329. DOI: 10.1080/13688790.2012.728371.

- (2016). Writing the South Seas: Imagining the Nanyang in Chinese and Southeast Asian Postcolonial Literature. Singapore: NUS Press.

Brasor, P. (2008). 'Yasukuni Film and NHK's Declaration to Promote National Interests. Government Funding, Free Expression and Propaganda in Japan', The Asia-Pacific Journal|Japan Focus, 6/4: 4-6.

Brubaker, R. (2015). Grounds for Difference. Cambridge, MA; London: Harvard University Press. 
Chan, Y. (2011). Abandoned Japanese in Postwar Manchuria: The Lives of War Orphans and Wives in Two Countries. London; New York: Routledge.

Chen, L.L. (2015). 'When Does “Diaspora” End and “Sinophone” Begin?', Postcolonial Studies, 18/1: 52-66. DOI: $10.1080 / 13688790.2015 .1050975$.

Chen, T. (2007). 'Minorities "in between" China and Japan: Complexity of Legal Status and Identity', Bulletin of the National Museum of Ethnology, 31/3: 419-437.

Chiang, H., and Heinrich, A.L. (eds.) (2014). Queer Sinophone Cultures. London; New York: Routledge. DOI: 10.4324/9780203590928.

Colebrook, C. (2001). Gilles Deleuze. London; New York: Routledge.

DeBoer, S. (2014). Coproducing Asia Locating Japanese-Chinese Regional Film and Media. Minneapolis: University of Minnesota Press.

Dew, O. (2016). Zainichi Cinema: Korean-in-Japan Film Culture. Cham, Switzerland: Springer International Publishing; Palgrave Macmillan

Dirlik, A., and Zhang, X. (1997). 'Introduction: Postmodernism and China', Boundary 2 : AJournal of Postmodern Literature and Culture, 24/3: 1-18.

Efird, R. (2012). 'Regionalism and National Dis-integration: Li Ying's Yasukuni and the Cocreation of East Asia'. In Otmazgin N. and Ben-Ari A. (eds.), Popular Culture Co-production and Collaborations in East and Southeast Asia, pp. 171-184. Singapore: NUS Press; Kyoto: Kyoto University Press. DOI: 10.1386/eapc.1.1.163.

- (2010). 'Distant Kin: Japan's "War Orphans" and the Limits of Ethnicity', Anthropological Quarterly, 83/4: 805-838. DOI: 10.1353/anq.2010.0021.

- (2004).Japan's War Orphans and New Overseas Chinese: History, Identification and (Multi) ethnicity. Dissertation (Ph.D.), University of Washington. Retrieved from $<$ http://proquest. umi.com $/$ pqdweb?did $=813777381 \&$ Fmt $=7 \&$ clientId $=15403 \&$ RQT $=309 \& V N a m e=P Q D>$.

Erni, J.N. (2017). 'Introduction: Affect and Critical Multiculturalism in Asia'. In Erni J.N. (ed.), Visuality, Emotions and Minority Culture: Feeling Ethnic, pp. 1-10. Berlin: Springer-Verlag GmbH Germany.

Guo, F. (1999). Zainichi kakyō no aidentiti no hen'yō : Kakyō no tagenteki kyōsei [The Changing Identity of Chinese in Japan: Their Multidimensional Acculturation]. Tokyo: Toshindo.

Harootunian, H. (1999). 'Memory, Mourning, and National Morality: Yasukuni Shrine and the Reunion of State and Religion in Postwar Japan'. In Veer P.T. van der and Lehmann Hartmut (eds.), Nation and Religion: Perspectives on Europe and Asia, pp. 144-16o. Princeton, NJ: Princeton University Press.

Kirsch, G. (2015). Contemporary Sino-Japanese Relations on Screen: A History 1989-2005. London; New York: Bloomsbury Academic.

Ko, M. (2010).Japanese Cinema and Otherness: Nationalism, Multiculturalism and the Problem of Japanesenesss. London; New York: Routledge. DOI: 10.4324/9780203866719.

Kotzathanasis, P. (2017). 'Interview with Lim Kah-Wai'. Asian Movie Pulse. Retrieved 20 September 2018 from <https://asianmoviepulse.com/2017/o1/interview-lim-kah-wai/>.

Lebow, A. (2012). 'The Camera as Peripatetic Migration Machine'. In Lebow, A. (ed.), The Cinema of Me: The Selfand Subjectivity in First Person Documentary, pp. 219-232. New York: Wallflower Press.

Li, Y. (2009). Yasukuni. Tokyo: Asahi Shimbun Publications Inc.

—, \& Jinno, T. (200o). 'Hōkai o kizamu "kao" - Li Ying' [The "face" that bears witness to the collapse - an interview with Li Ying], Eureka, 32/15: 235-239.

Lim, K.-W. (2014). 'Lim Kah-Wai'. In Teraoka Y. and Morimune A. (eds.), Eiga wa dokoni aru: indipendento eiga no atarashi nami [Where is Cinema: New Waves of Independent Cinema], 1st ed., pp. 327-356. Tokyo: Firumu Ātosha. 
Lim, S.H. (2014). Tsai Ming-liang and a Cinema of Slowness. Honolulu: University of Hawaii Press. Liu-Farrer, G. (2012). 'Becoming New Overseas Chinese: Transnational Practices and Identity Construction Among the Chinese Migrants in Japan'. In Plüss C. and Chan K. (eds.), Living Intersections: Transnational Migrant Identifications in Asia, Inernational Perspectives on Migration 2, pp. 167-19o. New York: Springer. DOI: 10.1007/978-94-007-2966-7.

- (2013). 'Chinese Newcomers in Japan: Migration Trends, Profiles and the Impact of the 2011 Earthquake', Asian and Pacific Migration Journal, 22/2: 231-257.

Lu, S. (2014). 'Genealogies of Four Critical Paradigms in Chinese-Language Film Studies'. In Yue A. and Khoo O. (eds.), Sinophone Cinemas, pp. 13-25. Basingstoke, UK; New York: Palgrave Macmillan.

- (2007). Chinese Modernity and Global Biopolitics: Studies in Literature and Visual Culture. Honolulu: University of Hawaii Press.

Marks, L.U. (2000). The Skin of the Film: Intercultural Cinema, Embodiment, and the Senses. Durham; London: Duke University Press.

Mori, H. (1997). Immigration Policy and Foreign Workers in Japan., 1st ed. Basingstoke; London: Macmillan Press Ltd.

Mori, T., Suzuki, K., and Miyadai, S. (eds.) (2008). Eiga yasukuni joei chushi o meguru daigiron [Overall debates upon the terminated screenings of the film Yasukuni]. Tokyo: Tsukuru Shuppan.

Naficy, H. (2001). An Accented Cinema: Exilic and Diasporic Filmmaking. Princeton, NJ: Princeton University Press. DOI: 10.1177/1470412907075071.

Nagano, T. (ed.) (2010). Chainizunesu to toransunashonaru aidentiti [Chineseness and Transnational identity]. Nitchū shakaigaku sōsho: Gurōbarizēshon to higashiajia shakai no shinkōsō. 2. Tokyo: Akashishoten.

—, and Guo, F. (2010). 'Sengo zainichi kakyō shakai no kōsei oyobi hendō to "rō kakyō" no soshiki nettowāku keisei [Postwar social structure of Overseas Chinese and its transformations and the formation of “older generations" Overseas Chinese' organization and network]'. In Nagano T. (ed.), Chainizunesu to toransunashonaru aidentiti [Chineseness and Transnational Identity], pp. 26-64. Tokyo:Akashishoten.

Ng, K.C. (2018). 'Shi Shumei de "fanlisan" daodizai fan shenme? [What Shih Shu-mei is Against in her "Against Diaspora"?]'. Speaking of Books [shuoshu]. Retrieved 3 January 2018 from $<$ https://sobooks.tw/sinophone-literature-review/>.

Ryang, S. (2009). 'Introduction: Between the Nations: Diaspora and Koreans in Japan'. In Ryang S. and Lie J. (eds.), Diaspora without Homeland:Being Korean in Japan, pp. 1-20. Berkeley; Los Angeles; London: University of California Press.

Ryū, B. (2016). Nicchu eiga kōryū shi [A History of Sino-Japanese Cinema]. Tokyo: Tokyo Daigaku Shuppankai.

- (2011). Shōgen: Nicchū eigajin kōryū [Testimony: Exchanges between Chinese and Japanese Film People]. Tokyo: Shūeisha.

Sato, H., and Sato, K. (2002). Seinan hinkan monogatari [Yhe Stories ofJi'nan Hotel]. Tokyo: Shunjusha.

Sato, K. (2019). Chugoku dokyumentarī eigaron [On Chinese documentary]. Tokyo: Heibonsha.

Shih, Shu-mei, Tsai, C., and Bernards, B. (eds.) (2013). Sinophone Studies: A Critical Reader. New York: Columbia University Press.

Shih, S.-M. (2011). 'The Concept of the Sinophone', PMLA, 126/3: 709-718.

- (2007). Visuality and Identity: Sinophone Articulations across the Pacific. Berkeley; Los Angeles; London: University of California Press.

- (2014). 'Foreword: The Sinophone Redistribution of the Audible'. In Yue A. and Khoo O. (eds.), Sinophone Cinemas, pp. viii-xi. Basingstoke, UK; New York: Palgrave Macmillan. 
Takenaka, A. (2009). 'Politics of Representation or Representation of Politics? "Yasukuni" the Film', Review ofJapanese Culture and Society, 21/December: 117-136.

Tan, E.K. (2013a). Rethinking Chineseness: Translational Sinophone Identities in the Nanyang Literary World. Amherst, New York: Cambria Press.

- (2013b). 'Sinophone Studies: Rethinking Overseas Chinese Studies and Chinese Diaspora Studies', Sun Yat-sen Journal of Humanities, 35: 1-26.

- (2012). 'Huayuyuxi yanjiu: haiwaihuaren yu lisanhuarenyanjiu zhifansi' [Sinophone Studies: Rethinking Overseas Chinese Studies and Chinese Diaspora Studies], Zhongguo xiandai wenxue [Modern Chinese Literature], 22: 75-91.

Wada-Marciano, M. (2012). Japanese Cinema in the Digital Age. Honolulu: University of Hawaii Press. DOI: 10.21313/hawaii/9780824835941.001.0001.

Wang, Y. (2012). 'Alter-centering Chinese Cinema The Diasporic Formation'. In Zhang Y. (ed.), $A$ Companion to Chinese Cinema, pp. 535-551. Hoboken, NJ: Wiley-Blackwell.

Yang, J. (2014). 'The Politics of Affect and Emotion: Imagination, Potentiality and Anticipation in East Asia'. In Yang J. (ed.), The Political Economy of Affect and Emotion in East Asia, pp. 3-28. New York; London: Routledge.

Yue, A. (2012). 'Notes on the Sinophone Mediascape in Australia', Chinese Journal of Communication, 5/1: 24-31. DOI: 10.1080/17544750.2011.647740.

—, \& Khoo, O. (2012). 'From Diasporic Cinemas to Sinophone Cinemas: An Introduction', Journal of Chinese Cinemas, 6/1: 9-14. DOI: 10.1386/jcc.6.1.9.

- (eds.) (2014). Sinophone Cinemas. Basingstoke, UK; New York: Palgrave Macmillan.

'Zairyū gaikoku ninzū ni tsuite' [number of foreign residents by the end of June 2018] (2018). Ministry ofJustice (Japan). Retrieved 10 March 2019 from <http://www.moj.go.jp/nyuukokukanri/ kouhou/nyuukokukanrio4_ooo76.html>.

'Zairyū gaikokujin tōkei (kyu tōroku gaikokujin tōkei) tōkeihyō' [Statistics of foreign residents] (n.d.). Ministry ofJustice (Japan). Retrieved 10 September 2018 from < http://www.moj.go.jp/ housei/toukei/toukei_ichiran_touroku.html>.

Zhang, Y. (2016). 'Chinese Film History and Historiography', Journal of Chinese Cinemas, 10/1: 38-47. DOI: $10.1080 / 17508061.2016 .1139802$. 


\title{
5 Okinawan Dream Show
}

\author{
Approaching Okinawa in Moving Image Works into the \\ New Millennium ${ }^{1}$
}

\begin{abstract}
This chapter deals with the oeuvre of Okinawan filmmaker Takamine Gō and video artist Yamashiro Chikako, with an emphasis on the former's feature Queer Fish Lane (Hengyoro, 2016). Taking as a point of departure Gilles Deleuze's framework of time-image, which underpins his explication of modern political cinema, this chapter examines how Takamine has experimented with textual strategies and forms of expression in configuring the 'stratigraphic image' apropos of Okinawa, wherein the boundaries between the actual and the virtual and between the real and the imagined are blurred. Meanwhile, I also turn to Yamashiro Chikako's recent narrative-oriented video works that have been intricately connected to the legacies of the Battle of Okinawa and the current waves of protests against the US military bases on the islands.
\end{abstract}

Keywords: time-image, stratigraphic image, modern political cinema, fabulation, appropriation

[...] when it comes to Okinawa, since 'the Disposition of Ryūkyū' (Ryūkyū shobun) in the Meiji Era, it is obvious that historical events such as the Battle of Okinawa, US military rule, and the reversion to Japan, together with all the problematics that people have encountered - all of them are closely associated with the 'place' called Okinawa and people's identities. Moreover, attention should be paid to the fact that identity is something that has been awakened

1 Unless otherwise indicated, all Japanese to English translations are mine. My deepest gratitude goes to Dr. Kosuke Fujiki for his insightful, sharp comments and revision suggestions for this chapter; I am also grateful for his immeasurable help with some of the precious image resources and for his meticulous, brilliant translations of the uchina guchi materials and proofreading of the Japanese language material.

Ma, Ran, Independent Filmmaking across Borders in Contemporary Asia. Amsterdam, Amsterdam University Press 2020 DOI: 10.5117/9789462986640_CHO5 
at the time of crisis, that is, when people are forced to respond to the state of emergency and harsh realities, they need to construct a 'place' called Okinawa which they could base their own existence upon.

(quoted in T. Takamine et al. 2018: 25-26)

Okamoto Keitoku

\section{Prologue: Okinawa, Rage, and Tears...}

On 15 May 1972, Okinawa was 'returned' to Japan after its 27-year rule under the US government - first under the United States Military Government of the Ryūkyū Islands (1945-1950), and then under the United States Civil Administration of the Ryūkyū Islands (Ryūkyū Rettō Beikoku Min Seifu, or USCAR, 1950-1972). For historian Arasaki Moriteru, Okinawa 'has been a historically and culturally unique place that both is and is not Japan' (Arasaki 2014: 50; emphasis in original). Sociologist Oguma Eiji points out that studies on the Okinawan people, who have been socially and spatially on the periphery of Japan, contribute to reconsidering the boundaries of Japanese identity. He proposes that "the Japanese" are constructed in concert with the construction of "the Okinawans" and the setting of boundaries between them' (Oguma 2014: 352).

Waves of anti-base protest movements in Okinawa re-emerged in the latter half of the 1990s (see Oguma), which have their roots in the 'historical intertwining of Japanese and American imperialism' (Dietz 2016: 219). Into the new millennium, these undercurrents and movements have been fuelled by the controversial US-Japanese agreement to relocate the Futenma airbase northward to the bay area near Henoko. As part of the 'solution', new landfill projects for the US military facilities had been planned and launched. ${ }^{2}$ If, as Arasaki has suggested, 'the Okinawan problem is the military base problem, especially the US bases' (Arasaki 2014: 48; emphasis in original), this raises

2 Around the turn of the millennium, Okinawa witnessed waves of political eruptions directly resulting from the controversial agreement in 2006 between the US and Japanese governments regarding the relocation of the Marine Corps Air Station (MCAS) from Futenma to the less congested northern bay area in Henoko, a village that currently hosts the US Marine Corps' Camp Schwab (est. 1959). As part of the relocation plan, the construction of offshore landfill for future US military facilities near Henoko was approved in 2013 by the then governor of Okinawa. Ever since, the protests and demonstrations against the US base have been fuelled not only by the Japanese government's approval of the Henoko landfill project but also by reports that new helicopter landing pads were scheduled to be built in Takae, a village located at the northernmost tip of the island that hosts one of the US military training grounds. 
the question regarding how to better understand the politics of Okinawan images, and how Okinawa-on-screen is related to the islands' history as well as its socio-political urgencies today.

In the Japanese Academy Award-winning ensemble drama, Rage (Ikari, 2016) by Lee Sang-il (a third-generation zainichi Korean filmmaker), the episode taking place in Okinawa not only features the anti-base protest, the real tragedy happens when the female teenaged protagonist is gang-raped by anonymous American soldiers, while her male friend, who is witnessing her suffering, can only turn his back on the scene because of shock, anger, and fear. Whereas Okinawa and its outlying islands evoke layered traumatic memories profoundly associated with the islands' entangled history tragically underwritten by the Battle of Okinawa, ${ }^{3}$ I suggest that this mystery story only uses 'Okinawa' as its background and the crime scene. However, I would also point out that Lee's approach to Okinawa, though not intended to be controversial, indirectly addresses the actual mass protests about Henoko as well as the crimes of the US Marines and reminds viewers of the inconvenient 'Okinawan Problem', which is rarely touched upon in Japanese mainstream media and cinema. ${ }^{4}$

Given how the images of unrest in Okinawa have been carefully mediated, censored and self-censored, and even become absent from mainstream, commercial Japanese films, it is understandable how the controversial issues around 'Futenma', 'Henoko', and 'Takae' have been predominantly featured in documentaries independently produced (and distributed). ${ }^{5}$ For instance, $W e$ Shall Overcome (Ikusaba nu tudumi, 2015) is the third documentary feature by the Okinawa-based television journalist/filmmaker Mikami Chie. Narrated in first-person voiceover (by Okinawa-born singer-songwriter Cocco), the work chronicles the struggles of several local Henoko/Takae protesters and

3 The Battle of Okinawa (1 April to 23 June 1945) is arguably the most traumatic event in Okinawan history and the most controversial site of remembrance in contemporary Okinawa. According to Andrew Gorden, 'By the time the United States took the island in June, the fighting had taken 12,500 American lives and left a stunning toll of 250,000 Japanese dead (including 150,000 civilians)' (Gorden 2003: 223).

4 As Mikami Chie's 2012 documentary Targeted Village (Hyōteki no mura, 2012) showed, even though the anti-base protesters blocked the gate of Futenma base for four consecutive days in 2012 (starting from 28 September), news about the blockage was not broadcast in the national mainstream media (newspaper and TV). For more on the deeply divided stances apropos the base-related conflictual issues between Okinawa's local news and broadcasters and their Tokyo counterparts, see Gushiken (2017).

5 Prior to We Shall Overcome, Mikami's Targeted Village specifically looks at the plight of the village of Takae, where the construction of helipads was scheduled by the Japanese government. Significant documentaries on the Okinawan problem also include but are not limited to John Junkerman's Okinawa: The Afterburn (Okinawa: Urizun no ame, 2015). 
their groups (as well as their families) who have played an active role in the anti-base movement until they celebrated the victorious election toward the end of 2014 of a new anti-base governor of Okinawa prefecture (Onaga Takeshi, who passed away in 2018 while in office). ${ }^{6}$ Impressive sequences include those captured by hidden cameras and Go-Pro devices that witness how some of the younger generations' campaigners/activists, during their 'sit-in-on-the-sea' on kayaks, were brutally confronted by the Japan Coast Guard (Kaijō Hoan-chō) and forced to retreat. Overall, one sees how this documentary seeks to evoke among its sympathetic spectators a strong sense of identification with the protestors, through close-ups of innocent smiles, clenched fists, and tearful eyes in addition to the emotionally scripted narration.

I argue that it would nevertheless be too arbitrary to assume that Lee's Rage is depoliticized, whereas Mikami's We Shall Overcome, characterized by its anti-base sentiments, proffers a better example of dissensual art. To understand the politics of images concerning Okinawa today, one needs to move beyond the facile categorizations of commercial genres and socially engaged documentaries, types that do not exhaust all the varieties and aesthetic styles concerning Okinawa-on-screen. Instead of a comprehensive study on the representation of Okinawa in moving image works from Japan into the new millennium, this chapter mainly focuses on the works of veteran filmmaker Takamine Gō (b. 1948) and video artist Yamashiro Chikako (b. 1976), with an emphasis on the former.

What makes their works significant, I shall argue, is not simply the image-makers' identities as 'Okinawan descendants' - Takamine was born on the outlying island of Ishigaki, and Yamashiro is from Naha, the capital city of Okinawa prefecture. In juxtaposing their works, the intention is not to compare the two; nor do I want to suggest that Yamashiro's background in contemporary art and the exhibitionary apparatus for her video works (mostly through gallery installations) should be approached in the same way as Takemine's films, even though the two artists have collaborated together

6 What cannot be further elaborated here is the social history of modern Okinawa since WWII, and particularly the period from the 1990 into the twenty-first century. Okinawabased independent journal Ekkyō Hiroba published a special issue in November 2018 titled 'Dokokara, dokoe: Fukkigo Okinawa no tenkanten' [From Where to Where: The Turning Points of Post-Reversion Okinawa], which used Onaga's (untimely) death as a departure point to examine Okinawa's socio-historical and cultural trajectories since 1972. The issues around the relocation agreement, far from being settled, are still featured prominently in Okinawa's social life today. In Febuary 2019, a referendum was held in Okinawa asking voters whether they approved or opposed the landfill project at Henoko Bay, and it turned out that more than $70 \%$ voted no to the base. Refer to The Japan Times reports on the referendum (Johnston 2019). 
on Takamine's Queer Fish Lane (Hengyoro, 2016; I shall refer to the work with its Japanese title in this chapter). It is nevertheless important to point out that Takamine debuted with an 8-mm short film titled Red Man in 1970 which reflects the heavy influence of American independent and experimental cinema as well as the domestic trends of experimental, avant-garde cinema/ filmmaking in the 1960 os and 1970s. ${ }^{7}$ Particularly, he was inspired by the works of Lithuanian-American avant-garde filmmaker Jonas Mekas (see Nakazato 2007). Hengyoro, the film that will be closely analyzed in this chapter, still carries strong experimental momentum. Yamashiro was also an art student who was trained in oil painting. Since finishing her studies, she has been more into photography, performance, video installation, and film. Performance and the artist's use of her own body feature prominently in Yamashiro's videos, especially her earlier works (see Suzuki 2008). However, her recent works such as the Beginning of Creation:Abduction/A Child (Sōzō no hottan: Abudakushon/kodomo, 2015) and Woman of the Butcher Shop (Nikuya no onna, 2012) were selected by the 2017 Yamagata International Documentary Film Festival, demonstrating Yamashiro's ambition to go beyond the conceptual framework in further pursuing narrativity (see Gerow 2017; Yamashiro et al. 2017). ${ }^{8}$ In this study, my attention is focused on how Takamine and Yamashiro's works have contributed to a rethinking of the dissensual politics and aesthetics relating to contemporary Okinawan image and visual culture.

\section{Okinawa-on-Screen: Beyond Representation}

\section{Movement-Image, Time-Image, and National Identity}

It is well known that Gilles Deleuze's thesis on time-image was formulated upon his observations mainly about post-WWII European cinema. In the

$7 \quad$ The development of Japanese experimental and underground cinema in the 1960 s and $1970 \mathrm{~s}$ cannot be further detailed here. I shall argue that the evolvement of Japanese experimental cinema and underground filmmaking (angura in Japanese) intersected with what is often researched as 'avant-garde' cinema, and the practices of the former also significantly extended to and overlapped with those in contemporary art (see Furuhata 2013; also see Japanese Expanded Cinema Revisited 2017). Film critic Nishimura Tomohiro nevertheless points out that 'avant-garde' was used 'even before the World Wars'. According to him, 'from around the mid-5os, the term "experimental cinema" emerged [and] about ten years later, the term "underground cinema" became popular' (Nishimura \& Nishikawa 2015: 32-33).

8 Yamashiro also co-directed (with Sunagawa Atsushi) a short film titled Unju nu hanamichi (The Path of Kumiodori) in 2013 , a project funded by the Okinawa Convention \& Visitors Bureau (OCVB). 
simplest terms, in movement-image, time is indirectly represented, manipulated, and modified through, for instance, the techniques of continuity editing, wherein the movement is necessarily spatialized and made coherent through the mediation of an acting protagonist's body. By contrast, timeimage envisions a model of time as the 'labyrinth without centre', wherein 'movement is no longer the measure of time and the imagining of time is released from its subordination to the sensory-motor action' (Maimon 2010: 86). As suggested, this labyrinthine model conceptualizes time in a pattern of infinitely bifurcating, forking paths onto which are closely knitted the actual (the present that passes) and the virtual (the past that preserves itself). As such, the present does not relate to the past or the future in a coherent, causal, teleological manner.

David Martin-Jones has proposed how the two interrelated, interlacing models of time - namely 'the straight line (the movement-image) and the labyrinth (the time-image)' - shed light on how national history and national identity can be discursively constructed and aesthetically approached in cinema. Dialoguing with Judith Butler's early theories on identity, MartinJones has turned to Homi Bhabha, who grasped 'the essential question of the representation of the nation as a temporal process' (Bhabha 2004: 204; emphasis mine). Bhabha, in his chapter of 'DissemiNation' illustrated how the nation is narrated in 'double time':

In the production of the nation as narration, there is a split between the continuist, accumulative temporality of the pedagogical, and the repetitious, recursive strategy of the performative. It is through this process of splitting that the conceptual ambivalence of modern society becomes the site of writing the nation (ibid.: 297; emphasis in original).

To put it differently, as Martin-Jones elucidates, the pedagogical discourse of national time 'aimed to establish one dominant view of national history, and identity', wherein 'its linearity is based upon the ability to make the present appear to be a repetition of the past, a repetition of the same that guarantees the status of official history as a singular truth' (Martin-Jones 2007:33). Meanwhile, whereas the pedagogical discourse assumes that the population performs the national identity as the repetition of the same (hence the match between the past and the present), the very process of the performance itself is embedded within 'the scraps, patches and rags of daily life' that 'must be repeatedly turned into the signs of a national culture' (Bhabha 2004: 209). That is to say, paradoxically, it is in everyday life that the resurgence of differences 'constantly threatens to erupt and unground' the illusory 
coherence and linearity of the narration (Martin-Jones 2007:34). Therefore, identity undergoes constant renegotiation and re-territorialization to close a disparity 'between an "us" and a "not us"' along the axis of temporality, while repeatedly replacing its origin in the past' (ibid.: 34 ). Here it may be helpful to look at Bhabha's 'double time', which signifies a process of 'de- and reterritorialisation of national identity' (Martin-Jones 2006: 27) in referring to the case of Okinawa. In his socio-historical studies, for instance, Oguma has examined how the Japanese state has approached and articulated 'Okinawa' differently in relation to the 'Japanese' under different historical contexts, wherein 'acceptance and exclusion were mechanisms used as a symbolic boundary process that acted to differentiate between "us" and "them"' (Oguma 2014: 352-353; also see Doak 2007).

Before proceeding further, it is necessary to note that in a different context, Martin-Jones has suggested that to apply the Deleuzian film theories to world cinema or 'Othered cinemas' does not mean to perpetuate 'the Eurocentric conclusions of the Cinema books' (Martin-Jones 2011: 7). A critical reinvigoration of Deleuze's works, as he suggests, requires us to go 'beyond Deleuze's choice of filmic examples to rethink his conclusions' so that these 'Othered films can "talk back" to existing theories' (ibid.: 8). Specifically, he has underscored the importance of contextualizing the understanding of time-image by situating it within specific national (cinema) cultures and visual regimes. I propose that the emergence of Okinawa's time-image, while responding to 'a cultural sense of disorder and unpredictability' (Rodowick 1997: 16) as other strands of time-image do, indeed draws our attention to Okinawa's fraught history since WWII, particularly in relation to the traumatic experiences of the Battle of Okinawa, the islands' socio-cultural movements of independence and reversion in the postwar era, and the persisting problem of the US military base.

Here the intention is not to make the simplistic claim that in contemporary Japanese cinema, Okinawa's movement-image is merely associated with the commercial, generic productions and the time-image with the arthouse, independent cinema. With the lensing of time-image, I aim to turn to temporality or the question of time as a crucial point of entry to examine Okinawa-on-screen.

\section{Narrating Okinawa/Japan: Genealogies}

Having mapped out a genealogy of Okinawa-on-screen, Aaron Gerow proposed that 'representing Okinawa in film' is 'itself a site of struggle between conflicting forces', given how Okinawa may function 'as a productive space 
for negotiating identities that have come into crisis in the post-bubble, post-Aum Shinrikyo Japan' (Gerow 2003: 274). He approaches the filmic representations by analyzing the 'gaze(s)' upon Japan's other, particularly regarding how Okinawa has been approached in 'the nationalist mode of knowing and the nihilism of detachment' by Japanese (Okinawan) auteurs. To be more specific, the nationalist mode functions 'within a dynamic of the sameness and difference of Okinawans and Japanese' (ibid.: 278). In this strand, Gerow for instance examines earlier works such as The Tower of Lilies (Himeyuri no tō, 1953) by the leftist filmmaker Imai Tadashi ${ }^{9}$ and Imamura Shōhei's ethnographical work The Profound Desire of the Gods (Kamigami no fukaki yokubō, 1968), which in Gerow's view used Okinawa to articulate Japanese national identity, in tandem with films characterized by a 'touristic vision' - namely those emphasizing the spectacular otherness of the island. The other mode of detachment, as Gerow attests, is best manifested in films directed by zainichi Korean filmmaker Sai Yōichi and the TV-celebrity-turned-filmmaker Kitano Takeshi (e.g. Fireworks/Hana-Bi; Boiling Point/3-4x1o-gatsu, 199o; Sonatine/Sonachine, 1993). ${ }^{10}$

In her study, Mika Ko looks at films within Gerow's nationalist and tourist mode with an aim to critique the 'cosmetic operation of Japanese multiculturalism' (Ko 2010: 91). In a similar stance to that of Arasaki, Ko suggests that 'it seems to be problematic both to include Okinawa in Japan and to exclude it from Japan, as, in either case, it is politics that determines Okinawa's status' (ibid.: 65 , emphasis in original). Here she has specifically explored how 'Okinawa' has been 'otherised' and consumed in popular Japanese imaginaries. For instance, in Japanese commercial films and media works that are set in Okinawa (not necessarily shot on location in some occasions), the islands may be constructed as the places for escape and healing (see I. Hein). ${ }^{11}$ According to Ko, 'in order to understand the current

9 Himeyuri, or the flower known as the 'princess lily', has become integral to the narrative of the Battle of Okinawa. It is always connected to the Himeyuri Corps, a group of over 200 female students from the upper class (they were studying at the leading Okinawa Daiichi Women's High School and Okinawa Shihan Women's School) who were recruited into a nursing unit for the Imperial Army. Most of the girls were killed on the battlefield. Imai Tadashi's 1953 film tells the story of the Himeyuri Corps students (see Angst 1997).

10 Among Sai's works, many were set in Okinawa, which include Rest in Peace My Friend (Tomo yo, shizuka ni nemure, 1985), Via Okinawa (A-Sain deizu, 1989), Attack (Shügeki, 1991), and Pig's Revenge (Buta no mukui, 1999). Sai's 1984 feature, Someone Will Be Killed (Itsuka dareka ga korosareru) features a diasporic Okinawan. Last but not least, Sai's Kamui (Kamuigaiden, 20o9), though not a film about Okinawa, was filmed there.

11 As Ina Hein illustrates, the 199os witnessed the so-called Okinawa boom emerging in Japanese popular culture and permeated the national media-scape. And yet, although positive images of 
political situation in Okinawa, paying attention to what is not presented may be as important as (or sometimes more important than) paying attention to what is presented' (2010: 85 , emphasis in original). This suggests that the politics of image indeed interrelates with a mode of appearance regarding how to draw and redraw the line between what is visible and what is invisible and for whom. I shall return to this point later.

It is intriguing that in their short historiography of Okinawa's postwar cinematic representations, both Gerow (2003) and Ko $(2006,2010)$ have highlighted fictional works such as Untamagiru (1989) and Tsuru-Henry (1998) by Takamine Gō, implying that Takamine's oeuvre has registered an alternative mode of approaching Okinawa-on-screen. Ko goes further to consider Takemine's oeuvre in terms of 'a possible Okinawan cinema', which invites (national) allegorical interpretations (2006). For Gerow, Takamine's images have successfully challenged 'the dominant representations of Okinawan identity' by 'using representational strategies to contest and reshape definitions of that identity' (2003: 297). Before I move on to scrutinize Hengyoro to better engage the critiques above, I suggest that Takamine's works can be approached as time-image that, while having ungrounded the narration of Japanese national identity, has also resisted fixating itself with an essentialized Okinawan identity, as the Other. That is, his works have gone beyond the symbolic signification and authentic 'representation' of Okinawa, its people, their collective identities, and the 'Okinawan problem', if representation is understood here as 'a form of thought that is based on notions of resemblance, truth, and identity' (Maimon 2010: 85).

Here, one cannot help but realize that in his mapping, Gerow refrains from deploying any Deleuzian terms but actually foregrounds a survey of Okinawa's movement-image regarding how it is characterized by two dominant, sometimes overlapping visual styles (in addition to the detached alternative): a vernacular version of classical Hollywood style and a visually tantalizing and spectacular type. Gerow's careful analysis of some mainstream works, for instance, suggests that Okinawa's movement-image has not essentially disturbed or redistributed what is visible and speakable about Okinawa/Okinawan people, given how the nationalist mode 'renders otherness readable, understandable, and part of the familiar world of conventional distinctions between self and other' (Gerow 2003: 275). And the detached

Okinawa were widely circulated, the sometimes stereotypical and exoticized representations might also have obfuscated how people engage the prefecture's social discontents into the 2000 s (see I. Hein 2010). 
style, arguably, while somehow liberating the inhabitants of Okinawa from pedagogical processes or, in Gerow's terms, 'from cinematic processes that assume knowledge of Okinawa and tie it into mainland assumptions about cultural essence, homogeneity, and national identity', actually still risks creating 'a version of "us" (the viewers) versus "them" (the Okinawans being viewed)' (ibid.: 296).

To advance the discussion about aesthetics and politics, I also shift the lens to Deleuze's thesis on modern political cinema, which for the philosopher concerns a situation that 'the people no longer exist, or not yet [...] the people are missing' (Deleuze 1989: 216). Deleuze explains how the people no longer emerge and exist as a unified revolutionary subject. Or, as perceptively interpreted by Vered Maimon, 'what is missing' is actually 'the organic formation of the collective, a process that is presented as identical to the teleological unfolding (or progressive linear movement) of history, and more concretely the history of the revolution' (Maimon 2010: 86). In Maimon's terms, Deleuze finds problematic classical political cinema's emphasis on the 'organic totality and legibility' (ibid.), regarding how the classical model conforms to 'the idea that the collective has a pre-given identity as the people are always already there, "real before being actual, ideal without being abstract"' (quoted in ibid.).

We may return to Mikami's We Shall Overcome to interrogate the conundrum of classical political cinema. Despite its pronounced political stance in interweaving local memories of the Battle of Okinawa and ongoing waves of protests in Henoko today, in We Shall Overcome, the struggles are portrayed as a highly emotional, sometimes spectacular tug of war between 'us' (the 'Okinawan people') and 'them' (the Japanese state and the American military power). The resistant images of Okinawa have been built upon a teleological narrative about the island's history of subordination and suppression since WWII, wherein the 'Okinawan people' have been represented as an organic, historically consistent collective. Yet what has been only occasionally mentioned if not excluded in the construction of the 'people' within Mikami's oeuvre is Okinawans who do not show up at the mass demonstrations and who even endorse the relocation of the bases (even if their issues and reluctance were briefly brought up in the documentary). When it comes to the 'people', how about the 'internal disparity and discrimination' within the Okinawans themselves (Oguma 2014: 355)? Wouldn't the exclusion/inclusion of these non-protesters and onlookers exactly define how a 'people' could be configured and imagined (see Inoue 2012)? Not intending to downplay the significance of Mikami's anti-base series per se, I consider that they have so far mostly satisfied 
Japanese leftist filmmakers' political imagination in envisioning Okinawa as a potential space to contest and a tool to critique state power and American imperialism.

With the above discussions in mind, I shall turn to Takamine's works, with an emphasis on Hengyoro. With the Deleuzian idea of time-image and particularly of stratigraphic image, one could understand how Takamine's films seek to create an interplay between the actual and the virtual and blur the boundaries between reality, imagination, and memories in falsifying and multiplying - if not disrupting - the singular, teleological narrative of the Japanese nation.

\section{Okinawan Dream Show}

For cultural critic Nakazato Isao, the works of Takamine Gō do not belong to the category of Nihon eiga (Japanese cinema) (Nakazato 2007: 214). In 1969, prior to Okinawa's 'reversion' to Japan, Takamine won himself a scholarship as an 'overseas student' to study oil painting in mainland Japan and has since based himself in Kyoto. So far, Takamine has had a majority of his works independently produced, and most of them are not widely circulated or exhibited beyond the domestic arthouse theatres and various film festivals. ${ }^{12}$

In a piece explaining his earlier works, Takamine expressed, 'For me, to have my film shot in Okinawa is closely related to my filmmaking. Cinema and Okinawa are like two sides of the same coin. It is not like you only approach Okinawa as a motif or theme, but to film Okinawa in itself should be completely equated with what cinema is all about. For me, there is no cinema without Okinawa, and no Okinawa without cinema' (quoted in Takamine Gō Eiga Koten Jikkō Iinkai). The filmmaker here is not aspiring for mimetic art, say, in representing Okinawa in its organic totality and authenticity, which for him would run the risk of reducing it to symbols, stereotypes, or in his own terms, motifs or themes. His art is arguably about how to move beyond representation, a tendency that also underlines Takamine's discussions of landscape.

12 Untamagirū might be an exception among Takemine's independent productions, which was funded by PARCO Co., Ltd., one of the mega retail companies in Japan that has been running its own entertainment branch. Okinawa Island Songs Echoing in The Parisian Sky (Mugen ryūkyū: Okinawa shimauta pari no sora ni hibiku, 2003) is also an exception, which was produced by and aired on NHK. 
Referring to the starting point of his filmmaking, his debut documentary feature Okinawan Dream Show (1974), which was shot on 8-mm film, Takamine elaborated:

The question of the Okinawan landscape (Okinawa no fūkei) does not concern political issues such as to have Okinawa symbolized, but the landscape as it is (arinomama no fükei sonomono, emphasis mine). The landscape does not carry a core of its own, and there is no hierarchy attached, so there is no centre (in landscape) either. What has become important is my personal perspective. Leveraging this personal instead of a generalizing perspective, I could take a grip on the non-differentiational/ equal value (tōka-sei) of the landscape.

For instance, on the one hand, there are the base, the blue sea and the market (a landscape that could be easily symbolized). They are not necessarily my concern, and I think I could turn the everyday and chirudai into films. ${ }^{13}$ If the everyday time cannot be tapped into, we cannot reach the real landscape. Of course, the Okinawan problem (Okinawa mondai) cannot be ignored, and I don't mean that works concerning the problem are no good, but human subjects as well as the politics are already contained in the landscape (quoted in Takamine Gō Eiga Koten Jikkō Iinkai).

Underlying ideas such as 'personal perspective', 'landscape with no centre', and the 'equal value of landscape', Takamine's 'theory of landscape' is arguably one that seeks to configure 'a self-speaking island' by turning away from the representational tropes consisting of, for instance, 'the base, the blue sea, and the market', in order to resist the imaginary of a 'symbolized Okinawa', namely the consensual articulations apropos Okinawa-on-screen, such as those of the nationalist and the tourists (including the leftist intellectuals), if we return to Gerow's mapping. Meanwhile, for Nakazato, the fact that Takamine went to study in Kyoto should also be taken into consideration along with the filmmaker's translocal movements between 'mainland' Japan and his plural 'hometowns' (e.g. his birthplace, Kabira in Ishigaki, and Naha, the city where he was brought up) when analyzing his approach to Okinawan landscape ( fükei) and his 'landscape films' (fükei eiga) (Nakazato 2007: 213-230). In search of the 'non-differentiational/equal value' or the tōka-sei of the landscape, I shall propose that Takamine has approached 'Okinawa' through/in its time-image. 
5.1 8-mm image of an old lady and kids in Okinawan Dream Show

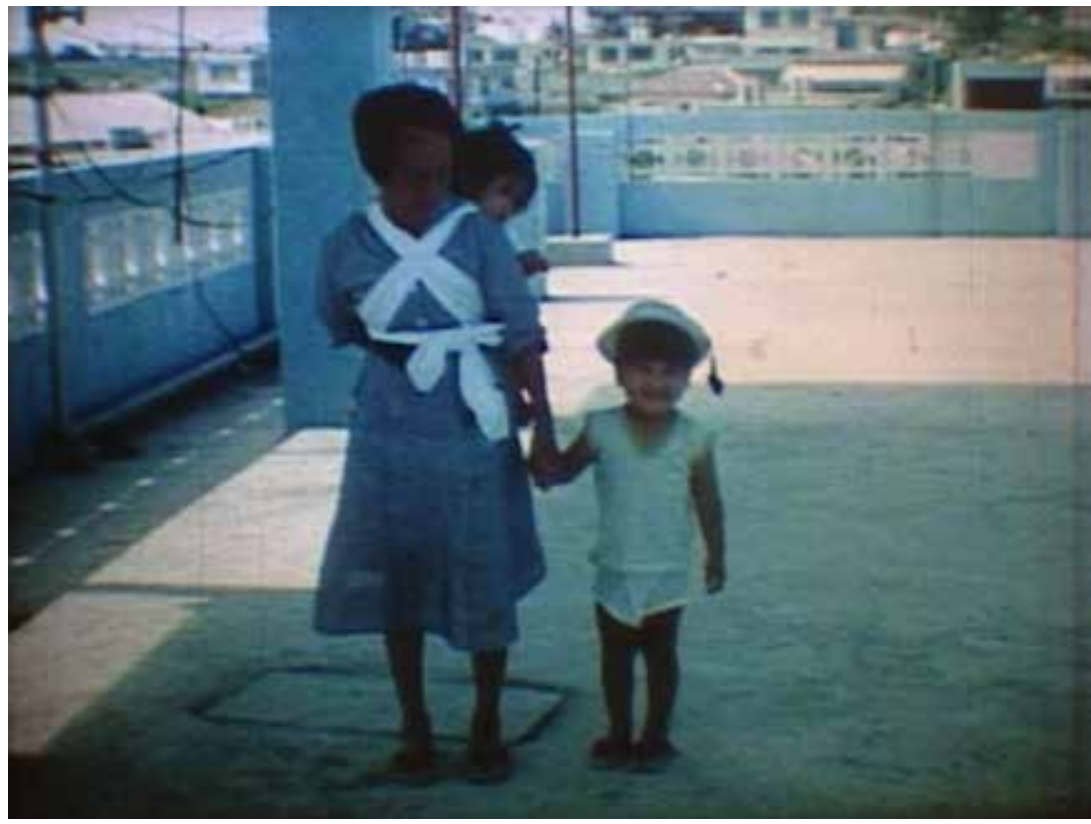

5.2 8-mm image of the street view in Okinawan Dream Show

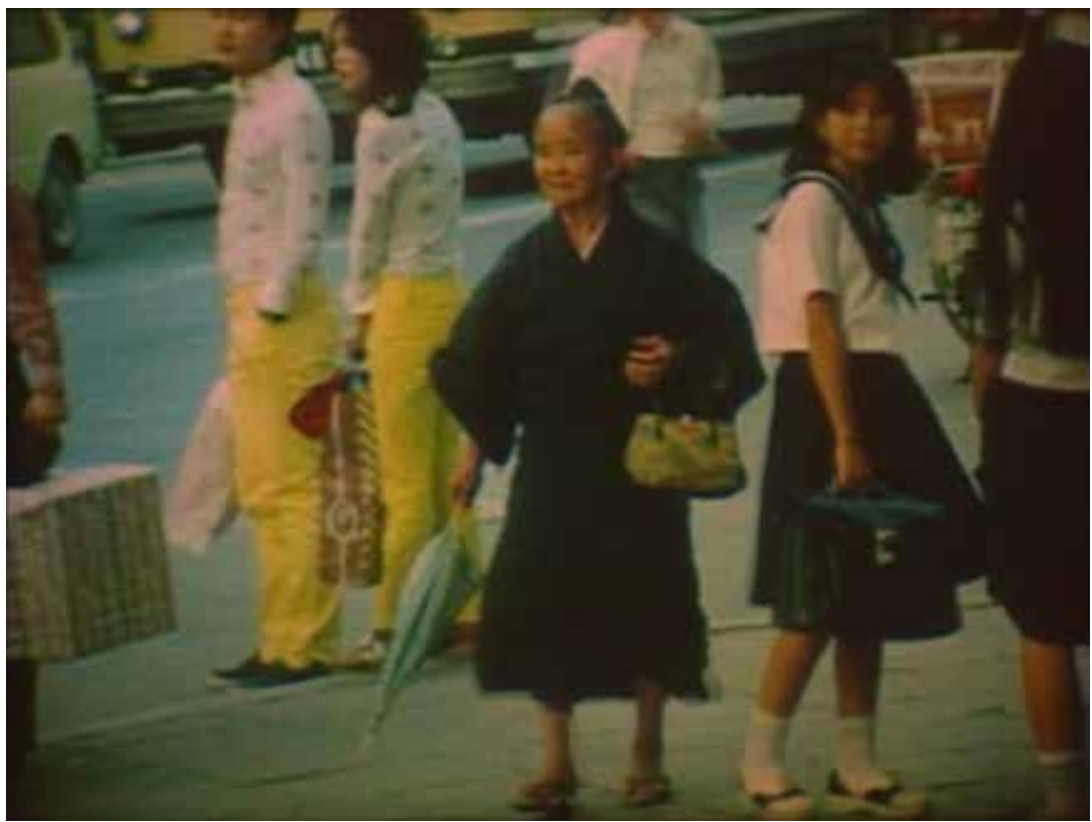


Here we may turn to Okinawan Dream Show for better illustration. Takamine reminisced how he was making this documentary feature in the fashion of a road movie: together with his then sound recordist friend Tarugani, they toured around the islands on a Honda motorcycle as if they were the protagonists from Easy Rider (1969). Nakazato nonetheless explains how Okinawan Dream Show, which took Takamine almost four years to shoot and finalize (1971-1974), had been inspired by Jonas Mekas' essay film, Reminiscences of a Journey to Lithuania (1972). ${ }^{14}$ Therefore, Takamine's essay take was on the one hand profoundly personal: it cast a nostalgic gaze upon the filmmaker's native island of Ishigaki and his families there as a way to memorialize his father who passed away around the time of its shooting. On the other hand, Takamine also used the documentary as a way to canvass the Okinawan landscape as it underwent the profound social transformation of the 1972 reversion (see Nakazato 2007: 227-229; G. Takamine \& Nakazato 2003).

Grasping Okinawan Dream Show as a 'landscape film', Nakazato has however pointed out that the documentary turns to Okinawa's everyday life without necessarily creating hierarchies between the profilmic objects and subjects. The mode of expression of this documentary is noteworthy in that it is an assemblage of observational long-takes (sometimes long shots) wherein the women, men, kids, the young, and the old appearing on the viewfinder are none other than wanderers, flaneurs, and passengers in life engaging in their mundane routines. Even though the film does capture figures acting whimsically and bizarrely (e.g. a man sitting on the street corner who seems to be talking to himself), the moment of encounter is so brief that it only reaffirms the filmmaker's interest in the banality and contingency of the everyday. Both the urban view and the rural space in the documentary seem generic (despite the occasional appearance of some typical Ryūkyū-style stone walled villages), wherein one can hardly see any grand-scale, era-defining setting or imaginaries that help to distinguish Okinawa's ongoing socio-historical transitions or its geopolitical conditions at the time of its shooting. Moreover, devoid of any diegetic monologues or dialogues, Okinawan Dream Show leverages no specific narrative devices to thread together the long takes and render the shot-to-shot interconnections meaningful. For instance, there is a sequence of a black American soldier who seems to be talking to the director, yet no clue is given about his story

14 In one of his earlier interviews, Takamine mentioned that he saw Mekas' Reminiscences ofa Journey to Lithuania in the fourth year after he started shooting Okinawan Dream Show, which inspired him to see that what he had been shooting for could be considered a film after all (see Nakazato 2007). 
5.3 A black American soldier in Okinawan Dream Show, the footage of which is later being 'treated' by Papajō in Hengyoro

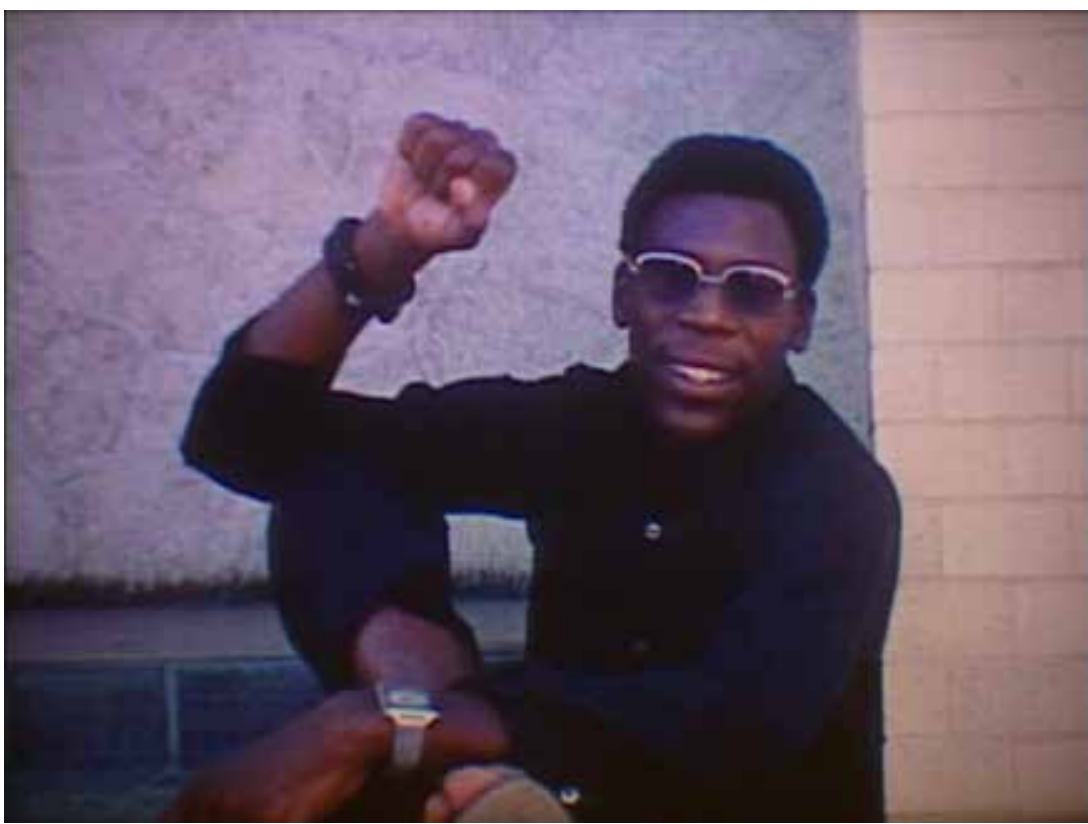

(unused part of this footage with the soldier would appear in Hengyoro). Most importantly, as integral to Takamine's negotiation with Okinawa's idiosyncratic landscape (Toguchi 1992; Nakazato 2007), the 8-mm images were carefully edited and purposefully slowed down so that a loosened, diluted sense of time is made palpable. The unique rhythm of the film (mainly achieved through the editing) is interconnected with and reinforced by Takamine's highly experimental soundscape, which assembles together traditional music (with the sanshin), folk songs, and multilingual radio tracks (e.g. recorded soundtracks from radio programmes). Accompanied by the mesmerizing soundtrack, what the audience is engaging with is some very contrived temporality - that is, a dream show.

The treatment of time can also be related to Takamine's 1978 essay film Okinawan Chirudai (originally shot on 16-mm film, also known as Okinawa no seinaru kedarusa [The sacred lethargy of Okinawa]), a compilation of several stories. In this work, Takamine entertains the idea of chirudai, the dictionary definition of which refers to a type of physical, mental condition of feeling down, discouraged, and lethargic (Kokuritsu Kokugo Kenkyūsho: 163). But I would agree with what Nakazato suggests in contending that chirudai as a specific affectivity also signifies a different conceptualization 
of time that is not necessarily delimited by the progressive, teleological temporality of the Japanese nation (Nakazato 2007).

Eighteen years after he made his last fictional feature, Tsuru-Henry in 1998, in 2016 Takamine came back with a new digital feature Hengyoro, which was premiered at the 2016 Aichi Triennale (the largest contemporary art exhibition in Japan). Instead of reviewing and canvassing Takamine's creative career as a whole, which is beyond the focus of this chapter, I want to use Hengyoro to illustrate how the filmmaker's textual strategy and form of expression can help us not only to understand his particular auteurist tendencies and trajectories but, more importantly, to rethink the dissensual potentialities of Okinawa's contemporary images.

\section{Island Voyages: Travelling in Time}

It is noteworthy that Gerow examines Tsuru-Henry in terms of its innovative collage style that 'foregrounds the problem of textuality and representation, thus emphasizing Okinawa as an issue of performance' (Gerow 2003: 298). The same observations can be applied to Hengyoro, which is not so different from other fictional films by Takamine in showing no interest in conventional storytelling but is structured upon and works with 'a set of intermeshing texts' (ibid.). Meanwhile, although Ko has emphasized that Takamine's persistent use of the Okinawan language (uchina guchi) is highly political in how it underlines part of the 'strategy of presenting Okinawa's struggle, resistance and challenge to the linguistic, cultural and political hegemony of Japan and the US' (Ko 2010: 92), it is my intention not to deal with uchina guchi simply in terms of its anti-hegemonic potentiality perse. Instead, I would like to turn now to the performativity and circulation of the voice, sound, music, and so forth.

Hengyoro starts with the lines from Okinawan folk singer Kadekaru Rinshō's song The Passage of Time. ${ }^{15}$ In the film, the two ageing protagonists, Tarugani (Taira Susumu) and Papajō (Kitamura Saburō), are good friends. Papajō runs a 'film plastic surgery lab' and keeps himself busy with surgeries on villagers as well as on damaged, ruined celluloid films (with sea snake soup, though!). Both friends work at a place called Wifē-pataijō where they

15 Kadekaru Rinshō's lyrics goes like this: 'From a Chinese to Japanese era / From a Japanese to American era / From an American to Japanese era / From a Japanese to Okinawa era / This Okinawa belongs to nobody / This Okinawa, will things work out somehow?'. Translation is taken from the film's English subtitles. 
treat the villagers of Patai Village, all of whom have been constantly troubled by a strong will to die after a mysterious yet long-forgotten incident known as the Shima Pshoo (Shima pushü; shima means 'island') took place.

A few more words on the 'treatment' provided by Tarugani and Papajō: the villagers first experience the 'plastic underwater explosion' operated by Tarugani, for which they go through a ritual-like procedure of body casting and have their plaster exploded by some bizarre-looking, balloon-like installation apparatus. The next step is to visit Papajō's lab to have their faces 'changed', wherein the audience sees how the operation involves having images of other people's faces projected onto the patients in order to accomplish the face-swap.

One day, however, Tarugani is wrongly accused of being a thief after he mistakenly takes a fictional aphrodisiac named 'Tottorō B13' (a variation of which

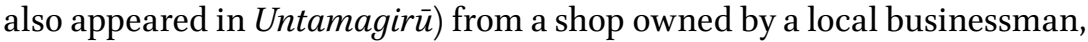
Seitoku. After learning that Seitoku sends out his three bibijū wives, namely nymphs always in wet, dripping clothes, to chase after them and threaten to cut off their ears, Tarugani and Papajō set out on their road trip to escape. While being tracked by the bibijū, the two good friends wander around the island to show itinerant 'chain plays' (rensageki), a hybrid presentation of film segments and stage performance, which I shall explain later.

If one approaches Hengyoro as a 'road movie', as its publicity materials want the spectators to believe, it is necessary to see how the roaming does not seek to bring the audience any new refreshing experience of sightseeing, say, via the exploration of a specific geographical landscape (in spite of the location shooting in Okinawa), but is in itself an unfolding of a distended temporality that is non-linear and acausal. That is, the protagonists are travellers in time. If we return to the two bus rides heading for Patai Village (the three bibiju wives are among the passengers), for example, they are not about the characters' journeys across the island per se but a manifestation of the mesmerizing loop of time (at an unimaginable interval of fifteen years!) wherein the passengers and ticket conductor might be travelling in their own reveries, dreams, or memories.

It is, however, worth noting that Hengyoro takes place in an abandoned, haunting place called Patai Village ${ }^{16}$ where the villagers are suffering from the aftermath of the 'Shima Pshoo', experiencing symptoms in which 'the head goes empty', expressed in Okinawan language as muduruchun. Instead

16 In Hengyoro, Papa Hijā (played by the filmmaker himself) reminds us that Patai Village does not exist; according to Takamine in his interview, patai in the Philippine's Tagalog language means 'death'. 
of taking action and pushing the story forward, these villagers are indeed characters who are entrapped in their own conditions of amnesia and impossibility. Nakazato points out that it is the memories of the Battle of Okinawa that propel the 'unconsciousness' of Tarugani and Papajō, and in his view 'Shima Pshoo' is none other than the island's traumatic war experience (Nakazato 2017).

Unlike Takamine's previous works, wherein the 1972 Okinawa reversion was repeatedly re-enacted and re-imagined as a crucial point of reference, Hengyoro's temporal-spatial setting becomes even more ambiguous if not evasive. In Tsuru-Henry, for example, the intricate issue of Okinawan identity is brought up through the story of James, the young protagonist whose mother is Okinawan (the protagonist of the film, Tsuru), and whose father is presumably the high commissioner of the USCAR. Also, archival footage of the legendary 1970 anti-American Koza Riot is shown, with James' voiceover confessing his 'lack of identity': 'I am not an American. I am not a Japanese. I might not even be an Okinawan' (Gerow 2003: 300).

Regarding Hengyoro, Takamine has repeatededly emphasized in his interviews that he is mostly interested in capturing the 'smell' (nioi) of the land/island and the 'steam' (yuge) of Okinawa, evoking an image that is abstract, intangible, and fragile while avoiding any straightforward political rhetoric (Takamine \& Tsurusaki 2017). It seems that any direct references to the Ryūkyūs or Okinawa, regarding its historical problematics and the intricate issues of identities, have become uncertain, if not absent from this film. Nevertheless, Nakazato has proposed that what is intriguing about Hengyoro is a diegetic world devoid of visible reference to any power entanglements - whether related to Japan or America (see Nakazato 2017). He therefore contends that Takamine leverages Patai Village to envision how 'Okinawa' would be like when it 'belongs to nobody'. I shall argue that the imagined 'state of independence' - or a temporality the Okinawan people do not have yet could have had - interlinks with what according to Mika Ko is 'a process of constant interpretation and re-interpretation in the present of what has happened, what did not happen, and what could have happened' (Ko 2010: 99). As such, Hengyoro is not an experimental work that can be easily dislocated from the shifting socio-political context of Okinawa in the 200os. As Wakabayashi points out, the arrival of the $21^{\text {st }}$ century and the so-called era of globalization has posed challenges requiring us to rethink the place called Okinawa and the issue of identity (see T. Takamine et al. 2018). In Hengyoro, to be more specific, the 'state of independence' is not explored through a specific dramatized plot or through action but is rendered precisely through time-image. 


\section{Loops of Rensageki (Chain Play): Toward a Stratigraphic Image}

Here we can take a closer look at the mode of expression or stylization of Hengyoro. Shot and edited digitally, the film constitutes a multi-layered meta-project synthesizing heterogenous media texts (e.g. contemporary art installations, painting, photography, documentary footages, experimental fragments, digital animation) and cultural genres (e.g. folk music, theatre, dance, rock'n roll, film). Accomplished when Takamine was in his seventies, Hengyoro could be considered an archive of his own creative universe, wherein archival footage from his earlier films, drawings, posters, family photo albums, soundtracks, recording clips, and so forth are recycled and reassembled. The filmmaker himself also emphasizes how he enjoyed the creative liberty brought about by digital filmmaking (Takamine \& Yomota 2017: 70-71). The work has specifically utilized the possibilities brought about by digital technologies to overlay and superimpose one type of image upon another, usually through the creation of multiple, overlaying screens within the film (see webDICE 2017). Nonetheless, I suggest there is no specific differentiation or degree of veracity assigned to the various visual formats or medium. While Takamine does lament the fading of analogue materials/images, he nevertheless experiments with how the seemingly incompatible media and images may revive each other and thus generate new modes of expression, similar to what Papajō's surgery of face-swap has magically achieved. With the collaged-images and overlayed-screens, however, the cinematic narrative has been complicated by the heterogeneous temporalities they have registered and evoked.

According to Japanese film historian Donald Richie, rensageki (joined drama) refers to 'an early twentieth-century form of drama, part film, part stage presentation' (2005: 301). Discussing the use of rensageki performance in Tsuru-Henry in association with the hybrid genre's historical development in Okinawa, Gerow reminds us how in rensageki, the 'staged scenes' and 'scenes on film' played by the same actors would be 'presented alternately in a kind of "chain" (the "rensa" of rensageki, which is sometimes translated as "chain drama") to compose a single story' (2003: 302). ${ }^{17}$ It is noteworthy that there are several roughly similar rensageki or 'chain play' segments

17 Gerow mentioned that rensageki 'was quite popular on the mainland in the 1910s until theater fire regulations, which banned the showing of films (which were made of flammable stock in those days) in stage theaters unequipped for motion pictures'. He pointed out that, although rensageki was waning on the mainland, 'the form continued well into the 1960 s in Okinawa, and it was one of the few kinds of film produced locally' (Gerow 2003: 302). 
5.4 Tarugani's installation apparatus in Hengyoro, onto which images from Takamine's family album are projected

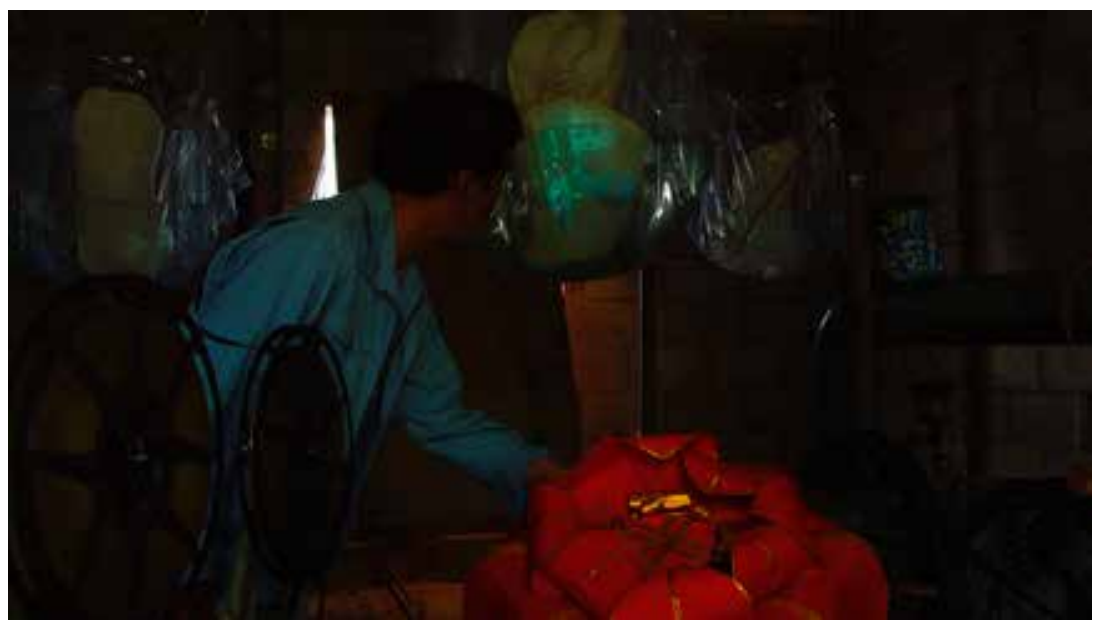

reappearing throughout Hengyoro, including those at the very beginning and at the end, when Tarugani and Papajō are seen rehearsing/playing their roles with makeup and costumes. Importantly, not only is the rensageki performance integral to the film narrative in Hengyoro, I would argue that the format/structure of rensageki itself is leveraged by the filmmaker to configure and channel the free flow of time-image. The film therefore becomes highly self-reflexive of its own use of hybrid cultural media and genres, especially with regard to the performativity of images and their intertextuality (see Takamine \& Tsurusaki 2017).

At the very beginning of the film, for instance, a male voiceover (probably Tarugani's) explains to the audience what is expected of a rensageki performance. What is simultaneously shown to us is the black-and-white film scene from Tarugani and Papajō's itinerant show, wherein the two good friends are seen playing their roles based on a well-known Okinawan folklore story about the mimichiri bōji (in uchinā guchi, literally translated as 'a monk whose ear is cut off'). The story is about an evil monk known as Kurukani zāshi, who, after his death due to his tragic defeat by Prince Chatan (a.k.a. Chatan ojji), has returned as a spectre to haunt the locals and especially the descendent of the prince, out of hatred. ${ }^{18}$ The rensageki in Hengyoro highlights the scene in which, during their confrontation

18 Across Okinawa, each local place may add a different twist to story of the mimichiri bōji (see 'mimichiri bōji'). 


\subsection{The projected images from the Takamine family album in Hengyoro}

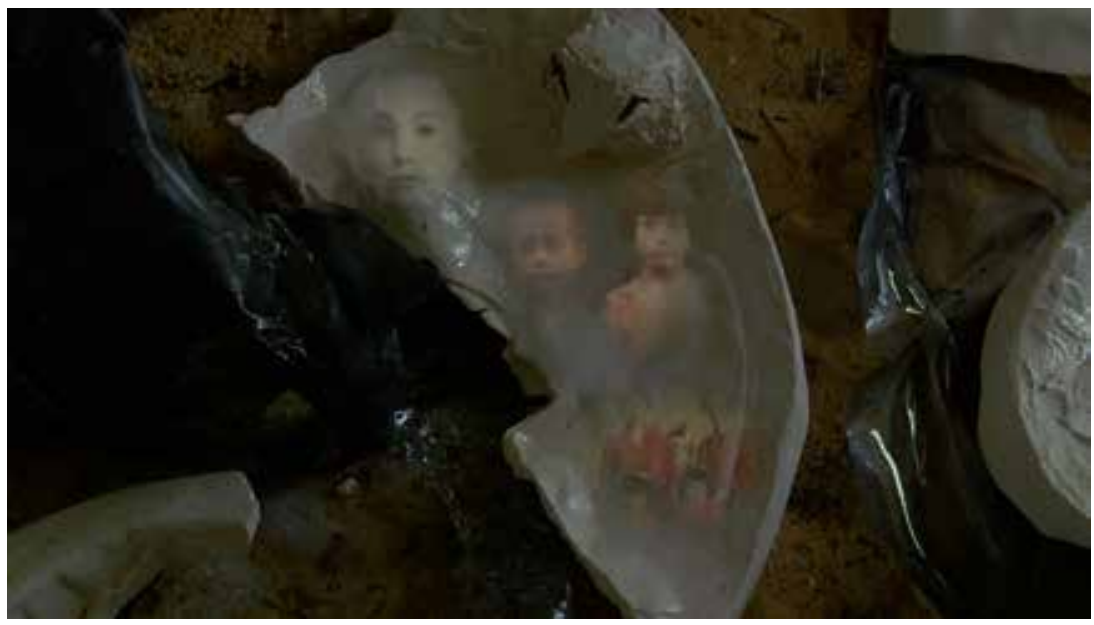

at a session of Go (Japanese chess), as the folktale has it, Kurukani zāshi, played by Papajō, has his ear cut off during a sudden attack by Chatan ōji, impersonated by Tarugani. Tarugani and Papajoj's rensageki programme and the story of mimichiri bōji have added one important layer onto the film's intertextuality, as the plot of 'ear-cutting' is further pursued if we consider the mission of the three bibiju ladies who are chasing after the two friends throughout the film.

Intriguingly, in the next sequence, Takamine shows how the rensageki is exhibited: together with several audiences of theirs, we see Tarugani and Papajo watching the film clips projected onto the wall in a rundown house, throughout which images of anonymous characters (including a cameo by Takamine himself) surprisingly pop up and superimpose upon each other. As part of the rensageki film scenes projected on the wall, for example, the black-and-white footage featuring a long-haired character impersonated by Okinawan rock musician Kawamitsu Katsuhiro (a.k.a. Katchan) is played. Audiences who are familiar with Takamine's cinematic oeuvre may find this particular footage of Katchan's uncannily nostalgic: it was originally from the 16-mm Okinawa Chirudai (1978) and has also been re-edited and used in other works by Takamine such as Paradise View (1985).

In the next shot, however, the audiences see how a digital, coloured sequence featuring the same character is suddenly superimposed upon the black-and-white one, wherein a long-haired, well-dressed yet conspicuously older Katchan, recognized later in Hengyoro also as a rock musician called 'Missiler' (Misairā), is observing the image of his 'younger self' projected in 
the background. Seemingly, 'Missiler' is trying hard to demonstrate what is presumed to be his signature performance of a 'train dance' to compete for more attention from the crowds. The opening suggests how the film is highly reflexive of its own mise-en-abime structure in operating with and channelling in between the different layers of diegesis and more crucially, in between the disparate layers of time-image. As such, Hengyoro has forcibly evidenced Patricia Pisters' observation of 'the contemporary image culture' wherein 'all images (actual and virtual) refer to other images (actual and virtual)' (Pisters 2010: 204).

In considering a new analytic of the image following the collapse of the sensory-motor situation, Deleuze envisions how time-image becomes 'stratigraphic':

In this sense, the archaeological or stratigraphic image is read at the same time as it is seen [...] Not in the sense that it used to be said; to perceive is to know, is to imagine, is to recall, but in the sense that reading is a function of the eye, a perception of perception, a perception which does not grasp perception without also grasping its reverse, imagination, memory, or knowledge (Deleuze 1989: 243).

The lensing of stratigraphic image, then, in foregrounding 'a free play between reality and imagination, memory and knowledge' (Pisters 2010: 210), helps to grasp Hengyoro's mode of expression, through which the boundaries between the real and the imaginary, original and copy, and subjective and objective are constantly defied, blurred, and redefined (see Rodowick 1997).

Crucially, if we return to Tarugani and Papajojs treatment, and specifically their quirky gadgets and procedures for 'surgeries', these have arguably turned out to be the technologies and apparatus of editing, remoulding, and collaging that are utilized to mediate the circulation between the virtual and the actual, to facilitate the operations on images as well as on time. Little wonder that film scholar Yomota Inuhiko considers Tarugani and Papajō to be like two therapists who have repeatedly shown in front of our eyes the forsaken and damaged images of Okinawa. For Yomota, both characters perform the operations not only to restore the deteriorated images (however anonymous and humble their origins are) but also to cure the people who are in possession of these images (Yomota 2017: 9), which I believe underlines at the same time the significance of Takamine's authorial intervention through/with Hengyoro.

Also, it is necessary to point out that the format of rensageki has laid a basis for and allowed for diverse narrative viewpoints and multiple voices (including 
singing voices) to interlace with each other and flow freely in between the disparate diegetic layers, illustrating how the stratigraphic structure also concerns the acoustic/the audible. Whereas Tarugani and Papajo take up their roles as a duo of storytellers who navigate the spectators both within and beyond their rensageki shows as narrators, other known or unknown narrators' voices whose gender and age remain unrevealed also participate and offer their monologues and perspectives in an indeterminate manner.

What corresponds with the stratigraphic images is 'stratigraphic reading', because to grasp the former 'requires a considerable effort of memory and imagination, in other words, a reading' (Deleuze 1989: 245; emphasis in original). What makes a work like Hengyoro highly political, I contend, is how it avoids designating any fixated ways of reading on the part of the spectators - because the audience is not interpellated in an apparatus working with the mechanisms of identification. As Rodowick has pointed out, "The spectator is no longer included in an expanding totality constructed by the narration, and thus must provide the relation himself or herself' because the relation between the spectator and the film becomes 'indeterminate' (Rodowick 1997: 150). We can argue that Okinawa can also be liberated from its own representations given how the audience is mobilized to read Okinawa in as many ways as possible, also with the help of 'memory and imagination'(ibid.).

\section{Art of Fabulation}

For Deleuze, according to Maimon, the situation wherein 'the people are missing' redefines the role of modern artists and filmmakers alike, whose task is no longer about how to represent the people as unified but to address a people 'who do not yet exist or whose existence is precisely what is at stake' (Maimon 2010: 86). This daunting yet liberating task is achieved through 'fabulation', namely narration or storytelling that leverages the 'power of the false'. By 'falsifying narration', as Deleuze believes, the real is not negated but strengthened and enriched, given how the fabulating power 'poses the simultaneity of incompossible (sic) presents, or the coexistence of not-necessarily true pasts' (Deleuze 1989: 131).

Deleuze further explicates that fabulation can be achieved through the speech act of 'double-becoming', wherein 'the author takes a step towards his characters, but the characters take a step towards the author' (ibid.: 222), and thus it becomes difficult to differentiate the auteur's speech from that of diverse characters/narrators, with the boundaries between both becoming 
ambiguous. Scrutinizing Deleuze's thesis in his Cinema books, Rodowick articulates that 'double-becoming' concerns how 'both the representer and the represented, the individual and the collective, are caught up in an indiscernible or undecidable relation where each stands in for the other as intercessor' (Rodowick 1997: 16o). Hence, double-becoming is to make visible and address the virtuality of a people before it becomes real and envisions it as 'collective without unifying' (ibid.: 154), which also brings us back to Deleuze and Guattari's discussions on the 'minor' examined in Chapter One. Throughout this process, importantly, the filmmaker 'does not give a voice to the people in the sense that he doesn't speak for them' but rather creates the space to allow the people to take the stage and speak (Frangville 2016:114; emphasis in original).

One could further argue that, within the context of Okinawan image works, the labour of fabulation not only disturbs or falsifies the linear and teleological time that underlines the dominant narration(s) of Japanese national identity or an Othered Okinawan identity. New subjectivities can also be introduced and envisioned when previously marginalized or repressed histories and identities are (re-)incorporated and (re-)examined in relation to the present, without being assimilated into and tamed by pedagogical time, as Bhabha defines it.

In Hengyoro, as with his earlier films, it is noteworthy that Takamine has cast a collective of Okinawa-based performers and artists, himself included, who are closely associated with the diverse repertoire of vernacular filmic, artistic materials and cultural genres deployed in the film. These are the transgenerational creators and successors of Okinawa's sound (such as folk singers Ōshiro Misako and Kadekaru Rinshō and rock musician Kawamitsu Katsuhiro), and performing art and image (veteran performers/actors Taira Susumu and Kitamura Saburō; photographer Ishikawa Ryūichi; and as a contemporary artist, Yamashiro Chikako works as the film's art designer).

Collaborating with these performers, musicians, and artists (some of whom have worked with him on several film projects), Takamine does not necessarily recruit them for their personal stories in real life as a neorealist filmmaker might prefer to do. Neither does he aim to celebrate any essentialist or elitist understanding of an 'authentic' Okinawan culture, although he has been fascinated with folk singers such as Kadekaru Rinshō and Ōshiro Misako and celebrated their art and life by shooting documentaries about them. ${ }^{19}$

19 Takamine also made musician-centred documentaries such as Kadekaru Rinshō:Uta to katari [Kadekaru Rinshō: Singing and Talking] (1994) as well as Okinawan Shimauta Queen: Ōshiro Misako (2007). Also, Kawamitsu was the main feature in Takamine's Wild Umaku: Okinawan Condition Green (1979). 
Instead, through a method of participatory improvisation and collage, as emphasized in his interview (Takamine \& Tsurusaki 2017), Takamine has recruited these artists to engage with the stratigraphic space so their bodies, performance, and affective labour (including the uchina guchi speaking ability of the older generations' artists) would interweave with Takamine's art of fabulation, complementing the latter while also modifying it with the incommensurable temporalities, memories, dreams, and imagination their artistic intervention evokes. For Takamine, what Hengyoro renders is not 'a personal story' nor 'an impersonal myth or an "ethnography" of the "authentic" people' (Maimon 2010: 90). It is a collective enunciation testifying Patricia Pisters' proposition that a political cinema 'does not represent reality, but instead operates as a performative speech act that plays a part in constructing reality'. Its power does not lie in whether the cinematic images have achieved 'accurate representation in or as reality' but rather in how it does 'something (if only to affect us and cause debate) to reality' (Pisters 2010: 208; emphasis in original).

I believe another perspective can be suggested to consider Takemine's art of fabulation. Jacques Rancière leverages the idea of 'the labour of fiction' as a way to engage 'the framing of the dissensus'. He illustrates that 'fiction' should not be understood simply as the construction of 'an imaginary world' nor as oppositional to the 'real'. Rather, for Rancière, 'fiction' comprises 'a way of changing existing modes of sensory presentations and forms of enunciation; of varying frames, scales and rhythms; and of building new relationships between reality and appearance, the individual and the collective' (Rancière 2010: 141). I propose that within a context discussing artistic intervention including that of cinema and visual art, the labour of fabulation can be also examined in terms of the framing of the dissensus, and its politics concerns how to modify and rearrange the mode of appearance regarding how the image works can be leveraged to 'make the invisible visible or to question the self-evidence of the visible; to rupture given relations between things and meanings and, inversely, to invent novel relationships between things and meanings that were previously unrelated' (ibid.).

The brief discussions regarding how the labour of fabulation interrelates with the labour of fiction also help to elucidate what I mean by 'appearance'. In light of Rancière's articulation of 'fiction', I also grasp 'appearance' as the framing of the dissensual: it is where the disruption of 'commonsense', namely a disagreement, may occur pertaining to how the boundaries between the visible and invisible may be drawn and redrawn in the fashion of a 'permanent guerrilla war', if we borrow Rancière's wording. As Vered Maimon proposes, 'To stage an appearance thus does not mean 
to reveal a "secret" through contradictions, but to make incompatible claims - rational and irrational - with regard to what is perceived to be communally shared'. Hence, an event of appearance involves how to 'delimit new realms of intelligibility and visibility in a way that moves beyond any "rational" notion of "common sense"' (Maimon 2009: 96). The framing of 'appearance' will also enlighten how we approach Yamashiro Chikako's video works.

\section{How to Remember the Battle of Okinawa?}

The creative momentum and trajectories of Takamine Gō and Yamashiro Chikako could be grasped by looking at the different socio-historical situations they have been engaging with and emplaced within. Whereas Takamine is usually considered part of the 'Okinawan diaspora' living away from the islands, Yamashiro still mainly bases her activities in Naha. She belongs to a younger generation that has been distanced from the memories of war as well as the 1972 reversion, the latter of which was repeatedly brought up in Takamine's earlier films, as I have mentioned previously. Whereas this study does not seek to highlight the transgenerational gaps between the two artists, it should be noted that Yamashiro's generation grew up witnessing how Okinawa has been transformed into the 'island that lives by the three Ks $(k a n k \bar{o}=$ tourism, kich $i=$ bases, and $k \bar{o} k y \bar{o} j i g y \bar{o}=$ public works' (Oguma 2014: 346), illustrating how Okinawa has been relying on subsidies from the Japanese government while negotiating with the continued presence of US military bases. On the other hand, on the artistic-cultural front, the early 199os not only saw a globalizing Japanese popular culture that was integral to Okinawa's urban imaginary, the era also witnessed how 'a downright Okinawa boom took hold of Japanese popular culture and mass media' (I. Hein 2010: 180). ${ }^{20}$

Analyzing how Harun Farocki works with archival footage that include memories of the Holocaust, Thomas Elsaesser explicates appropriation as 'the transfer of knowledge, cultural memory, images of symbols from one generation to another, or as the making one's own what once belonged to another' (Elsaesser 2009: 6o-61). Believing that 'it was impossible to understand any of the issues faced by Okinawa unless you understand

20 In a public talk at Kyoto Seika University on 19 July 2018, Yamashiro mentioned that in 1992, still a high school student then, she was so impressed by popular singer Miyazawa Kazufumi's 'Shimauta' (1992), that it awakened an early consciousness in her about Okinawa's 'own music'. 
the significance of the Battle of Okinawa in 1945' (Yamashiro, quoted in Yamashiro Chikako Artist File, 2017), Yamashiro has shown great interest in exploring how Okinawa's war memories and experiences could be passed down and shared not only transgenerationally but also translocally and transregionally. Her interventions through 'appropriation' arguably concern reinventing the ways of remembering, for which I mainly look at the forms of expression deployed in works such as Your Voice Came Out Through My Throat (Anata no koe wa watashino nodo wo tōtta, 2009; Your Voice hereafter), and MudMan (Tsuchi no hito, 2016).

One major incident that cannot be ignored when looking at the sociopolitical context of Your Voice is the controversial announcement in 2007 by the Ministry of Education that 'all references to military coercion in the compulsory mass suicides (shüdan jiketsu) of Okinawan residents during the Battle of Okinawa were to be eliminated' (Masaaki 2008:1). Yamashiro described how in 2008 she grasped an opportunity offered by the local media to start a workshop interviewing senior citizens at an Okinawan day care centre, where the artist came to realize that many of the ageing survivors of the Battle of Okinawa were 'unable to talk about the painful tragedies' (Yamashiro, quoted in Yamashiro Chikako Artist File, 2017; also see L. Hein \& Jennison 2011; Jennison 2017, 2014). Based on her interviews at the day care centre with a survivor who witnessed, at the age of nine, how his mother and sister committed suicide during the fierce battle at Saipan, Yamashiro created a 7-minute video, the last video work where she plays a role herself. ${ }^{21}$

In this video, we see that the artist in a white shirt is framed in a typical 'talking head' style against a white background. Looking away from the camera into the off-screen space, she tries to lip-sync the interviewee's traumatic memories. What the spectators hear is the testimony given by the survivor in his own voice, word by word, acted out by Yamashiro with a slightly perceptible delay. As she goes on, the lip-syncing becomes difficult. One sees how the artist is obviously getting more emotional and involved in her telling as the survivor himself starts to pause when describing how he saw his loved ones 'jumped off the cliff and killed themselves'. Here Yamashiro stops her lip-sync and becomes silent, trying hard to withhold her tears. In the next sequence, the camera seems to wander its own way around what seems to be an archive or library, where documents are piling

21 In Your Voice, the survivor himself is one of the Okinawan diasporas who migrated to Saipan during the early 1930 s to 1945, and therefore his experiences of the Battle of Saipan (1944) are also considered relevant to the memories of the Battle of Okinawa (see Jennison 2017: 172). 
5.6 The image of the survivor's face is projected onto Yamashiro's face in Your Voice Came Out Through My Throat

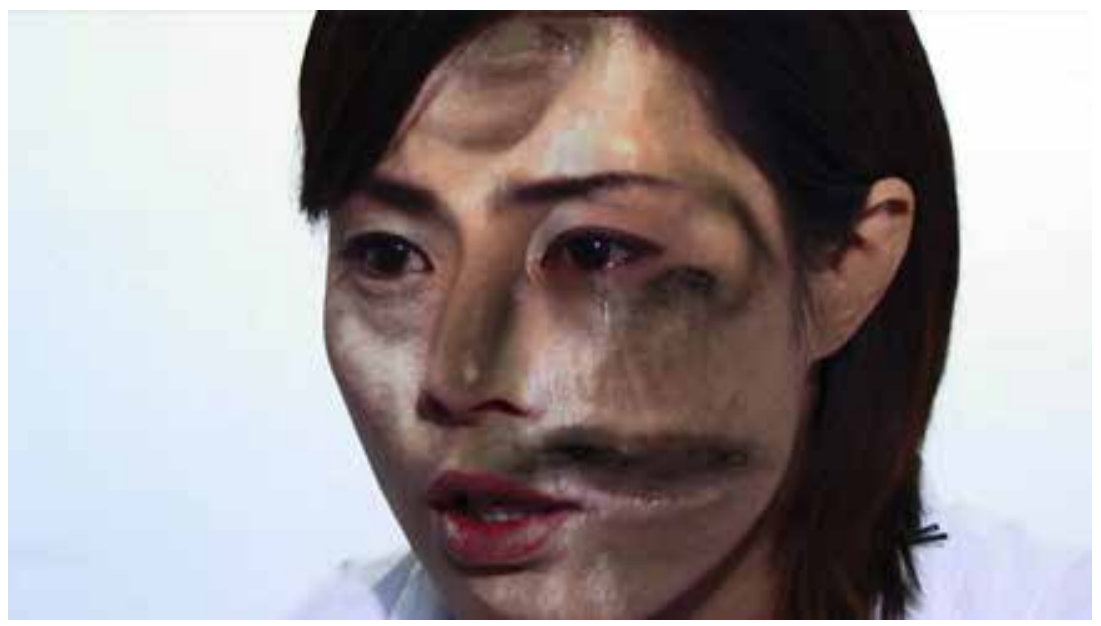

up. Then, the camera returns to Yamashiro's lip-sync. As the interviewee's 'talking head' projected onto the artist's face, she is finally speaking in her own voice.

Working on Your Voice, Yamashiro admitted, 'To a certain extent, I was able to empathize with the stories they narrated, but in the course of the interviews, there were definite moments when I felt that it was impossible for me to share their experiences' (Yamashiro, quoted in Yamashiro Chikako Artist File, 2017). I contend that the artist has illustrated the potentiality and dilemma involved in the work of appropriation through her performance, via her own voice and body. A crucial aspect underlying Yamashiro's gesture of appropriation starts from 'a position of not knowing' (Elsaesser 2009: 74), which is not to say that she is ignorant about history but rather concerns 'a process of reflexive identification and self-implications' (ibid.: 61) regarding how the artist uses performance as a methodology of remembering or at least to demonstrate how to learn to remember.

Specifically, in projecting the witness's face upon her own, which is strikingly reminiscent of Papajō's face-swapping surgeries, Yamashiro is struggling to get access to things that 'could not be put into words' or 'could not be talked about' for her interviewee(s), without pretending that she could relate to them by simply listening and interviewing. Hence the point of the artist's lip-sync is not about how perfectly the performance could be in 'matching' the gesture with contents (a heart-wrenching personal 
narrative about the war memories) but is precisely about making visible and audible the incommensualities between the virtuality of history and memory and the actuality/presence of the survivor. Hence, it is little wonder that the survivor/witness himself indeed remains 'absent' from the video: when the audience of the video work hears him, they cannot see him (only to see Yamashiro doing the lip-sync), and when they do see him (with the projected image), they cannot hear him (as Yamashiro uses her own voice to repeat his testimony).

Analyzing how Chris Marker's Level Five (1997) confronts the gap between the survivors in Okinawa and 'those who learn about it afterwards', Catherine Lupton indicates that 'this acknowledgement of historical distance between past and present registers a contemporary shift in cultural perceptions of World War Two at a moment when the fragile burden of remembrance is palpably shifting from survivors to public museums, archives, recordings, and broadcasts' (Lupton 2003: 59). Yamashiro's video somehow argues for a different perspective to grasp the shift toward musealization and memorialization apropos of the Battle of Okinawa. The seemingly abrupt sequence of archives in Your Voice therefore also has the effect of questioning the very limitations of musealization, which may risk knowing the war from the too-well-narrated, neatly preserved tropes that invite its very forgetting.

Using her body as a surface to mediate the unspeakable trauma, Yamashiro makes her role interchangeably connected to that of a viewer's, a position that no matter how emotionally engaged is still distanced from the memories/past experiences of the survivor(s). Her performance, then, in dynamizing and staging the process of appropriation, is about the split roles of the 'self/selves' that registers the perpetual, fluid position/role-shifting in between that of an enunciating subject and that of an embodied spectator, between not-knowing and knowing, moving in between the past, the present, and the future. It is also through such uncertainties and suspension of any fixed positions that the positioning of the spectators of this video is implicated and challenged.

\section{Secrets of Time}

Yamashiro's 2016 video work, Mud Man, is a more ambitious attempt to experiment with the narrative form. The work has usually been exhibited as a three-channel screen installation at museums/galleries, but here I mainly look at its 26 -minute theatrical version. The video sketches a group 
of 'mud men and women'22 who have discovered in the droppings of birds from faraway places the seeds of poems, through which they learn about the stories from 'other people who also lived similarly in a place they cannot see and in the past' (Yamashiro, quoted in Yamashiro Chikako Artist File, 2017). Arguably, Jeju Island in South Korea was chosen as one of the major filming locations because people on the scenic island have also been protesting against the construction of Korea's military base that is designed to play a vital role in the US's regional deployment. Also, Jeju is similarly haunted by 'the long-suppressed national trauma inflicted by the post-WWII authoritarian state' (Lee 2015: Kindle Locations 4281-4282), namely the Jeju Uprising in 1948, during and immediately after which many innocent islanders were massacred.

As evidenced by Your Voice, Yamashiro's works emphasize the use of sound and voice. Whereas MudMan starts with the quotes from Takahashi Yüji's poetry, recited by unknown narrators, what accompanies the images throughout the work are almost-indiscernible murmuring voices in Japanese (and uchina guchi) and Korean (Jeju dialect), the meaning of which is difficult to pin down.

Following the sequences wherein the mud men/women are seen circulating the seeds of poems and whispering the messages to each other, they fall into a deep tunnel and find themselves re-emerging from a ditch in darkness. ${ }^{23}$ However, their surroundings are unexpectedly turned into a virtual/theatrical battlefield, the visual effect of which is enhanced with the

22 I was reminded that Yamashiro might have gotten her inspiration from the traditional folk ritual known as Pāntū of the Shimajiri district of Miyako Island, one of the Okinawan outlying islands. It is said that during the ritual, three visiting gods (Pānt $\bar{u})$ covered in mud would roam around the town, splashing mud on people, houses, and cars to help banish evil spirits.

23 The imaginary of the cave/tunnel in MudMan is impressive, which can be further historicized, although I cannot offer a more detailed analysis here. It is well known that the Jeju Uprising consisted of a series of armed uprisings and counterinsurgency actions that occurred between 1947 and 1954 in Jeju Province, when Korea was under US-backed military rule. As Hun Joon Kim points out, 'The counterinsurgency strategy was extremely brutal, involving mass arrests and detentions, forced relocations, torture, indiscriminate killings, and many large-scale massacres of civilians' (Kim 2012: 727). In his debut film, an independently produced feature entitled Jiseul, which was shot on location mainly with the locals, Jeju filmmaker O Meul was inspired by one particular story about 'a group of villagers [...] who fled into hiding in a huge mid-mountain lava tube cave only to be discovered by troops and executed in December of 1948' (Lee 2015: Kindle Locations 4286-4287). In Okinawa, some 'gama' (the term for natural caves in uchinā-guchi) were historical sites where Okinawan civilians committed mass suicide during the Battle of Okinawa. For instance, relics such as the Himeyuri Cave, part of today's Himeyuri Memorial Tower (est. 1946), have become important sites for the memorialization and musealization of the Battle. 
5.7 The mud men and women, trapped in the tunnel, are showered in the light and sound of the moving images of the Battle of Okinawa

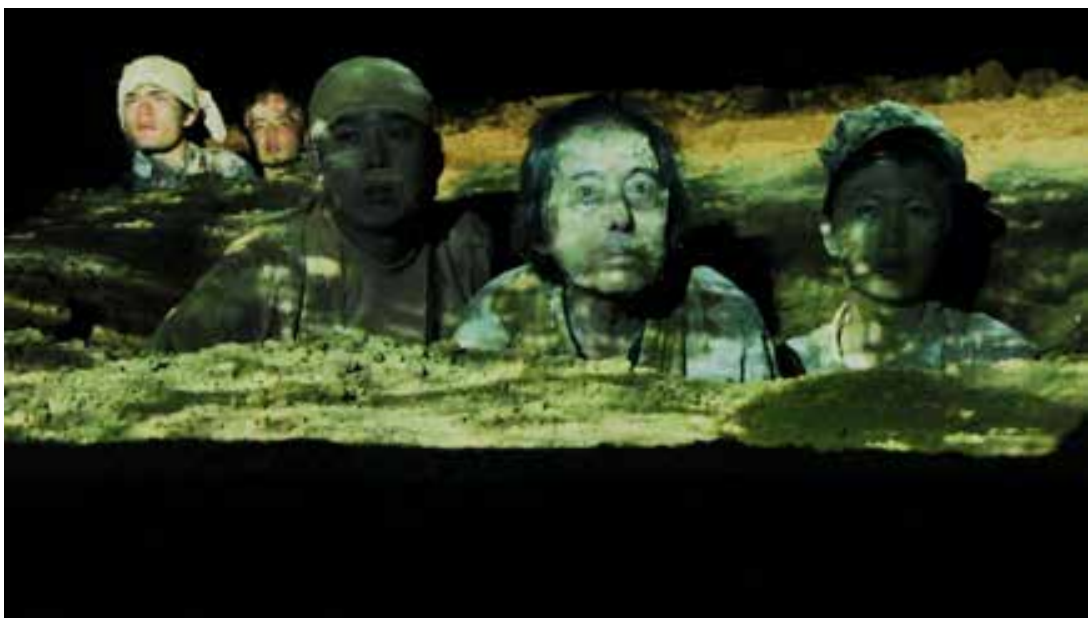

light and smoke created by fireworks (added onto which are the digitized stage effects of lighting and shadow). What the audience sees on the screen are anonymous villager-looking soldiers who have shown up from nowhere, crawling forward. Their presence also shocks the mud men/women, who are observing them while being entrapped in the tunnel.

Seemingly placed within a dispositif similar to the apparatus of a movie theatre, the mud men/women have been turned into a group of entrapped spectators. What they see then, as is directly shown to the video's audience, is the fast-edited montage sequence composed of archival footage of the Battle of Okinawa projected in front of them, each capturing one specific yet similarly framed historical moment of the Battle, with battleships firing, an aeroplane crashing, and the landscape being scorched. ${ }^{24}$ The rhythmed sound effect accompanying the montage compilation - including the sound of bombing and gunfire - is done through human beatbox, a technique often used in hip hop music to mimic various sound effects.

With their faces bathed in the reflected light from the montage sequence projected in front of/onto them, the mud men/women appear mesmerized if not shocked by their close encounter with the secrets of time, which were supposedly sealed in the seeds of poems carried by the birds from far away. As Wang Ban illuminates, though in a different context addressing

24 Yamashiro has used around ten segments of archival footages, most of which were shot by the filming crew of the US (such as clips in the Naval Photographic Center collection). 


\subsection{The field of himeyuri toward the end of Mud Man}

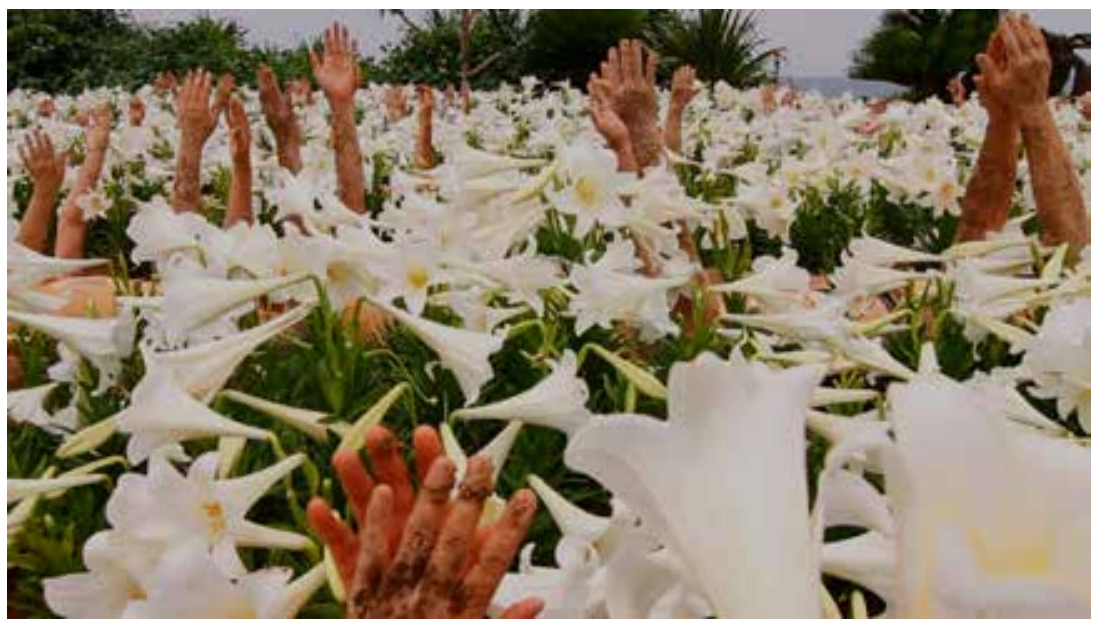

the use of montage in modern Chinese cinema, 'The broken mirror that montage holds up to history is a veritable experience of flux, fragmentation, destruction, and reconstruction, a history going to pieces, broken to its foundation with catastrophe, war, and revolution' (Wang 2004: 87). As part of his critique of modernity, Wang therefore suggests that it is impossible to ignore how the spectators engage montage through their visceral, sensorial responses, partially in disorientation but also as something transformative (ibid.). Here I focus on the dispositif of showing and viewing and argue how it becomes a vital aspect of Mud Man. The production of meaning regarding the montage, however, is less about Sergei Eisenstein's pedagogy in indoctrinating the spectators to produce a third image retrospectively based upon the juxtaposition of the two; rather it is contingent upon the tension between the cinematic dispositif within the video work, which highlights the conditions of the spectators-cum-mud men/women, and a different layer of screen dispositif that emphasizes the position of us the audience vis-à-vis the video work.

It is therefore possible to realize how, when they are trapped in the tunnel/ cave, the mud men/women are positioned not only within a dispositif of vision but also one of affect, which operates on and circulates in between the stratigraphic layers of image and sound, simultaneously interconnecting with Okinawa's historical memories of war and trauma (in particular, the memories of mass suicide associated with the cave/gama) and its precarious present of various struggles. Toward the end, as the mud men/women emerge from the underground and the darkness, what they and the audience see 
and experience are sequences of contemporary images assembled from heterogenous sources, including that of Okinawa's American military base, a kamikaze suicide plane, an unknown surveillance tower, and, importantly, scenes of protest against the Japan Coast Guard captured from the perspective of sit-in protestors, reminiscent of Mikami Chie's We Shall Overcome. A new flow of affectivity is created by the fast-edited sequence that reaches its apex with the uplifting clapping of hands rising high up from the extensive fields of white lilies, namely, the himeyuri.

Through this nameless collective of mud men/women, whose identity remains ambiguous, Yamashiro is also able to move beyond the local experiences of either Jeju or Okinawa and to situate both experiences within a translocal, transnational socio-historical context in suggesting how an inter-Asia collective is to 'become' by configuring itself upon the circulation and intersection of transregional memories and affectivities. It is exactly through these operations, I would contend, that Okinawa's 'new politics of images' has been experimented with and achieved.

\section{Works Cited}

Angst, L. (1997). 'Gendered Nationalism: The Himeyuri Story and Okinawan Identity in Postwar Japan', PoLAR: Political and Legal Anthropology Review, 20/1: 100-113. DOI: 10.1525/ pol.1997.20.1.100.

Arasaki, M. (2014). 'Can Okinawa be the "Catalyst” for peace in East Asia?', Inter-Asia Cultural Studies, 15/1: 43-62. DOI: 10.1080/14649373.2014.88804.

Bhabha, H. (2004). The Location of Culture., 2nd ed. London; New York: Routledge.

Deleuze, G. (1989). Cinema 2: The Time-Image. (H. Tomlinson and R. Galeta, transl.). Minneapolis: University of Minnesota Press. DOI: 9781472512604 .

Dietz, K. (2016). 'Transnationalism and Transition in the Ryūkyūs'. In Iacobelli P., Leary D., and Takahashi S. (eds.), Transnational Japan as History: Empire, Migration, and Social Movements, pp. 211-241. New York: Palgrave Macmillan US.

Doak, K.M. (2007). A History of Nationalism in Modern Japan: Placing the People. Leiden; Boston: Brill.

Elsaesser, T. (2009). 'Holocaust Memory as the Epistemolog of Forgetting?: Re-wind and Postponement in Respite'. In Ehmann A. and Eshun K. (eds.), Harun Farocki, Against What? Against Whom?, pp. 57-68. London: Koenig Books.

Frangville, V. (2016). 'Pema Tseden's The Search: the Making of a Minor Cinema', Journal of Chinese Cinemas, 10/2: 106-120.

Furuhata, Y. (2013). Cinema of Actuality:Japanese Avant-Garde Filmmaking in the Season of Image Politics. Durham: Duke University Press.

Gerow, A. (2003). 'From the National Gaze to Multiple Gazes: Representations of Okinawa in Recent Japanese Cinema'. In Hein L. and Selden M. (eds.), Okinawan Responses to Japanese and American Power, pp. 273-303. Lanham, MD: Rowman \& Littlefield Publishers.

- (2017). 'Yamagata International Documentary Film Festival 2017'. Tangemania. Retrieved 12 December 2018 from <http://www.aarongerow.com/news/yamagata-international.html>. 
Gordon, A. (2003). A Modern History ofJapan: From Tokugawa Times to the Present. New York: Oxford University Press. DOI: 10.2307/20033555.

Gushiken, K. (2017). 'Beigun kichi mondai to masukomi hōdō' [The US Base Problem and Mass Media Report], Masu komyunikeishon kenkyu [Journal of Mass Communication Studies], 91: 3-21. DOI: https://doi.org/10.2446o/mscom.91.o_3.

Hein, I. (2010). 'Constructing Difference in Japan: Literary Counter-images of the Okinawa Boom', Contemporary Japan, 22/1-2: 179-204. DOI: 10.1515/cj.2010.011.

Hein, L., and Jennison, R. (2011). 'Against Forgetting: Three Generations of Artists in Japan in Dialogue about the Legacies of World War II', The Asia-Pacific Journal |Japan Focus, 9/30: 1-18. Inoue, M.S. (2012). Okinawa and the U.S. Military Identity Making in the Age of Globalization. New York: Columbia University Press.

'Japanese Expanded Cinema Revisited' (2017). Tokyo: Tokyo Photographic Art Museum; Tokyo Metropolitan Foundation for History and Culture.

Jennison, R. (2014). 'Unspeakable Bodies of Memory: Performance and Precarity in Recent Works by Yamashiro Chikako', Journal of Kyoto Seika University, 44: 181-200.

- (2017). 'Reimagining Islands: Notes on Selected Works by Oh Haji, Soni Kum, and Yamashiro Chikako', Asian Diasporic Visual Cultures and the Americas, 3/1-2: 155-177. DOI: $10.1163 / 23523085^{-00302008 . ~}$

Johnston, E. (2019). 'More than $70 \%$ in Okinawa vote no to relocation of U.S. Futenma base to Henoko'. The Japan Times. Retrieved 1 March 2019 from <https://www.japantimes.co.jp/ news/2019/02/24/national/politics-diplomacy/okinawa-residents-head-polls-referendumrelocation-u-s-futenma-base-henoko/\#.XOZHatMzaPc>.

Ko, M. (2006). 'Takamine Go: A Possible Okinawan Cinema', Inter-Asia Cultural Studies, 7/1: 156-17o. DOI: 10.1080/14649370500463844.

- (2010).Japanese Cinema and Otherness: Nationalism, Multiculturalism and the Problem of Japanesenesss. London; New York: Routledge. DOI: 10.4324/9780203866719.

Kokuritsu kokugo kenkyūsho (ed.) (1963). Okinawagojiten [Dictionary of Okinawan Language]. Tokyo: Ōkurashō Insatsu Kyoku.

Lee, S. (2015). 'Cinema as Ritual Space: O Muel's Jiseul'. In Chee L. and Lim E. (eds.), Asian Cinema and the Use of Space: Interdisciplinary Perspectives, Kindle edition. New York: Routledge.

Maimon, V. (2009). 'The Third Citizen: On Models of Criticality in Contemporary Artistic Practices', October, 129/2009: 85-112. DOI: 10.1162/octo.2009.129.1.85.

- (2010). 'Towards a New Image of Politics: Chris Marker's Staring Back', Oxford Art Journal, 33/1: 83-101.

Martin-Jones, D. (2006). Deleuze, Cinema and National Identity: Narrative Time in National Contexts. Edinburgh: Edinburgh University Press. DOI: 10.1093/screen/hjmoo8.

- (2011). Deleuze and World Cinemas. London; New York: Continuum International Publishing Group. DOI: $10.1080 / 17400309.2012 .714973$.

Masaaki, A. (2008). 'Compulsory Mass Suicide, the Battle of Okinawa, and Japan's Textbook Controversy', The Asia-Pacific Journal, 6/1:1-13.

'Mimichiri bōji' (2002). Kaii yōkai denshō dētabēsu [Database for the mysterious and yōkai]. Retrieved 10 March 2019 from <http://www.nichibun.ac.jp/YoukaiCard/o380oo1.shtml>.

Nakazato, I. (2007). Okinawa, imeji no edge [Okinawa, the Edge of Image]. Tokyo: Miraisha.

- (2017). 'Dareno mono demonai okinawa toiu raiyā karini raiku a rōringumūbī to nazukete' [The Layer that Okinawa Belongs to Nobody is Temporarily Named 'Like a Rolling Movie']. Cinematrix (ed.), Pamphlet of Hengyoro. Tokyo: Cinematrix.

Nishimura, T., and Nishikawa, T. (2015). 'Film Independents and Japanese Underground Cinema - An Interview with Tomohiro Nishimura', Millennium Film Journal, 61: 30-37. 
Oguma, E. (2014). The Boundaries of 'the Japanese'. Volume 1: Okinawa-Inclusion and Exclusion. (L. R. Stickland, transl.). Melbourne: Trans Pacific Press.

Pisters, P. (2010). 'Violence and Laughter: Paradoxes of Nomadic Thought in Postcolonial Cinema'. In Bignall S. and Patton P. (eds.), Deleuze and the Postcolonial, pp. 201-219. Edinburgh: Edinburgh University Press.

Rancière, J. (2010). Dissensus: On Politics and Aesthetics. (S. Corcoran, transl.). London; New York: Continuum International Publishing Group. DOI: 10.1007/s13398-014-0173-7.2.

Richie, D. (2005). A Hundred Years ofJapanese Film: A Concise History., revised version. Tokyo; New York; London: Kodansha International.

Rodowick, D.N. (1997). Gilles Deleuze's Time Machine. Durham; London: Duke University Press. DOI: 10.1353/sub.2000.0010.

Suzuki, K. (2008). 'Ranhansha suru Okinawa' [The diffused reflection of Okinawa]. Okinawa Purizumu 1872-20o8[Okinawa Prismed 1872-20o8], pp. 138-145. Tokyo: The National Museum of Contemporary Art.

Takamine, G., and Nakazato, I. (2003). 'Nippon no dokyumentarī sakka intabyū No. 2o: Takamine Gō' [Interview with Japanese Documentary Autuers]. Documentary Box \#22. Retrieved 13 January 2019 from <https://www.yidff.jp/docbox/22/box22-1-1.html>.

Takamine, G., and Tsurusaki, A. (2017). 'Hengyoro Takamine Go kantoku intabyū' [Interview with the Director of Hengyoro]. QUOTATION magazine.jp. Retrieved 20 August 2018 from $<$ http://quotationmagazine.jp/column/post-15967>.

Takamine, G., and Yomota, I. (2017). 'Intabyū: Hengyoro' [Hengyoro: An Interview], Kinema Junpō, 1738: 70-75.

Takamine Gō eiga koten jikkō innkai [Executive Committee of Takamine Gō’s Film Exhibition] (ed.) (1992). Dakara yo v chirudai nu ashibi okinawan dorīmu shō Takamine Gō Eiga Koten [Indeed! Playful Lethargy: Okinawan Dream Show, A Solo Film Exhibition by Takamine Gō]. Naha: Takamine Gō eiga koten jikkō innkai [Executive Committee of Takamine Gō's Film Exhibition].

Takamine, T., Nagamoto, T., Wakabayashi, C., and Nakazato, I. (2018). 'Fukigo Okinawawo megutte' [Canvassing the Post-Reversion Okinawa], Ekkyo Hiroba, 5: 6-34.

Toguchi, M. (1992). 'Okinawan Dream Show'. Executive Committee (ed.), Dakarayo 、 chirudai nu ashibi okinawan dorīmu shō Takamine Gō Eiga Koten[Indeed! Playful Lethargy: Okinawan Dream Show, A Solo Film Exhibition by Takamine Gō]. Naha: Takamine Gō eiga koten jikkō innkai [Executive Committee of Takamine Gō's Film Exhibition].

Wang, B. (2004). Illuminations from the Past: Trauma, Memory, and History in Modern China. Stanford, CA: Stanford University Press.

webDICE (2017). 'Kono eiga wo kiruto Okinawa no haīronochi ga nagareru - Takamine Gō kantoku jūhachi nen burino gekieiga "hengyoro" wo kataru' [If you cut open this film there oozes the grey blood of Okinawa - fimmaker Takamine Gō talks about his coming back feature film Hengyoro]. webDICE. Retrieved 11 January 2019 from <http://www.webdice.jp/ dice/detail/5339/>.

Yamashiro, C., Nahata, F., and Abenoki, T. (2017). 'An Interview with Yamashiro Chikako: Searching for a Way to Survive'. (K. Simpson, transl.)Yamagata International Film Festival 2017. Retrieved 11 January 2019 from <https://www.yidff.jp/interviews/2017/17io5o-e.html>.

'Yamashiro Chikako Artist File'. (2017). Tokyo: Yumiko Chiba Associates.

Yomota, I. (2017). 'Eizō wo irabūjiru ni tsukekomu - Takamine Gō “Hengyoro” ni tsuite' [To Preserve Images with Sea Snake Soup - Regarding Takamine Gō's Hengyoro]. Pamphlet of Hengyoro. Tokyo: Cinematrix. 



\title{
6 Homecoming Myanmar
}

\author{
Midi Z's Migration Machine and a Cinema of Precarity ${ }^{1}$
}

\begin{abstract}
This chapter highlights Taipei-based, Chinese-Burmese filmmaker Midi $\mathrm{Z}$, whose 'homecoming' oeuvre includes three fictional films and two documentaries shot at Myanmar's most (in)famous high-quality jade deposit, Hpakant in northern Myanmar. Reframing precarity from the theoretical framings in sociology and biopolitical theories, I first argue that Midi has explored how the disenfranchised diasporic Chinese subjects gamble on gaining access to other possibilities in life. My focus then shifts to City ofJade (Feicui zhicheng, 2016). Leveraging the notion of 'risk-taking' at both the textual and inter-textual levels, with an emphasis on the gendered perspective, I survey how Midi has leveraged a personal, subjective point of view to interweave the struggles of the Zhao family (particularly his brother's) with those of the male labourers on location.
\end{abstract}

Keywords: Chinese diaspora, precariousness, frame, family portrait, risk-taking

\section{Points of Departure}

The border-crossing oeuvre of Taipei-based auteur Midi Z (Zhao Deyin, hereafter referred to as Midi; in Yunnanese, midi means small; Midi is

1 All Chinese to English translations are mine unless otherwise indicated. The title of 'Homecoming Myanmar' is also inspired by an eponymous Midi Z retrospective programme, presumably the 'first US survey' of Midi's film oeuvre taking place in New York in March 2015, curated by the Asia Society ('Homecoming Myanmar: A Midi Z Retrospective'). I am also grateful to the Film Academy of Hong Kong Baptist University, which gave me the chance to present a draft of this chapter at an international conference titled 'Documentary Film: Regional, Theoretical \& Political Parameters' (25-27 June 2018).

Ma, Ran, Independent Filmmaking across Borders in Contemporary Asia. Amsterdam, Amsterdam University Press 2020 DOI: $10.5117 / 9789462986640 \_$CHo6 
the youngest child of his family), particularly his 'Homecoming Trilogy' (Guixiang sanbuqu, hereafter the Trilogy), consisting of three digital features inspired by the filmmaker's own transborder experience between Myanmar, Thailand, and Taiwan, provides fascinating case studies of the translocal, transnational dynamics of Sinophone diasporic cinema from Asia. Born and having grown up in an ethnic Chinese community in the northern Myanmar city of Lashio in Shan state, Midi won a chance to study in Taipei at the age of 16 and has stayed there ever since. He had already obtained Taiwanese citizenship by the time he finished his debut feature film Return to Burma (Gulai de ren) in 2011, the inaugural work of his Trilogy.

I shall argue that the generalizing denomination of 'Chinese-Burmese' or 'Burmese-Taiwanese' only captures one façade of Midi Z's identity, which risks eclipsing the migratory trajectories that have been historically shaped and interrupted by regional geopolitics from World War II to the present, which is integral to approaching and contextualizing the filmmaker's diasporic subjectivity and cinematic imaginaries. ${ }^{2}$ Before I proceed further, it is necessary to stress how, in foregrounding Midi Z's creative trajectory in relation to his diasporic identity and subjectivity, the critical framing of 'Sinophone' should not be leveraged to simply overwrite or exclude the perspectives and articulations that are 'Chinese' - a point that has been partly elucidated in my survey of Chinese-in-Japan filmmaker Li Ying and his early documentaries (see Chapter Four). In his inspirational take, E.K. Tan leverages Sinophone to provoke a rethinking of Chinese diaspora studies. Instead of rejecting the concept of diaspora as such, he proposes that 'Chineseness' can be foregrounded as the potential ground for meaning-production instead of 'a mere organizational principle', and one can therefore grasp and retool diaspora in terms of a dynamic negotiation that (re-)configures new subjectivities within what Shu-mei Shih describes as 'the multiangulated and multiaxiological contexts of the local, the global, the national, the transnational, and above all, the place

2 Zhao Deyin's grandparents migrated from Nanjing, the then capital of Republican China, to the southwestern province of Yunnan, the inland frontier, for the construction of the legendary Burma Road (dianmian gonglu) in the late 1930s. It was not until the turmoil of Chinese civil war (1945-1949) that the family fled to Myanmar. Although not a graduate of film school, Midi started Digital Video productions since his college years. When he was one of the shortlisted talents at the inaugural Golden Horse Film Academy in 2009, mentors like Hou Hsiao-Hsien and Ang Lee advised him to discover stories related to his most intimate feelings, which inspired Midi to interweave into his works both personal and collective experiences associated with the diasporic Chinese communities in border towns like Lashio (Zhao et al. 2015; also see Lim 2018). 
of settlement and everyday practice' (Shih 2007: 31). More importantly, Tan encourages us to reconsider Sinophone's disavowal of China and (continental) Chinese culture. As he explicates, 'Sinophone theory - while focusing on the local contexts of its global communities - cannot imagine a network of relations without including a certain rethinking of China as a part of its relations', and Sinophone's 'dialogue with the national, be it China or the settler societies, cannot be overlooked, even in a postnational, deessentialized, non-China-centric discourse' (Tan 2013: 36). Tan has thus proposed a 'Sinophonization paradigm' under which Sinophone is viewed as 'a succeeding stage to reinvent Chinese culture with respect to the time and space of distinct Sinophone communities and their network of relations' (ibid.: 37).

With the critical emphasis on Sinophone clarified, in this study I also use the concept of diaspora to consider how 'Chineseness' may possibly constitute the ground for meaning-production while dialoguing with Chinese diaspora studies that intersect interrelated fields such as sociology, geography, and anthropology (see Ong 1999; Ong \& Nonini 1997). Specifically, here I look at Sinophone diasporic subjectivity as an assemblage of multifarious, heterogenous articulations negotiating the Chinese diaspora's experiences of movement, displacement, and (re)settlement that are situated within specific socio-historical circumstances and geopolitical trajectories. It is crucial to point out how these articulations in ungrounding 'the notion of Chineseness as a centre for cultural and social ties' underline Melissa Chan's conceptualization of 'Sinophone-Burmeseness' in her survey of Midi's 'Burma trilogy' (namely the 'Homecoming Trilogy') (Chan 2017:13-14).

Following his acclaimed Trilogy, Midi produced two documentaries under the sponsorship of Taiwan Public Television Service (Taiwan gonggong dianshi),Jade Miners (Wayushi deren, 2015) and City ofJade (Feicui zhicheng, 2016), both of which were shot roughly during the similar period of time in the town of Hpakant in Kachin State in northern Myanmar, which is known as the 'Jade City' for its high-quality jade deposits. The shooting of both works coincided with Midi's reunion with his brother Zhao De-Chin (the eldest among the five siblings of the Zhao family) back in Myanmar in 2012; prior to this De-Chin had not seen his family for 16 years.Jade Miners is shot in an observational style that also distinguishes Midi's fictional trilogy, wherein Midi patiently chronicles the daily routines and chores of jade labourers at the over-exploited mining pits. In this austere work, a crew of Burmese miners (who were actually hired by De-Chin as his workers, the affiliation of which remains unclarified in Jade Miners and was only to be illuminated in City ofJade) are seen trapped in their life cycle of seemingly 


\subsection{Hpakant's barren landscape of mining pits dotted with almost unrecognizable human figures}

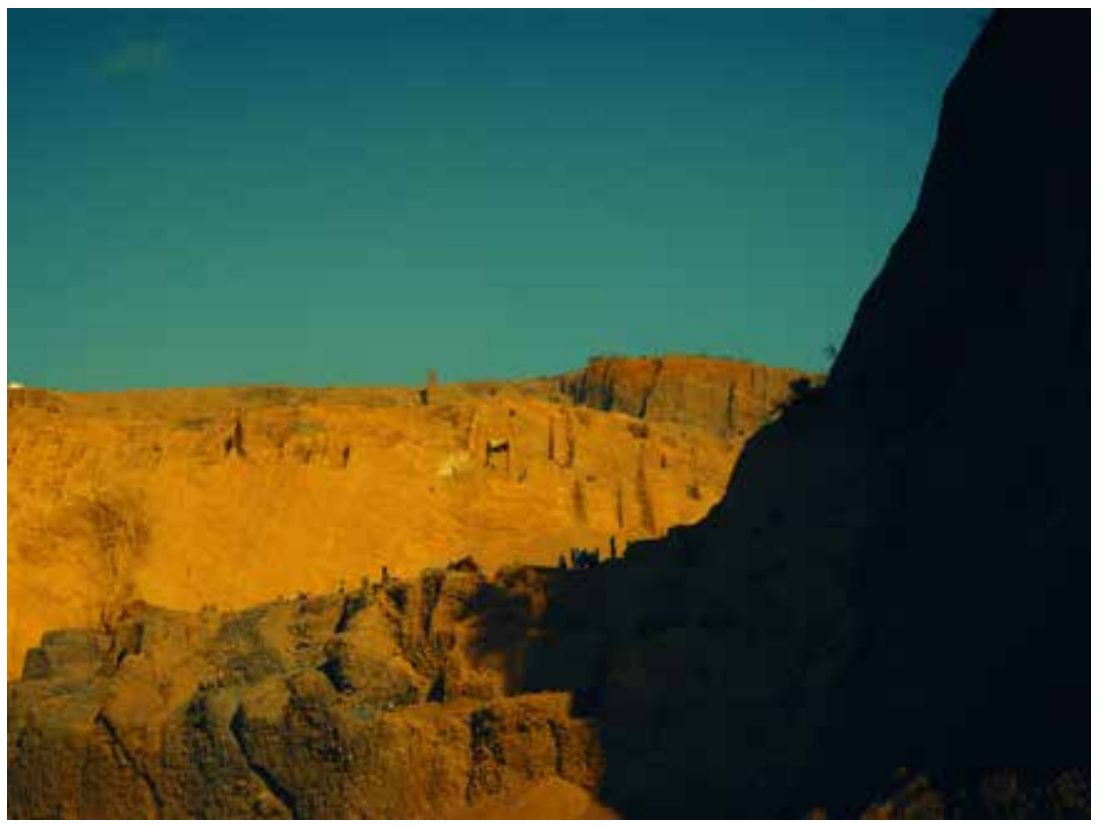

endless, repetitive hard manual labour, the stress and void of which could hardly be alleviated by their occasional breaks and time for leisure.

Narrated by the filmmaker himself in Yunnanese dialect, City of Jade nevertheless stands out as a first-person documentary. Here Midi has proffered a confessional, intimate perspective looking back on the Zhaos' humble family history since his childhood, which is interlaced with his parents' as well as his siblings' desperate yet persistent struggle for survival and for a better life.

Leveraging the inter-related theoretical framings on precarity, this chapter draws on Midi's 'homecoming' films, and in particular his two Hpakant documentaries, to consider a 'cinema of precarity' and its politics. Specifically, I emphasize how Midi's homecoming projects foreground the precarious condition of diasporic Chinese subjects whose migratory movement (internally within the society of settlement and externally) is characterized by the wild, dangerous, and unpredictable strategies of 'Chinese transnationalism' (see Ong \& Nonini 1997) and intersects with the translocal informal economic networks in contemporary East and Southeast Asia. Importantly, I would contend that Midi also leverages the struggles of Chinese-Burmese communities as a critical angle to examine 
and critique the very teleological narrative about Myanmar's contemporary transformations toward democracy and development as well as its presumed integration into the global socio-economic system since 2011, the year in which economic and political reforms were introduced by the militarybacked government.

Furthermore, in my analysis of Midi's Hpakant documentaries, a gendered perspective will be used to highlight how the vagrant trajectory of the eldest brother, De-Chin, also becomes symptomatic of the precarious masculinity of the multi-ethnic Burmese jade miners, who pursue their ambitions by performing male mobility and physical prowess. Such a vantage point interconnects with Midi's own 'affective-authorial risk-taking' throughout his border-crossing filmmaking (Trice 2017; also see Hjort 2013; Naficy 2013) and sheds light on how we can rethink inter-Asia translocal independent cinema as a whole.

\section{Reframing Precarity}

This chapter approaches precarity from two broadly interrelated perspectives. To start with, Guy Standing has utilized 'precariat' - a neologism combining 'precarious' with 'proletariat' - to refer to 'a new dangerous class', or a 'class-in-the-making' to be more exact (Standing 2011: 7), consisting of a workforce that has experienced a process of precariatization and deprivation symptomatic of neoliberal globalization's new norm of 'contingent employment, social risk and fragmented life situations' (Schierup \& Jørgensen 2016: 948). Whereas Standing's simplified categorization of 'precariat' has attracted much criticism, 'precarity' in connoting a social condition can not only be leveraged to recognize and scrutinize the politics of neoliberal capitalism, which 'produces the precarity of labour, livelihoods, and citizenship' (ibid.: 949) but also enables the envisioning of the possibilities for resistance, in configuring 'a point of departure for creating a common space for social struggles and for producing new political subjectivities' (ibid.: 960). Particularly, critical linkages can be established between precarity and migration, so that we can focus on the issues of the 'migrant precariat' within an Asian context, and thus turn to the livelihoods and political conditions (e.g. citizenship) of the Chinese diaspora on the move.

More importantly, to better grasp Midi's aesthetic interventions and its politics, I also want to intersect the critical tropes in sociology and migration studies with Judith Butler's biopolitical take on precarity, so as to take into consideration issues regarding 'who is effected how and where' (Puar, 
quoted in Berlant et al. 2012: 170; emphasis in original). Butler conceptualizes 'precariousness' as a 'shared condition' of bodily vulnerability and corporeal fragility in all human lives, which then elucidates how the bodily life depends on what is outside of itself to be sustained; through which process it is subjected to illness and risks. The body, therefore, 'is always given over to modes of sociality and environment that limit its individual autonomy' (Butler 2009: 30-31), which lays the basis for the reciprocal recognition of the grievability of life and an understanding of human interdependence. Butler then directs her attention to how the 'generalized condition of precariousness and dependency is exploited and disavowed in particular political formations' (ibid.: 30). Hence precarity is used by her to describe and distinguish the politically intervened distribution of precariousness wherein inequality would impose particular vulnerability 'on the poor, the disenfranchised, and those endangered by war or natural disaster' (Watson 2012:1). Butler then considers precarity not in terms of 'existential fact' but rather as 'a social condition of political life' (quoted in Berlant et al. 2012: 170). Arguing how 'precarity exposes our sociality, the fragile and necessary dimensions of our interdependency', she suggests that the 'very particular ethos and politics' of 'a shared precariousness' would be 'one that underscores global interdependence and objects to the radically unequal distribution of precarity (and grievability)' (quoted in Schierup \& Jørgensen 2016: 170).

We could further draw on Butler's dialectics of precariousness vis-à-vis precarity to fathom how the 'neoliberal technologies, along with other governing projects, create contradictory spatio-temporal configurations where some populations are subjected to intense and unjust regulations and confinement, while others circulate with ease' (McCormack \& Salmenniemi 2016: 7). Understandings such as these can shed light on our discussions about migration and the diasporic movement across East Asian and Southeast Asian places, in foregrounding the 'political effort' and 'normative operations' that underpin and facilitate the differentiated distribution of precarity apropos the translocal subjects. Also, the biopolitical lensing allows us to turn to the precarious and persistent bodies in relation to 'forms of social and political agency where that is possible' (Butler, quoted in Berlant et al. 2012: 168).

My study of Midi's 'cinema of precarity', particularly in the case of City of Jade, is formulated in relation to the sociological and biopolitical perspectives on precarity as outlined above, highlighting the cinematic text, style, and the conditions of producing and circulating these works. Through his observational takes, on the one hand, Midi has brought to our attention the socio-economic conditions and historical contingencies of diasporic Chinese communities across Southeast Asian border zones that are scarcely 
highlighted in mainstream transnational film projects. Meanwhile, fully understanding the importance in approaching how 'Sinophone Burmese subjects' as 'part of the global and local economic precariat' also occupy 'a position of cultural precarity in relation to their Chineseness', as pointed out by Mellissa Chan in her analysis of Midi's Trilogy features (Chan 2017: 19), I want to extend and think beyond such interpretative delimitations. Departing from the Butlerian thesis, my discussion underscores what I have observed in Midi's Hpakant documentaries: a strong tendency to connect in between the disenfranchised conditions of Sinophone diasporal persons and the commonly shared circumstances of precarious labour - as is common for the multi-ethnic, multilingual translocal Burmese workers.

It is also crucial to see how Butler pays particular attention to the significance of 'frame', namely the established, existing norms and schemas as well as articulations of these norms that are used to produce, allocate, and attribute 'recognizability' to certain subjects, in knowing and acknowledging their personhood while making it difficult for other people and their lives to be understood and recognized as such. In particular, Butler associates frame (or framing) with operations upon the 'sphere of appearance', the organization of which for her has been orchestrated and determined by 'specific mechanisms of power' (Butler 2009: 1). I contend that her interrogation of 'frames of recognition' can be grasped in light of Jacques Rancière's thesis on politics and aesthetics which, as I have illustrated throughout this book, correlates with an 'event of appearance' (Panagia 2014: 103). To further elaborate on the shared philosophical grounds between Butler and Rancière is out of the question here. Nonetheless, it is important to see that Butler has explicated 'recognizability' in terms of a certain perceptual and epistemic arrangement where 'recognition can and does take place' (Butler 2009: 6). She pinpoints that such a configuration, which correlates with a 'reciprocal action' involving multiple actors/subjects, is firstly contingent upon and works with 'apprehension', namely a 'mode of knowing'; and secondly, it is formulated upon the force field of 'intelligibility', which is approached here as 'the general historical schema or schemas that establish domains of the knowable' (Butler 2009: 6).

Arguing that 'schemas of intelligibility condition and produce norms of recognizability', Butler indeed illumines the contingency and uncertainty underlying the 'frames of recognition'. She has on the one hand underscored how the 'frames' have been installed or even perpetuated to delimit a space of consensus. On the other, Butler does lay emphasis on the dissensual potentialities enacted through the (re-)distribution of the sensible. And as succinctly suggested by her, "The problem is not merely how to include 
more people within existing norms, but to consider how existing norms allocate recognition differentially' (ibid.: 6). Understandably, Butler has called for a critical, reflexive gesture to 'frame the frame', namely 'to show that the frame never quite contained the scene it was meant to limn', so that 'something occurs that does not conform to our established understanding of things' (ibid.: 8-9). Meanwhile, emphasizing how the frame 'depends upon the conditions of reproducibility in order to succeed', and highlighting the changing contexts that the 'frame' necessarily works with and breaks away from, Butler illustrates that 'the frame never quite determined precisely what it is we see, think, recognize, and apprehend' (ibid.: 9-10). She therefore sees the frame as 'a kind of perpetual breakage, subject to a temporal logic by which it moves from place to place', proposing that the circulation of images (or texts) throughout various contexts also implicates the very subversion of any given frame itself (ibid.: 10-12).

I contend that 'frame' or 'framing' can be examined as a constant dispute or disruption over the 'conventional forms of looking, of hearing, of perceiving' that determines what may be considered a life when, where, and for whom (Panagia 2014: 103). Crucially, within the context of this chapter, the politics of precarity firstly concerns how global film and media cultures contribute to and play roles in generating, circulating, and distributing multifarious 'frames' about precariousness and vulnerability across their disjunctive power configurations. Furthermore, the politics of precarity relates to how a given frame can be reconfigured and redistributed so that one may come to 'apprehend something about what or who is living but has not been generally "recognized” as a life' (Butler 2009: 12). As a case in point, Midi's Hpakant documentaries constitute an intervention in making visible and audible subjects such as the migrant precariat De-Chin, together with all the anonymous jade miners and labourers who have been condemned to the shadowy presence or fixed genres of representability (e.g. in news reports as well as in mainstream and/or television documentaries) in the visual regime of neoliberal globalization and its affective economy.

\section{Homecoming Trilogy}

\section{Midi Z's 'Migration Machine'}

It is tempting to view the other two instalments in Midi's Trilogy, namely Poor Folk (Qiongren, liulian, mayao, touduke, 2012) and Ice Poison (Bingdu, 2014), as sequels to Return to Burma, all three of which thread together the 
life and struggle of a protagonist played by Midi Z's alter-ego on screen, Wang Shin-hong. ${ }^{3}$ While most of the Chinese protagonists in the Trilogy often speak an accented Yunnan dialect (which for a Yunnanese like myself sounds quite familiar, even though it was impossible for me to tell the exact 'area' of Yunnan they are from by simply listening to the tones and terms used), the three films proffer a heterogenous soundscape featuring a somehow creolized Yunnanese, Mandarin Chinese (putonghua), Burmese, and Thai. In Return to Burma, Chinese-Burmese labourer 'Shin-hong' (played by Wang Shin-hong), after having worked at Taipei's construction sites for 10 years, brings the ashes of his friend who died in a recent accident back to their hometown in Myanmar. The film is set in its production year of 2010 when Myanmar was on the eve of an unprecedented presidential election. Feeling like a stranger back in his home city of Lashio, Shin-hong wanders around the once familiar neighbourhood and local markets trying to find out about future options for earning a living, while his friends and relatives are leaving for Malaysia, Dubai, or China for (illegal) job opportunities. In Poor Folk, 'A-hong' (also played by Shin-hong) becomes the sidekick of a long-term Burmese refugee 'A-fu' (played by Midi Z's second-eldest brother Zhao De-fu, who is currently living in Bangkok), who has recently settled in Bangkok. To make extra money to save his younger sister, who has been sold by his family to transborder human traffickers, A-hong follows A-fu to a Chinese-Thai community called Dagudi at the Thai-Burmese border to trade raw materials for amphetamine production.

Ice Poison offers a more desperate scenario wherein an unnamed young man (impersonated by Wang) earns his living as a scooter-taxi driver by picking up passengers at Lashio's bus terminal. One day he encounters San Mei, who has returned to Lashio from Yunnan to bring back funeral clothes for her dying grandpa (the part of the story that was developed into the 'Hometown and Diaspora' short film, Burial Clothes). Dreaming of breaking free from her marriage in China, which she was tricked into at a young age, and also eager to take her kids back to Lashio, San Mei teams up with the scooter driver which starts their desperate adventure of drug delivery. The romantic bonding between San Mei and the anonymous biker is loosely and aloofly portrayed: their relationship is consummated when they both get high under the influence of drugs. However, their separation

3 Wang came from a better-off Chinese family in Lashio and has followed a life trajectory similar to Midi's in relocating to Taiwan and finishing his degree there. Although Wang collaborated with Midi Z in founding a film company in Myanmar, the business was unsuccessful. He is currently running his own business in Myanmar (personal interview with the filmmaker). 
arrives abruptly, when the biker narrowly escapes upon seeing the arrest of San Mei, without a proper farewell.

Alisa Lebow grasps the significance of camera as the 'peripatetic migration machine' not only in documenting/evidencing transnational migration and family displacement but also in configuring a 'cinematic apparatus' that constructs, intervenes, and symptomizes/symbolizes the very experiences of the transnational movement. She particularly stresses how first-person journey films (her cases are mainly documentaries) have become 'a catalyst' for migration in providing the 'pretense for the journey' (Lebow 2012: 24). As a series of transborder projects and events that best exemplify Lebow's understanding of the 'migration machine', the Trilogy has been primarily driven by Midi's own questioning over where his 'native place' (yuanxiang) is and what it really means for his 'homecoming' (guixiang) (Zhao et al. 2015: 30). The projects have necessitated Midi Z's meandering translocal trips between Myanmar, Taiwan, mainland China (as a transfer point to avoid possible trouble for flying directly to Myanmar), and Thailand, evidencing that his filmmaking practice itself is creative, flexible, and adventurous enough to engage with and work through various limitations in terms of locations, technologies, infrastructures, and institutional regulations. To work with the variables on location, for instance, Midi often travelled with a minimal crew, armed with digital video cameras and other lightweight digital audio-visual gadgets (e.g. iPhone and GoPro), and he usually started editing in situ while still shooting. Central to his low-budget productions, except for his constant female lead, Taiwan-born Wu Kexi, most actors in the Trilogy are non-professionals whom Midi cast from local communities, some of whom are members of the filmmaker's extended family and acquaintances in town. ${ }^{4}$

Since 2011, Myanmar has witnessed an incremental process of democratic transformation in its ideo-political and cultural realms, with young local filmmakers starting to enjoy increasing artistic liberty (see Tin Htet Paing

4 For Return to Burma, for instance, there were altogether three crew members for location shooting, including Midi himself and Wang Shin-Hong (actor and also the executive producer); the filmmaker himself did the editing and post-production. In the case of Ice Poison, Midi confessed that although the idea of developing the Phoenix TV-commissioned short into a feature-length film only occurred to him when his seven-people crew (the largest one used in the Trilogy) was wrapping up the short, he actually had already developed a rather clear mental map for the overall structure and individual shots. His seemingly nonchalant documentation of the daily life and routine activities is to a great extent realities mediated and re-enacted, and in most cases, it is a mixture of carefully choreographed, planned sequences and settings, with accidental occurrences and improvisational performance on the part of the actors and the involuntary extras. 
2017). However, the imbalanced sociopolitical development between various regions and ethnic communities, with some areas still experiencing unrest and military conflicts, suggest that 'independent filmmaking' in Myanmar says less about the creators' non-commercial, arthouse aspirations to identify their domestic audience and more about a modus operandi on the filmmaker's part struggling to articulate his/her own voice without necessarily giving in to the bureaucratic procedure of applying for the government's filming permit and going through the censorship check (see Eimer 2016). Understandably, the production of the Trilogy in Myanmar encountered infrastructural shortcomings as well as surveillance and constraints, even though the filmmaker (so far) has no intention of showing his films in public in Myanmar (quoted in 'Fei cui zhi cheng' [City of Jade]; also see Zhao et al. 2015). ${ }^{5}$ When analyzing the Trilogy as 'poor cinema', Song Hwee Lim suggests, 'Midi Z's modus operandi resonates with practices of guerrilla and underground filmmaking, bordering on the margins of legality, circumventing censorship, and dealing with corruption by any means possible' (Lim 2018: 135). ${ }^{6}$

I contend that Midi's Taiwanese citizenship and his double diasporic status (apropos both Burmese and Chinese) have allowed him relatively more freedom and space regarding artistic creation and social critique, specifically when it comes to issues related to present-day Myanmar. This has added to the filmmaker's already complex positionality intersecting contemporary, post-military-rule Burmese cinema and Taiwan national cinema when he engages the international film festival network as what Thomas Elsaesser has examined as a 'global auteur' (see Elsaesser 2017), a topic that cannot be fully explored here but has been partly touched upon in an earlier take of mine on the film festival circulation of films from Taiwan (see Ma 2017). Questions can be posed regarding how we may grasp Sinophone film auteurs' multi-layered investment in the 'local', that is, the society of settlement as well as the 'national', from the perspectives of production, circulation, and exhibition (also see Chapter One). It is intriguing to see how, as previously illustrated, Midi's translocal authorship has complicated how the 'local' and

5 Midi $\mathrm{Z}$ was able to show his The Road to Mandalay back in Myanmar for the first time at Yangon's 2016 Memory!International Film Heritage Festival, which the filmmaker called 'a historical moment' (see 'Myanmar gets first glimpse of its most famous director Midi Z's film, The Road to Mandalay').

6 As pointed out by Midi, even when his shooting took place in Lashio, where the filmmaker has strong local connections and was streetwise enough to deal with governmental officials, the police, and militants and gangsters from various backgrounds, there was the danger that somebody would report their 'illegal' filmmaking to the government (see Zhao et al. 2015). 
especially how the 'national' might be critically engaged. I believe the focus could also be shifted to his entanglements with Taiwan and 'Taiwanese-ness', especially when considering how diasporic filmmakers like Midi engage with the questions of cultural identity and identification. For instance, whereas Midi Z has been wildly/widely celebrated as the Burmese auteur, ${ }^{7}$ it is equally important to look at how his auteurship dialogues with the discursive construction of a 'national cinema' of Taiwan, especially when such correlations cannot be neatly explained by merely turning to Midi's passport identity as a Taiwanese citizen. On the one hand, as indicated earlier, Midi's Ice Poison represented Taiwan in the Best Foreign Language Film category at the 2015 Academy Awards. He was also named Outstanding Taiwanese Filmmaker of the Year at Taiwan's 53rd Golden Horse Awards in 2016. Moreover, Midi has been featured in the official webpage by the Ministry of Foreign Affairs of Taiwan under their 'New Southbound Policy' (NSP, xinnanxiang zhengce) which highlights the collaboration with Pacific and specifically Southeast Asian countries ('Midi Z: Taiwan, Cradle of My Cinema'). On the other hand, the filmmaker mentioned in a 2016 interview that he was 'not looking for government funding' in Taiwan (quoted in Yang 2016). To obtain subsidies, as Midi explained when talking about his 2018 documentary 14 Apples (Shisike pingguo), at least $20 \%$ of the location shooting must take place in Taiwan, which actually limits his translocal film shooting to some extent (Buff 2018). ${ }^{8}$ Although I cannot further elaborate on this point here, I want to suggest that it is exactly in situating himself 'in between' Taiwan/Taipei and Myanmar/Lashio as a minor transnational auteur that Midi has been able to carve out the 'spaces of play' (as used by Rancière) for himself to disgage/engage with the national in 'national cinema'.

\section{The State of Precarity: Chinese Diaspora on the Move}

I contend that Midi's Trilogy has made visible the multiple and diverse migratory routes for the scattered Sinophone communities across the Asian region. The filmmaker has specifically switched the focus of existing

7 Midi's interview at the 2016 Berlinale is illustrative of my point, where he was asked to answer questions related to the censorship in Myanmar such as 'What are the conditions like for artists in Myanmar now? What do you see as the main changes for you and your work?' and 'What do you consider your main challenge in working in present-day Burma/Myanmar?'(see 'Fei cui zhi cheng' [City of Jade] 2016: 55-56).

8 In July 2018, Midi Z's production company of Seashore Image Productions announced that it had for the first time applied for and won government subsidies for the domestic production of feature-length films (see '107niandiyitici guochandianying changpian fudaojin huoxuan mingdan'). 
transborder imaginaries and visual idioms in inter-Asia transnational films from the coastal areas, islands, and sea voyages to adventures across the mountains, valleys, forests, and jungles, namely the inland frontier in Southeast Asia. Configuring a trope reinforcing and complementing the discourse of Nanyang or that of the 'South Seas' in Sinophone articulations (see Bernards 2016), the narratives of inland frontier potentially help to redefine and contest any homogenous imaginaries about the diasporic Chinese communities and their mobility (or immobility, as may be the case).

The places canvassed in the Trilogy - including the border town of Dagudi in Chiangmai, Thailand appearing in Poor Folk and the Road to Mandalay (Zaijian wacheng, 2016) ${ }^{9}$ - are sites where the expansive, incongruous grassroots translocal, transnational networks of human trafficking, illegal immigration, sex industry, and drug trafficking intersect. In their socioanthropological mapping, Aihwa Ong and Donald M. Nonini have explored how the Chinese diaspora have sought to elude three interrelated 'regimes of truth and power' under neoliberal capitalism in the Asia Pacific, namely 'the Chinese family', 'the capitalist workplace', and 'the nation-state', and have thus avoided being disciplined as the 'locatable and confinable' docile citizens, while taking advantage of 'the disjunctures in space, and therefore in power, between them' (Ong \& Nonini 1997: 23-24). Having proposed their thesis on Chinese transnationalism almost two decades ago, Ong and Nonini paid attention to the asymmetrical power relations in the global 'time-space compression' and mentioned various types of 'semi-unfree labourers', including the sans-papiers or the 'undocumented transnational labour migrants' (ibid.: 10). However, what was implied but was less satisfactorily addressed in their formulation of the Chinese transnationalists was how migration and displacement have intricately associated with precarity, of which the migrant has become its very emblematic figure.

9 Boasting the largest Chinese population in Northern Thailand, Dagudi has been intricately linked with the Kuomintang/Nationalist Party's military deployment since the end of WWII and during the Cold War. It was formerly notorious for opium production; it has recently been redeveloped by the Thai government as a tourist site that now grows tea. Most residents of the border town are descendants of the Nationalist's No. 93 Army, which retreated from the southwestern province of Yunnan to Myanmar towards the end of China's civil war in 1949, when they lost to the military force led by the Chinese Community Party. Their retreat was partially strategic in that Taiwan's Kuomintang government still believed that setting up their military footing in Myanmar would facilitate their overall aim of recapturing Mainland China. In the 196os, the remaining part of the army was finally given permission by the Thai government to settle in Northern Thailand including Dagudi. Even today, the Chinese communist party-state and Taiwanese government still stage diplomatic programmes in Dagudi and rival each other in emphasizing its 'Chinese roots'. 
I argue that Midi's aesthetic intervention in his fiction and documentary works has set the stage for translocal diasporic Sinophone subjects who have rarely been taken into account or have resisted assimilation into these biopolitical regimes as mapped out by Ong and Nonini. These subjects are migrant workers, refugees, human traffickers, mail-order brides, drug dealers, jade traders and miners as well as sex workers who cross the borders between Taiwan, Myanmar, Thailand, and China to earn their living. In other words, what the filmmaker has foregrounded are the precarious conditions of the non-elite diasporic persons whose life stories do not easily subscribe to the triumphant narrative apropos the Chinese transnationalists' flexible accumulation and economic success (see Ong \& Nonini 1997).

As suggested earlier, Midi has leveraged precarity as a narrative theme and also a critical lens to zoom in on the diasporic folks' predicaments in everyday life. One could turn to Ice Poison where, after failing to find a job in town, the unnamed biker and his ageing father have no other choice but to mortgage the impoverished family's only asset, a yellow cow used for farming, for a second-hand motorcycle. While the audience may somehow be able to relate to the biker's hectic yet desperate dancing in the family's barren farmland under his drug-led ecstasy, a more powerful demonstration of his nervous breakdown and the family's dire situation would be the ending sequence wherein the yellow cow is being slaughtered. In this harrowing long take, the cow is seen tightly tied up and pressed onto the ground to be strangled alive, its throat finally being slit by the butchers in a skillful manner. Then the camera pans slightly to the right so the audience can have a better sense of the spatiality of this shabby slaughterhouse, with skulls and beef parts scattered everywhere, until the screen turns dark and we can only hear the sound of blood splattering. The bloody scene documented by Midi at the actual site of a local abattoir is uncannily reminiscent of the killing of an old Tibetan mastiff dog toward the end of Old Dog (2013) by Qinghai-based Tibetan filmmaker Pema Tseden. For the Tibetan auteur, his protagonist still seems to have a choice whether or not to kill his dog when he is confronted with the dilemma that he can neither abandon it nor guard it against external perils. With the scene of a slaughterhouse in Ice Poison, however, Midi has looked at people whose last choice in life is to take the risk of losing everything. It is reminiscent of a vernacular Yunnanese term that Midi has often used to underscore the motivation of his characters, namely 'taoshenghuo', or 'begging for life'.

It is the Chinese-Burmese peoples' hopeless, disadvantaged socioeconomic situations at home that have also necessitated their transborder mobility, with whichever means it may take. Whereas their minority status 
as Chinese-in-Myanmar has already alienated them from Myanmar's fraught public space, their citizenship has been further fractured and jeopardized by their transnational movement as migrant workers (illegal or otherwise). For instance, even though the project of Return to Burma and Midi/Wang ShinHong's homecoming trip in 2010 was inspired by Myanmar's most exciting moment of democratic transformation in decades, the filmmaker chose to turn to the bleak quotidian lives of the underprivileged folks in Lashio, a locale that is both politically and geographically distant from the state's centre. Intriguingly, the mainstream rhetoric about a future democratic regime is only hinted at during Shin-Hong's long-distance bus ride home. What the audience sees is that when the audio-visual entertainment system on the bus starts to play a music video of a campaign song (in Burmese) encouraging the public to vote, Shin-Hong has already fallen asleep.

It is noteworthy that most of Midi's protagonists are no longer those who are entrapped in their rural native places. Even for the nameless motorcycle biker in Ice Poison, he has enjoyed his brief yet exhilarating moments of a wild, carefree ride along the mountain trails. However, the Trilogy emphasizes how the routes, directions, and even speed of the characters' movement (or the lack thereof) are pre-scripted and determined by their underprivileged positions within the local community in the first place and are also contingent upon the multi-scalar networks of the informal economy that is inconsistently entwined with the economy and labour imperatives of neoliberal globalization. Here, migration and border-crossing are not pursued as any happy solution but foregrounded as the very symptom of their plight. It is telling that for the protagonists in the Trilogy, passport identity or nationality is no longer considered essential to their sense of belonging but is simply a type of commodity that can be traded for or forged in exchange for another modus vivendi in life. In his powerful fourth feature Road to Mandalay, for instance, the female protagonist, a Chinese-Burmese woman named Lianqing, has left Myanmar in order to find herself illegal odd jobs in Thailand. She works hard in the hope not only of supporting her families back in Myanmar but also of purchasing identity papers so that she can gain more access to working opportunities as a Thai citizen.

It becomes clear that the 'begging for life' trajectories that Midi has painstakingly documented and interrogated are not only specific to the diasporic Chinese in Myanmar. These experiences nevertheless interlace with stories of other migrant precariats who are determined to risk losing everything but who nevertheless share common feelings of 'anger, anomie, anxiety, and alienation' (Standing 2011: 19). In order to grasp this better, I now turn to Midi's Hpakant documentaries. 


\section{Between Lashio and Hpakant: A Family Portrait}

In the director's statement for the City ofJade, Midi mentions an image that he saw when he was younger,

For years, a photo has hung in our living room in which my father faces the camera smoking while my mother cooks noodles behind him. In the background is a muddy street in a market. My mother told me that the photo was taken by a mad photographer in Jade City in 1990 (quoted in 'Fei Cui Zhi Cheng' [City of Jade]: 55).

The documentary starts with a slow panning shot overlooking Hpakant's moonscape of the jade mine area, which glows with an uncanny orange colour with no human figures in sight. In his own soft voiceover, Midi narrates how, since his childhood, many of his family members and folks back in Lashio had been fascinated with 'this place' (zhege difang) and ended up working here. When his father was still alive, Midi reminisces, he told the filmmaker that 'if the poor want to get rich overnight, this is where they go!' This is followed by a tracking shot where one sees a dark-skinned, middle-aged man sitting on a tricycle facing the camera emotionlessly - this is De-Chin. Accompanying this sequence, the filmmaker recounts how he visited De-Chin together with their mother at a prison in Mandalay, after having not heard from him for 16 years. Wondering why his brother still cannot give up his dream about the jade business' right after his release, the filmmaker followed the journey of De-Chin and his team of freelance workers (all male) into Hpakant, the 'Jade City'.

Here Midi is not only the one who is hiding behind the camera as a traveller and an intimate witness but also the one whose point of view (as well as narration) constitutes the very site of articulation, proffering a different mode of subjectivity to be distinguished from other 'homecoming' works of his. It is particularly tempting to consider City ofJade a semi-family portrait, given how Midi has interwoven the narrative about how the 'prodigal son', De-Chin, is trying to restart all over again from the jade mine, with(in) the diasporic family's micro-history. It seems that without a trip returning to Hpakant, not only De-Chin's past and present but also the history of the whole family cannot be properly interrogated or fully understood. Nonetheless, Midi's narration of his family story is surprisingly devoid of any accompanying sequence featuring the domestic, interior setting of 'home'. As one can infer from the absent family photo that inspired Midi to start this project in the first place: his parents appear to be a duo of travellers/ migrant peddlers, working hard away from their home/town. 
Whereas Zhao's grandparents, parents, and other family members remain absent from view in the documentary, the eldest son of the family becomes their substitute. Hence, it is not difficult to understand why in the documentary, what one repeatedly sees are similarly composed tracking shots taken from the back of De-Chin as he is riding a motorcycle or walking along the seemingly endless muddy road. Accompanying these mobile long takes is Midi's narration that tries to piece together, chronologically, how his family coped with life before and after De-Chin's disappearance.

We can for a moment turn to Alisa Lebow's observations about the 'domestic autobiographies' of Jewish first-person films, wherein the filmmakers would leverage the autobiographical mode to perform 'almost miraculous feats that unite long lost family members, revive the dead, or (re)introduce a harmony that may or may not have existed in their families' (Lebow 2008: 38). Lebow posits: 'This process of remapping enables the filmmaker to conjure his or her preferred version of the family narrative ... [and] to repair certain ruptures or disunities of the filmmaker's identity, as conceived in and through the context of the family' (ibid.).

Here one needs to closely examine the story told by Midi, whose telling is in itself calm, neutral, and descriptive. Interconnecting with a progressive account of Myanmar's social transformations since the late 1980s, however, what Midi offers is a paralleling trajectory regarding how his family had been through rounds of economic breakdown and crises, of which De-Chin's departure constituted one of its most poignant episodes. I shall contend that this 'remapping' by Midi is not necessarily meant to be 'a preferred version of the family narrative', if the 'preferred version' emphasizes an idealized, harmonious imaginary; instead, in a mode of confession, the filmmaker honestly reopens the wounds of the family, confronting and staring at them.

Specifically, Midi's telling uses several historical events demarcating Myanmar's timeline toward democratization as a context to chart out the Zhaos' unpretentious history of precarity. Nevertheless, the gap between the two strands of histories becomes so obvious and even absurd that it further underscores how Midi's family had been alienated and marginalized by Myanmar's progressive leitmotif. For instance, by selling medicines smuggled from China, De-Chin could for some time support the whole family sufficiently. But his success did not last long. When Myanmar society was thrown into turmoil amidst the nationwide pro-democratic protests under the leadership of Aung San Suu Kyi in 1988, the only business bolstering their family collapsed, when 'everything was back to where it was' according to Midi. With great honesty, Midi then reveals how his mother was thrown into prison because she took up the risky job of trafficking drugs to lessen 
the burden of the family, which is reminiscent of the fate of the female protagonist San Mei in Ice Poison. However, it was also when the junta government put Aung San Suu Kyi under house arrest and proclaimed an amnesty that Midi's mother was luckily released. Seeing how the family was enmeshed in economic deterioration, other older siblings were then forced to find work in neighbouring countries such as Thailand, whereas Midi left Myanmar for Taiwan in 1998 at the age of 16 .

According to Donna McCormack and Suvi Salamenniemi, precarity makes visible the fact that neoliberalism 'instantiates a shift in time' and encourages us to think of the present as 'a series of self-regulatory processes that are supposed to enable the prospect (and fantasy) of one day not being vulnerable' (McCormack \& Salmenniemi 2016: 8). Thinking along the lines of 'the biopolitics of temporality' in relation to precarity (ibid.), I suggest that with City ofJade, Midi has leveraged his first-person narration and subjective point of view as a site to locate the disenfranchised Chinese diasporic selves (himself and his family members like De-Chin included) within the temporalities of multiple biopolitical regimes, namely that of the diasporic community, of the presumably modernizing and democratizing, self-reforming nation of Myanmar, and also the teleological time of global neoliberalism. Midi's confession thus brings to light how the underprivileged translocal, transnational subjects, not only limited to members of the Chinese diaspora themselves, have disturbed the hegemonic narratives of progress in emerging from and testifying to the very incongruencies and tensions between these biopolitical regimes and their entwined temporalities.

Midi's film project, in trying to reconnect and reconcile with his estranged brother, can be considered an effort to position the displaced family members, himself included, back into a family portrait that was incomplete in the first place. The work in itself also constitutes a repository for the diasporic family's identity that is full of 'ruptures' and 'disunity', given how the family members are still spatially dispersed. For the Zhaos, homecoming is always an ongoing, unfinished project through and throughout which a small history of precarity unfolds and persists.

\section{Road to Jade City}

\section{Affective-Authorial Risk-Taking}

To further explore the Hpakant documentaries at the extra-textual and production level, I turn to Hamid Naficy, who has usefully explored how 
'accented filmmaking by exilic, diasporic, and ethnic filmmakers inherently involves taking risks'. Accordingly, risks are integrated into the film's narrative, style, and its 'extratextural material' (Naficy 2013: 143). At the same time, Midi Z's creative efforts can be studied in line with what Mette Hjort has termed as 'flamboyant risk-taking', for which she incisively relates to a trend in the context of European-American documentary filmmaking inspired by Werner Herzog that emphasizes 'the display of the film practitioner's subjective involvement with avoidable and excessive risks' (Hjort 2013: 40).

Furthermore, scrutinizing Hollywood films' transnational production in the Philippines in relation to risk-taking, Jasmine Nadua Trice has looked at how location shooting has become 'an arena' for the filmmakers to construct and negotiate 'multiple discourses of white masculinity' through their 'risk talk' (Trice 2017: 989-990). Trice's perspective in intersecting the survey of transnational location shooting and risk-taking with gender has been inspirational, even though her case studies mainly focus on global Hollywood and its power geometry. In her framing of the affective-authorial risk-taking for Francis Coppola's location shooting in the Philippines for Apocalypse Now (1979), Trice discusses how the filmmaker's risk talk foregrounded the performance of frontier white masculinity in boosting a discourse about directorial agency and artistic credibility and virtuosity (ibid.: 996). This raises an interesting question regarding how we shall approach the 'affective-authorial risk-taking' during the location shooting of films by border-crossing independent filmmakers like Midi: Is his documentary what Hjort has framed as the benign flamboyant type characterized with the sacrificial gestures of activism? Does Midi's risk talk (e.g. in his interviews and within the documentary, via voice-over) similarly enhance his authorial profile internationally, furbishing it with authenticity and romantic heroism?

Given what has been outlined earlier regarding the circumstances of independent filmmaking in Myanmar, it may not be surprising that in Midi's interview book-cum-semi-autobiography published before his double documentary project, the filmmaker talked extensively about the risks of filming the Trilogy back in Myanmar (Zhao et al. 2015). As the making of City ofJade progressed, it also became clear that what made the filming so dangerous, besides the frequent jade mine disasters triggered by excessive, unregulated mining in the aftermath of the retreat of multinational mining companies from Hpakant, was the larger socio-political picture, more specifically the occasional conflicts that flared up between the ethnic rebel militant group known as the 'Kachin Independent Army' (KIA) and 
the government's military force. ${ }^{10}$ Therefore, while working in the pits, small-time jade mine dealers and their contracted freelance labourers also had to guard against unexpected raids by both the military force and the police, which knowingly used tricks of intervention and surprise raids by confiscating drilling machines and goods, arresting the workers, and asking for fine payments in order to profit from the illegal mining business.

Although City ofJade is distinguished with high post-production value, including the rare use of background music composed by the award-winning musician Lim Giong, for Midi, the work itself should not be evaluated solely by turning to its form of expression. As he reminds us, the viewers need to bear in mind the contingency and risks taken throughout his location shooting,

Many times while shooting Fei Cui Zhi Cheng, I could not see through the viewfinder; it appeared to simply not be there. Moreover, the ideas of 'frame' and 'composition', or concepts such as 'aesthetics', 'poetic feel', and 'image' as analyzed in cinema studies did not seem to exist either. Back then, they meant nothing, let alone helping me explain what was happening before my eye ('Fei Cui Zhi Cheng' [City of Jade]: 55).

For instance, forcibly evidencing his risky position, Midi's long-focus lens were accidentally used to detect and record a surprise attack by the KIA during which the mining machines of De-Chin's team were confiscated and his workers only narrowly escaped. The filmmaker also used hidden cameras to document their unexpected encounter with the patrolling soldiers who asked to check their belongings when they spotted Midi's DV camera, where the audience is left with a screen that has suddenly turned black and can do nothing but imagine their intense confrontations while listening to their dialogues in Burmese and reading the translated subtitles.

\section{At the Edges of Jade and Drug: Men at Work}

Unlike in his fictional trilogy, what Midi in his Hpakant documentaries has specifically looked into are male labourers at the ad hoc mining camps. ${ }^{11}$ In

\footnotetext{
10 For instance, it was reported that both the KIA and the national armed force, locally known as the Tatmadaw, 'use their off-the-books jade money to finance the fighting in Kachin state' (Combs 2018).

11 Also refer to Gender Equality and Women's Rights: A Situation Analysis (2016), which provides detailed statistics regarding the participation of women in mining, quarrying, and other extractive industries. For instance, the report mentions that $' 2.2 \%$ of total male employment and $0.7 \%$
} 


\subsection{Male labourers at work in Midi's Hpakant documentaries}

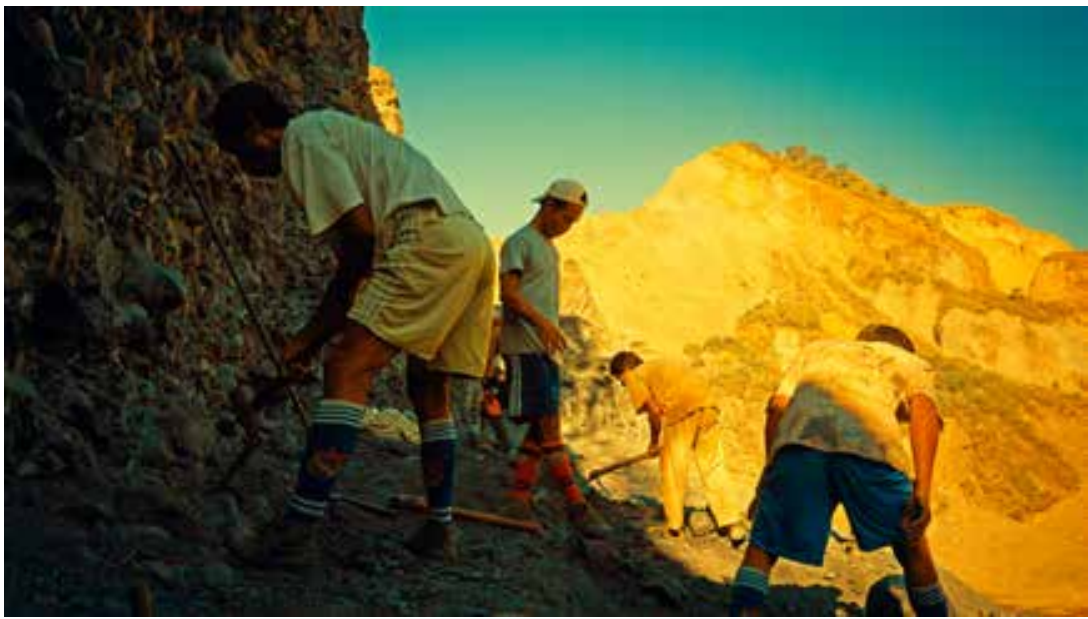

both documentaries, the 'Jade City' is constructed as contested ground, if not a stage, for male miners or small-time dealers like De-Chin to project their imaginaries for success (usually as the family's breadwinner), male mobility, and labour power. Nevertheless, except for the episode where the viewers see one of De-Chin's workers calling back home talking to his wife and child (a sequence that is also used in Jade Miners), little if any accounts are provided regarding how the workers relate to their partners and families, who are usually physically far away from the pits. The narration (telling) and observation (showing) reveal how the performed masculinity is jeopardized and the male bodies made vulnerable because of the unequal distribution of precariousness on various scales. At the same time, the performance of masculinity on the part of the workers (and the filmmaker) is arguably built upon the tension between the demonstration of precarity as their working/living conditions, and their risk-taking in relation to their ambition and agency to disrupt the status quo.

As expected, at the mining pit, De-Chin appears in front of Midi's camera to confess about his years of disappearance, gradually shedding light on his obsessions with jade and drugs (e.g. opium and heroin), the typically 'hard' and 'soft' edges underwriting a precarious life pattern that most of Hpakant's (male) guerrilla miners and dealers have plunged into. Although rumours suggest that De-Chin made a fortune in Jade City when he was away from

of women's employment in 2010 was in the mining sector. Increased mechanization means fewer people need to be employed. Even when jobs are created, they tend to be associated with heavy labor and, hence, for men' (Gender Equality and Women's Rights: A Situation Analysis 2016: 56). 


\subsection{De-chin on the way to Hpakant in City of Jade}

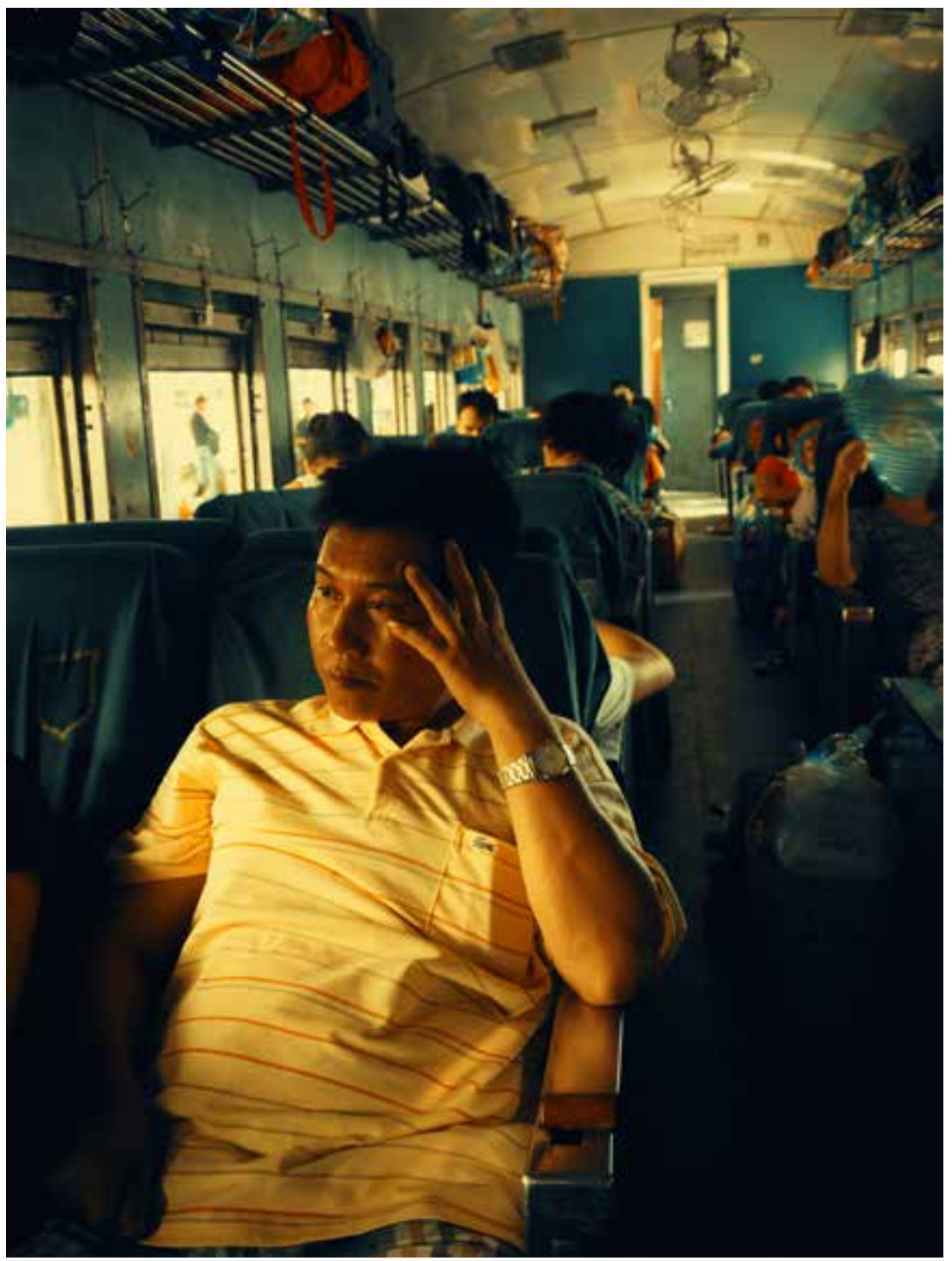

home (while abandoning his wife and children and neglecting to fulfil his duty as the eldest son to support his family), the brother conceded to Midi that he only ended up making a meagre living despite his repeated attempts trying his luck with jade.

I argue that both narrative tropes of 'jade' and 'drugs', while associated with the imagined male adventurousness, unboundedness, and bodily 
power for the labourers as we can also see in Midi's Jade Miners, highlight the contingency and crisis of the performative masculinity. What is particularly striking may be De-Chin's accounts of his traumatic experience of skindiving in his earlier trials when he was employed by a Chinese businessman to dive into the freezing river in search of gemstones for long hours carrying very rudimentary diving equipment with barely any protective measures. As his story goes,

I tried so hard and got up early in the freezing weather. I only grabbed something before jumping into the river. We dived with three bicycle air pumps [...] but however hard we worked, no jade was found. It was dangerous to dive for jade, because you also dived with a stone attached to your waist by a string ... I had done this for over a year.

Midi then picks up De-Chin's story and reminds the audience that in order to reward and mostly to stimulate their workers for the tough task, the boss would often prepare opium for the divers on their return. This suggests that even though De-Chin may seem to be reckless and free in his efforts of 'making a fortune', his struggles never actually break him free of the vicious cycle of precarity. This episode, though shrugged off by De-Chin as if it is somebody else's, reveals the cruel fact that, even when the worker himself accepts the excessive risks involved in mining, he may not be aware of, or pretend not to be aware of, the degree to which his body can be abused, exploited, and made fragile throughout the adventure.

I would also add that although in City ofJade there are other sequences of drug abuse filmed with a high degree of performativity, wherein De-Chin even gives the cinematographer advice on how to shoot them in the darkness, with the brother's episode of diving in mind, these scenarios should not be simply romanticized as the manifestation of sensorial pleasure integral to such gendered freedom, as somewhat implied by Midi in his interview. Rather, these seemingly playful sequences juxtapose with and also complicate imaginaries of the strong, persistent labouring male bodies in the mining pits, as the haunting images of precarity.

Midi's own 'flamboyant risk-taking' also constitutes an indispensable aspect of grasping the politics of precarity, which is achieved through the vérité documentation of precariousness as a condition shared by the filmmaker and his subjects. For example, one can also turn to the only sequence in City ofJade where we see Midi himself. Here the filmmaker has retreated from the shooting location and is lying on the hospital bed, acknowledging later that he is diagnosed with malaria. Accompanying a shaky tracking 
shot taken from the back of several jade miners who are heading for their pit in the darkness, Midi delivers his monologue: 'my situation is unstable'. He admits, 'when my body experiences the shaking chills, my skin burns but my inner part feels cold. When the symptoms are gone, I feel normal again [...] workers who suffered from malaria told me that it could be cured by a puff of opium. Sometimes, when the seizures feel so unbearable, I have seriously considered the option'.

Whereas the 'flamboyant risk taking' in documentary-making is often charged with 'narcissism and self-indulgence', as Hjort illustrates (Hjort 2013: 45), it is important to realize how Midi has preferred a minimalist, austere style of the 'self' in his undertaking, diverging from the poetic, self-absorptive mode of conventional first-person documentaries. If we refer to Hjort's observations on the activist strand of flamboyant risk-taking, in foregrounding his own risk position, Midi achieves 'a position of commonality' with his subjects. Moreover, this encourages us to reconsider the 'gains achieved by moving from a position of "I speak about them to you" to "I or We speak about us to you"' in City ofJade (ibid.: 44; emphasis in original).

Specific to Midi's Hpakant documentaries, the achieved 'position of commonality' with his subjects is a gendered one. Midi's unusual demonstration of his own body under risk highlights a position of 'weakness' intersecting the masculinity in crisis and the precarious diasporic identity. Refusing to speak from the moral high ground, neither seeking to elicit sympathy among his viewers, in this rare but candid gesture of self-inscription, the filmmaker leverages his own bodily vulnerability to register the epidemic precarization of the migrant labourers at Hpakant, where drug addiction is no longer simply judged in terms of moral decadence and criminality but as the very indicator of how the suffering, self-abandoned male body desperately fights against its adverse environments.

More research should still be done to scrutinize the great diversity of risk-taking in minor translocal filmmaking in Asia from the viewpoint of gender. For one thing, questions of gender help us rethink the male authorship of inter-Asia border-crossing cinema as a whole, a topic that I shall also turn to in the postscript. Whereas this chapter cannot proffer a more detailed survey of similar risk-taking projects by border-crossing filmmakers across Asia today, it is intriguing to see how Lee Yong-chao, who is also a Chinese-Burmese filmmaker based at Taipei, made his debut documentary feature Blood Amber (Xuehupo, 2017) by venturing into an ad hoc, illegal amber mining camp in Kachin when the war between the KIA and the Myanmar army burst out. Here Lee even followed his young male protagonist/miner who dove down into the holes they had dug deep into 
the earth. Not very different from the mining pits canvassed by Midi, the only female appearing in Blood Amber, for instance, is a young girl hired to cook for the freelancers.

Importantly, in relation to what I have demonstrated with Butler's explication of frames of recognition vis-à-vis the mode of appearance, I suggest that the politics of precarity also contains a dimension of spectatorship. Here I want to highlight a sequence included in both Jade Miners and City ofJade, the one that witnesses and records in a timely fashion the aftermath of a landslide at the mining pit. In this two-minute-long take, Midi positioned his camera at the top of a ditch overlooking how, right below him, workers have gathered at a collapsed pit, the entrance/exit to which is already partially buried by the rubble. Among the tightly packed crowd who rub against each other, several labourers in the centre have lined up to try to dig out manually and excavate their co-workers who are still trapped inside, while the onlookers around the pit are trying hard to push their way through the crowds. There is no voice-over accompanying the sequence in City of Jade, except for the ambient sound, people's whispering comments on the situation, and their cursing and warning against the danger of another cave-in if more people come closer. The background of the rescue scenario is the hauntingly bare landscape of the overexploited 'jade mountains' that both inspire and crush the miners' dreams.

Observing the scene of the accident without participating in the rescue more actively, largely due to his own risk position, Midi does not assume a superior position to elevate himself above the onlookers on the site. Instead, in demonstrating the limitations of his witnessing, he indicates and acknowledges the insufficiency of his own aesthetic intervention. However, in capturing the critical moment of the catastrophe, Midi's camera nonetheless takes up an inconvenient position for his global spectators, most of whom can only access his films at international film festivals or at themed exhibitions in galleries and museums. Along the lines of Hjort's argument, I would suggest that even though Midi's Hpakant documentaries are not necessarily activism-oriented, the works indeed challenge the viewer to at least 'respond appropriately' to not only the filmmaker's but also the miners' suffering (Hjort 2013: 44). Furthermore, instead of a critique of the political economy of the global film festival network in tandem with their affiliated exhibitory institutions, I contend that when Midi's oeuvre is circulated on the expansive network and is brought to engage global audiences, there is always the possibility of enacting the dissensual in challenging and regenerating the frames 'that govern the relative and differential recognizability of lives' (Butler 2009: 12). 


\section{Coda: In the Name of a Visual Record}

In this concluding note, I propose that one can better understand the cinema of precarity by considering the scarcity of visual evidence in the City ofJade. Similar documentary works often include visual evidence (e.g. photographs and home videos) relating to the diasporic family and the filmmaker. Unlike several other 'family portrait' documentaries shot from the first-person perspective by diasporic filmmakers from East and Southeast Asia, such as Dear Pyongyang (2005) by Koreans-in-Japan/zainichi filmmaker Yang Yong-hi and Absence without Leave (Bujibuli, 2016) by Chinese-Malaysian filmmaker Lau Kek Huat, in Midi's take, there is hardly any visual register for the family members: there appear to be no photographic documents or filmic footages at his disposal to start from or to proceed with, including the 'original' family photo that has haunted Midi for all these years. As much as Alisa Lebow has emphasized how the self-reflexive use of visual medium/formats, archival materials and footages, and performance foreground the power of the camera in creatively inscribing and articulating the displaced subjectivities, Midi's first-person style in City ofJade is arguably minimalist and 'weak'.

On a surface level, the fact that Midi has deployed very little archival material or home video footages to reconstruct the family's history per se connotes the conditions of material life of Midi's family. The family struggled to make ends meet for all these years and had little interest or extra resources, if any, to build up or take care of its own photographic/image records. However, I would suggest that the scarcity of visual documents highlights the precarious condition of the family and their community, wherein, as earlier suggested, the underprivileged, marginalized subjects could hardly claim and inscribe to an image of their own in the official repertoire (sometimes ideological laden) or the mainstream, commercialized visual culture.

This is why the ending of City ofJade becomes particularly significant. Here, Midi starts to reflect on how, no matter how hard he tries, it is impossible for him to picture what De-Chin went through in the past 20 years at the jade mines. Therefore, what his documentary offers is to a great extent a mixture of De-Chin's fragmented accounts and the filmmaker's own imaginative work. Following Midi's line that, 'He (De-Chin) is not so different from all the workers who have left their home behind', the camera turns to a jade miner who asks the filmmaker to 'take a photo' of him. As this nameless labourer poses in front of the DV, Midi continues, 'they are beleaguered by nostalgia, loneliness, frustration, poverty, despair, war, and malaria. In freezing winter, they dive into the river for jade. Because of the 
6.4 Miners posing for the camera in Midi's installation work 'My Folks in Jade City' for the 2016 International Film Festival Rotterdam

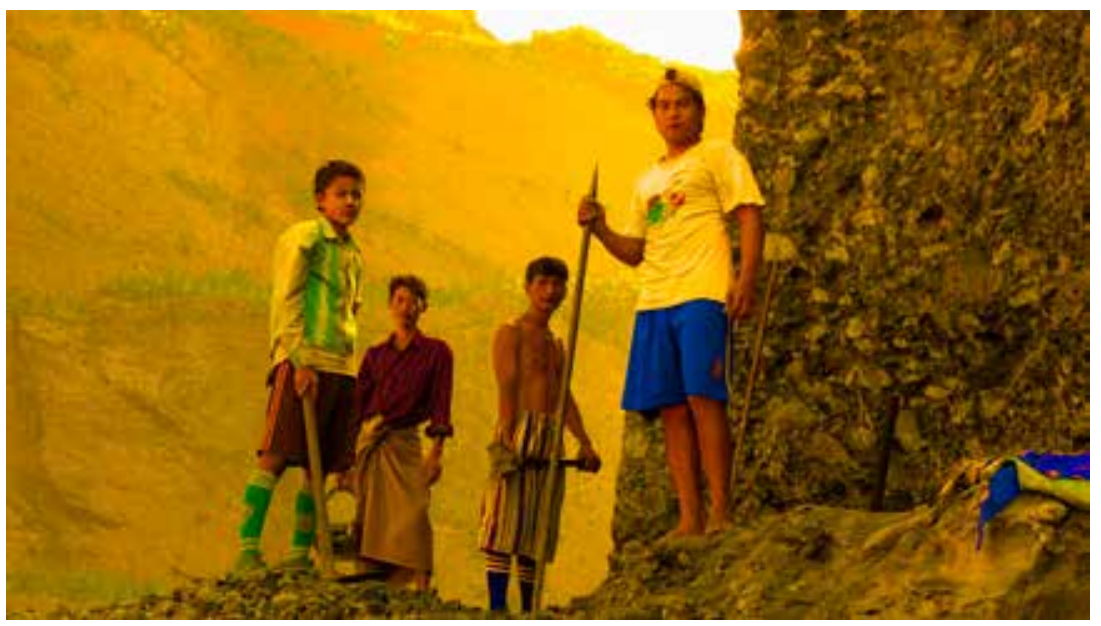

water pressure, their noses bleed once they are on shore. They miss home. They want to get rich. They think about the future, and think about the jade, getting so excited that they could not fall asleep'. Midi's narration has shifted from the third-person-singular to third-person-plural, and De-Chin's personal story has been modified by the filmmaker to highlight the situation of precarity shared by a collective of nameless subjects. What the audience sees at the same time are sequences of jade miners who are posing for the filmmaker either alone or in a group, sometimes with a gemstone in hand.

The powerful ending reminds the audience of the absent family photo of Midi's parents taken at Jade City, presumably by the mad photographer (see 'Fei Cui Zhi Cheng' [City of Jade]). The ending of the photo-taking sequences allows the filming subjects to stare back at the filmmaker as well as its global viewers. Moreover, in recognizing and making visible the collective presence of the jade miners, Midi foregrounds his filmmaking as a practice of archivebuilding, and thus his oeuvre constitutes an alternative audio-visual archive not only for the diasporic Chinese subjects but also for other disenfranchised labourers who strive for survival. Such an archive contests the situation of precarity that always threatens to devour the nameless workers and subject them to invisibility and unrecognizability. Arguably, it is precisely in the filmmaker's gesture that the viewer sees the miners as well as labourers 'emerging from scenes of extraordinary subjugation' and witnesses how they 'remain proof of stubborn life, vulnerable, overwhelmed, their own and not their own, disposessed, enraged, and perspicacious' (Butler 2009: 62). 


\section{Works Cited}

'107niandiyitici guochandianying changpian fudaojin huoxuan mingdan' [First round of receipients for 2018 domestic feature film assistance grant application] (2019). Ministry of Culture (Taiwan). Retrieved 11 January 2019 from <https://grants.moc.gov.tw/Web/ PointPublish.jsp? $\mathrm{M}=2 \& \mathrm{R}=1 \& \mathrm{PT}=2334 \& \mathrm{~B}=3021 \& \mathrm{fbclid}=\mathrm{IwARoXNCQLboehMO} \mathrm{rc}$ zZ-KXsRW6MJNwLoo7VNiPWptdT6A_XgWv-4dnmkxRM>.

Berlant, L., Butler, J., Cvejic, B., Lorey, I., Puar, J., and Vujanovic, A. (2012). 'Precarity Talk', TDR: The Drama Review, 56/4: 163-177.

Bernards, B. (2016). Writing The South Seas: Imagining The Nanyang In Chinese And Southeast Asian Postcolonial Literature. Singapore: NUS Press.

Buff (2018). 'Interview with Midi Z: On 14 Apples' [Zhuanfang: shisike pingguo zhaodeyin]. Hypesphere. Retrieved 3 October 2018 from <https://www.hypesphere.com/news/15154>.

Butler, J. (2009). Frames of War: When is Life Grievable?. London; New York: Verso. DOI: 10.1080/00335631003796701.

Chan, M.M. (2017). 'Mail-Order Brides and Methamphetamines: Sinophone Burmeseness in Midi Z' s Burma Trilogy', Concentric: Literary and Cultural Studies, 43/September: 11-31. DOI: 10.6240/concentric.lit.2017.43.2.02.

Combs, D. (2018). 'Myanmar's Jade Fueled War'. The Diplomat. Retrieved 3 October 2018 from $<$ https://thediplomat.com/2018/o6/myanmars-jade-fueled-war/>.

Eimer, D. (2016). 'Myanmar's once-booming film industry gears up for act two'. South China Morning Post. Retrieved 3 October 2018 from <https://www.scmp.com/magazines/post-magazine/ film-tv/article/1900617/myanmars-once-booming-film-industry-gears-act-two $>$.

Elsaesser, T. (2017). 'The Global Auteur: Control, Creative Constraints, and Performative Selfcontradiction'. In Jeong S. \& Szeniawski J. (eds.), The Global Auteur: The Politics of Authorship in 21st Century Cinema, pp. 21-42. New York; London: Bloomsbury Academic.

'Fei cui zhi cheng' [City of Jade] (2016). Forum/Forum Expanded, pp. 54-56. Berlin: The International Forum of New Cinema, Berlinale.

Gender Equality and Women's Rights: A Situation Analysis (2016). Mandaluyong City, Philippines: Asian Development Bank.

Hjort, M. (2013). 'Flamboyant Risk Taking'. In Hjort M. (ed.), Film and Risk, pp. 31-54. Detroit: Wayne State University Press.

'Homecoming Myanmar: A Midi Z Retrospective (Film Series)' (2015). Asia Society. Retrieved 1 May 2018 from <https://asiasociety.org/new-york/homecoming-myanmar-midi-z-retrospective-film-series>.

Lebow, A. (2008). First Person Jewish. Minneapolis: University of Minnesota Press.

- (2012). 'The Camera as Peripatetic Migration Machine'. In Lebow A. (ed.), The Cinema of Me: The Selfand Subjectivity in First Person Documentary, pp. 219-232. New York: Wallflower Press.

Lim, S.H. (2018). 'Towards a Poor Cinema: Ubiquitous Trafficking and Poverty as Problematic in Midi Z's Films', Transnational Cinemas, 9/2: 131-146. DOI: 10.1080/20403526.2018.1454700.

Ma, R. (2017). 'Contesting the National, Labelling the Renaissance: Exhibiting Taiwan Cinema at Film Festivals in Japan since the 1980s'. In Chiu K., Rawnsley M., and Rawnsley G. (eds.), Taiwan Cinema: International Reception and Social Change, pp. 53-68. London; New York: Routledge.

McCormack, D., and Salmenniemi, S. (2016). 'The Biopolitics of Precarity and the Self', European Journal of Cultural Studies, 19/1: 3-15. DOI: 10.1177/1367549415585559.

'Midi Z: Taiwan, Cradle of My Cinema' (2017). Ministry of Foreign Affairs, Republic of China (Taiwan). Retrieved 10 August 2018 from <https://nspp.mofa.gov.tw/nsppe/news. php?post $=11588$ \& \&unit $=410>$. 
'Myanmar gets first glimpse of its most famous director Midi Z's film, The Road to Mandalay' (2016). South China Morning Post. Retrieved 10 September 2018 from <https://www.scmp.com/culture/ film-tv/article/2044393/myanmar-gets-first-glimpse-its-most-famous-director-midi-zs-film>.

Naficy, H. (2013). 'Accented Filmmaking and Risk Taking in the Age of Postcolonial Militancy, Terrorism, Globalization, Wars, Oppression, and Occupation'. In Hjort M. (ed.), Film and Risk, pp. 143-164. Detroit: Wayne State University Press

Ong, A. (1999). Flexible Citizenship: The Cultural Logics of Transnationality. Durham: Duke University Press.

Ong, A., and Nonini, D.M. (eds.) (1997). Ungrounded Empires: The Cultural Politics of Modern Chinese Transnationalism. New York; London: Routledge. DOI: 10.1111/j.1467-8322.2009.00676.x.

Panagia, D. (2014). “"Partage du sensible”: The Distribution of the Sensible'. In Deranty J.-P. (ed.). Jacques Rancière: Key Concepts, pp. 95-130. Durham, UK: Acumen Publishing Limited.

Schierup, C.U., and Jørgensen, M.B. (2016). 'An Introduction to the Special Issue. Politics of Precarity: Migrant Conditions, Struggles and Experiences', Critical Sociology, 42/7-8: 947-958. DOI: $10.1177 / 0896920516640065$.

Shih, S.-M. (2007). Visuality and Identity: Sinophone Articultions across the Pacific. Berkeley; Los Angeles; London: University of California Press.

Standing, G. (2011). Precariat: New Dangerous Class. London; New York: Bloomsbury Academic.

Tan, E.K. (2013). Rethinking Chineseness: Translational Sinophone Identities in the Nanyang Literary World. Amherst, NY: Cambria Press.

Teng, P. (2017). 'Taiwan Ministry of Culture to offer grants to award-winning filmmakers'. Taiwan News. Retrieved 3 October 2018 from <https://www.taiwannews.com.tw/en/news/3309550 $>$.

Tin Htet Paing (2017). 'Independent Cinema Resists Censorship at Local Film Festival'. The Irrawaddy. Retrieved 3 October 2018 from $<$ https://www.irrawaddy.com/culture/independentcinema-resists-censorship-local-film-festival.html>.

Trice, J.N. (2017). 'Location Shooting in "the Wild East": Risk and Masculinity in Hollywood Productions in the Philippines', Feminist Media Studies, 17/6: 988-1004. DOI: 10.1080/14680777.2017.1313290.

Watson, J. (2012). 'Butler's Biopolitics: Precarious Community', Theory and Event, 15/2:1-16. DOI: http://dx.doi.org/10.1108/17506200710779521.

Yang, O. (2016). 'INTERVIEW: Film Director Midi Z on the "Taiwanese Dream" in Myanmar (Part Two)'. The News Lens. Retrieved 3 October 2018 from <https://international.thenewslens. com/article/56409>.

Zhao, D., Zheng, Y., and Fang, P. (2015).Ju, san, Bingdu: Zhao Deyin de dianyingrensheng jishi [Gathering, Parting. Ice Poison: Chronicles of Zhao Deyin's Filmmaking Life]. Taipei: Commonwealth Publishing. 



\title{
Postscript
}

\section{The Promise of Subversive Art}

\begin{abstract}
In this concluding section, I summarize what I have examined in the preceding chapters to foreground the significance of this study. More importantly, I highlight some of the research concerns that could be explored further in the future. In proposing potential 'ways of seeing', I briefly look at how we can grasp border-crossing filmmaking in relation to current developments in visual technologies, especially apropos the ubiquitous use of drones, as instantiated in Ai Weiwei's documentary project Human Flow (2017). Secondly, I suggest that in extending the questions of gender and sexuality, it would be useful for a future project to realign and re-examine the border-crossing auteurs and their films, both within and beyond the inter-Asia context.
\end{abstract}

Keywords: drone, gender, sexuality, pornography, minor objects

In the end, in thinking about the Asia question, we are not led to being absorbed in the question 'What is Asia?', but rather to reflect on 'What sort of issues in fact are set forth in discussions with regard to Asia?' In other words, Asia is merely a medium, through which we are effectively led to our history, and it is precisely because of this historical significance that it is important we keep asking 'How does Asia mean?'

Sun Ge, 2000

For me, the fundamental question is to explore the possibility of maintaining spaces of play. To discover how to produce forms for the presentation of objects, forms for the organization of spaces, that thwart expectations. The main enemy of artistic creativity as well as of political creativity is consensus - that is, inscription within given roles, possibilities, and competences.

Jacques Rancière, 2007

Ma, Ran, Independent Filmmaking across Borders in Contemporary Asia. Amsterdam, Amsterdam University Press 2020 DOI: 10.5117/9789462986640_POST 
Independent Filmmaking across Borders in Contemporary Asia has been structured as a series of journeys initiated by the film auteurs and their protagonists, each of which departs from and/or traverses across specific Asian locales, while the translocal and transnational interrelations between these places and localities have also been foregrounded and examined. I hope that in this book I have illustrated how the analytic heuristic of 'bordercrossing cinema' can help us to better interrogate cinematic transnationalism in the contemporary setting from within the socio-political and cultural spaces across Southeast Asia and East Asia. I have also illustrated how this study, in turning to the auteur-centred independent filmmaking within/ from Asia, contributes to re-envisioning a cinema that 'crosses lines, zigzags, derails, rerails, reroutes, jumps from one continent to another, [and] relies on artifice to create its imaginary spaces'(quoted in Hunt \& Leung, 2008: 3) so that we can re-examine the politics and aesthetics of contemporary cinema and global image cultures as a whole and reconsider how they 'engage with the realities of globalization'(Hinderliter et al. 2009: 2). If we return to Jacques Rancière, whose quote opens not only this chapter but also Chapter One, I suggest that this project has revolved around and reflected upon the promise of subversive art, in particularly pinpointing the dissensual potentialities of film and other moving image works. Nevertheless, my case studies have not aimed to provide an easy checklist to determine whether a film title or artwork is 'qualified' to be considered the art of the dissensual. As Rancière believes, 'The work of dissensus is to always reexamine the boundaries between what is supposed to be normal and what is supposed to be subversive, between what is supposed to be active, and therefore political, and what is supposed to be passive or distant, and therefore apolitical' (Rancière et al. 2007:264). Arguably, the subversive art under examination is not enframed by sets of existing criteria or standards but is underpinned by the very dynamics of an unsettled 'permanent guerrilla war' regarding how the mode of appearance may be constantly re/configured (ibid.: 266).

Departing from the framing of translocalism, this book has foregrounded an assemblage of various aesthetic practices that have disrupted the consensual understandings of mobilities and identities. On the one hand, along with the meandering cinematic journeys throughout the whole book, I have located the politics of border-crossing cinema by turning to the diverse strands of practices and discourses of location shooting. While it is true that each filmmaker or film collective analysed here has theorized and worked differently with the location and cinematic spatiality, they have similarly leveraged the 'place-based imagination' while attending to a politics of place (see Dirlik 1999; Zhang 2010) in modifying how we might perceive and 
envisage transborder subjects' intricate engagement with the local-nationalglobal spatial configurations. I have, for instance, demonstrated how the Japanese independent film collective Kuzoku approaches the landscape or $f u \overline{k e} i$ within contemporary Japanese society and across Southeast Asian metropolises and border towns (Chapter Three). It would nevertheless be intriguing to see how Kuzoku's transborder movement is also reminiscent of its 'predecessor', the Nihon Documentarist Union/NDU (Chapter One), an independent documentary collective most active in the late 196os and early 1970s. It is significant that despite the disparate socio-historical environments they have respectively engaged with, NDU and Kuzoku arguably share the provocative vision that critique of Japanese imperialism and the legacies of colonialism cannot be dissociated from a rethinking of Japan's positioning within Asia, both then (e.g. in the high season of students protests and social movements) and now (in post-3.11 Japan). I contend that, not unlike other translocal practices explored in this book, NDU and Kuzoku's border-crossing filmmaking has exemplified how the crucial question of 'How does Asia mean?', raised by Chinese intellectual Sun Ge in her attempt to reconceptualize 'the question of Asia', can be addressed cinematically. As Sun notes, 'the question of Asia must not merely be pursued within the framework defined by the dichotomy of East versus West, but also should be considered as dealing with internal problems in the Asian region' (Sun 2000:14). Therefore, I do believe the specific strand of inter-Asia independent transnational filmmaking examined here has proffered creative praxis and refreshing perspectives for us to approach and further interrogate the meaning-production of 'Asia', Asian regionalism and cultural collaborations, and Asia's interconnections with globalization. In elucidating dynamics and complicacies as such, this project has also sought to illustrate how the 'Other' cultures and 'Other' cinemas can talk back to the Eurocentric underpinnings of the Rancièrian survey of dissensual politics and aesthetics.

At the same time, in emphasizing the auteurs' (as well as the artists') positionality of being 'minor transnational', which interconnects with their multi-layered identities of being ethnic, diasporic, and/or postcolonial, I have looked at how the image-makers have leveraged their contingent positionings as a transformative edge to redistribute what is visible, audible, and speakable about Asian places and translocal subjects. My project has specifically turned to the multiple, complicated ways in which the minor transnational subjects, while remaining 'invested in their respective geopolitical spaces' (Lionnet \& Shih 2005: 8), potentially traverse the 'national, local, or global spaces across different and multiple spatialities and temporalities' (ibid.: 6). Accordingly, I have highlighted, as examples, Korean-Chinese filmmaker 
Zhang Lu (Chapter Two), becoming 'Chinese-in-Japan' cinema with Li Ying's early documentaries (Chapter Four), the moving image works by Okinawan filmmaker Takamine Gō and Naha-based visual artist Yamashiro Chikako (Chapter Five), and the 'homecoming' films by Taipei-based, Myanmar-born filmmaker Midi Z (Chapter Six).

It is nonetheless necessary to point out that, so far, as Independent Filmmaking across Borders in Contemporary Asia has foregrounded minority, diasporic, and postcolonial subjectivities and identities by reconceptualizing the 'minor' with Gilles Deleuze and Félix Guatarri, my research has aimed to rethink the critical paradigms in transnational cinema studies, such as Hamid Naficy's 'accented cinema' (2001) and Laura Marks' 'intercultural cinema' (2000). I have attempted to illustrate that the 'minor' authorship under examination has registered a politics of identity not formulated upon the norms and standards that 'police cultural expressions and practices' (Lionnet \& Shih 2005: 10); rather, it concerns how the identity is always 'in the process of creation', in its becoming (Colebrook 2001: 118). It is not upon the politics of recognition or the parameters of authenticity that a minor filmmaker envisions and expresses a community of hers/his. With Rancière, I shall propose that what the minor filmmakers and artists have ultimately aspired to create is a 'community of sense', and a community as such only becomes possible via 'a frame of visibility and intelligibility that puts things or practices together under the same meaning' (Rancière 2009: 31). Paradoxically, it is a community that 'works toward being-together only through a consistent dismantling of any idealized common ground, form, or figure' (Hinderliter et al. 2009: 2). Whereas 'the same meaning' referred to by Rancière does not merely register the commonly shared feeling that gives shape to and unite a collective, I believe the meaning-production necessarily engages the 'new taxonomies, paradigms, and palettes of sensibilities' generated through the dynamics of dissensus (Tolia-Kelly 2019: 124). Therefore, in this project, I have specifically turned to affect and foregrounded an affective critique in situating my survey of the cinematic texts within the specific socio-historical contexts of film production, circulation, and exhibition. On the one hand, this study has explored how the articulation of identities as well as the manifestation of bodily, emotional, and affective states are contingent upon various modes of mobilities and translocal dynamics. On the other hand, I have zoomed in on the question of spectatorship. Instead of considering spectators to be those who occupy rather passive and pre-scripted positions waiting to be enlightened, I have illustrated how the viewers are encouraged to formulate indeterminate and therefore more provocative and productive relations with the independent image works. 
To conclude, I want to highlight some of the research concerns that could be explored further in the future. In proposing potential 'ways of seeing', I briefly look at how we can grasp border-crossing filmmaking in relation to current developments in visual technologies, especially apropos the ubiquitous use of drones, as instantiated in Ai Weiwei's documentary project Human Flow (2017). Secondly, I suggest that in extending the questions on gender and sexuality, it would be useful for a future project to realign and re-examine border-crossing auteurs and their films, both within and beyond the inter-Asia context.

\section{'From a High Vantage Point'}

Chinese dissident artist Ai Weiwei's English-language documentary Human Flow (2017), co-produced by several international film and media companies, is an epic travelogue film that records and reflects upon the problems encountered by refugees and migrants worldwide. The production crew had over 200 professional members, including 12 credited cameramen - some of whom are themselves veteran cinematographers (such as Christopher Doyle) or documentary filmmakers (e.g. Chinese filmmaker Zhang Zanbo, Huang Wenhai) as well as 'a half dozen drone operators' (see Dargis 2017). Also, importantly, the crews (some of whom the filmmaker himself never met) admirably travelled for the film through 40 refugee camps in 23 countries around the world. Human Flow turns its cameras to the displaced persons who are either stopped, entrapped, or already on their way to unknown destinations/destinies. Along these extraordinary global journeys, although he did not have a plan to include himself and the crew in the film in the first place, Ai plays the role of a motivated, sympathetic interviewer/observer (see Buder 2017). For instance, the work interweaves Ai's meetings with world leaders, politicians, and spokespersons from international non-governmental organizations, including their commentary on some of the burning issues underlying this crisis.

While being interviewed for a written article, Ai Weiwei confessed that 'I was a refugee for most of my lifetime'(ibid.), closer to a condition of 'being displaced without changing physical location' (Dirlik 1999: 169). ${ }^{1}$ Nevertheless, Human Flow hardly concerns Ai's personal 'exilic' trajectory 
as such (he based himself in Berlin after he was permitted to go abroad by the Chinese government in 2015); rather, his work aspires to provide its spectators 'a better understanding of the refugee crisis in global conditions, with context' (Buder 2017). This documentary extends the geopolitical scale and cinematic imaginary of the inter-Asia transborder projects examined in the previous chapters; that is, it engages the global.

Intriguingly, art historian Georges Didi-Huberman found Ai's documentary work most problematic with its 'point of view'(2018), that is, the fact that 'high vantage points' made possible by drones are dominating the work. Performing a meticulous analysis of the opening sequence of Human Flow, Didi-Huberman contends that 'a film - particularly a film that creates images to "look at the plight of refugees" - ought, therefore, to be understood as an image gesture, one which reveals, to a certain degree, the nature of its own honesty or justice: a gesture that is therefore both ethical and aesthetic'. Hence, he questions the very act of 'looking down from airborne devices', in viewing the 'anonymous moving masses', namely the refugees, at a height, from a distance, and in their abstract form, which for Didi-Huberman ends up 'producing visual clichés - as opposed to truthful images - of our world'. Meanwhile, the critic also problematizes Ai's 'own involvement in the story', wherein Ai's 'greatness' as an 'activist artist' on screen has been staged and magnified with carefully chosen angles and editing work (Didi-Huberman 2018), a point that is closely connected to what I have previously explored regarding the 'flamboyant risk taking' in documentary filmmaking.

Ultimately, the French art historian wonders 'what happens at a human level' with Human Flow if the work itself has decorated its humanist discourse with 'dehumanizing' (emphasis in original), objectifying images, and if those who are speaking and who can be heard most throughout the film are not the refugees themselves but rather the authorities and spokespersons that Ai interviews. The analytical typology proposed by Didi-Huberman then suggests a documentary tackling such a topic should encompass a critical eye (on the part of the filmmakers) and critical form (that is, without necessarily resorting to the high vantage point).

I have organized the discussions in preceding chapters around the framing of the dissensus, thereby mapping out and exploring a specific strand of independent transnational filmmaking across various places in contemporary Southeast Asia and East Asia. Didi-Huberman's uncompromising stance also sheds light on how the politics of such a strand of border-crossing cinema essentially concerns a politics of place. It is worth turning to Lisa Rofel who has proffered insights into the dialectics between the 'local' and the 'global', wherein she illumines: 
The local and the global are both acts of positioning, perspectives rather than merely locales, used as signifiers of difference [...] The local, rather than a synonym for particularity, is a spatial category given meaning through specific signifying practices. Similarly, the global does not exist above and beyond the cultural processes of attaching meaning to places (2007: 93).

Arguably, the critical form stressed by Didi-Huberman entails a critical authorial positioning, and thus it demands a critical eye that goes lower and deeper, to hover at the street level and to reach the height of humans, in resisting the allure of seeing from the 'high vantage points', which aspires to grasp the transborder flows on their global dimensionality and construct certain cartographic and systematic knowledge about the world. Interestingly, if not self-conflicting in explaining how Ai Weiwei has 'repurposed' the drone in Human Flow, for instance, Rohan Crickmar actually analyzes one sequence where the drone camera is brought 'down from above' and is 'pulled down to earth', getting closer to the displaced children in a camp 'so that the mass becomes recognisable, familiar, relatable, and all too human' (Crickmar 2018). Here I cannot help but think of the miners featured in the documentaries by Midi Z or Lee Yong-chao (see Chapter Six), or the mud men and women who slide into the cave and tunnel in Yamashiro Chikako's video work (see Chapter Five).

Despite Didi-Huberman's sharp criticism, I do not think it is the drone technology and drone footage that he is ultimately critical of. In his discussions on 'drone age cinema', Steen Ledet Christiansen argues that 'The drone relation thus entangles power, agency and dominance with fear, trauma and terror' (Cristiansen 2016: 19) to illustrate what he refers to as Harun Farocki's 'operative images', which are images that do not 'inform or entertain (though they may do either)' but aim to 'perform an action, i.e. to do something' (ibid.). What is at stake in our interrogation of the 'high vantage point', then, concerns how the drones - or other technologies of visuality that are integral to our present-day socio-political conditions - are repurposed to (re)distribute the sensible in relation to agency and power.

Along the lines of the Rancièrian debates, with Human Flow, we can emphasize how there is nothing 'naturally political' with regard to independent filmmaking as a 'way of doing and making'. And as Rancière attests, 'there is a whole school of so-called critical thought and art that, despite its oppositional rhetoric, is entirely integrated within the space of consensus' (Rancière et al. 2007: 266). In some cases, independent film practices could claim their activist, anti-establishment stances without ever disrupting 
'conventional forms of looking, of hearing, of perceiving', that is, without necessarily enacting the dissensual (Panagia 2014: 103). Furthermore, as I have demonstrated earlier in the book, the rhizomatic networking in producing, circulating, and exhibiting independent films intersects them with the mainstream - and sometimes official mainstream - socio-cultural and economic infrastructures, institutions, and their corresponding ideoeconomic apparatus. Such networking, together with the variously scaled media ecology that independent filmmaking is embedded within, has further complicated how it can be examined as an aesthetic practice, which I believe could be pursued in future studies.

\section{Gendering Border-Crossing Cinema}

As my writing progresses, it has become increasingly clear that the intersection between 'gender and other axes of difference' is critical for the study of border-crossing cinema, even though this book has not foregrounded feminism as its primary framework (Silvey 2004: 490). Throughout this book I have shown in films and artist videos how females, as minor transnational subjects, are given the stage to emerge - they are the North Korean defector, the mail-order bride, the sex worker, the human trafficker (and those who have been exploited are also girls) and the smuggler, the migrant labourer, the displaced artist, the overseas student, the returnee chef, and so on and so forth. Although I do not deploy any reflectionist reading to approach these image works wherein women are featured, some of them have intricately related to and proffered insights into the actual conditions of the translocal and transborder movement and migration of women in East and Southeast Asia into the new millennium. ${ }^{2}$

Rachel Silvey has outlined four strands of theoretical themes that she believes feminist theories have productively interwoven with geography and migration studies - namely 'the politics of scale, mobility as a political process, place and space, and subjectivity/identity' (Silvey 2004: 491). Her quadripartite framework has illustrated how the gendered perspective and feminist approach can contribute to retooling translocalism. Particularly, just as translocalism reconceptualizes scale, mobility, and place in terms

2 According to Yamanaka and Piper, 'By the dawn of the millennium, it was estimated that more than two million Asian women were working abroad in the region, making up a third of the estimated six million migrant workers there'. Both scholars suggest that East and Southeast Asia is increasingly witnessing 'feminized and gendered migration' (Yamanaka \& Piper 2005: 2, 4). 
of contingent social construction and the processes as such, feminism and gender studies ask useful questions regarding how relations of gender and difference are constructed, maintained, and reworked through spatial mobility' (Silvey 2004: 499). As suggested, for instance, feminism has elucidated the epistemological masculinist framing of borders and boundaries. Accordingly, feminist scholarship in intersecting gender with other forms of identity explores how the translocal self has been spatially positioned 'as central to, associated with, or at the margins of political machinations and power relations' (Fluri 2015: 237).

Throughout this book, I have presented several border-crossing filmmakers to engage 'the perspectives and experiences of the marginalised and disenfranchised' (ibid.: 238). I believe this current project could have been more comprehensive if I had asked more constructive questions regarding, for example, how gender might reframe how we approach borders and boundaries at the levels of both discourse and practice, if it is true that 'movement never occurs through neutral physical space' and 'it involves gendered bodies through gendered space' (Lee 2017: 85). As translocalism is opened up to intersectionality analysis to highlight the politics of gender and difference, it is necessary to underscore a gendered perspective to rethink how inter-Asia border-crossing cinema engages the experiences of journeying and displacement in relation to questions of subjectivity and identity as well as body and affectivity. It also helps to reframe translocal auteurship, which interlinks with my previous discussions of location shooting and place-based imagination. At the same time, it is crucial to highlight that my analysis also interrelates with the issues of sex, sexuality, and queer theory - this reinforces a rethinking of 'the centrality of heteronormativity to the relationships between migration, the operation of power, and the construction of social order' (Silvey 2004: 500).

\section{Identity: A Document of Minor Objects}

In Identity (2004; also known as 'Seki $\star$ Rara'), ${ }^{3}$ a documentary-cumpornographic video by Matsue Tetsuaki (b. 1977), the filmmaker recorded how he travelled to several Japanese cities with a small crew to meet his cast and shoot hardcore adult videos. A third-generation zainichi himself, Matsue was naturalized and obtained Japanese nationality when he was

3 A different version of Identity was also released by the Adult Video media products brand HMJM under the title of Identity: A Document of South and North Koreans and Chinese in Japan (Aidentiti: Kan-Chō-Chū zainichi dokyumento). 
5 years old. Writing on Matsue's engagement with the pornography genre, Jasper Sharp has pointed out that some of his works produced in the Japanese adult video (AV) industry 'present a fascinating conjunction between sex, politics, and representation' (Sharp 2008: 314). In his debut documentary Annyong Kimchi (2000), a film considered an 'intimate ethnography' by Oliver Dew, Matsue 'explores his grandfather (who was born Yū Chonsik) Matsue Yūkichi's utter disavowal of his Koreanness' (Dew 2016: 90-91). In the short shooting postscript for Identity, Matsue nevertheless states:

Years ago, I said that 'I shall no longer do anything related to the zainichi material'. I didn't think to question the history of the past would suit me and simply to listen to 'the sad past' could be exhausting. (In the latter scenario) I can relate to the mood when you (as a listener) have to respond with just 'oh [...] is that so?' However, when I was told by someone that 'several decades later there would be no zainichi Koreans', I remember for a moment I indeed felt repulsed by such an idea. Therefore, ever since then, I was thinking, 'if so I must make films on such topics'. And if I shall ever make such a film, I would try best to look at my own generation (dōsedai). Not the grandpas and grandmas of the Issei (the first generation), but the younger generations such as the third and the fourth generation (Aidentiti: Kan-Chō-Chū zainichi dokyumento [Identity: A Document of South and North Koreans and Chinese in Japan]).

Identity indeed did turn the camera towards Matsue's peers - the second and third-generation zainichi subjects. The first part of the documentary mainly followed first-time AV actress (who are also labelled shirōto in Japanese) Aikawa Hiromi (born in 1983; nationality is South Korean) to several places to trace her nothing-out-of-the-ordinary life trajectories since childhood. During their road trip to Okayama, Tokyo, Kyoto, Osaka, and Onomichi of Hiroshima, however, Matsue encouraged Aikawa to share her locationspecific memories and experiences as she grew up as a third-generation zainichi Korean. In their dialogues, which mostly take place in moving vehicles, during their city walks, or in hotel rooms, Aikawa shared with Matsue her personal accounts that shed light on how her zainichi identity was closely interlaced with the seemingly abstract ideas of ethnicity, nation(ality), family, and finally, sex(uality) in everyday life. Also, Matsue periodically inserted short intertitles to comment on and respond to Aikawa's opinions and remembrance, including several brief explanations on the history of the zainichi and commonly-shared conditions of zainichi Koreans (e.g. the issue of naturalization; the Korean ritual known as 'Jesa' performed in memory 
of one's ancestors). Such stylistic form continued into the second part, wherein the audiences see Matsue, after bidding farewell to Aikawa, meeting up with an overseas Chinese student named Anna (Zhang Xinjia, born in 1979) - who was excited about her AV debut, and Anna's on-screen partner, the handsome and muscular AV actor Hanaoka Jitta, a second-generation zainichi whose estranged father is from North Korea.

In the first part, three sequences of hardcore sex are interwoven between the interviews with Aikawa (and also her Japanese AV partner) and segments of the actress strolling in the cities she once lived. A similar structure can be observed in the second part where Matsue has alternated Anna and Hanaoka's ecstatic performance on screen with sequences wherein the crew was seen doing their location shooting in Yokohama's Chinatown (the largest in Japan) - like ordinary tourists, they are busy trying Chinese food and helping Anna purchase a 'China Dress' (qipao, the traditional one-piece dress).

Jasper Sharp reminds us how Matsue knowingly played with the generic conventions of both documentary and hardcore (heterosexual) pornography in his AV work but only ended up with more interesting results produced 'in theory' than 'in practice' (Sharp 2008: 314). Sharp suggests that Matsue only offered 'a conception of documentary as merely a record of events, or of footage of people talking or revealing themselves directly to the camera' (ibid.). However, I cannot totally agree with Sharp that the potential political charge of Identity, which for the critic interconnects with the zainichi subjects' life stories throughout the documentary, has been compromised if not cancelled out by the filmmaker's emphasis on 'a series of explicit hardcore sequences' they perform (ibid.).

To grasp Matsue's intervention into both genres of documentary and pornography, it is necessary to see that it is the very filmmaking mechanisms of both genres that Matsue has sought to expose and make visible. For instance, Identity can be regarded as a 'document' (as its subtitle suggests) demonstrating 'the making-of' of adult videos, wherein the filmmaker is often heard (rather than seen) interacting with his cast through a handheld cam-recorder at an intimate distance. We can argue that Matsue mobilizes the techniques of self-referentiality and self-reflexivity to disturb the given conventions and therefore to comment not only on the generic cycles of repetitions and differences but also on his own authorial position within the so-called 'nonfiction' work (e.g. intertitles explaining how he directs the cast).

I somehow understand why Sharp feels disappointed by the incongruency between Matsue's interrogation of identity and his handling of the sex scenes. For Sharp, while the former is resolutely political, the latter is less 
certain. Nevertheless, I propose that the incongruency or gap should be grasped in terms of a dynamic process that re-distributes the sensible and the affect, during which any given division between the political and the pornographic becomes muddy - even though I do share Sharp's concern over the problematic gender politics with the pornography genre and specifically within Japan's AV industry. Instead of proposing cliched themes that sex/sexuality can transcend cultural differences and national borders, I contend that Identity leverages the love-making bodies and the ecstatic moans, namely the 'visible' and the 'audible' distinguishing the genre, to interrelate with what is less visible, audible, and speakable about body, sexuality, and, more importantly, the uneasy questions about identity and sense of belonging.

Meanwhile, with the differentiation between the interiority/exteriority collapsed by the self-reflexive 'making-of' sequences, as a travel film of sorts, Identity has created a contingent 'community of sense' wherein feelings and emotions are generated and circulated so that the audience is also invited to engage with Anna's euphoric feeling of liberation in 'being herself' in Japan, Hanaoka's anger and frustration over his family's zainichi legacy (specifically apropos North Korea) and the dysfunctional father-son relationship, and Aikawa's sentimental identification with Matsue as her 'family member'. Therefore, Identity can be understood as a text, if not an archive, consisting of 'minor objects' that can be grasped as 'those marginal forms, persons, and worlds that are mobilized in narrative (including archival) constructions to designate moments of crisis' (Nguyen 2015:12). As indicated by Mimi Thi Nguyen, 'By way of a minor object, exclusion and normativity might be laid bare (though perhaps in no straightforward manner), and the contingent quality of knowledge or other claims fold under scrutiny' (ibid.).

While a thorough discussion about Matsue's work from the feminist perspective and affectivity, in tandem with a socio-historical survey of pornography in Japan, is beyond the scope of this work, I argue that future studies can look at Identity from several interrelated aspects that extend the survey of 'minor objects'. First, there is Matsue's positioning as an independent auteur of zainichi background who traverses in and out of the AV industry (now he mostly works in television). Second, a topic that needs to be further explored is zainichi subjects' on-screen presence/performance in the non-mainstream industry/genre of pornography in relation to their socio-historical circumstances and cultural representation within Japanese society. And finally, it would be worth examining the role of females in heterosexual pornography across the spheres of filmmaking (performance and production), circulation, exhibition, and spectatorship. 


\section{ARAGANE: Wo/Men at Work}

In the future, more attention can be given to women as well as LGBTQ (lesbian, gay, bisexual, transsexual, queer) auteurs and visual artists to grasp their travelling and migratory trajectory at the intersection of gender, national/ethnic identity, and citizenship. Instances of new-millennium female border-crossing auteurs include Chinese-Malaysian filmmaker Tan Chuimui, zainichi Korean director Yang Yong-hi, ${ }^{4}$ and South Korean filmmaker Kim So-young (a.k.a. Jeong Kim), whose oeuvre has been mentioned at different lengths in preceding chapters. Here I want to briefly turn to the 1987-born Japanese filmmaker Oda Kaori, who has so far accomplished several short films and two features - documentary debut ARAGANE (2015) and an essay film, Toward a Common Tenderness (Ano yasashi-sa e, 2017). Born in Osaka, Japan, Oda possesses quite a cosmopolitan background as a translocal filmmaker. After she finished her undergraduate study in the US, Oda made a semi self-documentary short entitled Thus the Noise Speaks (Noizu ga iu niwa, 2010), through which she came out as a lesbian, or to be more exact, as someone whose gender identity remains undefined, as the 'X-gender' (personal interview with Oda). With Thus the Noise Speaks, Oda applied for the Film Factory Project (2013-2017) - a Sarajevo-based PhD level programme in filmmaking that had Hungarian maestro Béla Tarr as its head mentor, and was accepted. ${ }^{5}$ Shot at a Bosnian coal mine, ARAGANE is an observational work in which Oda carried her Canon $5^{\mathrm{D}} 300$ metres underground with the male coal miners to single-handedly record how they worked in an alien, dark, and noisy space that deeply fascinated Oda in the first place (neoneoweb). For Jonathan Rosenbaum, Oda has demonstrated with ARAGANE 'what cinema is and can be' with a work of 'exquisite formal and even abstract beauty' (2018).

It is not Oda's displaced identity that $A R A G A N E$ foregrounds, although the trailer accompanying the film's nationwide theatrical release in Japan highlights the filmmaker's authorial positioning as a 'Nihonjin/Japanese' (in Bosnia-Herzegovina). Neither does the documentary underscore the precarious conditions of the coal miners and labourers as we might expect from the works by Midi Z, Lee Yong-chao, or even in some documentaries by

4 Yang is most acclaimed for her 'Pyongyang Trilogy' consisting of Dear Pyongyang (2005), Sona, the Other Myself (2009), and Our Homeland (2012), the last of which is a fictional feature that was entered for the $85^{\text {th }}$ Academy Awards in 2013 as Japan's nominee for Best Foreign Film. 5 The pedagogical system of film.factory is currently merged into the curriculum of the Sarajevo Film Academy (see 'FILM FACTORY', n.d.) 


\subsection{Rusty machine at the coal mine in ARAGANE}

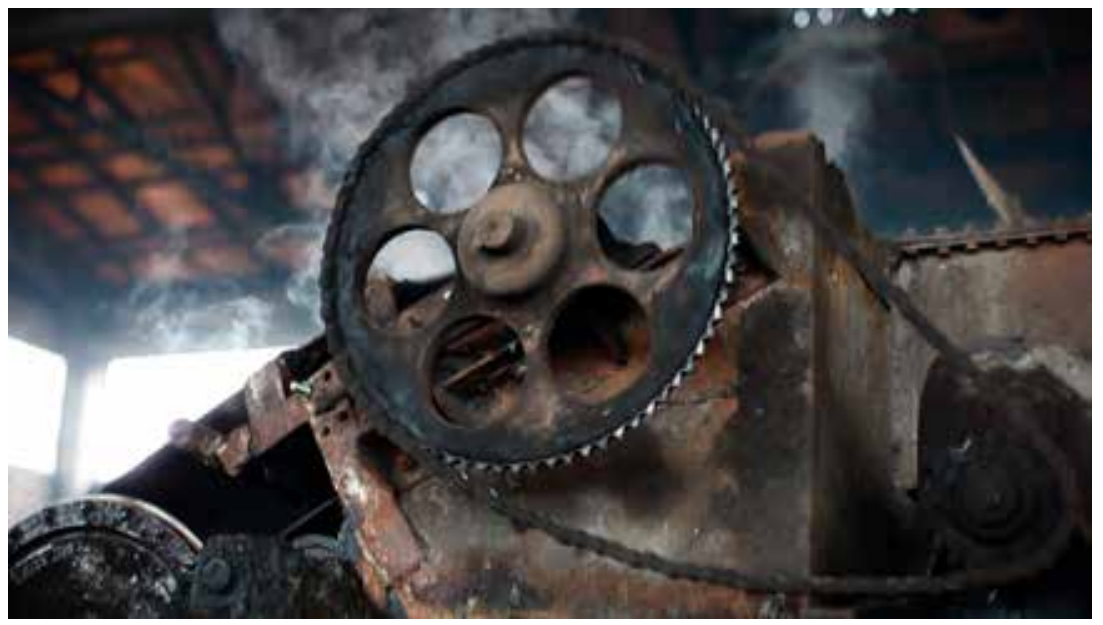

Chinese documentarist Wang Bing. As Oda pointed out, 'I didn't approach the subject from the angle of the hard conditions of miners, unfairness, and danger of their works (even though it is there in the film because it was just there)'. She explains that 'focusing on a social issue can be something good for miners, to say what is the problem and how ignorant we are about the issue, but I think the best I can do with my filmmaking is to try to be with the subject (space/people/time) and make them seen by being with them' (quoted in Matteo 2016).

As Oda has reminded us, ARAGANE and all of her other films shot in Bosnia-Herzegovina feature an all-male cast. She confesses that, although it was not her conscious choice to privilege 'the men's world' on screen, what might have attracted her most on location was the beauty of 'manual labour' (nikutai rōdō) and the miners' 'muscle movement' (kinniku no ugoki) (quoted in Kobayashi). ${ }^{6}$ One may argue that the filmmaker's camera has somehow empowered her, so she found it no longer intimidating to spend 4-hour sessions underground to shoot in the claustrophobic space of the coal mine, as one of the few women, if not the only one, down there. However, even though knowledge about the filmmaker's gender/sexual identity might reshape the spectatorial perception regarding the tension between Oda

6 In our email interview, Oda shared with me that the male miners recognized her as 'a filmmaker' instead of a 'female filmmaker'. Also, the filmmaker confessed to me that 'being $\mathrm{X}$ gender' may be related to her fascination with the miners' bodies. Actually, there were also three women miners working in the pit (personal interview with Oda). 
and her filming subjects at both the textual and extra-textual levels, what Oda's 'authorial-affective-risk-taking' (a term from Trice, see Chapter Six) has disrupted is exactly the power grid structured upon the dichotomies of female/male, to-be-looked-at-ness/look-at-ness, and submission/domination. I would argue that her camera gaze is not meant to resist, overwrite, or claim control over the male gaze per se but functions in one way or another to shed light on the miners - making visible their risk-taking bodies and the underground coal mine mise-en-scène regardless of - or to be more accurate, in spite of - their gender differences. I suggest that it is also in disrupting the given 'roles, possibilities, and competences' assigned to a 'woman filmmaker' like herself (Rancière et al. 2007: 263) that Oda has carved out her 'space of play' in experimenting with dissensual art.

In an essay explicating her 'Exile Trilogy' - three documentaries (Heart of Snow, Heart of Blood, 2014; Sound of Nomad: Koryo Arirang, 2016; Goodbye My Love, North Korea, 2017) on the Koryo people, the ethnic Koreans in Central Asia and Russia - Korean film scholar and filmmaker Kim Soyoung posits that 'The documentary practice can be an endeavour to bring back the dead, to illuminate the present of the past, to place the dead in a critical constellation' (Kim 2016; also see Chapter Two). She used the last instalment of the trilogy, Goodbye My Love, North Korea, to illustrate the 'technology of the dead'. It is a documentary about ten North Korean students who, during their studies at the Moscow Film School in the 1950s, decided to seek political asylum in the former Soviet Union in a gesture to condemn Kim Il-sung. By the time Kim So-young's documentary project was wrapping up, nine of the ten subjects/interviewees had already passed away. Nevertheless, in the finished work, with the aid of archival material, interview footage, and 'imaginative techniques', Kim suggests that the dead return to 'tell tales of history that tore their lives apart'. As claimed by Kim, 'To bring them back is particularly significant for a contemporary Korean peninsula haunted by the last sediments of the Cold War', given how the technology of the dead 'can illuminate a history shadowed by persisting cold war, against a neoliberal bio-politics which perceives history as dead' (ibid.). Inspired by Kim's articulation of the 'technology of the dead', I suggest that Oda Kaori's ARAGANE might have embodied a 'technology of the living' not simply in foregrounding the observational aesthetics that captures the 'present' on location but also through specific practices of 'authorial-affective-risk-taking'. Oda has achieved her risk-taking not in an activist manner, nor is it the 'charitable form' adopted by Ai Weiwei, but rather by 'being with them', namely with the miners, in hiding behind the camera: she looks at them at the human height in 'a gesture of giving 
7.2 Following the miners to the underground world in ARAGANE

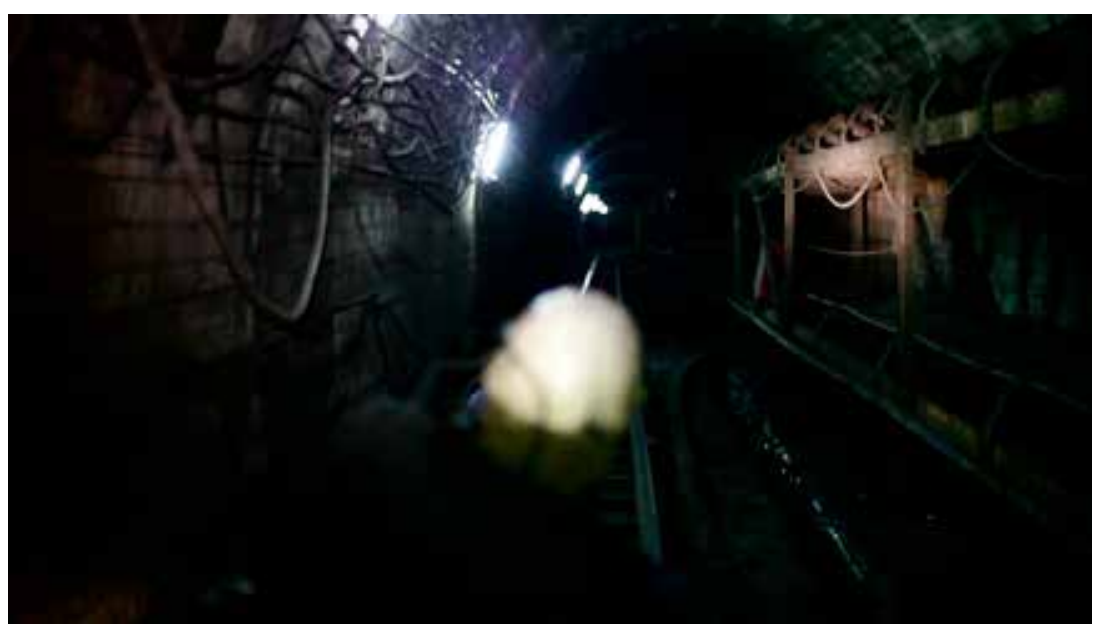

\subsection{Observing the dark universe in ARAGANE}

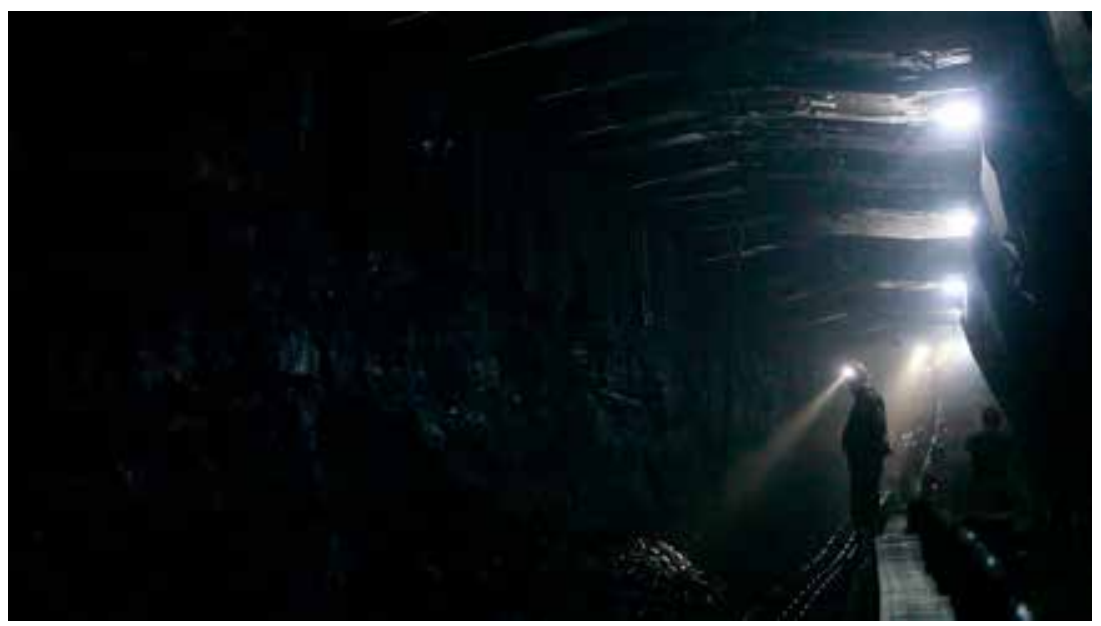

back to the other person - the person whose image is being shaped - their imperilled dignity' (Didi-Huberman 2018; emphasis in original). Both the technology of the dead and that of the living, I shall contend, potentially constitute a poetics/politics intersecting with the 'partition of the sensible', which works through the 'very organization of communicable form' (Demos 2013: 92) in embracing the promise of subversive art. 


\section{Works Cited}

Ai, W. (2018). 'The refugee crisis isn't about refugees. It's about us'. The Guardian. Retrieved 10 October 2018 from <https://www.theguardian.com/commentisfree/2018/feb/o2/ refugee-crisis-human-flow-ai-weiwei-china>.

Aidentiti: Kan-Chō-Chü zainichi dokyumento [Identity: A Document of South and North Koreans and Chinese in Japan] (2004). Tokyo: HAMAJIM.

Buder, E. (2017). 'Humanity Is Subjective'. The Atlantic. Retrieved 29 October 2018 from <https:// www.theatlantic.com/entertainment/archive/2017/10/ai-wei-wei-human-flow/542556/>.

Christiansen, S.L. (2017). 'War of the Senses'. Drone Age Cinema: Action Film and Sensory Assault, pp. 10-25. London: I.B.Tauris.

Colebrook, C. (2001). Gilles Deleuze. London; New York: Routledge.

Crickmar, R. (2017). 'Repurposing the Drone: Ai Weiwei's Human Perspective Shift'. Filmhouse. Retrieved 29 October 2018 from <https://www.filmhousecinema.com/latest/ repurposing-drone-ai-weiweis-human-perspective-shift >.

Dargis, M. (2017). 'Review: Ai Weiwei's “Human Flow” Tracks the Global Migrant Crisis'. The New York Times. Retrieved 29 October 2018 from <https://www.nytimes.com/2017/10/12/movies/ human-flow-review-ai-weiwei.html>.

Dew, O. (2016). Zainichi Cinema: Korean-in-Japan Film Culture. Cham, Switzerland: Springer International Publishing; Palgrave Macmillan.

Didi-Huberman, G. (2018). 'From a High Vantage Point'. Eurozine. Retrieved 28 October 2018 from <https://www.eurozine.com/high-vantage-point/>.

Dirlik, A. (1999). 'Place-based Imagination: Globalism and the Politics of Place', Review (Fernand Braudel Center), 22/2: 151-87. DOI: 10.2307/40241454.

'FILM FACTORY' (n.d.). Sarajevo Film Academy. Retrieved 20 October 2018 from $<$ https://www. sfa.ba/programs/film-factory-2>.

Fluri, J.L. (2015). 'Feminist Political Geography'. Agnew J., Mamadouh V., Secor A.J., and Sharp J. (eds.), The Wiley Blackwell Companion to Political Geography, pp. 235-247. New Jersey, US: Wiley-Blackwell.

Hinderliter, B., Kaizen, W., Maimon, V., Mansoor, J., and McCormick, S. (2009). 'Introduction: Communities of Sense'. In Hinderliter B., Kaizen W., Maimon V., Mansoor J., and McCormick S. (eds.), Communities of Sense: Rethinking Aesthetics and Politics, pp. 1-28. Durham; London: Duke University Press.

Hunt, L., and Leung, W.-F. (2008). 'Introduction'. In Hunt L. and Leung W.-F. (eds.), East Asian Cinemas: Exploring Transnational Connections on Film, pp. 1-13. London; New York: I.B. Tauris.

Kim, S. (2016). 'Towards a Technology of the Dead: Kim Soyoung on Her "Exile" Documentary Trilogy', Senses of Cinema, 78. Retrieved 10 May 2017 from $<$ http://sensesofcinema.com/2016/ feature-articles/kim-soyoung-exile-trilogy/>.

Kobayashi, E. (2017). 'Dokyumentarī eiga "kō ARAGANE” Oda Kaori kantoku intabyū' [Interview with the director of documentary ARAGANE]. DOTPLACE. Retrieved 20 October 2018 from $<$ http://dotplace.jp/archives/29278>.

Lee, A. (2017). 'Gender, Everyday Mobility, and Mass Transit in Urban Asia and Mass Transit in Urban Asia', Mobility in History, 8: 85-93. DOI: 10.3167/mih.2017.080110.

Lionnet, F., and Shih, S.-M. (2005). 'Introduction: Thinking through the Minor, Transnationally'. In Lionnet F. and Shih S. (eds.), Minor Transnationalism, pp. 1-23. Durham; London: Duke University Press.

Marks, L.U. (2000). The Skin of the Film: Intercultural Cinema, Embodiment, and the Senses. Durham; London: Duke University Press. 
Matteo, B. (2016). 'Interview with Oda Kaori'. Documentary in East and Southeast Asia. Retrieved 21 October 2018 from <https://storiadocgiappone.wordpress.com/2016/o3/11/ interview-with-oda-kaori/>.

Naficy, H. (2001). An Accented Cinema: Exilic and Diasporic Filmmaking. Princeton, NJ: Princeton University Press. DOI: 10.1177/1470412907075071.

neoneoweb2017 (2017). “Kō ARAGANE” Oda Kaori kantoku bosunia no kōzan to iū "michi no sekai" to no komyunikeishon' [Interview: Filmmaker Oda Kaori on the communication with the "unknown world" of the Bosnian coal mine]. NeoNeo. Retrieved 21 October 2018 from <http://webneo.org/archives/44031/2>.

Nguyen, M.T. (2015). 'Minor Threats', Radical History Review, May/122: 11-24. DOI: $10.1215 / 01636545^{-2849495}$.

Rancière, J. (2009). 'Contemporary Art and the Politics of Aesthetics'. In Hinderliter B., Maimon V., Mansoor J., and McCormick S. (eds.), Communities of Sense: Rethinking Aesthetics and Politics, pp. 31-50. Durham; London: Duke University Press.

Rancière, J., Carnevale, F., and Kelsey, J. (2007). 'Art of the Possible: Fulvia Carnevale and John Kelsey in conversation with Jacques Rancière'. Artforum International, March: 256-269.

Rofel, L. (2007). Desiring China: Experiments in Neoliberalism, Sexuality, and Public Culture. Durham: Duke University Press.

Rosenbaum, J. (2018). 'Notes on Oda Kaori's ARAGANE (from Lisbon)'. jonathanrosenbaum. net. Retrieved 10 October 2018 from <http://www.jonathanrosenbaum.net/2018/o2/ notes-on-aragone-from-lisbon/>.

Sharp, J. (2008). Behind the Pink Curtain: The Complete History ofJapanese Sex Cinema. Godalming, Surrey: FAB.

Silvey, R. (2004). 'Power, Difference and Mobility : Feminist Advances in Migration Studies', Progress in Human Geography, 4/28: 490-506.

Sun, G. (2000). 'How Does Asia Mean? (Part I)', (S.-L. Hui and K. Lau, transl.) Inter-Asia Cultural Studies, 1/1: 13-47. DOI: 10.1080/14649370050141186.

Tolia-Kelly, D.P. (2019). 'Rancière and the Re-Distribution of the Sensible: The Artist Rosanna Raymond, Dissensus and Postcolonial Sensibilities within the Spaces of the Museum', Progress in Human Geography, 43/1: 123-40. DOI: 10.1177/0309132517739141.

Trice, J.N. (2017). 'Location Shooting in "the Wild East": Risk and Masculinity in Hollywood Productions in the Philippines', Feminist Media Studies, 17/6: 988-1004. DOI: 10.1080/14680777.2017.1313290.

Yamanaka, K., and Piper, N. (2005). Feminized Migration in East and Southeast Asia: Policies, Actions and Empowerment. UNRISD Occasional Paper. Retrieved 10 January 2019 from <http:// hdl.handle.net/10419/148824>.

Zhang, Y. (2010). Cinema, Space and Polylocality in a Globalizing China. Honolulu: University of Hawaii Press. 


\section{Filmography}

2H. Dir. Ying Li. Dragon Films, 1999.

14 APPLES (Shisike pingguo). Dir. Midi Z. Cin. Midi Z. Seashore Image Production. 2018.

100 YEARS OFJAPANESE CINEMA (Nihon eiga no hyaku nen). Dir. \& Sc. Nagisa Oshima. Oshima

Productions, British Film Institute (BFI), Asahi National Broadcasting Company, 1995.

ABOVE THE CLOUDS (Kumo no ue). Dir. Katsuya Tomita. Sc. Katsuya Tomita, Taku Igawa, Takako

Takano. Cin. Takako Takano. Kuzoku, 2004.

ABSENCE WITHOUT LEAVE (Bujibuli). Dir. Kek-huat Lau. Hummingbird Production, 2016.

AFTER ALL THESE YEARS (Qihou). Dir. Kah-Wai Lim. 2010.

A GUIDE OF THE SLEEPLESS TOWN (Kabukicho Annaijin). Dir. Jiabei Zhang. Sc. Fumio Kōnami,

Keishi Nagi. Cin. Jun Tanaka. Perf. Chūyan, Tairo Yamamoto. 2004.

AJI (Dream Cuisine). Dir. Ying Li. Dragon Films, NHK, 2003.

A.K.A SERIAL KILLER (Ryakushō renzoku shasatsuma). Dir. Masao Adachi. Cin. Yutaka Yamazaki. 1968.

ALL UNDER THE MOON (Tsuki wa dochi ni dete iru). Dir. Yōichi Sai. Sc. Wui-Sin Chong, Yōichi

Sai. Cin. Jun'ichi Fujisawa. Perf. Gorō Kishitani, Ruby Moreno. Cine Qua Non Films, 1993.

ANNYONG KIMCHI. Dir. Tetsuaki Matsue. Perf. Masako Matsue, Tetsuaki Matsue. Japan Academy

of Visual Arts, 1999.

A NIGHT IN MALACCA (Maliujia yehua). Dir. Chuimui Tan. DaHuang Pictures, 2013.

APOCALYPSE NOW. Dir. Francis Ford Coppola. Sc. John Milius, Francis Ford Coppola. Cin.

Vittorio Storaro. Perf. Martin Sheen, Marlon Brando, Robert Duvall. Zoetrope Studios, 1979. ARAGANE. Dir. \& Cin. Kaori Oda. Bosnia and Herzegovina \& Japan: film.factory \& FieldRain, 2015. ASIA IS ONE (Ajia wa hitotsu). Dir. Nihon Documentarist Union. 1973.

ATTACK(Shūgeki). Dir. Yōichi Sai. Sc. Wui-Sin Chong. Toei Video, 1991.

A TIME TO LIVE AND A TIME TO DIE (Tongnian wangshi). Dir. Hsiao-Hsien Hou. Sc. T'ien-wen

Chu, Hsiao-Hsien Hou. Cin. Ping Bin Lee. Perf. Ru-Yun Tang, Feng Tien, Li-Yin Yang, An-Shun

Yu. Taiwan: Central Motion Pictures, Yi Fu Films, 1986.

A QUIET DREAM (Chun-mong). Dir. Lu Zhang. Sc. Lu Zhang. Cin. Young-jik Jo. Perf. Ye- ri Han,

Ik-joon Yang, Jung-bum Park. Lu Films, 2016.

BABYLON 2: THE OZAWA - GUNS OF BABYLON. Dir. \& Sc. Toranosuke Aizawa. Kuzoku, 2012.

BANGKOK NITES. Dir. Katsuya Tomita. Sc. Toranosuke Aizawa, Katsuya Tomita. Cin. Studioisi.

Perf. Katsuya Tomita, Subenja Pongkorn, Yohta Kawase. Bangkok Planning, Flying Pillow

Films, Kuzoku, Lao Art Media, Les Films de L'Etranger, Trixta, 2016.

BEGINNING OFCREATION: ABDUCTION/A CHILD (Sōzō no hattan: abudakushon/kodomo). Dir.

Chikako Yamashiro. 2015.

BOILING POINT (3-4xı-gatsu). Dir. \& Sc. Takeshi Kitano. Cin. Katsumi Yanagijima. Perf. Takeshi

Kitano, Yūrei Yanagi, Yuriko Ishida. Bandai Visual Company, Shochiku-Fuji Company, Yamada

Right Vision Corporation, 1990.

BLOOD AMBER (Xiehupo). Dir. \& Cin. Yong-chao Lee. 2017.

BUMMING IN BEIJING - LAST DREAMERS (Liulang Beijing - zuihoude mengxiangzhe). Dir.

Wenguang Wu. 1990.

CHONGQING. Dir. Lu Zhang. Sc. Lu Zhang. Perf. Ke-Yu Guo, Xiao He. South Korea: Sponge, 2008. CITY OFJADE (Feicuizhicheng). Dir. Midi Z. Seashore Image Production, 2016.

DEAR PYONGYANG. Dir. Yong-hi Yang. CHEON, 2005.

DESERT DREAM (Hyazgar). Dir. \& Sc. Lu Zhang. Cin. Sung-tai Kim. Perf. Suh Jung, Osor Bat-Ulzii.

G21M, Arizona Films, Centre National de la Cinématographie (CNC), Korean Film Council, 2007. 
DOOMAN RIVER (Duman-gang). Dir. Lu Zhang. Sc. Lu Zhang. Cin. Wei Xu. Perf. Jian Cui, Lan Yin, Jin-Long Lin. Lu Film, Arizona Films, Arte France Cinéma et.al., 2010.

EASY RIDER. Dir. Dennis Hopper. Sc. Peter Fonda, Dennis Hopper, Terry Southern. Cin. László Kovács, Baird Bryant. Perf. Peter Fonda, Dennis Hopper. Pando Company Inc., Raybert Productions. 1969 .

ELEVEN(Shiyisui). Dir. Lu Zhang. 2000.

FLY ME TO MINAMI (Koisuru minami). Dir. Kah-Wai Lim. Sc. Kah-Wai Lim \&. Aki Itami. Cin. Sherine Wong, Kenji Kohashi, Baek Seol Ah. Perf. Tetsuhiro Kato. Duckbill Entertainment, 2013. FLY WITH THE CRANE (Gaosu tamen wocheng baihe qule). Dir. Ruijun Li. Sc. Ruijun Li (adaptation), Su Tong (novel). Perf. Xing Chun Ma, Tang Long, Si-yi Wang. A Heavenly Pictures Culture and Media, Beijing Golden Days Co., Li Ruijun Film Studio, Nanjing Reade Cultural Communications, 2012.

FIREWORKS (Hana-Bi). Dir. \& Sc. Takeshi Kitano. Cin. Hideo Yamamoto. Perf. Takeshi Kitano, Kayoko Kishimoto, Ren Osugi. Bandai Visual Company, TV Tokyo, Tokyo FM Broadcasting Co. (as Tokyo FM), Office Kitano, 1997.

FURUSATO. Dir. Katsuya Tomita. Kuzoku, 2009.

GAISHANXI AND HER SISTERS (Gaishanxi he tade jiemei). Dir. Zhongyi Ban. SIGLO, 2007.

GIVE ME THE SUN (Taiyo ga Hoshii). Dir. Zhongyi Ban. SIGLO, 2016.

GOODBYE MYLOVE, NORTH KOREA. Dir. So-young Kim. Cinema DAL, 2017.

GRAININ THE EAR (Mangzhong). Dir. Lu Zhang. Sc. Lu Zhang. Cin. Yonghong Liu. Doo Entertainment Company, Doo Entertainment, Shu Film Workshop, 2005.

GYEONGJU. Dir. Lu Zhang. Sc. Lu Zhang. Cin. Young-jik Jo. Perf. Hae-il Park, Min-a Shin, Jin-seo Yoon. South Korea: Invent Stone, Lu Film, 2014.

FLOWER STORY BABYLON (Hana Monogatari Babylon). Dir. \& Sc. Toranosuke Aizawa. 1997

FUKUOKA. Dir. \& Sc. Lu Zhang. Cin. Jung-hun Park. Perf. Hae-hyo Kwon, So-dam Park, Yukari Yamamoto. Lu Film. 2019.

QUEER FISH LANE (Hengyoro). Dir. \& Sc. Gō Takamine. Cin. Mamoru Hirata. Perf. Susumu Taira,

Saburo Kitamura, Misako Ohshiro. Hengyoro Film Committee, 2017.

HEART OF SNOW, HEART OF BLOOD. Dir. So-young Kim. 2014.

HUMANFLOW. Dir. Weiwei Ai. Sc. Chin-Chin Yap \& Tim Finch \& Boris Cheshirko. Cin. Weiwei

Ai, Murat Bay, Christopher Doyle et al. 24 Media Production Company, AC Films, Ai Weiwei Studio et. al., 2017.

I WANT TO RUN FOR OFFICE (Senkyo ni detai). Dir. \& Cin. Fei Xing. Temjin TV, 2016.

ICE POISON (Bingdu). Dir. \& Sc. \& Cin. Midi Z. Perf. Shin-Hong Wang, Ke-Xi Wu. DaHuang Pictures, 2014.

IDENTITY (Aidentiti: Kan-Chō-Chū zainichi dokyumento/Identity: A Document of South and North Koreans and Chinese in Japan). Dir. Tetsuaki Matsue. HMJM, 2004.

JADE MINERS (Wayushi deren). Dir. Midi Z. Seashore Image Production, Taiwan Public Television Service, 2015.

JISEUL. Dir. \& Sc. Meul O. Cin. Jung-hoon Yang. Perf. Min-chul Sung, Jung-won Yang, Young-soon Oh. Japari Film, 2012.

KADEKARU RINSHŌ: SONGS AND STORIES (Kadekaru Rinshō: Uta to katari) Dir. Gō Takamine. Sesco Japan, 1994.

KAMUI (Kamui gaiden). Dir. Yôichi Sai. Sc. Kankurô Kudô, Yôichi Sai, Sampei Shirato (comic). Cin. Tomoo Ezaki, Jun'ichi Fujisawa. Perf. Ken'ichi Matsuyama, Koyuki, Kaoru Kobayashi. Eisei Gekijo, Horipro, Kinoshita Komuten et.al. 2009.

LEGEND OF THE DEMON CAT (Yaomaozhuan/Kukai:utsukushi ōhino nazo). Dir. Chen Kaige. Sc. Baku Yumemakura, Kaige Chen, Hui-ling Wang. Cin. Yu Cao. Perf. Shota Sometani, 
Xuan Huang. 21 Century Shengkai Film, Emperor Motion Pictures, Kadokawa, New Classics Media, 2017.

LEVEL FIVE. Dir. \& Sc. Chris Marker. Perf. Catherine Belkhodja, Kenji Tokitsu, Nagisa Ōshima.

Les Films de l'Astrophore, Argos Films et al. 1997.

LIFE TRACK. Dir. \& Sc. Guang-Hao Jin. Yanbian Broadcast. 2007.

A LONG JOURNEY BACK HOME: STRANDED WAR WIVES AND THEIR

FAMILIES'JOURNEYS (kokyō karukani: chūgokuzanryūfujin kazokunotabiji). Dir. Yan Feng. Kansai Telecasting Corporation., 1997.

LOVE AND ...(Pilreumsidaesarang). Dir. \& Sc. Lu Zhang. Cin. Young-jik Cho. Perf. Hae-il Park,

Sung-Ki Ahn, So-Ri Moon, Ye-ri Han. Smile Entertainment, Lu Film, 2015.

LOVE AND BRUISES (Hua). Dir. Ye Lou. Sc. Ye Lou, Liu Jie Falin. Cin. Lik-wai Yu. Perf. Corinne

Yam, Tahar Rahim. Les Films du Lendemain. 2011.

LOVE IN LATE AUTUMN(Aizaishenqiu). Dir. Kah-Wai Lim. Sc. Li Fei, Kah-Wai Lim, Freddie Wong.

Cin. Henry Chung. Perf. Irene Wan, Patrick Tam, Bingrui Zhao. Emperor Film Production, Irene Production, 2016.

THE MAN WHO LEFT HIS WILL ONFILM (Tokyo Sensō Sengo Hiwa). Dir. Nagisa Oshima. Sc. Nagisa

Ōshima, Tsutomu Tamura, Masato Hara \& Mamoru Sasaki. Cin. Tōichirō Narushima. Perf.

Kazuo Goto, Sukio Fukuoka, Kenichi Fukuda. Art Theater Guild, Sōzōsha, 1970.

MOUNTAINS MAY DEPART (Shan he gu ren). Dir. \& Sc. Zhangke Jia. Cin. Lik-wai Yu. Perf. Tao

Zhao, Yi Zhang, Jing Dong Liang. Xstream Pictures, Shanghai Film Group, MK2. 2015.

MUD MAN (Tsuchi no hito). Dir. Chikako Yamashiro. 2016.

MY LYRICAL TIMES (Watashitachi no jojō tekina jidai). Dir. \& Sc. Shujian Ren. Perf. Lam Pui Lim. 2009.

NEW WORLD (Shin Sekai). Dir. \& Sc. Kah-Wai Lim. Perf. Shi Ka, Tomonaga Koumei, Takeru Ogawa. Cinema Drifters, 2011.

ODE TO THE GOOSE (Gunsan: geowireul noraehada). Dir. \& Sc. Lu Zhang. Cin. Young-jik Cho.

Perf. Hae-il Park, So-ri Moon. Lu Film. 2018.

OFF HIGHWAY 20 (Kokudō nijū gōsen). Dir. Katsuya Tomita. Sc. Toranosuke Aizawa, Katsuya

Tomita. Cin. Toranosuke Aizawa. Perf. Jin Ito, Tsuyoshi Takano. Kuzoku, 2007.

OKINAWA CHIRUDAI (a.k.a Okinawa no seinaru kedarusa). Dir. Gō Takamine. Takamine Productions, 1979.

OKINAWAN DREAM SHOW. Dir. Gō Takamine. Takamine Productions, 1974.

OKINAWA: THE AFTERBURN (Okinawa: Urizun no ame). Dir. John Junkerman. Sc. Kōji Kobayashi. Japan: SIGLO Ltd., 2015.

OKINAWA ISLAND SONGS ECHOING IN THE PARISIAN SKY(Mugen Ryūkyū: Okinawa shimauta

Pari no sora ni hibiku). Dir. Gō Takamine. NHK, 2003.

OKINAWA SHIMAUTA QUEEN: Oshiro Misako. Dir. Gō Takamine. 2007.

OLD DOG (Laogou). Dir. \& Sc. Pema Tseden. Cin. Sonthar Gyal. Perf. Yanbum Gyal, Drolma Kyab, Lochey. Himalaya Audio \& Visual Culture Communication Co, Ltd., 2011.

THE OLD DONKEY(Laolutou). Dir. Ruijun Li. Sc. Ruijun Li. Cin. Jin Yang. Perf. Xing Chun Ma, Chun Yan Sun, Da Zhi Wang. China: Li Ruijun Film Studio, Indie Workshop, 2010.

ONIKKO - A RECORD OF THE STRUGGLE OF YOUTH LABORERS (Onikko: Tatakau senen rodosha no kiroku). Dir. Nihon Documentarist Union. 1969.

OUR HOMELAND (Kazoku no kuni). Dir. \& Sc. Yong-hi Yang. Cin. Yoshihisa Toda. Perf. Sakura Andô, Arata Iura, Ik-joon Yang. Star Sands, Slow Learner. 2012.

OVER THERE. Dir. Lu Zhang. Jeonju International Film Festival, 2013.

PARADISE VIEW (Paradaisu byū). Dir. \& Sc. Gō Takamine. Cin. Takao Toshioka. Perf. Kaoru Kobayashi, Jun Togawa, Haruomi Hosono. Heatburn Productions, 1985. 
PERFUMED NIGHTMARE (Mababangong Bangungot). Dir. \& Sc. Kidlat Tahimik. Cin. Hartmut Lerch, Kidlat Tahimik. Perf. Mang Feld, Dolores Santamaria. Zoetrope Studios. 1977.

PERSISTING WITH TEARS IN EYES (Hanlei huozhe/naginagara ikite). Dir. Liling Zhang. Fuji Television, 2009.

PIG'S REVENGE (Buta no mukui). Dir. Yōichi Sai. Sc. Wui-Sin Chong, Yôichi Sai. Cin. Yasushi Sasakibara. Perf. Michiko Ameku, Yoshie Hayasaka, Ittoku Kishibe. WOWOW, 1999.

PLATFORM (Zhantai). Dir. Zhangke Jia. Sc. Zhangke Jia. Cin. Nelson Lik-wai Yu. Perf. Hongwei Wang, Tao Zhao, Jing Dong Liang. Artcam International, Bandai Entertainment Inc., Hu Tong Communications, Office Kitano, T-Mark, 2000.

POOR FOLK (Qiongren, liulian, mayao, touduke). Dir. \& Sc. \& Cin. Midi Z. Perf. Shin-Hong Wang,

Ke-Xi Wu, De-Fu Zhao. Montage Film Production, Seashore Image Production, 2012.

POPIAH (Baobing). Dir. Royston Tan. DaHuang Pictures, 2013.

THE PROFOUND DESIRE OF THE GODS (Kamigami no fukaki yokubō). Dir. Shōhei Imamura.

Sc. Keiji Hasebe, Shōhei Imamura. Cin. Masao Tochizawa. Perf. Rentarō Mikuni, Chôichirô Kawarasaki. Nikkatsu, 1968.

RAGE (Ikari). Dir. Sang-il Lee. Sc. Shūichi Yoshida, Sang-il Lee. Cin. Norimichi Kasamatsu. Perf. Ken Watanabe, Mirai Moriyama, Aoi Miyazaki. Chunichi Shimbun \& Chūōkōron Shinsha et al. 2016.

RED MAN. Dir. Gō Takamine. 1970.

REMINISCENCES OF A JOURNEY TO LITHUANIA. Dir. \& Sc. Jonas Mekas. Cin. Adolfas Mekas, Jonas Mekas. Vaughan Films, 1972.

RETURN TO BURMA (Guilai de ren). Dir. \& Sc. \& Cin. Midi Z. Perf. Shin-Hong Wang. Flash Forward Entertainment, Montage Film Production, Seashore Image Production, 2011.

REST IN PEACE MY FRIEND (Toma yo, shizuka ni nemure). Dir. Yōichi Sai. Sc. Kenzo Kitakata (novel), Shoichi Maruyama. Cin. Takeshi Hamada. Perf. Tatsuya Fuji, Mitsuko Baishô, Yoshio Harada. Kadokawa Haruki Jimusho, 1985.

ROAD TO MANDALAY (Zaijian wacheng). Dir. \& Sc. Midi Z. Cin. Tom Fan. Perf. Kai Ko, Ke-Xi Wu.

Bombay Berlin Film Productions, CMC Entertainment, Seashore Image Production et al. 2016. RIVER ROAD (Jiazai shuicaofengmao de difang). Dir. \& Sc. Ruijun Li. Cin. Yonghong Liu. Perf. Long Tang, Songtao Guo. Laurel Films, 2014.

SACRIFICED YOUTH (Qingchunji). Dir. Nuanxing Zhang. Sc. Manling Zhang, Nuanxing Zhang. Cin. Teyuan Mu, Wei Teng. Perf. Yuanzheng Feng, Fengxu Li. Youth Film Studio of Beijing Film Academy. 1986.

SAUDADE. (Saudāji). Dir. Katsuya Tomita. Sc. Toranosuke Aizawa, Katsuya Tomita. Cin. Takako Takano. Perf. Dengaryū, Chie Kudō, Tsuyoshi Takano, Yasushi Sumida, Shinji Miyadai. Kuzoku. 2012

SCENERY (Pung-gyeong). Dir. Lu Zhang. Jeonju International Film Festival, Lu Films, 2013. SINGAPORE PANDA (Xinxin xiongmao). Dir. Sun Koh. DaHuang Pictures, 2013.

SONA, THE OTHER MYSELF. Dir. \& Sc. \& Cin. Yang Yong-hi. Wahaha Hompo, Zio Entertainment. 2009 .

SOMEONE WILL BE KILLED (Itsuka darekaga korosareru). Dir. Yōichi Sai. Sc. Jun Takada, Jirō Akagawa (novel). Cin. Takeshi Hamada. Perf. Noriko Watanabe, Masato Furuoya. Kadokawa Haruki Jimusho, Toei Company. 1984.

SONATINE (Sonachine). Dir. \& Sc. Takeshi Kitano. Cin. Katsumi Yanagijima. Perf. Takeshi Kitano, Aya Kokumai, Tetsu Watanabe. Japan: Bandai Visual Company, Shouchiku Co., Shōchiku Eiga, Yamada Right Vision Corporation, 1993.

THE STORY OF JIN YUJI (Jin Yuji). Dir. Jiayi Wang. Sc. Jiayi Wang, Ye Ji. Perf. Yang Bai, Yan She, Kefu Shi. 1959. 
SUMMER PALACE (Yihe Yuan). Dir. Ye Lou. Sc. Ye Lou, Feng Mei, Yingli Ma. Cin. Hua Qing. Perf. Lei Hao, Xiaodong Guo. Centre National de la Cinématographie, Dream Factory, Flying Moon Filmproduktion. Et al. 2006.

SUMMER VACATION IN NORTH KOREA (Kitachōsen no natsuyasumi). Dir. Shujian Ren. 2005. SUZHOU RIVER (Suzhou he). Dir. \& Sc. Ye Lou. Cin. Yu Wang. Perf. Xun Zhou, Hoogsten Jia. Coproduction Office, Essential Filmproduktion GmbH. 2000.

TANG POETRY (Tang shi). Dir. Lu Zhang. Sc. Lu Zhang. Doo Entertainment, 2003.

TARGETED VILLAGE (Hyōteki no mura). Dir. Chie Mikami. Sc. Izumi Matsuishi. Cin. Toshiki Terada. Ryukyu Asahi Broadcasting, 2012.

THUS THE NOISE SPEAKS (Noizu ga iu niwa). Dir. \& Sc. Kaori Oda. Cin. Miho Nishimura. Perf. Chigusa Oda, Kaori Oda, Sayuri Oda. 2010.

TOWARD A COMMON TENDERNESS (Ano yasashi-sa e). Dir. \& Cin. Kaori Oda. 2017.

TOWER OF LILIES (Himeyuri no tō). Dir. Tadashi Imai. Sc. Yōko Mizuki. Cin. Shunichiro Nakao. Perf. Komaki Kurihara, Yûko Kotegawa, Yoshiko Tanaka. Geiensha Company, 1953.

TSURU-HENRY. Dir. Gō Takamine. Sc. Go Takamine, Isao Nakazato. Perf. Misako Oshiro, Katsuma Miyagi, Miezo Toma, Susumu Taira. Takamine Productions, 1998.

TUYA'S MARRIAGE (Tuya de hunshi). Dir. Quan'an Wang. Sc. Wei Lu, Quan'an Wang. Cin. Lutz Reitemeier. Perf. Nan Yu, Ba'toer, Sen'gel. Maxyee Culture Industry, Xian Motion Picture Company, 2006.

UNCLE BOONMEE WHO CAN RECALL HIS PAST LIVES. Dir. Apichatpong Weerasethakul. Sc. (inspired by the book of) Phra Sripariyattiweti, Apichatpong Weerasethakul. Cin. Sayombhu Mukdeeprom. Perf. Thanapat Saisaymar, Jenjira Pongpas, Sakda Kaewbuadee. Kick the Machine, Illuminations Films, et al. 2010.

UNTAMAGIRŪ. Dir. \& Sc. Gō Takamine. Cin. Makasi Tamura. Perf. Chikako Aoyama, Kaoru Kobayashi, John Sayles. Parco Co. Ltd., 1989.

VIA OKINAWA (A-Sain deizu). Dir. Yōichi Sai. Sc. Yōichi Sai, Hiroshi Takahashi. Cin. Takeshi Hamada. Perf. Anna Nakagawa, Ryo Ishibashi, Leona Hirota. Daiei Motion Picture Company, 1989.

WALKING ON WATER (Xingzai shuishang). Dir. Ming-liang Tsai. DaHuang Pictures, 2013. WE SHALL OVERCOME (Ikusaba nu tudumi). Dir. Chie Mikami. Cin. Chizuna Okubo \& Chie Mikami. DOCUMENTARY JAPAN, TOFOO FILMS, 2015.

WOMAN OF THE BUTCHER SHOP (Nikuya no onna). Dir. Chikako Yamashiro. 2012.

YASUKUNI (Jingguo shenshe). Dir. \& Sc. Ying Li. Dragon Films, Japanese Agency for Cultural Affairs, Asian Network of Documentary, Beijing Youth Film Studio. Et al. 2007.

YOUR VOICE CAME OUT THROUGH MYTHROAT (Anata no koe wa watashi no nodowo tsuji da). Dir. Chikako Yamashiro. 2009. 



\section{Bibliography}

'107niandiyitici guochandianying changpian fudaojin huoxuan mingdan [First round of receipients for 2018 domestic feature film assistance grant application]'. (2019). Ministry of Culture (Taiwan). Retrieved 11 January 2019 from <https://grants.moc.gov.tw/Web/ PointPublish.jsp? $\mathrm{M}=2 \& \mathrm{R}=1 \& \mathrm{PT}=2334 \& \mathrm{~B}=3021 \& \mathrm{fbclid}=\mathrm{IwARoXNCQLboehMO} \mathrm{rc}$ zZ-KXsRW6MJNwLoo7VNiPWptdT6A_XgWv-4dnmkxRM>.

'2016 Foreigner Labour Force Survey'. (2016). Statistics Korea. Retrieved 1o October 2017 from $<$ http://kostat.go.kr/portal/eng/pressReleases/1/index.board?bmode=read\&aSeq=358181 $>$.

Abbas, A. (2010). 'Affective Spaces in Hong Kong/Chinese Cinema'. In Braester Y. and Tweedie J. (eds.), Cinema at the City's Edge: Film and Urban Networks in East Asia, pp. 25-35. Hong Kong: Hong Kong University Press.

Abé Nornes, M. (2011). 'Asian Film Festivals, Translation, and the International Film Festival Short Circuit'. In Iordanova D. and Cheung R. (eds.), Film Festival Yearbook 3: Film Festivals and East Asia, pp. 42-45. St. Andrews: St Andrews Film Studies.

- (2014). 'Yamagata-Asia-Europe: The International Film Festival Short Circuit'. In Miyao D. (ed.) The Oxford Handbook ofJapanese Cinema, pp. 245-62. New York: Oxford University Press.

'About Midnight Blur Films' (n.d.). Midnight Blur Films. Retrieved 1 February 2019 from <https:// www.midnightblurfilms.com/about $>$.

Ahmed, S. (2014). The Cultural Politics of Emotion. Second edition. Edinburgh: Edinburgh University Press.

Ai, W. (2018). 'The refugee crisis isn't about refugees. It's about us'. The Guardian. Retrieved 10 October 2018 from <https://www.theguardian.com/commentisfree/2018/feb/o2/ refugee-crisis-human-flow-ai-weiwei-china $>$.

Aidentiti:Kan-Chō-Chüzainichi dokyumento [Identity: A Document of South and North Koreans and Chinese in Japan] (2004). Tokyo: HAMAJIM.

Ambaras, D.R., and McDonald, K. (2019). 'What We're Doing'. Bodies and Structures:Deep-Mapping Modern East Asian History. Retrieved 10 February 2019 from <https://scalar.chass.ncsu.edu/ bodies-and-structures/what-were-doing>.

Ang, I. (2001). On Not Speaking Chinese: Living Between Asia and the West. London; New York: Routledge.

Angst, L. (1997). 'Gendered Nationalism: The Himeyuri Story and Okinawan Identity in Postwar Japan', PoLAR: Political and Legal Anthropology Review, 20/1: 100-13. DOI: 10.1525/pol.1997.20.1.100.

Arasaki, M. (2014). 'Can Okinawa be the "Catalyst" for peace in East Asia?', Inter-Asia Cultural Studies, 15/1: 43-62. DOI: 10.1080/14649373.2014.88804.

Argo Pictures (ed.) (2008). Li Ying's YASUKUNI. Tokyo: Dragon Films.

Asakura, T. (2002). '“Kabukicho guide" offers punters a walk on the wild side'. The Japan Times. Retrieved 1 December 2018 from <https://www.japantimes.co.jp/news/2002/og/29/national/ kabukicho-guide-offers-punters-a-walk-on-the-wild-side/\#.W81jAhMzZnY>.

'Asian Project Market (APM)' (2018). Busan International Film Festival. Retrieved 1o November 2018 from <http://apm.asianfilmmarket.org/eng/database/list_ppp_history.asp?this_year=2018>.

Balibar, E. (2002). Politics and the Other Scene. (C. Jones, J. Swenson, and C. Turner, transl.), first. London; New York: Verso. DOI: 10.1177/030981680608800115.

Ban, Z. (1992). So obasan no umi [Grandma Zeng's Sea]. Tokyo: Asahi Shinbunsha.

- (1996). Chikakute tōi sokoku [Near and Far Homeland]. Tokyo: Yumani Shobō. 
Baskett, M. (2008). The Attractive Empire: Transnational Film Culture in Imperial Japan. Honolulu: University of Hawaii Press.

Baumgärtel, T. (2012). 'Introduction: Independent Cinema in Southeast Asia'. In Baumgärtel T. (ed.), Southeast Asian Independent Cinema, pp. 1-10. Hong Kong: University of Hong Kong Press.

Ben-Ari, E., and Otmazgin, N. (eds.) (2012). Popular Culture Co-Productions and Collaborations in East and Southeast Asia (Kyoto Cseas Series on Asian Studies). Singapore: NUS Press; Kyoto: Kyoto University Press.

Bender, M. (2016). 'Ethnic Minority Literature'. In Zhang Y. (ed.), A Companion to Modern Chinese Literature, p. 302. West Sussex, UK: John Wiley \& Sons, Ltd.

Benjamin, W. (1978). 'Paris, Capital of the 19th Century'. In Demetz P. (ed.), Reflections: Essays, Aphorisms, Autobiographical Writings, pp. 146-162. New York: Schocken.

Berlant, L., Butler, J., Cvejic, B., Lorey, I., Puar, J., and Vujanovic, A. (2012). 'Precarity Talk', TDR: The Drama Review, 56/4: 163-177.

Bernards, B. (2012). 'Beyond Diaspora and Multiculturalism: Recuperating Creolization in Postcolonial Sinophone Malaysian Literature', Postcolonial Studies, 15/3: 311-329. DOI: 10.1080/13688790.2012.728371.

- (2016). Writing The South Seas: Imagining The Nanyang in Chinese And Southeast Asian Postcolonial Literature. Singapore: NUS Press.

Berry, C. (2010). 'What is Transnational Cinema? Thinking from the Chinese Situation', Transnational Cinemas, 1/2:111-127. DOI: 10.1386/trac.1.2.111_1.

- (2013). 'Transnational Culture in East Asia and the Logic of Assemblage', Asian Journal of Social Science, 41/5: 453-470. DOI: 10.1163/15685314-12341314.

- (2016). 'Pema Tseden and the Tibetan Road Movie: Space and Identity beyond the "Minority Nationality Film”,'Journal of Chinese Cinemas, 10/2: 89-105. DOI: 10.1080/17508061.2016.1167334.

-, Liscutin, N., and Mackintosh, J.D. (eds.) (2009). Cultural Studies and Cultural Industries in Northeast Asia: What a Difference a Region Makes. Hong Kong: Hong Kong University Press.

Bhabha, H. (2004). The Location of Culture. Second edition. London; New York: Routledge.

Blaney, M. (2009). 'Locarno's Open Doors to focus on Greater China'. SCREENDAILY. Retrieved 10 August 2017 from <http://www.screendaily.com/festivals/other-festivals/locarnos-opendoors-to-focus-on-greater-china/4043238.article>.

Boehler, N. (2014). 'Haunted Time, Still Photography and Cinema as Memory: The Dream Sequence in Uncle Boonmee Who Can Recall His Past Lives', Journal of Modern Literature in Chinese, 12/1: 66-78.

Boym, S. (2001). The Future of Nostalgia. New York: Basic Books.

Brasor, P. (2008). 'Yasukuni Film and NHK's Declaration to Promote National Interests. Government Funding, Free Expression and Propaganda in Japan', The Asia-Pacific Journal | Japan Focus, 6/4: 4-6.

Brickell, K., and Datta, A. (2011). 'Introduction: Translocal Geographies'. In Brickell K. and Datta A. (eds.), Translocal Geographies: Spaces, Places, Connections, pp. 3-20. Farnham, UK; Burlington, USA: Ashgate Publishing Limited. DOI: 10.1080/1369183X.2012.740986.

Brubaker, R. (2015). Grounds for Difference. Cambridge, MA; London, UK: Harvard University Press.

Buchanan, I. (2005). 'Space in the Age of Non-Place'. In Buchanan I. and Lambert G. (eds.), Deleuze and Space, pp. 16-35. Edinburgh: Edinburgh University Press.

Buder, E. (2017). 'Humanity Is Subjective', The Atlantic. Retrieved 29 October 2018 from <https:// www.theatlantic.com/entertainment/archive/2017/10/ai-wei-wei-human-flow/542556/>. 
Buff (2018). 'Interview with Midi Z: On 14 Apples' [Zhuanfang: shisike pingguo zhaodeyin]. Hypesphere. Retrieved 3 October 2018 from <https://www.hypesphere.com/news/15154>.

Butler, J. (2009). Frames of War: When is Life Grievable? London; New York: Verso. DOI: $10.1080 / 00335631003796701$.

Cathcart, A. (2010). 'Nationalism and Ethnic Identity in the Sino-Korean Border Region of Yanbian, 1945-1950', Korean Studies, 34: 25-53.

Chan, F. (2017). Cosmopolitan Cinema: Cross-Cultural Encounters in East Asian Film. London; New York: I.B. Tauris.

Chan, K. (2009). Remade in Hollywood: The Global Chinese Presence in Transnational Cinemas. Hong Kong: Hong Kong University Press.

Chan, M.M. (2017). 'Mail-Order Brides and Methamphetamines: Sinophone Burmeseness in Midi Z's Burma Trilogy', Concentric: Literary and Cultural Studies, 43/September: 11-31. DOI: 10.6240/concentric.lit.2017.43.2.02.

Chan, Y. (2011). Abandoned Japanese in Postwar Manchuria: The Lives of War Orphans and Wives in Two Countries. London; New York: Routledge.

Chan, Y.W. (2014). 'Asian Migration: Issues, Migrants, and Regional Updates'. In Chan Y.W., Haines D.W., and Lee J.H.X. (eds.), The Age of Asian Migration: Continuity, Diversity, and Susceptibility, Volume 1, pp. 1-17. Newcastle upon Tyne: Cambridge Scholars Publishing.

Chang, H.-H. (2009). 'Transnational Affect: Cold Anger, Hot Tears, and "Lust, Caution"', Concentric: Literary and Cultural Studies, 35/1: 31-50.

'Chaoxianzu yiminhoudai zhang lu:jiazaizhongguo, shiye zai hanguo' [The Descendant of Chaoxianzu Immigrant Zhang Lu: Home in China, Career in Korea] (2016). Tencent Video. Retrieved ${ }_{27}$ September 2018 from <https://v.qq.com/x/cover/oekd8sg2qed7ynl/foo2143bpb4.html>.

Chen, C.-T. (2014). 'Zugen yu zugen - Dongnanya huarendaoyan duanpianji “Nanfang laixin" [Ancestral Roots and Moving Feet: The Omnibus Film Letters from the South by Six Southeast Asian Filmmakers], Film Appreciation, 3: 97-107+135.

Chen, K.-H., and Chua, B.H. (2007). 'Introduction/The Inter-Asia Cultural Studies: Movement project'. In Chen K.-H. and Chua B.H. (eds.), The Inter-Asia Cultural Studies Reader, pp. 1-5. London; New York: Routledge.

Chen, L.L. (2015). 'When Does “Diaspora” End and “Sinophone” Begin?', Postcolonial Studies, 18/1: 52-66. DOI: 10.1080/13688790.2015.1050975.

Chen, T. (2007). 'Minorities "in between" China and Japan: Complexity of Legal Status and Identity', Bulletin of the National Museum of Ethnology, 31/3: 419-437.

Chiang, H., and Heinrich, A.L. (eds.) (2014). Queer Sinophone Cultures. Abingdon, Oxon New York, NY: Routledge. DOI: 10.4324/9780203590928.

-, and Wong, A.K. (2016). 'Queering the Transnational Turn: Regionalism and Queer Asias', Gender, Place \& Culture, 23/11: 1-14. DOI: 10.1080/0966369X.2015.1136811.

Choi, Jinhee, and Wada-Marciano, M. (eds.) (2009). Horror to the Extreme: Changing Boundaries in Asian Cinema. Hong Kong: Hong Kong University Press.

Choi, JungBong. (2011). 'National Cinema: An Anachronistic Delirium?', The Journal of Korean Studies, 16/2: 173-192. DOI: 10.1353/jks.2011.0012.

Christiansen, S.L. (2017). 'War of the Senses'. In Drone Age Cinema: Action Film and Sensory Assault, pp. 10-25. London: I.B.Tauris.

Clifford, J. (1992). 'Traveling Cultures'. In Grossberg L., Nelson C., and Treichler P.A. (eds.), Cultural Studies, pp. 96-116. New York: Routledge.

Colebrook, C. (2001). Gilles Deleuze. London; New York: Routledge 
Colin, S. (2003). 'A Border Opening onto Numerous Geopolitical Issues - The Yanbian Korean Autonomous Prefecture', China Perspectives, 48: 1-25.

Combs, D. (2018). 'Myanmar's Jade Fueled War'. The Diplomat. Retrieved 3 October 2018 from $<$ https://thediplomat.com/2018/o6/myanmars-jade-fueled-war/>.

Corcoran, S. (2010). 'Editor's Introduction'. In Corcoran S. (ed.), Dissensus: On Politics and Aesthetics, pp. 1-24. London; New York: Continuum International Publishing Group.

Crickmar, R. (2017). 'Repurposing the Drone: Ai Weiwei's Human Perspective Shift'. Filmhouse. Retrieved 29 October 2018 from <https://www.filmhousecinema.com/latest/ repurposing-drone-ai-weiweis-human-perspective-shift $>$.

'DaHuang Pictures' (2016). DaHuang Pictures. Retrieved 15 March 2018 from <http://www. dahuangpictures.com/about>.

Dargis, M. (2017). 'Review: Ai Weiwei's "Human Flow" Tracks the Global Migrant Crisis'. The New York Times. Retrieved 29 October 2018 from <https:/www.nytimes.com/2017/10/12/movies/ human-flow-review-ai-weiwei.html>.

Davis, N. (2013). The Desiring-Image: Gilles Deleuze and Contemporary Queer Cinema. Oxford, UK: Oxford University Press. DOI: 10.1093/acprof.

DeBoer, S. (2014). Coproducing Asia Locating Japanese-Chinese Regional Film and Media. Minneapolis: University of Minnesota Press.

Deleuze, G. (1989). Cinema 2: The Time-Image. (H. Tomlinson and R. Galeta, transl.). Minneapolis: University of Minnesota Press. DOI: 9781472512604.

Deleuze, G., and Guattari, F. (1983). 'What Is a Minor Literature?', (R. Brinkley, transl.) Mississippi Review, 11/3: 13-33.

Demos, T.J. (2013). The Migrant Image: The Art and Politics of Documentary during Global Crisis. Durham; London: Duke University Press.

Dew, O. (2016). Zainichi Cinema: Korean-in-Japan Film Culture. Cham, Switzerland: Springer International Publishing; Palgrave Macmillan.

Didi-Huberman, G. (2018). 'From a High Vantage Point'. Eurozine. Retrieved 28 October 2018 from <https://www.eurozine.com/high-vantage-point/>.

Dietz, K. (2016). 'Transnationalism and Transition in the Ryūkyūs'. In Iacobelli P., Leary D., and Takahashi S. (eds.), Transnational Japan as History: Empire, Migration, and Social Movements, pp. 211-241. New York: Palgrave Macmillan US.

Dirlik, A. (1999). 'Place-based Imagination: Globalism and the Politics of Place', Review (Fernand Braudel Center), 22/2: 151-187. DOI: 10.2307/40241454.

Dirlik, A., and Zhang, X. (1997). 'Introduction: Postmodernism and China', Boundary 2: AJournal of Postmodern Literature and Culture, 24/3: 1-18.

Doak, K.M. (2007). A History of Nationalism in Modern Japan:Placing the People. Leiden; Boston: Brill.

Efird, R. (2004).Japan's War Orphans and New Overseas Chinese: History, Identification and (Multi)ethnicity. Dissertation (Ph.D.), University of Washington. Retrieved from $<\mathrm{http}: / /$ proquest.umi.com/pqdweb?did $=813777381 \&$ Fmt $=7 \&$ clientId $=15403 \&$ RQT $=309 \& V N a m e=P Q D>$

- (2010). 'Distant Kin: Japan's "War Orphans” and the Limits of Ethnicity', Anthropological Quarterly, 83/4: 805-38. DOI: 10.1353/anq.2010.0021.

- (2012). 'Regionalism and National Dis-integration: Li Ying's Yasukuni and the Co-creation of East Asia'. In Otmazgin N. and Ben-Ari A. (eds.), Popular Culture Co-production and Collaborations in East and Southeast Asia, pp. 171-184. Singapore: NUS Press; Kyoto: Kyoto University Press. DOI: 10.1386/eapc.1.1.163. 
Eimer, D. (2016). 'Myanmar's once-booming film industry gears up for act two'. South China Morning Post. Retrieved 3 October 2018 from <https://www.scmp.com/magazines/post-magazine/ film-tv/article/1900617/myanmars-once-booming-film-industry-gears-act-two>.

Elsaesser, T. (2009). 'Holocaust Memory as the Epistemolog of Forgetting?: Re-wind and Postponement in Respite'. In Ehmann A. and Eshun K. (eds.), Harun Farocki, Against What? Against Whom?, pp. 57-68. London: Koenig Books.

- (2017). 'The Global Auteur: Control, Creative Constraints, and Performative Self-Contradiction'. In Jeong S. and Szeniawski J. (eds.), The Global Auteur: The Politics of Authorship in 21st Century Cinema, pp. 21-42. New York; London: Bloomsbury Academic.

Endō, T. (2009). Exporting Japan: Politics of Emigration toward Latin America. Urbana: University of Illinois Press.

Erni, J.N. (ed.) (2017). Visuality, Emotions and Minority Culture: Feeling Ethnic. Berlin; Heidelberg: Springer Berlin Heidelberg.

Ezra, E., and Rowden, T. (2006). 'General Introduction: What is Transnational Cinema?'. In Ezra E. and Rowden T. (eds.), Transnational Cinema: The Film Reader, pp. 1-12. New York; Abingdon, UK: Routledge.

'Fei cui zhi cheng' [City of Jade] (2016). Forum/Forum Expanded, pp. 54-56. Berlin: The International Forum of New Cinema, Berlinale.

'FILM FACTORY' (n.d.). Sarajevo Film Academy. Retrieved 20 October 2018 from $<$ https://www. sfa.ba/programs/film-factory-2>.

Fluri, J.L. (2015). 'Feminist Political Geography'. In Agnew J., Mamadouh V., Secor A. J., and Sharp J. (eds.), The Wiley Blackwell Companion to Political Geography, pp. 235-247. New York: John Wiley \& Sons.

Fowler, E. (1996). San'ya Blues: Laboring Life in Contemporary Tokyo. Ithaca, NY: Cornell University Press.

Frangville, V. (2016). 'Pema Tseden's The Search: The Making of a Minor Cinema', Journal of Chinese Cinemas, 10/2: 106-120.

Furuhata, Y. (2007). 'Returning to Actuality: Fūkeiron and the Landscape Film', Screen, 48/3: 345-362. DOI: 10.1093/screen/hjmo34.

- (2013). Cinema of Actuality:Japanese Avant-Garde Filmmaking in the Season of Image Politics. Durham: Duke University Press.

Gallagher, M., and Shin, C.-Y. (eds.) (2015). East Asian Film Noir: Transnational Encounters and Intercultural Dialogue. London: I.B. Tauris.

Gates, P., and Funnell, L. (eds.) (2012). Transnational Asian Identities in Pan-Pacific Cinemas: The Reel Asian Exchange. London; New York: Routledge.

Gender Equality and Women's Rights: A Situation Analysis (2016). Mandaluyong City, Philippines: Asian Development Bank.

Gerow, A. (2002). 'From Independence to Detachment in Recent Japanese Film' [cong dulizouxiang chouxiang: dangdai riben dianying]. Focus on Japan: Independent Cinema, pp. 6-12. Hong Kong: Hong Kong International Film Festival.

- (2003). 'From the National Gaze to Multiple Gazes: Representations of Okinawa in Recent Japanese Cinema'. In Hein L. and Selden M. (eds.), Okinawan Responses to Japanese and American Power, pp. 273-303. Lanham, MD: Rowman \& Littlefield Publishers.

- (2009). 'The Homelessness of Style and the Problems of Studying Miike Takashi', Canadian Journal of Film Studies, 18/1: 24-43. 
- (2016). 'Globalism, New Media, and Cinematically Imagining the Inescapable Japan'. In Iwabuchi Koichi, Tsai E., and Berry C. (eds.), Routledge Handbookfor East Asian Popular Culture, pp. 86-92. London: Routledge.

- (2017). 'Yamagata International Documentary Film Festival 2017'. Tangemania. Retrieved 12 December 2018 from <http://www.aarongerow.com/news/yamagata-international.html>.

Gomà, D. (2007). 'The Chinese-Korean Border Issue: An Analysis of a Contested Frontier', Asian Survey, 46/6: 867-880. DOI: 10.1525/as.2006.46.6.867.

Gordon, A. (2003). A Modern History of Japan: From Tokugawa Times to the Present. New York: Oxford University Press. DOI: 10.2307/20033555.

Greiner, C., and Sakdapolrak, P. (2013). 'Translocality: Concepts, Applications and Emerging Research Perspectives', Geography Compass, 7/5: 373-384. DOI: 10.1111/gec3.12048.

Groppe, A.M. (2013). Sinophone Malaysian Literature:Not Made in China. Amherst, NY: Cambria Press.

Gunning, T. (1989). 'Towards a Minor Cinema: Fonoroff, Herwitz, Ahwesh, Lapore, Klahr and Solomon', Motion Picture, $3(1 / 2): 2-5$.

Guo, F. (1999). Zainichi kakyō no aidentiti no hen'yō: Kakyō no tagenteki kyōsei [The Changing Identity of Chinese in Japan: Their Multidimensional Acculturation]. Tokyo: Toshindo.

Gushiken, K. (2017). 'Beigun kichi mondai to masukomi hōdō' [The US Base Problem and Mass Media Report], Masu komyunikeishon kenkyu [Journal of Mass Communication Studies], 91: 3-21. DOI: https://doi.org/10.2446o/mscom.91.o_3.

Hardt, M., and Negri, A. (200o). Empire. Cambridge, MA; London: Harvard University Press.

Harootunian, H. (1999). 'Memory, Mourning, and National Morality: Yasukuni Shrine and the Reunion of State and Religion in Postwar Japan'. In Veer P. T. van der and Lehmann Hartmut (eds.), Nation and Religion: Perspectives on Europe and Asia, pp. 144-16o. Princeton, NJ: Princeton University Press.

Hee, W.-S. (2018). Huayudianying zai houmalaixiya:tuqiang fengge, huayifeng yu zuozhelun [Post-Malaysian Chinese-Language Film: Accented Style, Sinophone and Auteur Theory]. Xinbei, Taiwan: Linking Publishing.

Hein, I. (2010). 'Constructing Difference in Japan: Literary Counter-images of the Okinawa Boom', Contemporary Japan, 22/1-2: 179-204. DOI: 10.1515/cj.2010.011.

Hein, L., and Jennison, R. (2011). 'Against Forgetting: Three Generations of Artists in Japan in Dialogue about the Legacies of World War II', The Asia-Pacific Journal |Japan Focus, 9/30: 1-18.

Higbee, W. (2007). 'Beyond the (Trans)National: Towards a Cinema of Transvergence in Postcolonial and Diasporic Francophone Cinema(s)', Studies in French Cinema, 7/2: 79-91. DOI: 10.1386/sfci.7.2.79.

Higbee, W., and Lim, S.H. (2010). 'Concepts of Transnational Cinema: Towards a Critical Transnationalism in Film Studies', Transnational Cinemas, 1/1: 7-21. DOI: 10.1386/trac.1.1.7/1.

Highmore, B. (2011). 'Out of Place: Unprofessional Painting, Jacques Rancière, and the Distribution of the Sensible'. In Bowman P. and Stamp R. (eds.), Reading Rancière: Critical Dissensus, pp. 95-110. London: Continuum.

Higson, A. (2000). 'The Limiting Imagination of National Cinema'. In Hjort M. and MacKenzie S. (eds.), Cinema and Nation, pp. 63-74. London; New York: Routledge.

Hinderliter, B., Kaizen, W., Maimon, V., Mansoor, J., and McCormick, S. (20o9). 'Introduction: Communities of Sense'. In Hinderliter B., Kaizen W., Maimon V., Mansoor J., and Mccormick S. (eds.), Communities of Sense: Rethinking Aesthetics and Politics, pp. 1-28. Durham; London: Duke University Press.

Hjort, M. (2009). 'On the Plurality of Cinematic Transnationalism'. In Durovicová N. and Newman K.E. (eds.), World Cinemas, Transnational Perspectives, pp. 12-33. New York: Routledge. DOI: 10.1017/CBO9781107415324.004. 
— (2013). 'Flamboyant Risk Taking'. In Hjort M (ed.), Film and Risk, pp. 31-54. Detroit: Wayne State University Press.

'Homecoming Myanmar: A Midi Z Retrospective (Film Series)' (2015). Asia Society. Retrieved 1 May 2018 from <https://asiasociety.org/new-york/homecoming-myanmar-midi-z-retrospectivefilm-series $>$.

Hunt, L., and Leung, W.-F. (2008). 'Introduction'. In Hunt L. and Leung W.-F. (eds.), East Asian Cinemas: Exploring Transnational Connections on Film, pp. 1-13. London; New York: I.B. Tauris

Ingawanij, M.A., and MacDonald, R.L. (2006). 'Blissfully Whose? Jungle Pleasures, Ultra-modernist Cinema and the Cosmopolitan Thai Auteur', New Cinemas: Journal of Contemporary Film, 4/1: 37-54. DOI: 10.1386/ncin.4.1.37/1.

Ingawanij, M.A., and McKay, B. (eds.) (2012). Glimpses of Freedom: Independent Cinema in Southeast Asia. Independent Cinema in Southeast Asia. Ithaca, NY: Cornell University Press.

Inoue, M.S. (2012). Okinawa and the U.S. Military Identity Making in the Age of Globalization. New York: Columbia University Press.

Inoue, O. (2012). 'What Was the NDU?--Forty Four Years of the NDU, from Onikko to Headhunter's Song'. In Yasui Y. \& Tanaka N. (eds.) The Legendary Filmmaking Collective NDU and Nunokawa Tetsurō, pp. 2-7. Tokyo: Cinematrix; Kobe: Kobe Documentary Film Festival Committee.

'Inter-Korea Archive and Research: “Koryo" Cinema' (2018). Trans-Asia Screen Culture Institute, Korea National University of Arts; Busan International Film Festival. Retrieved 1 November 2018 from <https://www.facebook.com/transkarts/posts/1083894721777753/>.

Ishikawa, E.A. (2009). 'The Return of Japanese-Brazilian Next Generations: Their Post-1980s Experiences in Japan'. Conway D. and Potter R.B. (eds.), Return Migration of the Next Generations: 21st Century Transnational Mobility, pp. 59-78. Farnham, UK: Ashgate Publishing.

Iwabuchi, Kōichi (2015). Resilient Borders and Cultural Diversity: Internationalism, Brand Nationalism, and Multiculturalism in Japan. Lanham: Lexington Books.

'Japanese Expanded Cinema Revisited' (2017). Tokyo: Tokyo Photographic Art Museum; Tokyo Metropolitan Foundation for History and Culture.

Jennison, R. (2014). 'Unspeakable Bodies of Memory: Performance and Precarity in Recent Works by Yamashiro Chikako', Journal of Kyoto Seika University, 44: 181-200.

- (2017). 'Reimagining Islands: Notes on Selected Works by Oh Haji, Soni Kum, and Yamashiro Chikako', Asian Diasporic Visual Cultures and the Americas, 3/1-2: 155-177. DOI: 10.1163/23523085-00302008.

Ji, Y. (2013). 'I Might Be Addicted to the Beauty of Documentaries: Interview with the director of Over There'. Korean Film Biz Zone. Retrieved 10 May 2017 from <http://www.koreanfilm. or.kr/jsp/news/interview.jsp? mode=INTERVIEW_VIEW\&seq=40\&blbdComCd=601019>.

Jin, D.Y., and Otmazgin, N. (2014). 'Introduction: East Asian Cultural Industries: Policies, Strategies and Trajectories', Pacific Affairs, 87/1: 43-51. DOI: 10.5509/201487143.

Jin, H., and Zijin (1992). 'Bianxie zhongguo chaoxianzuwenxueshi de jigewenti' [A few questions regarding the historiography of ethnic Korean literature], Journal of Yanbian University, 3: 86-92. DOI: : 10. 16154 /j . cnki . cn22 -1025/c . 1992. 03. 020.

Jin, X. (2002). 'Zhongguo chaoxianzuwenxuezuopin jingcui' [Selection of Chinese Chaoxianzu Literature]. Yanji: Yanbian People's Publishing House.

Johnston, E. (2019). 'More than $70 \%$ in Okinawa vote no to relocation of U.S. Futenma base to Henoko'. The Japan Times. Retrieved 1 March 2019 from <https://www.japantimes.co.jp/ news/2019/02/24/national/politics-diplomacy/okinawa-residents-head-polls-referendumrelocation-u-s-futenma-base-henoko/\#.XOZHatMzaPc>. 
Khoo, O. (2014). 'The Minor Transnationalism of Queer Asian Cinema: Female Authorship and the Short Film Format.', Camera Obscura, 29/1: 32-57. DOI: 10.1215/02705346-2408507.

Khorana, S. (2013). 'Crossover Cinema: A Genealogical and Conceptual Review'. In Khorana S. (ed.), Crossover Cinema Cross-Cultural Film from Production to Reception, pp. 3-13. London: Routledge

Kim, G. (1993). 'The History, Culture and Language of the Koryǒ Saram', Korea Journal, 33/1: 47-68. Kim, G.N. (2004). 'Koryo Saram, or Koreans of the Former Soviet Union: In the Past and Present', Amerasia Journal, 29: 23-30.

Kim, German N., and King, R. (2001). Koryô Saram: Koreans in the former USSR. New Haven, CT: East Rock Institute.

Kim, J. (2017). 'Globalization, Transnationalism, and "Mobile Societies" from a Sociological Perspective: Comments on Engseng Ho's "Inter-Asian Concepts for Mobile Societies"', The Journal of Asian Studies, 76/04: 935-41. DOI: 10.1017/Soo21911817000936.

Kim, S. (2016). 'Towards a Technology of the Dead: Kim Soyoung on Her "Exile" Documentary Trilogy', Senses of Cinema, 78. Retrieved 1o May 2017 from < http://sensesofcinema.com/2016/ feature-articles/kim-soyoung-exile-trilogy/>.

Kirsch, G. (2015). Contemporary Sino-Japanese Relations on Screen: A History 1989-2005. London; New York: Bloomsbury Academic.

Klein, C. (2004). 'Crouching Tiger, Hidden Dragon: A Diasporic Reading', Cinema Journal, 43/4: 18-42. DOI: $10.1353 / \mathrm{cj} .2004 .0035$.

Ko, M. (2006). 'Takamine Go: A Possible Okinawan Cinema', Inter-Asia Cultural Studies, 7/1: 156-70. DOI: 10.1080/14649370500463844

- (2010). Japanese Cinema and Otherness: Nationalism, Multiculturalism and the Problem of Japanesenesss. London; New York: Routledge. DOI: 10.4324/9780203866719.

- (2016). " Fūkeiron" saikō - kōsaku suru fūkei Saudade [Rethinking the Landscape Theory - The Intersecting Landscape of Saudade]'. In Kawai Y. (ed.), Kosaku suru tabunka shakai:Ibunka komyunikeshon o toraenaosu [Intersecting Multicultural socity: Reconsidering Cross-cultural communications], pp. 188-219. Kyoto: Nakanishiyashuppan.

Kobayashi, E. (2017). 'Dokyumentarī eiga "kō ARAGANE” Oda Kaori kantoku intabyū' [Interview with the director of documentary ARAGANE]. DOTPLACE. Retrieved 20 October 2018 from $<$ http://dotplace.jp/archives/29278>.

Kokuritsu kokugo kenkyūsho (ed.) (1963). Okinawago jiten [Dictionary of Okinawan language]. Tokyo: ōkurashō insatsu kyoku.

Kotzathanasis, P. (2017). 'Interview with Lim Kah-Wai', Asian Movie Pulse. Retrieved 20 September 2018 from <https://asianmoviepulse.com/2017/o1/interview-lim-kah-wai/>.

Kuma, K., Tomita, T., and Aizawa, T. (2012). "'Saudade" ni miru haikyo to mirai' [The Ruins and Future seen in Saudade], Sekai, 832: 212-219.

"Kuzoku ga hatsuno kuraudo fandingu ni "ikarinodesurōdo hōshiki" de idomu! Zenpen tai • raosu satsuei o kankō! saishinsaku 'Bangkok Nites'! [Kuzoku's first crowdfunding for their latest movie 'Bangkok Nites']' (2015). Motion Gallery. Retrieved 10 December 2015 from <https:// motion-gallery.net/projects/bangkoknites>.

Kuzoku, Mukoyama, M., Furuya, T., and YCAM (eds.) (2016). Senko Yisenri [Hidden Journey of a Thousand Miles by JRP]. Yamaguchi: Yamaguchi Center for Arts and Media [YCAM].

'Kuzoku tokushū jōei' [Retrospective of Kuzoku 2011] (2011). OUTSIDE IN TOKYO. Retrieved 2o May 2017 from <http://www.outsideintokyo.jp/j/news/kuzoku2011.html>.

Lamarre, T. (2015). 'Regional TV: Affective Media Geographies', Asiascape:Digital Asia, 2/January 2015: 93-126. DOI: 10.1163/22142312-12340021. 
Laplantine, F. (2015). Life of the Senses. Introduction to a Modal Anthropology. London: Bloomsbury Academic. DOI: 10.5040/9781474219204.0005.

Lebow, A. (2008). First Person Jewish. Minneapolis: University of Minnesota Press.

- (2012). 'The Camera as Peripatetic Migration Machine'. In Lebow A. (ed.), The Cinema of Me: The Selfand Subjectivity in First Person Documentary, pp. 219-232. New York: Wallflower Press

Lee, A. (2017). 'Gender, Everyday Mobility, and Mass Transit in Urban Asia and Mass Transit in Urban Asia', Mobility in History, 8: 85-93. DOI: 10.3167/mih.2017.080110.

Lee, H. (2007). 'Sacrificing showers to explore our mental desert'. Korea Joongang Daily. Retrieved 10 May 2017 from <http://koreajoongangdaily.joins.com/news/article/Article. aspx?aid $=287265^{2}>$.

Lee, S. (2015). 'Cinema as Ritual Space: O Muel's Jiseul'. In Chee L. and Lim E. (eds.), Asian Cinema and the Use of Space: Interdisciplinary Perspectives, Kindle Edition. New York: Routledge.

Lent, J.A. (2012). 'Southeast Asian Independent Cinema: Independent of What?'. In Baumgärtel T. (ed.), Southeast Asian Independent Cinema, pp. 13-19. Hong Kong: Univeristy of Hong Kong Press.

Leung, W.-F., and Willis, A. (eds.) (2014). East Asian Film Stars. London: Palgrave Macmillan UK. Li, Y. (2009). Yasukuni. Tokyo: Asahi Shimbun Publications Inc.

-, and Jinno, T. (2000). 'Hōkai o kizamu "kao" - Li Ying' [The "Face" that Bears Witness to the Collapse - An Interview with Li Ying], Eureka, 32/15: 235-239.

Lim, B.C. (2009). Translating Time: Cinema, the Fantastic, and Temporal Critique. Durham; London: Duke University Press. DOI: 10.1093/screen/hjqo33.

Lim, K.-W. (2014). 'Lim Kah-Wai'. In Teraoka Y. and Morimune A. (eds.), Eiga wa dokoni aru: indipendento eiga no atarashi nami [Where is Cinema: New Waves of Independent Cinema], 1st ed., pp. 327-356. Tokyo: Firumu Ātosha.

Lim, S.H. (2011). 'Transnational Trajectories in Contemporary East Asian Cinemas'. In Lee V.P.Y. (ed.), East Asian Cinemas: Regional Flows and Global Transformations, pp. 15-32. London: Palgrave Macmillan UK. DOI: 10.1057/9780230307186.

- (2014). Tsai Ming-liang and a Cinema of Slowness. Honolulu: University of Hawaii Press.

- (2018). 'Towards a Poor Cinema: Ubiquitous Trafficking and Poverty as Problematic in Midi Z's Films', Transnational Cinemas, 9/2: 131-146. DOI: 10.108o/20403526.2018.145470o.

Lionnet, F., and Shih, S.-M. (2005). 'Introduction: Thinking through the Minor, Transnationally'. In Lionnet F. and Shih S. (eds.), Minor Transnationalism, pp. 1-23. Durham; London: Duke University Press.

Liu-Farrer, G. (2012). 'Becoming New Overseas Chinese: Transnational Practices and Identity Construction Among the Chinese Migrants in Japan'. In Plüss C. and Chan K. (eds.), Living Intersections: Transnational Migrant Identifications in Asia, Inernational Perspectives on Migration 2, pp. 167-19o. New York: Springer. DOI: 10.1007/978-94-007-2966-7.

- (2013). 'Chinese Newcomers in Japan: Migration Trends, Profiles and the Impact of the 2011 Earthquake', Asian and Pacific Migration Journal, 22/2: 231-257.

Lo, D.H. (2015). Imaging Communities [electronic resource]: Location Shooting as Place-making in Contemporary Chinese and Taiwanese Cinemas. Dissertation (Ph.D.), University of California, Los Angeles.

Lu, S. (2007). 'Dialect and Modernity in Twenty-first-Century Sinophone Cinema'. In Chinese Modernity and Global Biopolitics: Studies in Literature and Visual Culture, pp. 150-163. Honolulu: University of Hawaii Press.

- (2014). 'Genealogies of Four Critical Paradigms in Chinese-Language Film Studies'. In Yue A. and Khoo O. (eds.), Sinophone Cinemas, pp. 13-25. Basingstoke, UK; New York: Palgrave Macmillan. 
Ma, R. (2017a). 'Asian Documentary Connections, Scale-making, and the Yamagata International Documentary Film Festival (YIDFF)', Transnational Cinemas, 9/2, 164-180. DOI: 10.1080/20403526.2017.1379733.

- (2017b). 'Contesting the National, Labelling the Renaissance: Exhibiting Taiwan Cinema at Film Festivals in Japan since the 1980s'. In Chiu K., Rawnsley M., and Rawnsley G. (eds.), Taiwan Cinema: International Reception and Social Change, pp. 53-68. London; New York: Routledge.

Maimon, V. (2009). 'The Third Citizen: On Models of Criticality in Contemporary Artistic Practices', October, 129/2009: 85-112. DOI: 10.1162/octo.2009.129.1.85.

- (2010). 'Towards a New Image of Politics : Chris Marker's Staring Back', Oxford Art Journal, 33/1: 83-101.

Maitra, A., and Chow, R. (2016). 'What's “in”?: Disaggregating Asia through New Media Actants'. In Hjorth L. and Khoo O. (eds.), The Routledge Handbook of New Media in Asia, pp. 17-27. London; New York: Routledge.

Marchetti, G., and Tan, S. K. (eds.) (2007). Hong Kong Film, Hollywood and the New Global Cinema: No Film is an Island. London: Routledge.

Marks, L.U. (200o). The Skin of the Film: Intercultural Cinema, Embodiment, and the Senses. Durham; London: Duke University Press.

Martin-Jones, D. (2006). Deleuze, Cinema and National Identity: Narrative Time in National Contexts. Edinburgh: Edinburgh University Press. DOI: 10.1093/screen/hjmoo8.

- (2011). Deleuze and World Cinemas. London; New York: Continuum International Publishing Group. DOI: 10.1080/17400309.2012.714973.

Masaaki, A. (2008). 'Compulsory Mass Suicide, the Battle of Okinawa, and Japan's Textbook Controversy', The Asia-Pacific Journal, 6/1: 1-13.

Massey, D. (1993). 'Power-Geometry and A Progressive Sense of Place'. In Bird J., Curtis B., Putnam T., Robertson G., and Tickner L. (eds.), Mapping the Futures: Local Cultures, Global Change, pp. 59-69. London; New York: Routledge.

Matteo, B. (2016). 'Interview with Oda Kaori'. Documentary in East and Southeast Asia. Retrieved 21 October 2018 from <https://storiadocgiappone.wordpress.com/2016/o3/11/ interview-with-oda-kaori/>.

May, T. (2010). 'Review of Dissensus: On Politics and Aesthetics'. Notre Dame Philosophical Reviews. Retrieved 10 December 2018 from <https:/ndpr.nd.edu/news/ dissensus-on-politics-and-aesthetics/>.

McCormack, D., and Salmenniemi, S. (2016). 'The Biopolitics of Precarity and the Self', European Journal of Cultural Studies, 19/1: 3-15. DOI: 10.1177/1367549415585559.

Mezzadra, S., and Neilson, B. (2013). Border as Method, or, the Multiplication of Labor. Durham; London: Duke University Press. DOI: 10.1215/9780822377542.

'Midi Z: Taiwan, Cradle of My Cinema' (2017). Ministry of Foreign Affairs, Republic of China (Taiwan). Retrieved 10 August 2018 from <https://nspp.mofa.gov.tw/nsppe/news. php?post $=115885 \&$ unit $=410>$.

'Mimichiri bōji' (2002). Kaii yōkai denshō dètabēsu [Database for the mysterious and yōkai]. Retrieved 10 March 2019 from <http://www.nichibun.ac.jp/YoukaiCard/o380oo1.shtml>.

Mitchell, J. (2011). 'Red and Yellow Songs: A Historical Analysis of the Use of Music by the United Front for Democracy against Dictatorship ( UDD ) and the People's Alliance for Democracy (PAD) in Thailand', South East Asia Research, 19/3: 457-494. DOI: 10.5367/ sear.2011.0058.

Mori, H. (1997). Immigration Policy and Foreign Workers in Japan., 1st ed. Basingstoke; London: Macmillan Press Ltd.. 
Mori, T., Suzuki, K., and Miyadai, S. (eds.) (2008). Eiga yasukuni joei chushi o meguru daigiron [Overall Debates upon the Terminated Screenings of the Film Yasukuni]. Tokyo: Tsukuru Shuppan.

Moriteru, A. (2014). 'Can Okinawa be the "catalyst" for peace in East Asia?', Inter-Asia Cultural Studies, 15/1: 43-62. DOI: 10.1080/14649373.2014.888042.

Morris, M., Li, S.L., and Chan, S.C. (eds.) (2006). Hong Kong Connections: Transnational Imagination in Action Cinema. Hong Kong: Hong Kong University Press.

Mulvey, J., Rascaroli, L., and Saldanha, H. (2017). 'For a Cosmopolitan Cinema - Editorial', Alphavile:Journal of Film and Screen Media, Winter/14: 1-15.

'Myanmar gets first glimpse of its most famous director Midi Z's film, The Road to Mandalay' (2016). South China Morning Post. Retrieved 10 September 2018 from <https://www.scmp.com/culture/ film-tv/article/2044393/myanmar-gets-first-glimpse-its-most-famous-director-midi-zs-film>.

Myers-Moro, P.A. (1986). 'Songs for Life: Leftist Thai Popular Music in the 197os', Journal of Popular Culture, 20/3: 93-113. DOI: 10.1111/j.0022-3840.1986.2003_93.x.

Naficy, H. (1994). 'Phobic Spaces and Liminal Panics: Independent Transnational Film Genre', East-West Film Journal, 8: 1-30.

- (2001). An Accented Cinema: Exilic and Diasporic Filmmaking. Princeton, NJ: Princeton University Press. DOI: 10.1177/1470412907075071.

- (2013). 'Accented Filmmaking and Risk Taking in the Age of Postcolonial Militancy, Terrorism, Globalization, Wars, Oppression, and Occupation'. In Hjort M (ed.), Film and Risk, pp. 143-164. Detroit: Wayne State University Press.

Nagano, T. (ed.) (2010). Chainïzunesu to toransunashonaru aidentiti [Chineseness and Transnational identity]. Nitchū shakaigaku sōsho: Gurōbarizēshon to higashiajia shakai no shinkōsō. 2. Tokyo: Akashishoten.

—, and Guo, F. (2010). 'Sengo zainichi kakyō shakai no kōsei oyobi hendō to "rō kakyō" no soshiki nettowāku keisei' [Postwar Social Structure of Overseas Chinese and its Transformations and the Formation of "Older Generations" Overseas Chinese' Organization and Network]. In Nagano T. (ed.), Chainizzunesu to toransunashonaru aidentiti [Chineseness and Transnational Identity], pp. 26-64. Tokyo: Akashishoten.

Nakamura, Y. (2013). 'Kokkyō no aru fūkei: Ajia wa hitotsu ni okeru riarizumu ni tsuite' [The Landscape of the National Borders: About the Realism in 'Asia is One']. In Onozawa N., Nakamura Y., and Yasui Y. (eds.), Moyuru kaikyō: NDU to Nunokawa Tetsurō no eiga:undō ni mukete [Ablazing Strait: The Cinema of NDU and Nunokawa Tetsurō: Toward a Movement], pp. 76-107. Tokyo: Inpakuto Shuppankai.

Nakazato, I. (2007). Okinawa, imeji no edge [Okinawa, the Edge of Image]. Tokyo: Miraisha.

- (2017). 'Dareno mono demonai okinawa toiu raiyā karini raiku a rōringumūbī to nazukete' [The Layer that Okinawa Belongs to Nobody is Temporarily Named Like a Rolling Movie]. Cinematrix (ed.), Pamphlet of Hengyoro. Tokyo: Cinematrix.

NDU (1973). 'Seisaku komento' [Production Notes]. Hanhakusho [Anti Whitepaper], p.122. Tokyo: Hanhakusho Henshūbu.

neoneoweb2017 (2017). "Kō ARAGANE" Oda Kaori kantoku bosunia no kōzan to iū "michi no sekai” to no komyunikeishon' [Interview: Filmmaker Oda Kaori on the Communication with the "Unknown World" of the Bosnian Coal Mine]. NeoNeo. Retrieved 21 October 2018 from $<$ http://webneo.org/archives/44031/2>.

Ng, K.C. (2018). 'Shi Shumei de "fanlisan" daodizai fan shenme?' [What Shih is Against in her "Against Diaspora"?]. Speaking of Books [shuoshu]. Retrieved 3 January 2018 from <https:// sobooks.tw/sinophone-literature-review/>. 
Nguyen, M.T. (2015). 'Minor Threats', Radical History Review, May/122: 11-24. DOI: $10.1215 / 01636545^{-2849495}$.

Nishimura, T., and Nishikawa, T. (2015). 'Film Independents and Japanese Underground Cinema - An Interview with Tomohiro Nishimura', Millennium Film Journal, 61: 30-37

Nunokawa, T. (2012). 'Asia is One'. In Yasui Y. and Tanaka N. (eds.), The Legendary Filmmaking Collective NDU and Nunokawa Tetsurō, pp. 15-16. Tokyo: Cinematrix; Kobe: Kobe Documentary Film Festival Committee.

- (2012). 'Motoshinkakarannu'. In Yasui Y. \& Tanaka N. (eds.) The Legendary Filmmaking Collective NDU and Nunokawa Tetsurō, pp. 11-12 Tokyo; Kobe: Cinematrix; Kobe Documentary Film Festival Committee.

Oakes, T., and Schein, L. (2006). ‘Translocal China: An Introduction'. In Oakes T. and Schein L. (eds.), Translocal China:Linkages, Identities, and the Reimagining of Space, pp. 1-35. London; New York: Routledge. DOI: 10.2307/20066191.

Ogawa, S.T. (2017). 'A Long Way Home: The Rhetoric of Family and Familiarity in Yang Yong-hi's Pyongyang Trilogy', Journal of Japanese and Korean Cinema, 9/1: 30-46. DOI: 10.1080/17564905.2017.1289296.

Oguma, E. (2014). The Boundaries of 'the Japanese'. Volume 1: Okinawa-Inclusion and Exclusion. (L.R. Stickland, transl.). Melbourne: Trans Pacific Press.

Ong, A. (1999). Flexible Citizenship: The Cultural Logics of Transnationality. Durham; London: Duke University Press.

Ong, A., and Nonini, D.M. (eds.) (1997). Ungrounded Empires: The Cultural Politics of Modern Chinese Transnationalism. New York; London: Routledge. DOI: 10.1111/j.1467-8322.2009.00676.x.

Paasi, A. (2012). 'Border Studies Reanimated: Going Beyond the Territorial/Relational Divide', Environment and Planning A, 44/10: 2303-2309. DOI: 10.1068/a45282.

Panagia, D. (2014). "Partage du sensible": The Distribution of The Sensible'. In Deranty J.-P. (ed.), Jacques Rancière:Key Concepts, pp. 95-130. Durham, UK: Acumen Publishing Limited.

Phillips, C. (2009). 'Difference, Disagreement and the Thinking of Queerness', Borderlands, 8/2:1-17.

Pisters, P. (2003). Matrix of Visual Culture: Working with Deleuze in Film Theory. Palo Alto: Stanford University Press.

Pisters, P. (2010). 'Violence and Laughter: Paradoxes of Nomadic Thought in Postcolonial Cinema'. In Bignall S. and Patton P. (eds.), Deleuze and the Postcolonial, pp. 201-219. Edinburgh: Edinburgh University Press.

Quan, Z., and Zhao, C. (1979). 'Zhongguo chaoxianzu wenxuegaikuang' [General Review of PRC's Chaoxianzu Literature], Journal of Yanbian University, 4: 43-59.

Rancière, J. (2009a). 'Contemporary Art and the Politics of Aesthetics'. In Hinderliter B., Maimon V., Mansoor J., and McCormick S. (eds.), Communities of Sense: Rethinking Aesthetics and Politics, pp. 31-50. Durham; London: Duke University Press.

- (2009b). The Emancipated Spectator. (G. Elliott, transl.). London; New York: Verso. DOI: 10.1111/wusa.12080.

- (2010). Dissensus: On Politics and Aesthetics. (Steven Corcoran, transl.). London; New York: Continuum International Publishing Group. DOI: 10.1007/s13398-014-0173-7.2.

- (2011a). The Politics of Aesthetics: The Distribution of the Sensible. (G. Rockhill, transl.). New York: Continuum International Publishing Group. 
— (2011b). 'The Thinking of Dissensus: Politics and Aesthetics'. In Bowman P. and Stamp R. (eds.), Reading Rancière: Critical Dissensus, pp. 1-17. London; New York: Continuum International Publishing Group.

- (2014). The Intervals of Cinema. (J. Howe, transl.). London; New York: Verso.

—, Carnevale, F., and Kelsey, J. (2007). 'Art of the Possible: Fulvia Carnevale and John Kelsey in conversation with Jacques Rancière', Artforum International, March: 256-269.

Richie, D. (2005). A Hundred Years of Japanese Film: A Concise History. Revised version. Tokyo; New York; London: Kodansha International.

Robinson, L. (2013). Independent Chinese Documentary: From the Studio to the Street. London: Palgrave Macmillan UK.

Rodowick, D.N. (1997). Gilles Deleuze's Time Machine. Durham; London: Duke University Press. DOI: 10.1353/sub.2000.0010.

Rofel, L. (2007). Desiring China: Experiments in Neoliberalism, Sexuality, and Public Culture. Durham: Duke University Press.

Rosenbaum, J. (2018). 'Notes on Oda Kaori's ARAGANE (from Lisbon)'. jonathanrosenbaum. net. Retrieved 10 October 2018 from <http://www.jonathanrosenbaum.net/2018/o2/ notes-on-aragone-from-lisbon/>.

Roth, J.H. (2002). Brokered Homeland:Japanese Brazilian Migrants in Japan. Ithaca, NY: Cornell University Press.

Ryang, S. (2009). 'Introduction: Between the Nations: Diaspora and Koreans in Japan'. In Ryang S. and Lie J. (eds.), Diaspora without Homeland:Being Korean in Japan, pp. 1-20. Berkeley; Los Angeles; London: University of California Press.

—, and Lie, J. (eds.) (2009). Diaspora without Homeland: Being Korean in Japan. Berkeley; Los Angeles; London: University of California Press.

Ryū, B. (2011). Shōgen: Nicchū eigajin kōryū [Testimony: Exchanges between Chinese and Japanese Film People]. Tokyo: Shūeisha.

— (2016). Nicchu eiga kōryū shi [A History of Sino-Japanese Cinema]. Tokyo: Tokyo Daigaku Shuppankai.

Sato, H., and Sato, K. (2002). Seinan hinkan monogatari [The Stories of Ji'nan Hotel]. Tokyo: Shunjusha.

Sato, K. (2019). Chugoku dokyumentarī eigaron [On Chinese Documentary]. Tokyo: Heibonsha.

Sato, T. (1981). 'Sukurin rōdōsha ron-37-hageshiku moeta jishu eiga undō--puro kino no hakkutsu to hozon' [Review of Laborers on Screen-37-flourshing autonomous film movement - the discovery and preservation of Prokino], Gekkan Sōhyō, 284: 88-91. Nippon Rōdō kumiai sōhyō gikai.

Schierup, C.U., and Jørgensen, M.B. (2016). 'An Introduction to the Special Issue. Politics of Precarity: Migrant Conditions, Struggles and Experiences', Critical Sociology, 42/7-8: 947-958. DOI: 10.1177/0896920516640065.

Seol, D.-H., and Skrentny, J.D. (2009). 'Ethnic Return Migration and Hierarchical Nationhood: Korean Chinese Foreign Workers in South Korea', Ethnicities, 9/2: 147-174. DOI: 10.1177/1468796808099901.

Sharma, D., and Tygstrup, F. (2015). 'Introduction'. In Sharma D. and Tygstrup F. (eds.), Structures of Feeling: Affectivity and the Study of Culture, pp. 1-19. Berlin; Munich; Boston: De Gruyter.

Sharp, J. (2008). Behind the Pink Curtain: The Complete History ofJapanese Sex Cinema. Godalming, Surrey: FAB.

Shen, Z., and Dong, J. (2011). 'Zhongchao bianjiezhengyi de jiejue (1950-1964nian)' [Resolutions of Sino-Korean Border (1950-64)], Twenty-First Century [ershiyishiji], 124:34-51. 
Shih, S.-M. (2007). Visuality and Identity: Sinophone Articultions across the Pacific. Berkeley; Los Angeles; London: University of California Press.

- (2011). 'The Concept of the Sinophone', PMLA, 126/3: 709-718.

—, Tsai, C., and Bernards, B. (eds.) (2013). Sinophone Studies: A Critical Reader. New York: Columbia University Press.

- (2014). 'Foreword: The Sinophone Redistribution of the Audible'. In Yue A. and Khoo O. (eds.), Sinophone Cinemas, pp. viii-xi. Basingstoke, UK; New York: Palgrave Macmillan.

Silvey, R. (2004). 'Power, Difference and Mobility: Feminist Advances in Migration Studies', Progress in Human Geography, 4/28: 490-506.

Standing, G. (2011). Precariat: New Dangerous Class. London; New York: Bloomsbury Academic.

Sun, G. (2000). 'How Does Asia Mean? (Part I)', (S.-L. Hui and K. Lau, transl.) Inter-Asia Cultural Studies, 1/1: 13-47. DOI: 10.1080/14649370050141186.

Suner, A. (2006). 'Outside In: “Accented Cinema" at Large', Inter-Asia Cultural Studies, 7/3: 363-82. DOI: 10.1080/14649370600849223.

Suzuki, K. (2008). 'Ranhansha suru Okinawa' [The Diffused Reflection of Okinawa]. Okinawa Purizumu 1872-2008 [Okinawa Prismed 1872-2008], pp. 138-145. Tokyo: The National Museum of Contemporary Art.

Szeto, K.-Y. (2011). The Martial Arts Cinema of the Chinese Diaspora: Ang Lee, John Woo, and Jackie Chan in Hollywood. Carbondale: IL : Southern Illinois University Press.

Takamine, G., and Nakazato, I. (2003). 'Nippon no dokyumentarī sakka intabyū No. 20: Takamine Gō' [Interview with Japanese documentary autuers]. Documentary Box \#22. Retrieved 13 January 2019 from $<$ https://www.yidff.jp/docbox/22/box22-1-1.html>.

-, and Tsurusaki, A. (2017). 'Hengyoro Takamine Go kantoku intabyū' [Interview with the director of Hengyoro]. QUOTATION magazine.jp. Retrieved 20 August 2018 from <http:// quotationmagazine.jp/column/post-15967>.

—, and Yomota, I. (2017). 'Hengyoro: An Interview', Kinema Junpō, 1738: 70-75.

Takamine Gō eiga koten jikkō innkai [Executive Committee of Takamine Gō's Film Exhibition] (ed.) (1992). Dakara yo 、 chirudai nu ashibi okinawan dorīmu shō Takamine Gō Eiga Koten [Indeed! Playful Lethargy: Okinawan Dream Show, A Solo Film Exhibition by Takamine Gō]. Naha: Takamine Gō eiga koten jikkō innkai [Executive Committee of Takamine Gō’s Film Exhibition].

Takamine, T., Nagamoto, T., Wakabayashi, C., and Nakazato, I. (2018). 'Fukigo Okinawawo megute' [Canvassing the Post-Reversion Okinawa], Ekkyo Hiroba, 5: 6-34.

Takano, Y., Ashizawa, A., and Tomita, K. (2011). 'Kanōse aruno fūkei]' [The Landscape with Possibility. NOBODY, 14-21. Tokyo.

Takenaka, A. (2009). 'Politics of Representation or Representation of Politics? "Yasukuni” the Film', Review ofJapanese Culture and Society, 21/December: 117-136.

Tan, E.K. (2012). 'Huayuyuxi yanjiu: haiwaihuaren yu lisanhuarenyanjiu zhifansi' [Sinophone Studies: Rethinking Overseas Chinese Studies and Chinese Diaspora Studies], zhongguo xiandai wenxue [Modern Chinese Literature], 22: 75-91.

- (2013a). Rethinking Chineseness: Translational Sinophone Identities in the Nanyang Literary World. Amherst, NY: Cambria Press.

— (2013b). 'Sinophone Studies: Rethinking Overseas Chinese Studies and Chinese Diaspora Studies', Sun Yat-sen Journal of Humanities, 35: 1-26.

Teh, D. (2011). 'Itinerant cinema: The Social Surrealism of Apichatpong Weerasethakul', Third Text, 25/5: 595-609. DOI: 10.1080/o9528822.2011.608973. 
Teng, P. (2017). 'Taiwan Ministry of Culture to offer grants to award-winning filmmakers'. Taiwan News. Retrieved 3 October 2018 from <https://www.taiwannews.com.tw/en/news/3309550>.

Teo, S., Erikawa, K., and Kazuyuki, K. (eds.) (2007). Asia Symposium 1989. Yamagata: Yamagata International Film Festival.

Tezuka, Y. (2013). 'Dynamics of the Cultures of Discontent: How Is Globalization Transforming the Training of Filmmakers in Japan?'. In Hjort Mette (ed.), The Education of the Filmmaker in Europe, Australia, and Asia, pp. 171-187. New York: Palgrave Macmillan US.

'The CFI Guide to Film Production in China' (2016). ChinaFilmInsider. Retrieved 1o May 2017 from <http://chinafilminsider.com/cfi-guide-10-things-know-working-film-china/>.

The Global Film Initiative (ed.) (2011). Dooman River: Global Lens 2011 Discussion Guide. San Francisco, CA: The Global Film Initiative.

Tin Htet Paing (2017). 'Independent Cinema Resists Censorship at Local Film Festival'. The Irrawaddy. Retrieved 3 October 2018 from <https://www.irrawaddy.com/culture/independentcinema-resists-censorship-local-film-festival.html>.

Toguchi, M. (1992). 'Okinawan Dream Show'. Executive Committee (ed.), Dakarayo v chirudai nu ashibi okinawan dorīmu shō Takamine Gō Eiga Koten [Indeed! Playful Lethargy: Okinawan Dream Show, a solo film exhibition by Takamine Gō]. Naha: Takamine Gō eiga koten jikkō innkai [Executive Committee of Takamine Gō's Film Exhibition].

Tolia-Kelly, D.P. (2019). 'Rancière and the Re-Distribution of the Sensible: The Artist Rosanna Raymond, Dissensus and Postcolonial Sensibilities within the Spaces of the Museum', Progress in Human Geography, 43/1: 123-140. DOI: 10.1177/0309132517739141.

Tomita, K. (2014). 'Interview'. Teraoka Y. and Morimune A. (eds.), Eiga wa dokoni aru: indipendento eiga no atarashi nami [Where is Cinema: New Waves of Independent Cinema], pp. 9-46. Tokyo: Firumu Ātosha.

- (2016). 'Director's Note'. Kuzoku (ed.), Bangkok Nites Pressbook. Tokyo.

Tomita, K., and Aizawa, T. (2016). 'Interview with Katsuya Tomita and Toranosuke Aizawa'. Kuzoku (ed.), Bangkok Nites Pressbook. Tokyo.

- (2017). Bankoku naitsu: Senkō issen ri [Bangkok Nites: Hidden Journey of a Thousand Miles]. Tokyo: Kawade Shobō Shinsha.

-, Aizawa, T., Arai, H., and Inagawa, M. (2017). 'Bangkok Nites', Eiga Gejutsu, 458: 58-63.

—, Aizawa, T., and Nomura, M. (2017). 'Bankoku Naitsu kyakuhon ka,kantoku Intabyū [Interview with Screenwriter and Director of Bangkok Nites]', Scenario, 73/4: 4-10.

- Aizawa, T., and Urasaki, H. (2011). 'Intabyū: Tomita Katsuya + Aizawa Toranosuke - Saudade kyakuhon • kantoku ni kiku [Interview with Saudade's Screenwriter and Director]', Scenario, 67/12:14-21. Shinario sakka kyōkai.

Trice, J.N. (2017). 'Location Shooting in "the Wild East": Risk and Masculinity in Hollywood Productions in the Philippines', Feminist Media Studies, 17/6:988-1004. DOI:10.1080/14680777.2017.1313290.

Trinh, M.-H. (2011). Elsewhere, Within Here: Immigration, Refugeeism and the Boundary Event. London: Routledge.

Tsuji, M. (2016). Senko Sanzenri [Hidden Journey of 3 ooo Li]. Tokyo: Mainichi Wanz.

Twaronite, L. (2017). 'Roving vans serve Japanese-Brazilian community's banking, food and other needs'. The Japan Times. Retrieved 10 March 2019 from < https://www.japantimes.co.jp/ news/2017/06/22/national/roving-vans-serve-japanese-brazilian-communitys-bankingfood-needs/\#.XKV2keszaPc>.

Valck, M. de (2007). Film Festivals: From European Geopolitics to Global Cinephilia. Amsterdam: Amsterdam University Press. 
Wada-Marciano, M. (2012).Japanese Cinema in the Digital Age. Honolulu: University of Hawaii Press. DOI: 10.21313/hawaii/9780824835941.001.ooo1.

Wang, B. (2004). Illuminations from the Past: Trauma, Memory, and History in Modern China. Palo Alto: Stanford University Press.

Wang, L. (2015). 'The Identification of Minorities in China', Asian-Pacific Law \& Policy Journal, 16/2:1-20.

Wang, Y. (2012). 'Alter-centering Chinese Cinema The Diasporic Formation'. In Zhang Y. (ed.), $A$ Companion to Chinese Cinema, pp. 535-551. Hoboken, NJ: Wiley-Blackwell.

Watanabe, S., and Yūki, H. (2017). 'Interview with MMM, Mr. Maro, YOUNG-G', NOBODY, 46:13-19. Watson, J. (2012). 'Butler's Biopolitics: Precarious Community', Theory and Event, 15/2: 1-16. DOI: http://dx.doi.org/10.1108/17506200710779521.

webDICE (2017). 'Kono eiga wo kiruto Okinawa no haīronochi ga nagareru - Takamine Gō kantoku jūhachi nen burino gekieiga "hengyoro" wo kataru' [If you cut open this film there oozes the grey blood of Okinawa - Filmmaker Takamine Gō talks about his coming back feature film Hen]. webDICE. Retrieved 11 January 2019 from $<\mathrm{http}$ ://www.webdice.jp/dice/detail/5339/>.

Wiese, D. (2014). The Powers of the False: Reading, Writing, Thinking beyond Truth and Fiction. Kindle edition. Chicago: Northwestern University Press. DOI: 10.2307/j.ctv43vs7s.

Wong, C.H.-Y. (2011). Film Festivals: Culture, People, and Power on the Global Screen. Piscataway: Rutgers University Press.

Xu, G.G. (2008). 'Remaking East Asia, Outsourcing Hollywood'. In Hunt L. and Leung W.-F. (eds.), East Asia Cinemas: Transnational Connections on Film, pp. 191-202. New York: I.B. Tauris.

Yamanaka, K., and Piper, N. (2005). Feminized Migration in East and Southeast Asia: Policies, Actions and Empowerment. UNRISD Occasional Paper. Retrieved 10 January 2019 from $<\mathrm{http}$ :/ hdl.handle.net/10419/148824>.

Yamashiro, C., Nahata, F., and Abenoki, T. (2017). 'An Interview with Yamashiro Chikako: Searching for a Way to Survive'. (K. Simpson, transl.) Yamagata International Film Festival 2017. Retrieved 11 January 2019 from <https://www.yidff.jp/interviews/2017/17io5o-e.html>.

'Yamashiro Chikako Artist File' (2017). Tokyo: Yumiko Chiba Associates.

'yanbian chaoxianzu zizhizhou 2017nian guominjingji he shehuifazhan tongjigongbao' [Statistical communique of Yanbian Korean Autonomous Prefecture on the 2013 national economic and social development ] (2018). People's Government of Jilin Province. Retrieved 29 April 2018 from <http://www.jl.gov.cn/sj/sjcx/nbcx/gdzs/201804/t20180412_4505365.html>.

Yang, J. (2014). 'The Politics of Affect and Emotion: Imagination, Potentiality and Anticipation in East Asia'. In Yang J. (ed.), The Political Economy of Affect and Emotion in East Asia, pp. 3-28. New York; London: Routledge.

Yang, O. (2016). 'INTERVIEW: Film Director Midi Z on the "Taiwanese Dream" in Myanmar (Part Two)'. The News Lens. Retrieved 3 October 2018 from <https://international.thenewslens. com/article/56409>.

Yomota, I. (2017). 'Eizō wo irabūjiru ni tsukekomu - Takamine Gō "Hengyoro" ni tsuite' [To preserve images with sea snake soup - Regarding Takamine Gō's Hengyoro]. Pamphlet of Hengyoro. Tokyo: Cinematrix.

Yü, D.S. (2014). 'Pema Tseden's Transnational Cinema: Screening a Buddhist Landscape of Tibet', Contemporary Buddhism, 15/1: 125-144. DOI: 10.1080/14639947.2014.890355.

Yu, S.Q. (2012). Jet Li: Chinese Masculinity and Transnational Film Stardom. Edinburgh: Edinburgh University Press. DOI: 10.3366/j.ctt3fgsrm. 
Yue, A. (2012). 'Notes on the Sinophone Mediascape in Australia', Chinese Journal of Communication, 5/1: 24-31. DOI: 10.1080/17544750.2011.647740.

Yue, A., and Khoo, O. (2012). 'From Diasporic Cinemas to Sinophone Cinemas: An Introduction', Journal of Chinese Cinemas, 6/1: 9-14. DOI: 10.1386/jcc.6.1.9.

- (eds.) (2014). Sinophone Cinemas. Basingstoke, UK; New York: Palgrave Macmillan.

'Zairyū gaikoku ninzū nitsuite' [Number of foreign residents by the end of June 2018] (2018). Ministry ofJustice (Japan). Retrieved 10 March 2019 from <http://www.moj.go.jp/nyuukokukanri/kouhou/nyuukokukanrio4_ooo76.html>.

'Zairyū gaikokujin tōkei (kyu tōroku gaikokujin tōkei)tōkeihyō' [Statistics of foreign residents] (n.d.). Ministry ofJustice. Retrieved 10 September 2018 from <http://www.moj.go.jp/housei/ toukei/toukei_ichiran_touroku.html>.

Zhang, Y. (1997). 'From “Minority Film” to "Minority Discourse”: Questions of Nationhood and Ethnicity in Chinese Cinema', Cinema Journal, 36/3: 73-9o.

- (2004). Chinese National Cinema. New York; London: Routledge.

- (2010). Cinema, Space and Polylocality in a Globalizing China. Honolulu: University of Hawaii Press.

- (2016). 'Chinese Film History and Historiography', Journal of Chinese Cinemas, 10/1: 38-47. DOI: 10.1080/17508061.2016.1139802.

Zhang, Z. (2007). 'Bearing Witness: Chinese Urban Cinema in the Era of "Transformation" (Zhuanxing)'. In Zhang Z. (ed.), The Urban Generation: Chinese Cinema and Society at the Turn of the Twentieth-first Century, pp. 1-33. Durham: Duke University Press. DOI: 10.1016/j. annemergmed.2012.11.003.

-, and Zito, A. (2015). 'Introduction'. In Zhang Z. and Zito A. (eds.), DV-Made China: Digital Subjects and Social Transformations after Independent Film, pp. 1-25. Honolulu: University of Hawai'i Press.

Zhao, D., Zheng, Y., and Fang, P. (2015).Ju,san,Bingdu: Zhao Deyin de dianyingrensheng jishi [Gathering, Parting. Ice Poison: Chronicles of Zhao Deyin's Filmmaking Life]. Taipei: Commonwealth Publishing.

'Zhongguo chaoxianzu shiliao quanji' [Complete historical accounts of Chaoxian nationality] (2016). Yanbian University. Retrieved 10 January 2019 from <http://skc.ybu.edu.cn/ info/1040/1201.htm>. 



\section{Index}

References to illustrations are in bold.

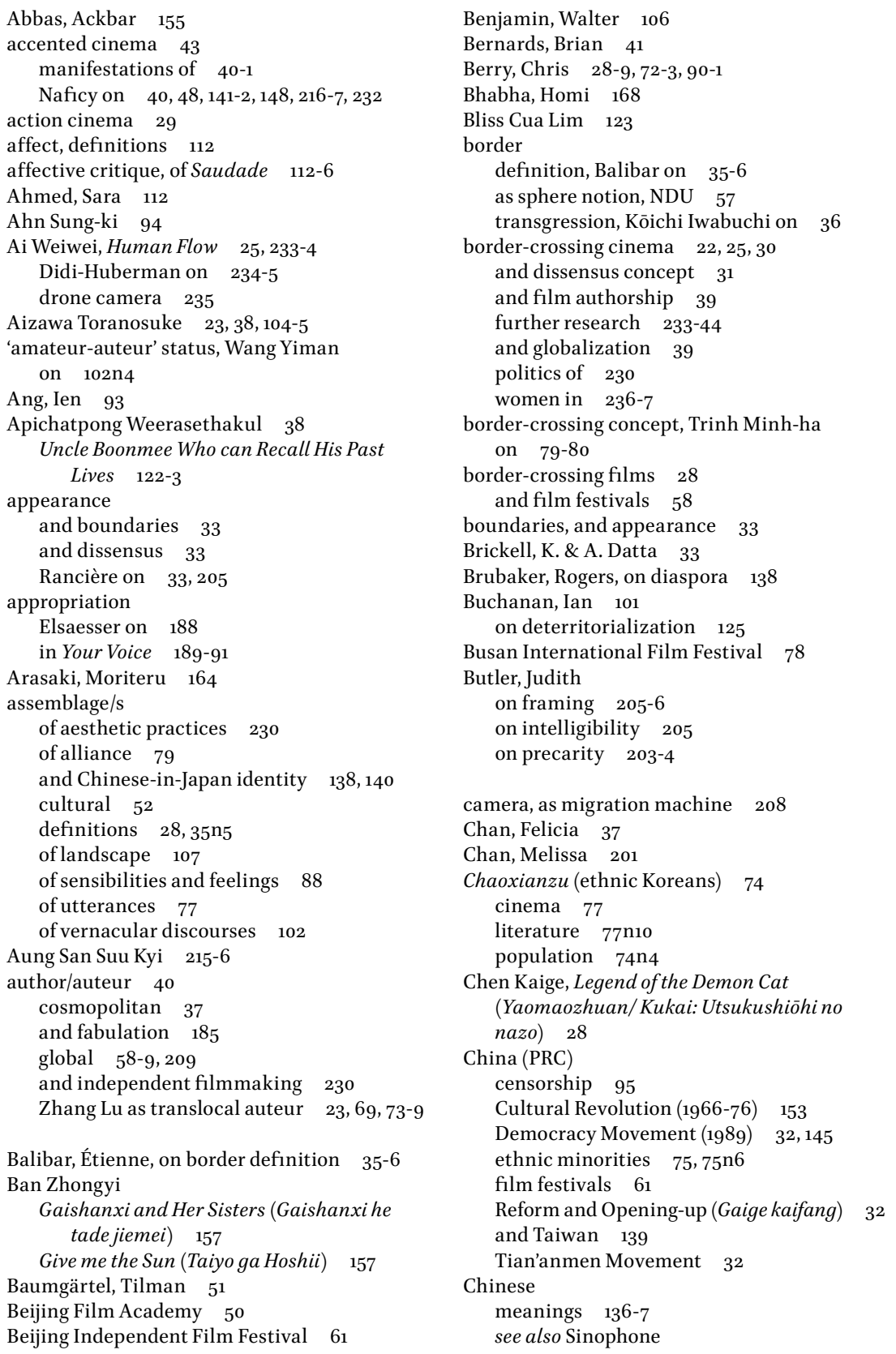


Chinese diaspora, and Trilogy $\quad 210-3$

Chinese independent cinema

diversification and differentiation 89

and DV technology 50,89,102n4

polylocality $\quad 92-3$

'Urban Generation' 89

Zhang Lu's influence on 89

see also New Chinese Cinema

Chinese-Burmese communities 202-3; see also Chinese-in-Myanmar

Chinese-in-Japan (zainichi chügokujin) $\quad 131$

$2 \mathrm{H}$ film $143-5^{2}$

Chineseness 156

cinema $24,155^{-9}$

communities $138,145^{-6}$

films, examples $\quad 157-8$

identity $135,138,140$

and assemblage 138,140

numbers 133

representation in film/tv $\quad 156$

Chinese-in-Myanmar 212-3; see also ChineseBurmese communities

Chineseness 21, 74, 9on15, 93, 135-6, 200

Chinese-in-Japan (zainichi chūgokujin) $\quad 156$

as discursive sphere $\quad 138$

see also Sinophone

Christiansen, Steen Ledet $\quad 235$

cinema

cosmopolitan $37 \mathrm{n} 6,42$

of displacement, Li Ying $\quad$ 140-3

of transvergence $\quad 42-3$

cinema of precarity

City ofJade 204-5, 221-2, 224

and Midi Z $\quad 202,204-5$

cinematic transnationalism, Hjort on $\quad 29,34$

cinematography, long takes 110

'Co-producing Asia Project', DeBoer $35^{n}$, 43

The Cold War 48

Colebrook, Claire $\quad 45^{-6}$

Coppola, Francis, Apocalypse Now 217

Crickmar, Rohan 235

cultural transversalism $\quad 42,45$

Dagudi (Thailand) 211, $211 n 9$

DaHuang Pictures (DaHuang dianying)

19

Dan Smyer Yü 91

Davis, Nick 48

DeBoer, Stephanie, 'Co-producing Asia Project' $35 \mathrm{n}_{5}, 43$

Deleuze, G.

Cinema 2: The Time-Image 46

on fabulation $\quad 185^{-6}$

minor cinema $\quad 45^{-7}$

on political cinema $24,45^{-6}, 107,120,172$

time-image framework $24,167-8$
Deleuze, G. \& and F. Guattari, on the minor $45-8,186,232$

Demos, T.J. $\quad 60-1$

deterritorialization $\quad 72$

Buchanan on 125

see also reterritorialization

Dew, Oliver $74,15^{6}$

diaspora

Brubaker on 138

'Homeland and Diaspora' project 19-20, $28,43-4$

Soviet/Russian Koreans (Koryo saram) 95

Didi-Huberman, Georges, on Human Flow 234-5

Dirlik, Arif 34,72

displacement films see cinema, of displacement

dissensus 22

and appearance 33

and border-crossing cinema 31

Rancière on 30,230

use of 31

distribution of the sensible see partage du sensible

double-becoming, and fabulation $\quad 185^{-6}$

drone camera, in Human Flow 235

DV (Digital Video) technology

and Chinese independent cinema 50,89 , $102 \mathrm{n} 4$

and independent filmmaking $\quad 5^{1}$

and inter-Asia independent cinema culture $5^{2}$

and Malaysian New Wave $44,44 \mathrm{n} 11$

Midi Z's use of $\quad 218,224$

Queer Fish Lane (Hengyoro) 181

Efird, Rob $\quad$ 132, 139n11

Elsaesser, Thomas 40, 209

on appropriation 188

on film festivals 59

on global authorship $\quad 5^{8}$

Emperor Motion Pictures 28

Erni, John, on minority affects 142

Eurocentrism 43

fabulation

and author/auteur $\quad 185$

Deleuze on $185^{-6}$

and double-becoming $\quad 185^{-6}$

in Queer Fish Lane (Hengyoro) $\quad$ 186-7

Farocki, Harun 188, 235

fiction, Rancière on $\quad 187$

film authorship 22

and border-crossing cinema 39

film festivals see international film festivals

film markets, and international film

festivals 59,61

film noir $\quad 29$ 
filmography $\quad 247-51$

framing, Butler on 205-6

Frangville, Vanessa 91

fükeiron (landscape theory) 23, 39, 106 films

A.K.A Serial Killer $\quad 107,108 \mathrm{n} 12$

The Man Who Left His Will on Film

(Tokyo sensō sengo hiwa) 107

Furuhata, Yuriko 106-8

Gando Agreement (1909) $\quad 75^{\mathrm{n}} 7$

Gerow, Aaron $110,169-72,178$

on Japanese independent cinema $\quad 100-1,103$

global authorship, Elsaesser on $\quad 5^{8}$

globalization, and border-crossing cinema 39

Gomà, Daniel $\quad 74-5$

Gunning, Tom 47

haptic visuality, Marks on 148

Hardt, Michael \& Negri, Antonio 28

Herzog, Werner 217

Higbee, Will 42-3

Higbee, Will \& Song Hwee Lim $\quad$ 52, 72

Hjort, Mette

on cinematic transnationalism $\quad 29,34$

on risk in film 217, 222

Hollywood, appropriation of Asian film genres 29

home/homeland negotiation, $2 H \quad 151$

'Homeland and Diaspora' project $\quad 19-20,28,43-4$

homing strategy, Wang Yiman on $\quad 142-3,153$

horror cinema 29

Hou Hsiao-Hsien, A Time to Live and a Time to Die (Tongnian wangshi) 84

Hpakant (Myanmar) 24-5, 201, 206

De-Chin on his way to $\mathbf{2 2 0}$

landscape of mining pits $\quad \mathbf{2 0 2}, 214$

male labourers at work $\quad \mathbf{2 1 9}$

Hwa Lo, Dennis, on location shooting 35

identities

Chinese-in-Japan $\quad 135,138$

Japanese, majoritarian and minoritarian modes 141

and mobilities $\quad 232$

zainichi/Koreans-in-Japan 134

see also national identity; Okinawan identity

Imai Tadashi, The Tower of Lilies (Himeyuri no tō) 170

Imamura Shohei, The Profound Desire of the Gods (Kamigami no fukaki yokubō) 170

independent filmmaking, and DV

technology 51

intelligibility, Butler on 205

intercultural cinema, Marks on $22,40-1,52$, 148,232 international film festivals and border-crossing films $\quad 5^{8}$

curatorial agendas $\quad 78-9$

Elsaesser on 59

and film markets $\quad 59,61$

networks 61

Rancière on 60

intersectionality, and translocalism 237

Isan region (Thailand) jungle $\quad 122-3$

liminal space 124

Japan

immigration policies $131 \mathrm{n}_{5}$

national identity 170

war orphans $\quad 139,139 n 11$

Japanese Brazilians $114 \mathrm{n} 14$

Japanese film studios, Wada-Marciano on 5o, 49n13, 62n24, 101-2, 102n 4

Japanese independent cinema $5^{0}$

Gerow on 100-1, 103

see also Kuzoku

Jeju Island 192

Jeju Uprising (1948) 192

Jeonju International Film Festival 85

Jia Zhangke 44,50

Platform (Zhantai) $\quad 78$

Jinno Toshifumi 148

jishu eiga (autonomous) cinema 38,50

Kuzoku origins in $\quad 102-3$

Tezuka on 102,102n3

Kadokawa Corp. $\quad 28$

Kafka, Franz 45-6

Kaori, Oda

ARAGANE 25

following miners underground $\mathbf{2 4 4}$

machine in coal mine $\mathbf{2 4 2}$

observing the dark universe $\mathbf{2 4 4}$

risks 243

Thus the Noise Speaks (Noizu ga iu niwa) 241

Toward a Common Tenderness (Ano yasashi-sae) 241

Keelung 55

Khoo, Olivia 47

KIA (Kachin Independent Army) 217-8

Kim Il-Sung 95

Kim So-young 241

Goodbye My Love, North Korea 95, 243

Heart of Snow, Heart of Blood 95, 243

Sound of Nomad: Koryo Arirang 243

Kim Su-jin 94

Kirsch, Griseldis $\quad 15^{6}$

Kitano Takeshi 170

Ko, Mika 106-8, 132

Kofu city 106, 106, 110

Kōichi Iwabuchi, on border transgression 35 


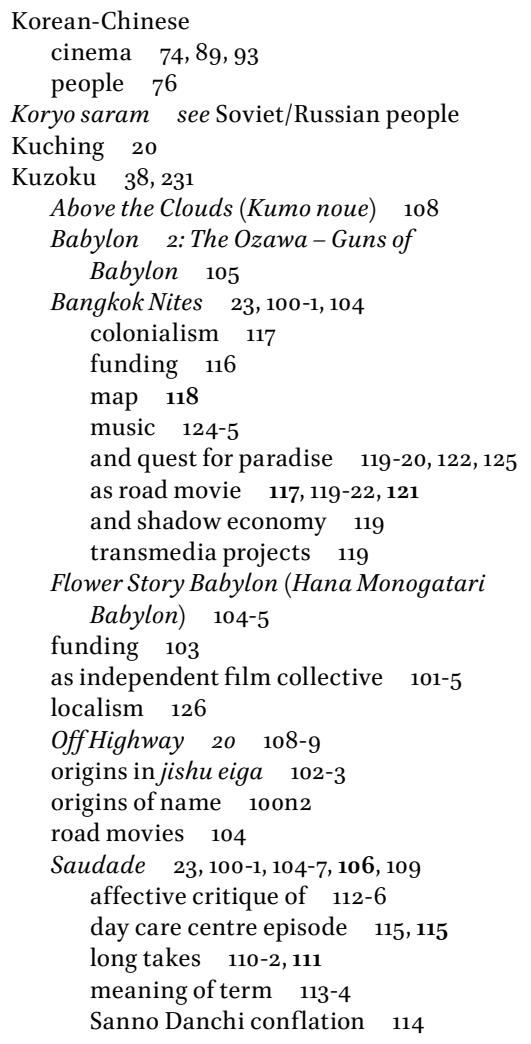

Lashio $\quad 20,214$

Lau Kek Huat, Absence Without Leave (Bujibuli) 224

Lebow, Alisa $\quad 151,215,224$ on camera as migration machine 208

Lee Bong-ou 94

Lee Sang-il, Rage (Ikari) 165

Lee Yong-chao 43 Blood Amber (Xuehupo) 222-3

Lent, John $\quad 5^{1-2}$

Letters from the South (Nanfang laixin) programme 20

Lhapal Gyal 50

Li Ruijun

Fly with the Crane (Gaosu tamen, wo cheng baihequle) 92

River Road (Jia zai shuicaofengmao de defang) 91

Li Ying

The Old Donkey (Laolutou) 91

${ }_{2} \mathrm{H} \quad 23,132$

accented style $\quad 146$

affective connections $\quad 151$

Asian Film Award 155

camerawork 151

and Chinese-in-Japan 143-52

Director's Note 147

fiction/non-fiction blurring 148

General Ma $144,147,149,15^{\circ}$

long takes $146,149-5^{1}$

non-linear structure 148

protagonists 144

cinema of displacement $\quad 140-3$

Dragon Films production company 140

Dream Cuisine (Aji) 23, 132, 152-5

cuisine, authenticity of 153-4

diasporic paradox 154

ending theme 155

home/homeland negotiation 153

early career 140

Yasukuni 23, 129, 155

poster $\mathbf{1 3 0}$

Lim Kah-Wai

After All These Years (Qihou) $\quad 158$

Fly me to Minami (Koisuru minami) $\quad 158$

Love in Late Autumn (Aizaishenqiu) ${ }_{15}^{8}$

New World (Shin Sekai) $\quad{ }_{15}^{8}$

liminal sites 20

Isan region (Thailand) jungle $\quad 124$

linguistic communities 135

Lionnet, Françoise \& Shu-mei Shih $\quad 22,42$, 45,143

localism, Kuzoku 126

locality, Maitra \& Chow on 52

Locarno International Film Festival $\quad 7_{8}^{8}$

Greater China project $\quad 79$

location shooting 38

Hwa Lo on 35

long takes

$2 H \quad 146,149-51$

cinematography 110

Okinawan Dream Show $\quad 176$

Saudade 110-2, 111

Lou Ye $5^{\circ}$

Lu, Sheldon 134-5

Lupton, Catherine 191

McCormack, Donna \& Suvi Salmenniemi $\quad 216$

Maimon, Vered $\quad 172,185,187-8$

on minority $\quad 46-7$

on politics of art $\quad 109-10$

Maire, Frederic 79

Maitra, Ani \& Chow, Rey, on locality $5^{2}$

Malacca 20

Yu Dafu's diary 44

Malaysian New Wave, and DV technology 44, 44n11

Marker, Chris, Level Five 191

Marks, Laura U. 40 on haptic visuality 148

on intercultural cinema $\quad 22,40-1,52,148,232$

Martin-Jones, David 168-9

masculinity, performance of $217,219,221$

Matsuda Masao 23, 106 


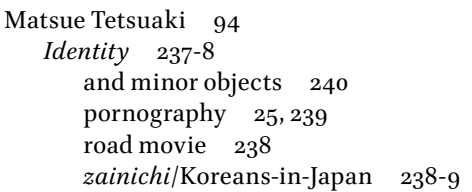

Mekas, Jonas, Reminiscences of a Journey to Lithuania 176

Midi Z 43-4

14 Apples (Shisike pingguo) 210

Burial Clothes 207-8

and cinema of precarity $\quad 202$

City ofJade (Feicuizhicheng) 24-5, 201 214,216

and cinema of precarity $\quad 204-5,221-2$, 224

De-Chin on way to Hpakant $\mathbf{2 2 0}$

ending 224-5

landslide $\quad 223$

risk in filming $217-8,222$

DV technology, use of 218,224

early life 2oon2

Ice Poison (Bingdu) 44-5, 206-7, 212

Academy Award 210

identity 200

Jade Miners (Wayushideren) 201

De-Chin's story $\quad 219-21,220,224-5$

'My Folks in Jade City' installation, miners posing 225

Poor Folk (Qiongren, liulian, mayao, touduke) 206-7

Return to Burma (Guilai de ren) 200, 206-7, 213

Road to Mandalay 213

Taiwanese citizenship 209

Trilogy 200, 201, 205-7

and Chinese diaspora $\quad 210-13$

non-professional actors $\quad 208,208$ n 4

Yunnan dialect 207

migration

and precarity/precariousness $\quad 203,211$

studies, translocalism $\quad 33-4$

Mikami Chie, We Shall Overcome (Ikusaba nu tudumi) 165-6, 195

political cinema 172

Mimi Thi Nguyen 240

the minor, Deleuze \& Guattari $\quad 45-8,186,232$

minor cinema, Deleuze $\quad 45^{-7}$

minor transnationalism $\quad 42,47,143$

minority, Vered on 46-7

minority affects, Erni on 142

minority films, Zhang Yingjin on 90

mobilities

and feminist theories $\quad 236-7$

and identities 232

Moon So-ri 94

Myanmar

independent filmmaking 209

socio-political developments $\quad 209,215$
Naficy, Hamid, on accented cinema 40,48 , 141-2, 148, 216-7, 232

Nakazato Isao 173

nation, as narration $\quad 168-9$

national identity $\quad 168-9$

Japanese 170

NDU (Nihon Documentarist Union)

Asia is One (Ajia wa hitotsu) 53

as dissensual work $\quad 57-8$

and kokkyō-ron $\quad 55,57$

border as sphere notion 57

Onikko - A Record of the Struggle of Youth

Laborers (Onikko: Tatakau seinenrodosha no kiroku) $53 \mathrm{n} 18$

predecessors, group photo $\mathbf{5 4}$

New Chinese Cinema 92n17; see also Chinese independent cinema

New York Korean Film Festival $\quad 78$

Ng Kim Chew $\quad$ 136-7

Novak, Marcos 42

Oakes, Tim \& Louisa Schein $\quad 72-3$

Translocal China 33-4, 71

on translocality 80,87

Oguma, Eiji 164

Okinawa 55

on film 169-71

landscape, Takamine on 174

military bases 188

representations $\quad 170-3$

reversion to Japan (1972) 164, 188

time-image framework 169

uniqueness 164

Okinawa, Battle (1945) 24, 165n3, 169

mass suicides $\quad 189$

montage in Mud Man 193-4

and Queer Fish Lane (Hengyoro) 180

Okinawan identity, Tsuru-Henry 180

Ong, Aihwa 21 on 'trans' meaning 57

Ong, Aihwa \& Donald M. Nonini 211

Oshima, Nagisa 155

The Man Who Left His Will on Film (Tokyo sensō sengo hiwa) $\quad 107$

Park Hae-il 94-5

partage du sensible (distribution of the sensible) 30, 34

Pema Tseden $\quad 5^{0,90-1}$ Old Dog 212

Phathanavirangoon, Raymond \& Visra Vichit-Vadakan $5^{2}$

Phoenix Television (Fenghuang weishi) 19

Pisters, Patricia $\quad 113,184$ on political cinema $\quad 187$

place

cultural approach to $\quad 72$

and translocalism 34

political cinema 


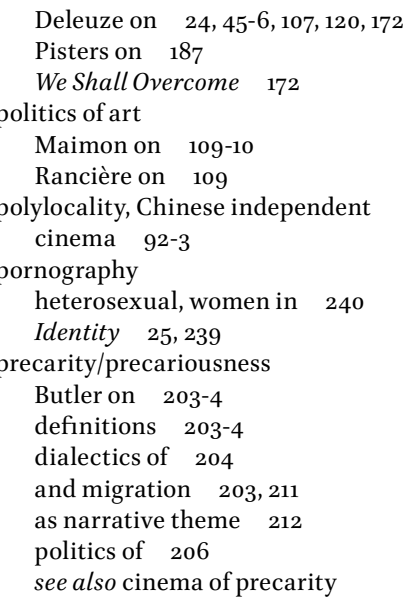

queer films 47

Rancière, Jacques $\quad 47-8,235$

on appearance 33,205

on dissensus 30,230

on fiction 187

on film festivals 60

on politics of art $\quad 109$

reterritorialization 125-6; see also deterritorialization

Ren Shujian

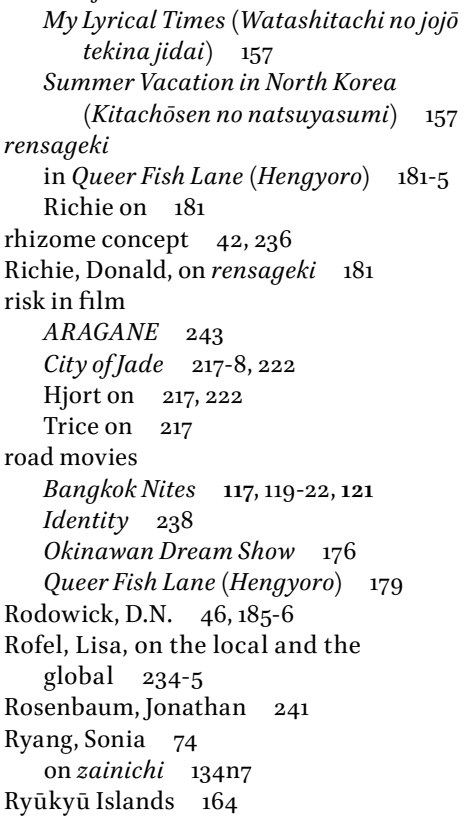

Sai Yoichi 94

All Under the Moon (Tsuki wa dochini deteiru) 155

films 170 n1o

San'ya gathering place $111 n 13$

SEAFIC (Southeast Asian Fiction Film Lab), aim $\quad 5^{2 n 17}$

Sharp, Jasper 238-40

Shih, Shu-mei $\quad 21-2,135,200-1$ on Sinophone 136

Silvey, Rachel, on feminist theories and mobilities $\quad 236-7$

Singapore 20

Sinophone

as anti-Sinocentrism $\quad 136$

definition 135

Shih on 136

Tan on 159, 200-1

see also Chinese; Chineseness

Sinophone cinema $\quad 41,74$

Sinophone Cinemas (anthology) 135

Sokurov, Alexander 59

Song Hwee Lim 43, 209

Sonthar Gyal 50

Soviet/Russian Koreans (Koryo saram) 41ng diaspora 95

Standing, Guy 203

stratigraphic imagery, Queer Fish Lane (Hengyoro) 184

Sun Ge, on Asia as medium 229, 231

Sun Koh, Singapore Panda (Xinxin xiongmao) 20

Taiwan, and China (PRC) 139

Takamine Gō 38

early works 173

Okinawan Chirudai $\quad 177,183$

Okinawan Dream Show 174

images 175,177

as landscape film $\quad 176$

long takes $\quad 176$

as road movie $\quad 176$

soundscape 177

on Okinawan landscape 174

Paradise View 183

Queer Fish Lane (Hengyoro) 24, 167

and Battle of Okinawa 180

DV technology 181

fabulation 186-7

heterogenous media texts 181

images $\mathbf{1 8 2}, \mathbf{1 8 3}$

monk story $182-3$

Okinawan language $\quad 178$

plastic surgery $\quad 178-9$

rensageki in 181-5

as road movie 179

rock musician scene $\quad 183-4$

stratigraphic imagery $\quad 184$ 


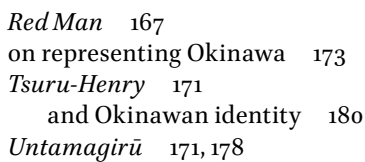

Takano Yoshiko 109-10

Tan Chuimui 43-4, 241

A Night in Malacca (Maliujia yehua) 20

Tan, E.K. $\quad$ 136-7

on Sinophone 159, 200-1

Tan, Royston, Popiah (Baobing) 20

Teh, David 122

Tezuka, Yoshiharu, on jishu eiga (autonomous) cinema $102,102 \mathrm{n} 3$

Tian'anmen Movement, China 32

Tian'anmen Square Incident (1989) 50

Tibetan New Wave cinema 90

Tihanov, Galin 37

time

labyrinthine model $\quad 168$

straight line model $\quad 168$

time-image framework

Deleuze $\quad 24,167-8$

Okinawa $\quad 169$

Tolia-Kelly, Divya P. $\quad 31-2$

Tomita, Katsuya $\quad 23,38,104,109,126$

'trans' meaning, Ong on 57

translingual filmmaking $\quad 29$

translocalism

and intersectionality 237

migration studies $\quad 33-4$

and place 34

and transnational cinema $\quad 72$

Zhang $\mathrm{Lu} \quad 76$

translocality

Oakes \& Schein on $\quad 80,87$

Zhang Yingjin on 72

translocality framework, Zhang $\mathrm{Lu} \quad 23$

transnational cinema, and translocalism $\quad 72$

transnational cultural formations 28

transnationalism

as manifestation of translocality $\quad 34$

see also minor transnationalism

transversalism, cultural 93

Trice, Jasmine Nadua, on risk in film 217

Trinh Minh-ha, on border-crossing concept $79-80$

Tsai Ming-liang, Walking on Water (Xingzai shuishang) 20

Valck, Marijke de 6 on23

Wada-Marciano, Mitsuyo, on Japanese film studios $\quad 49-50,49 n 13,62 \mathrm{n} 24,101-2,102 \mathrm{n}_{4}$

Wanda Media Corp. $\quad 28$

Wang Ban 193-4

Wang Quan'an, Tuya's Marriage (Tuya de hunshi) 91
Wang Xiaoshuai $\quad 5^{0}$

Wang Yiman 93

on 'amateur-auteur' status $\quad 102 \mathrm{n} 4$

on homing strategy $142-3,153$

Williams, Raymond 93

women

in border-crossing cinema $\quad 236-7$

in heterosexual pornography 240

Wong, Cindy 60

Wu Wenguang, Bumming in Beijing - Last

Dreamers (Liulang Beijing - zuihoude

mengxiangzhe) $\quad 32,34$

xianchang (on the scene/spot) 39

Zhang Zhen on $39 n 7$

Yamagata International Documentary Film

Festival (YIDFF) 51, 61, 167

Manifesto 51,51 n $^{15}$

Yamashiro Chikako 24, 166

MudMan (Tsuchi no hito) 189, 191-2

Battle of Okinawa montage 193-4

himeyurifields image 194

tunnel image 193

The Beginning of Creation: Abduction/A Child (Sōzō no hottan:Abudakushon) kodomo) $\quad 167$

Woman of the Butcher Shop (Nikuya no onna) $\quad 167$

Your Voice... 189-9o

appropriation $\quad 189-91$

artist's face 190

artist's lip-sync $\quad 189-91$

Yang Jie 142

Yang Yong-hi 94, 241

Dear Pyongyang 224

Yasukuni Shrine 129, 130

YKAP (Yanbian Korean Autonomous

Prefecture) 69

North Korea, border $\quad 76$

population $74 \mathrm{n}_{4}$

Yu Dafu

Malaccan diary 44

'South Seas'/ Nanyang 20

Yunnan Multicultural Visual Festival/

Yunfest 61

zainichi

becoming 141

meaning of term $\quad 134 \mathrm{n}_{7}$

Ryang on $134 \mathrm{n} 7$

zainichi/Koreans-in-Japan

cinema 74,156

filmmakers 94

identities 134

Identity 238-9

Zhang Jiabei, $A$ Guide of the Sleepless Town

(Kabukicho annaijin) $\quad 158$ 
Zhang Liling, Persisting with Tears in Eyes (Hanlei huozhe) $15^{8}$

Zhang Lu

A Quiet Dream (Chun-mong) $\quad 77-8$

at film festival networks $77-8$

Chinese independent cinema, influence on 89

Chongqing 79

Desert Dream (Gyeong-gye) 23, 80-2

Dooman River (Duman-gang) 23, 70, 79, $82-5,83,84,85$

Eleven (Shiyisui) 70, 80, 89

Father 79

Fukuoka 77

Grain in the Ear (Mangzhong) 90

Gyeongju 70,78
Love and... (Pilreumsidaesarang) 95

Ode to the Goose (Gunsan:geowireul noraehada) 77

Over There $85^{-6}$

Scenery (Pung-gyeong) $\quad 23,85^{-8}, 86,87$

South Korean connections $\quad 94-5$

Tang Poetry (Tangshi) 70, 79, 89-9o

as translocal auteur $23,69,73-9$

translocalism 76,95

translocality framework 23, 92

Zhang Yingjin 71-2

on minority films 90

on translocality $\quad 72$

Zhang Yuan, Mama 32

Zhang Zhen, on xianchang $\quad 39 n_{7}$ 